\title{
WestVirginiaUniversity
}

THE RESEARCH REPOSITORY @ WVU

Graduate Theses, Dissertations, and Problem Reports

2012

\section{Characterization of terrelysin, a potential biomarker for Aspergillus terreus}

Ajay Padmaj Nayak

West Virginia University

Follow this and additional works at: https://researchrepository.wvu.edu/etd

\section{Recommended Citation}

Nayak, Ajay Padmaj, "Characterization of terrelysin, a potential biomarker for Aspergillus terreus" (2012). Graduate Theses, Dissertations, and Problem Reports. 3598.

https://researchrepository.wvu.edu/etd/3598

This Dissertation is protected by copyright and/or related rights. It has been brought to you by the The Research Repository @ WVU with permission from the rights-holder(s). You are free to use this Dissertation in any way that is permitted by the copyright and related rights legislation that applies to your use. For other uses you must obtain permission from the rights-holder(s) directly, unless additional rights are indicated by a Creative Commons license in the record and/ or on the work itself. This Dissertation has been accepted for inclusion in WVU Graduate Theses, Dissertations, and Problem Reports collection by an authorized administrator of The Research Repository @ WVU.

For more information, please contact researchrepository@mail.wvu.edu. 


\title{
Characterization of terrelysin, a potential biomarker for Aspergillus terreus
}

\author{
Ajay Padmaj Nayak \\ Dissertation submitted to the School of Medicine \\ at West Virginia University \\ in partial fulfillment of the requirements \\ for the degree of \\ Doctor of Philosophy \\ in \\ Immunology and Microbial Pathogenesis
}

Donald H. Beezhold, Ph.D., Chair

John B. Barnett, Ph.D.

Brett J. Green, Ph.D.

Slawomir Lukomski, Ph.D.

Michael Miller, Ph.D.
Department of Microbiology, Immunology and Cell Biology
Morgantown, West Virginia
2012

Keywords: terrelysin, biomarker, Aspergillus terreus, monoclonal antibodies, diagnostics 


\title{
ABSTRACT \\ Characterization of terrelysin, a potential biomarker for Aspergillus terreus
}

\author{
Ajay Padmaj Nayak
}

Exposure to fungi can lead to diverse conditions from allergy to colonization to invasive and disseminated infection, depending on the status of the host immune system. Recent data suggests that fungal infections and especially Aspergillus species has been on the rise. Though mostly affecting immunocompromised individuals, more recent reports have identified infections in immunocompetent populations as well. Aspergillus terreus is of particular interest, since it causes rapid disseminating infections with high mortality rates, owing to its natural resistance to antifungal drugs and production of vegetative aleurioconidia during infection. These attributes coupled with poor current diagnostics and increasing costs involved with controlling the infection, have generated considerable interest in developing novel strategies for diagnosis of $A$. terreus infections. Fungal hemolysins have been proposed as biomarkers of exposure because of an association between exposures to the black mold Stachybotrys chartarum and an outbreak of idiopathic pulmonary hemorrhage. Using polyclonal antibodies, the hemolytic antigen was detected at concentrations of $371 \mathrm{ng} / \mathrm{ml}$ in patient sera. Our initial experiments were designed to develop monoclonal antibodies (mAbs) towards a stachylysin hemolytic preparation. IgM mAbs were developed with limited cross-reactivity within Stachybotrys species. ELISA and FHIA analysis showed that most stachylysin was present in hyphae. Using proteomic analysis, we could not confirm the identity of stachylysin because the genome of $S$. chartarum has not been sequenced. To better characterize hemolysins as biomarkers, the clinically relevant fungus $(A$. terreus) with a sequenced genome was chosen for analysis. Initial attempts at the characterization of a hemolytic fraction from A. terreus resulted in development of multiple $A$. terreus-specific $\mathrm{IgG}_{1} \mathrm{mAbs}$ to proteolytic enzymes including, leucine aminopeptidase and dipeptidyl peptidase $\mathrm{V}$. We were unable to identify the hemolysin of interest using this $\mathrm{mAb}$ approach. Alternatively, expression of recombinant terrelysin (rTerrelysin) using the pASKIBA6 vector in Escherichia coli yielded a protein with secondary structure similar to other Aegerolysin family proteins. Highly specific mAbs (10G4, 15B5 and 13G10) to the recombinant protein consistently recognized native terrelysin in different strains of A. terreus. Expression kinetics suggested that terrelysin is produced in high concentrations immediately after germination but levels decrease with increasing fungal biomass, and not present at the later time points when the previous hemolytic preparations were made. These data suggest interpretation of previous studies on detection of 'hemolysins' in exposed individuals and experimental animals are likely an error. The mAbs developed in this study for terrelysin, leucine aminopeptidase, and dipeptidyl peptidase $\mathrm{V}$ have potential for development of rapid and specific diagnostic assays. Tools developed in this study could be used for analysis in various animal models to determine combinatorial assays using mAbs developed to different proteins of A. terreus. 


\section{ACKNOWLEDGEMENTS}

One individual cannot achieve success of this nature on his own accord and neither was mine. Many people have put their time and effort in contributing towards this achievement and no one has sacrificed more than my parents. This marks an end of a long struggle of their aspirations for me. I am also very thankful to the roles played by many individuals without which I would not be here today. First of all I would like to thank Dr. Fred Minnear, Clair Noel and the rest of the Office of Research and Graduate Education for providing me with an opportunity to receive education at West Virginia University. I would also like to thank my aunt Sheela and my uncle Manohar for their generosity, which helped me pursue this opportunity.

Although receiving the opportunity was special, sustaining this was always going to be challenging and many people contributed towards helping me achieve my goals. None other has contributed more to this than my advisor Dr. Donald Beezhold. I am very thankful to Don for his constant encouragement and his belief in me. Thank you very much for challenging me to think and I will never forget the lessons I learned from our Monday afternoon meetings. Dr. Brett Green and Dr. Detlef Schmechel have imparted a tremendous wealth of knowledge to me and to this I express my gratitude. Dr. Green's commitment and dedication to his work has always inspired me to work hard. I would also like to thank my committee members Dr. John Barnett, Dr. Slawomir Lukomski and Dr. Michael Miller for their valuable contributions and constant encouragement. Some people have also contributed towards this success by filling up a lot of paperwork for this international student. My thanks to Brooke from WVU and Kathy from NIOSH for their dedication and promptness which ensured that I could perform my research duties uninterrupted.

Through last 6 years, I had the opportunity to make some great friends at work and outside of it. I would like to thank Abhijeet for being a great roommate. I wish him the best in his future endeavors as he too looks forward to life after his recent graduation. I would also like to thank EJ and Ashley for being very kind to me and I will always cherish my time at your wedding. I would also like to thank my American mothers Toni and Erika for their tremendous patience with me in the lab. I would like to thank my other lab mates Amanda, Bill, Itai and Steve for their valuable inputs.

I also express my gratitude to my fiancé Nedra for her love and support during the toughest times of my graduate life. Thank you for making me the better person that I am today. I am looking forward to spending the rest of our lives together working through many challenges and enjoying great times.

Last but not least I am very thankful to the taxpayers of United States. Their generous contributions have changed my life in more ways than they can imagine.

So many people have touched my life in so many different ways that it is hard to list all of them. I would like to thank all those who made my doctoral education one of the best times of my life. 


\section{TABLE OF CONTENTS}

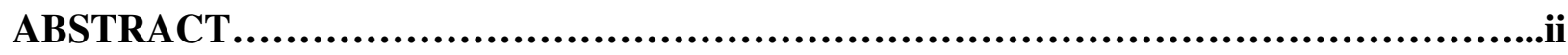

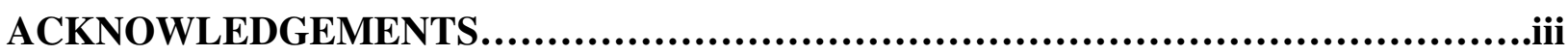

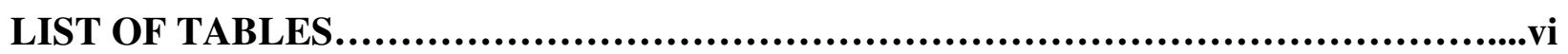

LIST OF FIGURES........................................................................vii

LIST OF ABBREVIATIONS...............................................................

1. CHAPTER 1- GENERAL INTRODUCTION/LITERATURE REVIEW .................1

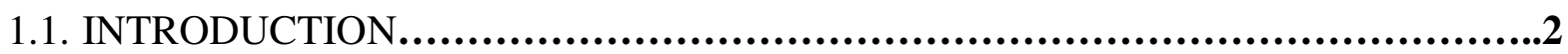

1.2. MORPHOLOGICAL CHARACTERISTICS....................................................3

1.3. FUNGAL DIAGNOSTICS ..............................................................5

1.4. FUNGAL HEMOLYSINS ........................................................

1.5. AEGEROLYSINS...................................................................11

1.6. FUNGAL HEMOLYSINS AS BIOMARKERS.......................................14

1.7. CONSLUSIONS ..........................................................................16

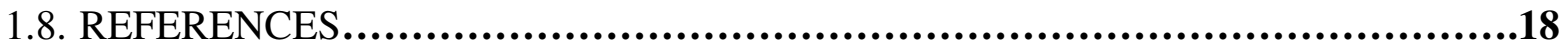

2. CHAPTER 2- CHARACTERIZATION OF MONOCLONAL ANTIBODIES DEVELOPED AGAINST A HEMOLYTIC PREPARATION (STACHYLYSIN) FROM STACHYBOTRYS..............................................................33

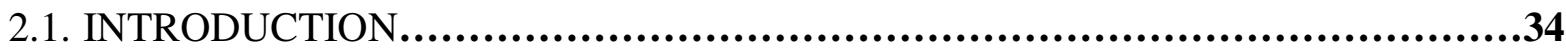

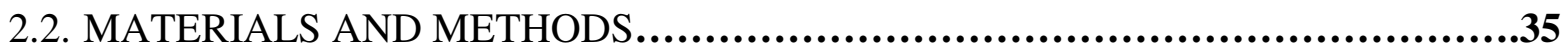

2.3. RESULTS...........................................................................41

2.4. DISCUSSION ......................................................................51

2.5. REFERENCES...................................................................55

3. CHAPTER 3- ASPERGILLUS TERREUS REVIEW AND FIRST APPROACH AT DEVELOPMENT OF MONOCLONAL ANTIBODIES TO PUTATIVE HEMOLYSIN AND ITS CHARACTERIZATION ..................................................59

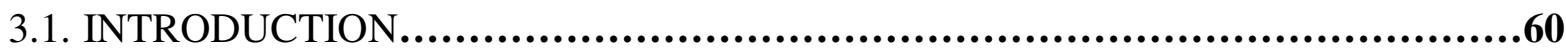

3.2. ASPERGILLUS SPECIES ...........................................................61

3.3. ASPERGILLUS TERREUS ........................................................62

3.4. MATERIALS AND METHODS................................................64

3.5. RESULTS .........................................................................74

3.6. DISCUSSION .....................................................................89

3.7. REFERENCES ................................................................93 
4. CHAPTER 4- CLONING, EXPRESSION AND PURIFICATION OF RECOMBINANT TERRELYSIN....................................................101

4.1. INTRODUCTION............................................................................102

4.2. MATERIALS AND METHODS .......................................................103

4.3. RESULTS.........................................................................107

4.4. DISCUSSION .......................................................................122

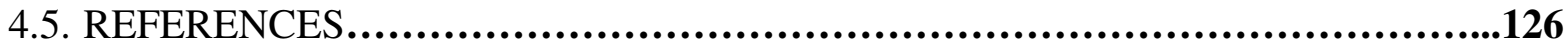

5. CHAPTER 5- DEVELOPMENT OF MONOCLONAL ANTIBODIES TO RECOMBINANT TERRELYSIN AND CHARACTERIZATION OF TERRELYSIN EXPRESSION IN ASPERGILLUS TERREUS.........................................131

5.1. INTRODUCTION...................................................................132

5.2. MATERIALS AND METHODS ..................................................133

5.3. RESULTS ............................................................................141

5.4. DISCUSSION ...................................................................160

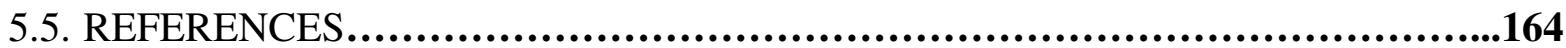

6. CHAPTER 6- GENERAL DISCUSSION...........................................167

6.1. INTRODUCTION ...............................................................168

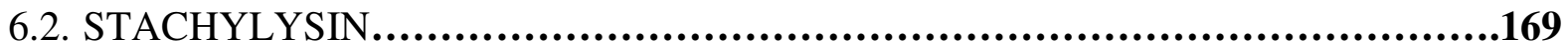

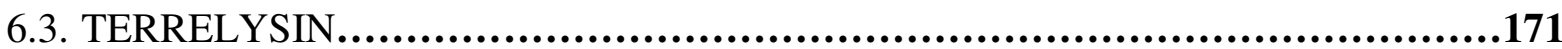

6.4. RECOMBINANT TERRELYSIN.............................................172

6.5. OTHER CONCLUSIONS.......................................................175

6.6. REFERENCES...............................................................177

APPENDIX .....................................................................................181

CURRICULUM VITAE.............................................................189 


\section{LIST OF TABLES}

Table

Page

Table 1.1: Hemolytic activity of different fungal species.

Table 2.1: Cross-reactivity profiles of the eight IgM anti-stachylysin mAbs analyzed by capture

ELISA. .46

Table 3.1: Fungal species tested for cross-reactivity of HEA-mAbs. .77

Table 3.2: Cross-reactivity profiles of HEA-mAbs analyzed by capture ELISA.... .79

Table 3.3: Proteomic analysis of HEA antigens

.87

Table 5.1: Cross-reactivity profiles of terrelysin-mAbs analyzed by Western blot 148

A1: Amino acid composition similarity search 182

A2: Sub divisions of Aspergillus species.

A3: List of species in which Aegerolysins have been identified. 184

A4: Cytotoxicity of Aegerolysin proteins on different cell lines. .185

A5: Protein A and G-based antibody immunoprecipitation. 186 


\section{LIST OF FIGURES}

Figure $\quad$ Page

Figure $2.1 \mathrm{a}: \mathrm{mAb}$ reactivity against the stachylysin protein preparation.....................42

Figure 2.1b: Reactivity of the $4 \mathrm{mAbs}$ against $S$. chlorohalonata conidial and hyphal extracts...43

Figure 2.2: Fluorescent halogen immunostaining of $S$. chlorohalonata.....................44

Figure 2.3: Western blot reactivity patterns........................................50

Figure 3.1: mAb reactivity to A. terreus extracts....................................... 76

Figure 3.2: Western blot analysis of anti-HEA mAbs using A. terreus CSN..................80

Figure 3.3: Time point kinetic assay of HEA in A. terreus hyphae and CSN.................82

Figure 3.4: Detection of HEA by mAbs in presence of serum............................83

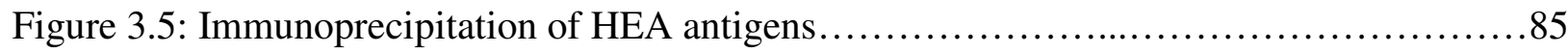

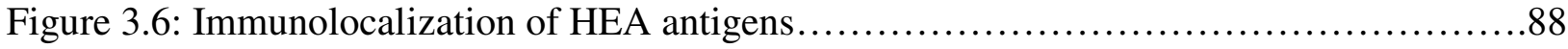

Figure 4.1: Sequence alignment of putative aegerolysin family proteins produced by various

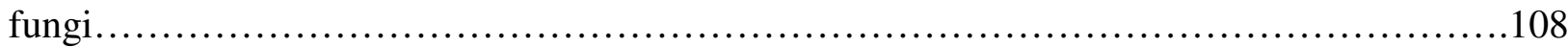

Figure 4.2: Cloning strategy for recombinant terrelysin in pASK-IBA6 vector and expression in Escherichia coli............................................................. 111

Figure 4.3: Agarose gel electrophoresis........................................ 113 
Figure 4.4a: SDS-PAGE for rTerrelysin.

Figure 4.4b: Protein blot for rTerrelysin......................................... 115

Figure 4.5: MALDI-TOF MS of rTerrelysin...................................... 116

Figure 4.6: Secondary structure analysis of rTerrelysin..............................119

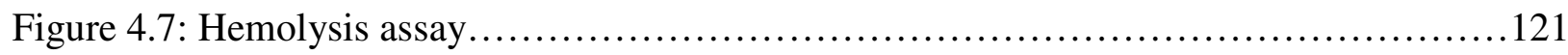

Figure 5.1: Reactivity of mAbs to rTerrelysin..................................... 142

Figure 5.2: Western blot analysis with pooled sera...................................144

Figure 5.3a: Western blot analysis of rTerrelysin with terrelysin mAbs....................146

Figure 5.3b: Western blot analysis of A. terreus mycelial extract with terrelysin mAbs........147

Figure 5.4: Epitope mapping of anti-terrelysin mAbs...............................151

Figure 5.5a: Kinetics of expression of terrelysin at RT ................................ 154

Figure 5.5b: Morphological changes and progression of A. terreus culture growth at RT......155

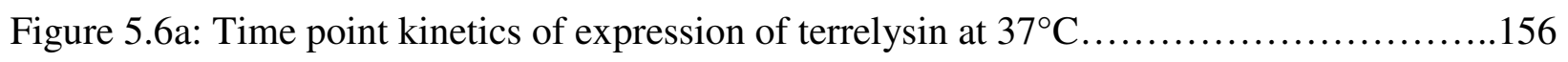

Figure 5.6b: Morphological changes and progression of $A$. terreus culture growth at $37^{\circ} \mathrm{C} \ldots . .157$

Figure 5.7: Immunolocalization of terrelysin in A. terreus hyphae..........................159 


\section{LIST OF ABBREVIATIONS}

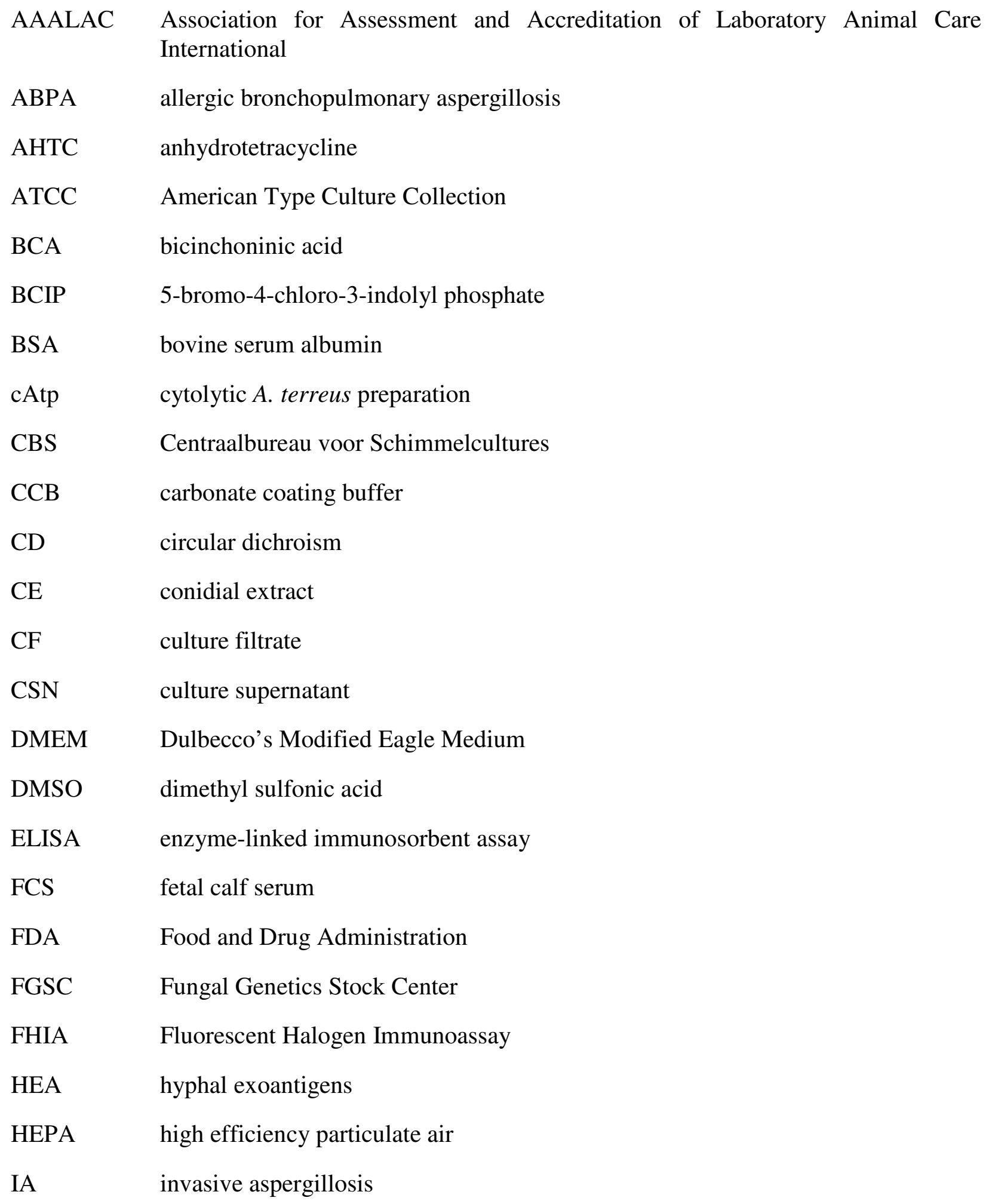




$\begin{array}{ll}\text { IBT } & \text { Instituttet for Bioteknologi } \\ \text { mAb } & \text { monoclonal antibody } \\ \text { MALDI-TOF } & \text { Matrix assisted laser desorption/ionization- time of flight } \\ \text { MCE } & \text { mixed cellulose ester } \\ \text { ME } & \text { mycelial extract } \\ \text { MEA } & \text { malt extract agar } \\ \text { NBT } & \text { nitro blue tetrazolium } \\ \text { NIOSH } & \text { National Institute for Occupational Safety and Health } \\ \text { NRRL } & \text { Agricultural Research Service Culture Collection } \\ \text { OD } & \text { optical density } \\ \text { pAb } & \text { polyclonal antibody } \\ \text { PBST } & \text { phosphate-buffered saline pH 7.4, 0.05\% (v/v) Tween 20 } \\ \text { PBSTM } & \text { PBST, 1\% non-fat dry milk } \\ \text { PBSTB } & \text { PBST, 5\% BSA } \\ \text { PCR } & \text { polymerase chain reaction } \\ \text { RT } & \text { room temperature } \\ \text { SBA } & \text { sheep red blood agar } \\ \text { SDS-PAGE } & \text { sodium dodecyl sulfate- polyacrylamide gel electrophoresis } \\ \text { SRBC } & \text { sheep red blood cells } \\ \text { TSB } & \text { tryptic soy broth } \\ & \end{array}$

UAMH University of Alberta Microfungus Collection and Herbarium 


\section{CHAPTER 1}

General Introduction/Literature Review 


\subsection{INTRODUCTION}

Fungi are one of the most ubiquitous groups of eukaryotic organisms in nature. Kingdom Mycota includes an estimated 1.5 million species of eukaryotic organisms including yeasts, molds and mushrooms. They characteristically lack chlorophyll and are saprophytes i.e. they depend on external sources of organic material for nutrition. In nature, they play an important role in recycling elements in soil. They are used in industry as a source of enzymes and important secondary metabolites that have tremendous economic and therapeutic value. Exposure of human population is ubiquitous and a growing number of individuals with impaired immune systems are susceptible to infections from these microbes, thus making them clinically relevant.

Within the Kingdom Mycota, fungi are divided based on distinguishing characteristics, with specific emphasis on the different reproductive stages. Kingdom Mycota is further divided into seven Phyla (1); Phylum Glomeromycota consists of fungi that have an important role in the ecosystem and form mutualistic symbiotic relationship with plants; fungi belonging to Phyla Chytridiomycota, Blastocladiomycota and Neocallimastigomycota are characterized by flagella and are present mostly in aquatic environment; Phylum Microsporidia consists of sporeforming unicellular obligate parasites; and Phyla Basidiomycota and Ascomycota represent the largest number of fungal species known and have been grouped together under the Sub Kingdom Dikarya.

Ascomycota, the largest and most diverse Phyla consists of approximately 64,000 species (2). Members of Ascomycota are present in most natural and industrial environments. They have also been surprisingly isolated from extreme environments (3-5). Ascomycetes include fungi that are important in industry for their enzymes and secondary metabolites that have nutritional and 
therapeutic value. Ascomycetes also include of large number of species that can cause opportunistic infections in humans, animals and plants particularly Aspergillus and Penicillium.

\subsection{MORPHOLOGICAL CHARACTERISTICS}

Stachybotrys and Aspergillus spp, two filamentous fungal species that are the focus of this work, are molds that exist in the form of non-motile conidia or hyphae. Their perseverance is highly dependent on the availability of moisture and nutritive material. Typically, filamentous fungi exhibit the following morphological structures (6);

1.2.1 Conidium- Conidium (pl. conidia) also referred to, as a spore, mitospore or conidiospore is the dormant form of the fungus that acts as a secure 'house' for survival of the fungus in presence of adverse environmental conditions. The conidium has a highly structured external cell wall composed of $\alpha$ or $\beta$ (1-3) glucan-proteins and chitin fibrils. In addition, pigments such as melanin are also associated with the conidial cell wall. Small hydrophobic proteins, called as hydrophobins coat the outer surface of conidia and this coating protects the conidia from dehydration and allows for attachment of conidia to various surfaces $(6,7)$. Ergosterol is present in the membrane and functions similarly to cholesterol in mammalian cells.

On access to nutrients and water, various signaling molecules initiate the process of germination, resulting in swelling of the conidia, differential expression of proteins, and changes in surface properties (8-10). The first evidence of hyphal growth is observed in the form of a developing germ tube. An important feature of germinated conidia is its increased adhesive property and a polarized cellular growth. At this stage, the outer coat that existed on the conidia is completely shed and is identified as a germling. 
1.2.2 Hypha- Hypha (Pl. hyphae) extends from germinating conidia and continues expansive cellular growth. These structures are identified as the vegetative form of the fungus, usually identified during infections. The hyphal cell wall is thinner than the conidial cell wall and this allows for an easy flow of nutrients into the cell. Hyphae are multicellular and may (Aspergillus species) or may not (Mucor species) be divided into compartments by septa. Septa are usually incomplete and do not lead to permanent compartmentalization i.e. they allow the transport of ribosomes, mitochondria, nuclei and other organelles between compartments.

1.2.3 Mycelium- Mycelium ( $\mathrm{Pl}$. mycelia) is an aggregate of an extensive network of intertwining hyphae. Mycelia play a critical role in the environment in cycling of elements by degrading organic material. The mycelial stage also allows for aggressive utilization of organic materials available in the environment.

1.2.4 Foot cell, conidiophore and vesicle- As nutrient and water availability decreases, the cell resorts to producing conidia for promoting survival. Along the hypha, a stalk-like structure emerges to form a conidiophore. The basal cell from which the conidiophore arises is identified as the foot cell. The conidiophore produces conidia on a funnel-like structure called a vesicle. Conidia are formed as chains at the apex of the vesicle and are dispersed back into the environment. 


\subsection{FUNGAL DIAGNOSTICS}

Diagnosis of fungal infections and specifically detection of filamentous fungal species has been challenging (11-14). Treatment of symptoms including prolonged fever and a condition of neutropenia with unresponsiveness to antibacterial therapy is usually followed by antifungal agents. This lag period can result in severe recalcitrant fungal infections, making it imperative to diagnose fungal infections early. The following methods have been used either singly or in combination to diagnose the fungal infection etiology (14);

1.3.1 Culture methods- Isolation of fungi has been possible from cutaneous and superficial infections (15), however fungal recovery from invasive infections is inconsistent and unreliable (16-23). Fungemia may not occur even though mycological evidence is clear in infected tissues (23-25). Detection of aleurioconidia (conidia produced by vegetative hyphae) can be definitive for identification of A. terreus (26) however, other fungi such as Fusarium, Paecilomyces, Scedosporium and Acremonium species may release morphologically similar vegetative conidia in tissues and blood during infection, thus making differentiation complicated (23). The overall low sensitivity and inconsistency of isolation and differentiation make macroscopic and microscopic determination difficult at species level.

1.3.2 Molecular methods- DNA based methods are rapid and definitive and the presence of fungal DNA from sterile sites such as blood or other affected tissues (except lung) could possibly hold diagnostic value. A few studies have reported success from using PCR based techniques at qualitative as well as quantitative levels $(27,28)$. PCR methods have been developed using specific genes such as ribotoxin (29), tRNA (30), cytochrome b (31) and 18S rRNA (32, 33) as 
primer targets. Notwithstanding the popularity and demand for PCR based diagnostics, currently there is no FDA-approved fungal diagnostic PCR testing systems available. Certain experimental and methodological limitations hinder the use of PCR methods. Isolation of fungal DNA from clinical samples is unreliable and success rate varies between various methods (34). Detailed information on advantages and disadvantages of using PCR based methods has been reviewed extensively elsewhere $(14,35)$.

1.3.3 Radiological techniques- Radiological scanning techniques used for diagnosis of invasive aspergillosis may be suggestive of an active infection but are not species specific for developing targeted therapeutics $(36,37)$. Chest radiograph can help in identification of aggregated fungal mass in the lungs (38). Computed tomography exhibits higher sensitivity compared to other radiological techniques especially during early stages of infection (39). Collectively, these observations in collaboration with clinical manifestations of aspergillosis have been used successfully in improving the outcomes of invasive aspergillosis, but limitations hinder the use of these techniques especially in pediatric populations (40).

1.3.4 Histology- The lung is not considered a sterile site for etiological determination during fungal infections, since many different fungi may also be isolated. This makes clinical samples such as bronchial lavage and sputum less than ideal for the diagnostic detection of fungal material. However, histological confirmation of invasive vegetative hyphae or positive culture from biopsies of sterile sites such as pleural fluid may hold diagnostic value (41). Commonly used staining procedures stain for carbohydrate moieties that are shared by most fungi aid in ascertaining fungal growth but are not species specific (14). 
1.3.5 Serology- One of the biggest advantages of developing serological diagnostics for invasive aspergillosis is that it obviates the need for invasive procedures (41). Historically however, serological immunodiagnosis has been difficult due to unreliable antibody responses and insensitive results (42-45). Humoral antibody responses to Aspergillus species during invasive infection can be weak due to the immunocompromised nature of these patients. Measurement of serum galactomannan (46) and $\beta$-D-glucans, which constitute the fungal cell wall have been widely used with some success in diagnosis of invasive fungal disease (35). Galactomannan is a polysaccharide with a mannose backbone and galactose side chains, while $\beta$ D-glucans are polysaccharides with D-glucose monomers linked by $\beta$-glycosidic bonds. While these assays are currently used for diagnosis of invasive fungal diseases, they lack sensitivity and detection is not species specific, which results in inconsistent determinations $(14,47,48)$.

1.3.6 Biomarkers for immunodiagnostics- Detection of circulating antigens expressed by vegetative hyphae using species-specific monoclonal antibodies holds potential for developing ideal immunodiagnostics (49). Some have reported the presence of circulating protein antigens in infected patients (50-52). To have diagnostic value, prospective biomarkers should be expressed in the vegetative hyphae and preferably secreted by the growing hyphae. Detection of the biomarker should be rapid and species specific. The development of monoclonal antibodies for detection of the biomarker is essential to maintain species specificity in detection. This also provides an opportunity to develop standardized quantitative assays. 


\subsection{FUNGAL HEMOLYSINS}

Fungal hemolysins have been suggested as specific biomarkers for fungal exposure (5355), as they have been detected in sera and tissues of patients and experimental animals $(53,56)$. Hemolysins are pore-forming toxins that can lyse membranes of red blood cells. Though they are typically called hemolysins because of their ability to lyse red blood cells, many are capable of lysing other eukaryotic cells as well. Hemolysins and their role as virulence factors have been extensively studied in bacteria $(57,58)$; however less is understood about fungal hemolysins and their role in pathogenesis.

Hemolytic activity was first identified in fungi by Henrici in 1939 in mycelial extracts of A. fumigatus and was later reported in other fungal species by Salvin in 1951 (59, 60). Subsequently, hemolytic activity has been reported for many fungal species and the hemolysins have been identified and are summarized in Table 1.1. The first fungal hemolysin to be purified was from A. fumigatus; called asp-hemolysin. Similar hemolysins have been identified in other fungi and are currently identified as a family of proteins called Aegerolysins. Increasing interest in these proteins has led to improved understanding of the mechanisms underlying their hemolytic activity, role as virulence factors, binding to lipoproteins, and diagnostic potential as biomarkers of fungal exposure (61). 


\begin{tabular}{|l|l|l|}
\hline FUNGI & $\begin{array}{l}\text { AEGERLOYSIN } \\
\text { IDENTIFIED }\end{array}$ & \multicolumn{2}{l|}{ REFERENCES } \\
\hline ASCOMYCETES & \multicolumn{2}{|l|}{} \\
\hline Aspergillus clavatus & YES & $(62)$ \\
\hline Aspergillus flavus & YES & $(59,63,64)$ \\
\hline Aspergillus fumigatus & YES & $(56,59,62,65-75)$ \\
\hline Aspergillus nidulans & YES & $(76,77)$ \\
\hline Aspergillus niger & YES & $(78-81)$ \\
\hline Aspergillus oryzae & YES & $(82,83)$ \\
\hline Aspergillus terreus & YES & $(84)$ \\
\hline Alternaria tenuis & NO & $(85)$ \\
\hline Blastomyces dermatidis & YES & $(60,86-88)$ \\
\hline Candida albicans & NO & $(60,89,90)$ \\
\hline Candida glabrata & NO & $(90)$ \\
\hline Coccidioides posadasii & YES & $(90)$ \\
\hline Cordyceps militaris & YES & $(90)$ \\
\hline Cryptococcus neoformans & NO & \\
\hline Fusarium oxysporum & YES & YEs \\
\hline
\end{tabular}




\begin{tabular}{|l|l|l|}
\hline Metarhizium anisopliae & YES & $(98)$ \\
\hline Nectria haematococca & YES & $(99)$ \\
\hline Neurospora crassa & YES & $(100)$ \\
\hline Neurospora tetrasperma & YES & $(101)$ \\
\hline Paracoccidioides brasiliensis & YES & $(102-104)$ \\
\hline Penicillium chrysogenum & YES & $(105,106)$ \\
\hline Sordaria macrospora & YES & $(107)$ \\
\hline Stachybotrys chartarum & NO & $(53,108-112)$ \\
\hline Trichophyton species & NO & $(113)$ \\
\hline BASIDIOMYCETES & \multicolumn{2}{|l|}{} \\
\hline Moniliophthora perniciosa & YES & $(114,115)$ \\
\hline Agrocybe aegerita & YES & $(116,117)$ \\
\hline Pleurotus eryngii & YES & $(118,119)$ \\
\hline Pleurotus ostreatus & YES & $(134-142)$ \\
\hline Pleurotus nebrodensis & NO & \\
\hline Amanita phalloides & NO & $(139)$ \\
\hline Amanita rubescens & NO & \\
\hline Hypholoma fasciculare & NO & \\
\hline Laetiporus sulphureus & NO & \\
\hline
\end{tabular}




\begin{tabular}{|l|l|l|}
\hline Rhodophyllus rhodopolius & NO & $(150)$ \\
\hline Flammulina velutipes & NO & $(151-156)$ \\
\hline Volvariella volvacea & NO & $(157)$ \\
\hline Termitomyces clypeatus & NO & $(158)$ \\
\hline Schizophyllum commune & NO & $(159)$ \\
\hline Wallemia sebi & NO & $(160)$ \\
\hline ZYGOMYCETES & & \\
\hline Rhizopus nigricans & NO & $(161,162)$ \\
\hline Rhizopus arrhizus & NO & $(161)$ \\
\hline
\end{tabular}

Table 1.1: Hemolytic activity of different fungal species. *This strain is now identified as Stachybotrys chlorohalonata (163).

\subsection{AEGEROLYSINS}

1.5.1 General characteristics- Current information on the Aegerolysin family proteins (Pfam: PF06355; InterPro: IPR 009413) is largely based on studies of asp-hemolysin (A. fumigatus) and ostreolysin (P. ostreatus) (61). The Aegerolysin protein domain is currently identified in 114 sequences spread across fungi, bacteria, plants and a virus (Appendix A2). The Pfam protein database provides information on species distribution of the aegerolysins (164). Aegerolysin proteins are typically $15-20 \mathrm{kDa}$ in size and are rich in negatively charged residues $(61,117$, 
165). The isoelectric point of aegerolysins is acidic and has been experimentally determined for ostreolysin (pI 5.0), and aegerolysin (pI 4.85) (117).

1.5.2 Hemolytic and cytolytic activity- Fungal hemolytic activity was initially reported from crude or partially purified mycelial extracts $(63,166-168)$. Improvements in biochemical techniques contributed to purification of asp-hemolysin from A. fumigatus (169). Asp-hemolysin was identified to form distinctive pores on the surface of cell membranes to induce lysis by the colloid-osmotic mechanism (170). Detection of asp-hemolysin in vivo during infection of $A$. fumigatus has led to suggestions that the protein may be important for pathogenesis $(49,171)$. The hemolytic activity is stable in a wide range of $\mathrm{pH}(65,119,123,169,170,172)$. Other studies have characterized the ability of these proteins in lysing red blood cells and other eukaryotic cells from different animal species (APPENDIX A3).

Pore forming toxins bind to diverse receptors on the surface of target cells (173-175). Membrane lipid receptors for aegerolysins were identified by partitioning of ostreolysin to detergent resistant membranes (DRMs) in natural and artificial systems (122). Ostreolysin did not bind pure cholesterol $(117,121)$. Binding occurred when cholesterol was combined with sphingomyelin $(122,126)$. In further studies, removal of cholesterol from membranes of CHOK1 cells by methyl $\beta$-cyclodextrin inhibited binding of ostreolysin (176).

1.5.3 Studies in experimental animals- Several studies have characterized the effects of fungal hemolysins in vivo $(59,61,63,125)$. The intravenous (i.v.) $\mathrm{LD}_{50}$ value for asp-hemolysin in mice is reported to be $750 \mu \mathrm{g} / \mathrm{kg}$ (169) and that for ostreolysin was higher at $1170 \mu \mathrm{g} / \mathrm{kg}$ for mice (125). For ostreolysin, concentrations higher than $\mathrm{LD}_{50}$ value resulted in death of 
experimental animals within 20 mins. In an interesting study, injecting asp-hemolysin i.v. simultaneously with non-lethal dose of A. fumigatus conidia increased the mortality rates in experimental mice (56). Injecting asp-hemolysin also aided in improved survival of A. fumigatus conidia within the animals. More interestingly, mice immunized i.p. with anti-asp-hemolysin antibodies before A. fumigatus conidial challenge promoted survival of the animals.

Asp-hemolysin has also been detected in infected tissues of mice challenged with $A$. fumigatus conidia (177). Intravenous administration of experimental animals with asp-hemolysin showed that it can bind to arterial walls in the kidneys, heart, liver and the brain. Binding resulted in thickening of epithelial cells in the kidney, degeneration and necrosis of the cardiac muscles in heart, necrosis of liver cells with pyknosis and focal lesion and hemorrhage in brain. Asp-hemolysin also induced contraction of guinea pig ileum.

Studies using ostreolysin have also yielded similar results in terms of toxicity. Intravenous administration of ostreolysin resulted in hyperkalaemia, which resulted from lysis of host cells (125). This observation was further supported in another study where increasing doses of ostreolysin lead to development of tension in isolated rat aortic rings and diminished the relaxation of endothelium (129). This in combination with cytotoxicity towards human umbilical vein endothelial cells suggests a possible role in cardiotoxicity for these proteins.

1.5.4 Role of aegerolysin proteins in biology of the organisms- Initial studies identified that expression of hemolysins is specific for the vegetative hyphae and suggest a role during the early stages of immature fruiting bodies (116). Studies with ostreolysin and aegerolysin highlighted that the expression of these proteins varies with the morphological changes occurring in developing mushrooms (117). Ostreolysin is expressed by the growing hyphae and it may play a 
role in aggregation and compaction of hyphae to form primordia $(117,124)$. Addition of ostreolysin externally enhanced hyphal aggregation and formation of fruiting bodies (127). A clearer understanding of the role of these proteins in filamentous fungi is needed.

\subsection{FUNGAL HEMOLYSINS AS BIOMARKERS}

Interest in use of hemolysins as specific biomarkers for fungal exposure developed first in cases of infant idiopathic pulmonary hemorrhage (IPH) reported from water damaged homes in Cleveland, $\mathrm{OH}$ which resulted in mortality $(178,179)$. Exposure to water-damaged homes resulted in 8 infants with IPH and 1 mortality and further investigation suggested the black mold, Stachybotrys chartarum was the etiological agent responsible for IPH (180-182).

S. chartarum is a dematiaceaous fungus that has been associated with a number of human and veterinary health problems (108). S. chartarum is particularly adept at growing on water infiltrated cellulose-based building materials. The morphological features of $S$. chartarum are characterized by septate hyphae and conidiophores that bear clusters of phialides from which chains of dematiaceaous conidia emerge. Identification of Stachybotrys conidia in tape lift or air samples in indoor environments is considered a biomarker of indoor fungal contamination by various federal, state, and academic institutions. Stachybotrys conidia and hyphae contain mycotoxins, allergens, proteases, and other immunostimulatory molecules $(183,184)$. Personal exposure to $S$. chartarum is also considered an etiological agent for respiratory disease (180182).

Initial investigation of the water-damaged homes in Cleveland, Ohio led to identification of mold contamination and isolation of multiple strains of $S$. chartarum $(108,185)$. Toxicity studied in strains isolated from water damaged homes and control homes suggested additional 
factors might be responsible for the pathogenicity. S. chartarum strains isolated from water damaged homes exhibited hemolytic activity in vitro when grown on wet wallboards at $37^{\circ} \mathrm{C}$ (108).

Hemolytic activity has often been associated with pathogenesis of various microorganisms $(58,186-190)$. Three strains of $S$. chartarum isolated from the homes in Cleveland where infants became sick (Cleveland strains) and from the lung of an infant patient in Houston (Houston strain) suffering from IPH showed high toxicity and hemolytic activity, suggesting a possible correlation between the hemolysin and IPH $(108,109,111,185,191)$. Cleveland and Houston strains of $S$. chartarum exhibited higher levels of hemolytic activity compared to control strains (109). In a later study it was reported that when all S. chartarum strains were grown in medium containing blood, culture supernatant (CSN) concentrate from all the strains exhibited hemolytic activity (111). These observations have been reported in a prior study (109).

Further studies led to partial purification of the hemolytic protein of S. chartarum, stachylysin and its initial biochemical characterization (110). The authors emphasized that purification of the hemolytic principle from the fungi and generation of antibodies could help develop diagnostic assays to determine fungal exposure. Detection of the hemolysin would in principle act as a surrogate biomarker for $S$. chartarum exposure. Initial characterization of stachylysin suggested it could be an aegerolysin including; 1) Using MALDI-TOF, stachylysin was identified as an $\sim 12 \mathrm{kDa}$ protein, which is the typical size of aegerolysin proteins. 2) Stachylysin contains large number of negatively charged amino acids also typically associated with aegerolysin proteins. 3) Kinetics of hemolysis was similar to that of ostreolysin, presenting an initial lag prior to hemolysis, suggesting aggregation of monomers on the surface of target 
cells. 4) The hemolytic activity of stachylysin was compromised on heat treatment at $60^{\circ} \mathrm{C}$ for 30 min. Aegerolysin proteins are heat-labile and lose their hemolytic activity at temperatures above $65^{\circ} \mathrm{C}$

Previously, the role of hemolysins in causing hemorrhagic lesions in experimental animals exposed to asp-hemolysin from A. fumigatus was established (169). The possible involvement of stachylysin in IPH was suggested based on studies performed in an earthworm (Lumbricus terrestis) model (111). Stachylysin injected into L. terrestis resulted in release of eythrocruorin hemoglobin and lethality. Furthermore, lung tissues from mice and rat exposed to S. chartarum conidia via intra-tracheal instillation developed granuloma and stachylysin was immuno-stained surrounding the conidia in the mouse lung suggesting its diffusion and possible role in damage to the tissue (112).

In a critical study in identifying this hemolysin as a biomarker for detection of exposure to $S$. chartarum, stachylysin was detected in sera of rats exposed to $S$. chartarum conidia using anti-stachylysin polyclonal antibodies raised in rabbits (53). In the same study, the data suggested that stachylysin could be detected in sera from human subjects exposed to $S$. chartarum in a water-damaged environment. Since, the levels recorded were extremely high (371 $\mathrm{ng} / \mathrm{ml})$, stachylysin was proposed as a potential quantifiable biomarker for personal exposure to S. chartarum.

\subsection{CONCLUSIONS}

Fungal hemolysins have been characterized for their role in fungal development and have been suggested as putative biomarkers for pathogenesis. Studies have identified that hemolysins are expressed in high concentrations in mycelium, which is the infective stage of fungi. There is 
limited evidence that these hemolysins might also be present in fungal conidia. Some studies have also used polyclonal antibodies to detect fungal hemolysins in sera of patients. Collectively, these observations substantiate the utility of hemolysins as putative biomarkers for fungal exposure.

We hypothesize that hemolysins are secreted during initial stages of germination and that high concentrations could be present in mycelium. Since mycelium is the invasive stage of infection, high concentration of hemolysins could be present during active infection. Hemolysins may be released into the surrounding tissues including blood and thus may be available for identification as a biomarker. In the following research we have characterized the production of hemolysins from Stachybotrys and Aspergillus terreus to determine their suitability as potential biomarkers. A previously uncharacterized hemolysin (terrelysin) from A. terreus was identified and further characterized by producing a recombinant protein expressed in Escherichia coli. Recombinant terrelysin was used to develop monoclonal antibodies (mAbs) as research tools for characterization of terrelysin production and expression in the fungi. Finally, we explore the potential use of these antibodies as diagnostic tools to test for terrelysin as a biomarker of fungal disease. 


\subsection{REFERENCES}

1. Hibbett, D. S., M. Binder, J. F. Bischoff, M. Blackwell, P. F. Cannon, O. E. Eriksson, S. Huhndorf, T. James, P. M. Kirk, R. Lucking, H. Thorsten Lumbsch, F. Lutzoni, P. B. Matheny, D. J. McLaughlin, M. J. Powell, S. Redhead, C. L. Schoch, J. W. Spatafora, J. A. Stalpers, R. Vilgalys, M. C. Aime, A. Aptroot, R. Bauer, D. Begerow, G. L. Benny, L. A. Castlebury, P. W. Crous, Y. C. Dai, W. Gams, D. M. Geiser, G. W. Griffith, C. Gueidan, D. L. Hawksworth, G. Hestmark, K. Hosaka, R. A. Humber, K. D. Hyde, J. E. Ironside, U. Koljalg, C. P. Kurtzman, K. H. Larsson, R. Lichtwardt, J. Longcore, J. Miadlikowska, A. Miller, J. M. Moncalvo, S. Mozley-Standridge, F. Oberwinkler, E. Parmasto, V. Reeb, J. D. Rogers, C. Roux, L. Ryvarden, J. P. Sampaio, A. Schussler, J. Sugiyama, R. G. Thorn, L. Tibell, W. A. Untereiner, C. Walker, Z. Wang, A. Weir, M. Weiss, M. M. White, K. Winka, Y. J. Yao, and N. Zhang. 2007. A higher-level phylogenetic classification of the Fungi. Mycol Res 111:509-547.

2. Kirk, P. M., P. F. Cannon, D. W. Minter, and J. A. Staplers. 2008. Ainsworth and Bisbyi's Dictionary of the Fungi. CAB International, Wallingford, UK.

3. Kohlmeyer, J. 1977. New genera and species of higher fungi from the deep sea. Rev Mycol 41:189-206.

4. Raghukumar, C., S. Raghukumar, G. Sheelu, S. M. Gupta, B. N. Nath, and B. R. Rao. 2004. Buried in time: culturable fungi in a deep-sea sediment core from the Chagos Trench, Indian Ocean. Deep Sea Res Part I: Ocean Res Pap 51:1759-1768.

5. Selbmann, L., G. S. de Hoog, A. Mazzaglia, E. I. Friedmann, and S. Onfori. 2005. Fungi at the edge of life: cryptoendolithic black fungi from Antarctic desert. Stud Mycol 51:112.

6. Eduard, W. 2006. Fungal spores. In The Nordic Expert Group for Criteria Documentation of health risks from chemicals. S. Marklund, ed. National Institute for Working Life, Stockholm, Sweden. 1-153.

7. Latge, J. P., and W. J. Steinbach. 2009. Aspergillus fumigatus and aspergillosis. ASM Press.

8. Osherov, N., and G. S. May. 2001. The molecular mechanisms of conidial germination. FEMS Microbiol Lett 199:153-160.

9. Osherov, N., and G. S. May. 2000. Conidial germination in Aspergillus nidulans requires RAS signaling and protein synthesis. Genetics 155:647-656.

10. Carlile, M. J., and S. C. Watkinson. 1994. The Fungi. Academic Press, London.

11. Stevens, D. A. 2009. Clinical aspergillosis for basic scientists. Med Mycol 47 Suppl 1:S14.

12. Bullock, W. E., and G. S. Deepe, Jr. 1983. Medical mycology in crisis. J Lab Clin Med 102:685-693.

13. Kurhade, A. M., J. M. Deshmukh, R. P. Fule, C. Chande, and S. Akulwar. 2002. Mycological and serological study of pulmonary aspergillosis in central India. Indian J Med Microbiol 20:141-144.

14. Hope, W. W., T. J. Walsh, and D. W. Denning. 2005. Laboratory diagnosis of invasive aspergillosis. Lancet Infect Dis 5:609-622.

15. Yuanjie, Z., D. Jingxia, W. Hai, C. Jianghan, and G. Julin. 2009. Primary cutaneous aspergillosis in a patient with cutaneous T-cell lymphoma. Mycoses 52:462-464. 
16. Paterson, D. L., and N. Singh. 1999. Invasive aspergillosis in transplant recipients. Medicine (Baltimore) 78:123-138.

17. Singh, N., and D. L. Paterson. 2005. Aspergillus infections in transplant recipients. Clin Microbiol Rev 18:44-69.

18. Young, R. C., J. E. Bennett, C. L. Vogel, P. P. Carbone, and V. T. DeVita. 1970. Aspergillosis. The spectrum of the disease in 98 patients. Medicine (Baltimore) 49:147173.

19. Meyer, R. D., L. S. Young, D. Armstrong, and B. Yu. 1973. Aspergillosis complicating neoplastic disease. Am J Med 54:6-15.

20. Fisher, B. D., D. Armstrong, B. Yu, and J. W. Gold. 1981. Aspergillosis and other systemic mycoses: the growing problem. Am J Med 71:571-577.

21. Tritz, D. M., and G. L. Woods. 1993. Fatal disseminated infection with Aspergillus terreus in immunocompromised hosts. Clin Infect Dis 16:118-122.

22. Schett, G., B. Casati, B. Willinger, G. Weinlander, T. Binder, F. Grabenwoger, W. Sperr, K. Geissler, and U. Jager. 1998. Endocarditis and aortal embolization caused by Aspergillus terreus in a patient with acute lymphoblastic leukemia in remission: diagnosis by peripheral-blood culture. J Clin Microbiol 36:3347-3351.

23. Girmenia, C., M. Nucci, and P. Martino. 2001. Clinical significance of Aspergillus fungaemia in patients with haematological malignancies and invasive aspergillosis. $\mathrm{Br} J$ Haematol 114:93-98.

24. Welsch, M. J., C. M. Moon, D. M. Elston, and P. Vogel. 2002. Invasive synergistic fungal infection after motor vehicle collision. Cutis 71:201-204.

25. Steinbach, W. J., J. R. Perfect, W. A. Schell, T. J. Walsh, and D. K. Benjamin, Jr. 2004. In vitro analyses, animal models, and 60 clinical cases of invasive Aspergillus terreus infection. Antimicrob Agents Chemother 48:3217-3225.

26. Balajee, S. A. 2009a. Aspergillus terreus complex. Med Mycol 47 Suppl 1:S42-46.

27. Loeffler, J., H. Hebart, U. Brauchle, U. Schumacher, and H. Einsele. 2000. Comparison between plasma and whole blood specimens for detection of Aspergillus DNA by PCR. $J$ Clin Microbiol 38:3830-3833.

28. Loeffler, J., K. Kloepfer, H. Hebart, L. Najvar, J. R. Graybill, W. R. Kirkpatrick, T. F. Patterson, K. Dietz, R. Bialek, and H. Einsele. 2002. Polymerase chain reaction detection of Aspergillus DNA in experimental models of invasive aspergillosis. J Infect Dis 185:1203-1206.

29. Garcia, M. E., J. L. Blanco, and V. P. Kurup. 1998. Identification of Aspergillus fumigatus by PCR. Rev Iberoam Micol 15:25-27.

30. Costa, C., J. M. Costa, C. Desterke, F. Botterel, C. Cordonnier, and S. Bretagne. 2002. Real-time PCR coupled with automated DNA extraction and detection of galactomannan antigen in serum by enzyme-linked immunosorbent assay for diagnosis of invasive aspergillosis. J Clin Microbiol 40:2224-2227.

31. Spiess, B., D. Buchheidt, C. Baust, H. Skladny, W. Seifarth, U. Zeilfelder, C. LeibMosch, H. Morz, and R. Hehlmann. 2003. Development of a LightCycler PCR assay for detection and quantification of Aspergillus fumigatus DNA in clinical samples from neutropenic patients. J Clin Microbiol 41:1811-1818.

32. Einsele, H., H. Hebart, G. Roller, J. Loffler, I. Rothenhofer, C. A. Muller, R. A. Bowden, J. van Burik, D. Engelhard, L. Kanz, and U. Schumacher. 1997. Detection and 
identification of fungal pathogens in blood by using molecular probes. J Clin Microbiol 35:1353-1360.

33. Kami, M., T. Fukui, S. Ogawa, Y. Kazuyama, U. Machida, Y. Tanaka, Y. Kanda, T. Kashima, Y. Yamazaki, T. Hamaki, S. Mori, H. Akiyama, Y. Mutou, H. Sakamaki, K. Osumi, S. Kimura, and H. Hirai. 2001. Use of real-time PCR on blood samples for diagnosis of invasive aspergillosis. Clin Infect Dis 33:1504-1512.

34. Loeffler, J., H. Hebart, U. Schumacher, H. Reitze, and H. Einsele. 1997. Comparison of different methods for extraction of DNA of fungal pathogens from cultures and blood. $J$ Clin Microbiol 35:3311-3312.

35. Buckley, M. 2007. The Fungal Kingdom: Diverse and essential roles in earth's ecosystem. A. A. o. Microbiology, ed. American Academy of Microbiology, Washington, DC. 1-44.

36. Maertens, J., K. Theunissen, G. Verhoef, J. Verschakelen, K. Lagrou, E. Verbeken, A. Wilmer, J. Verhaegen, M. Boogaerts, and J. Van Eldere. 2005. Galactomannan and computed tomography-based preemptive antifungal therapy in neutropenic patients at high risk for invasive fungal infection: a prospective feasibility study. Clin Infect Dis 41:1242-1250.

37. Hope, W. W., and D. W. Denning. 2004. Invasive aspergillosis: current and future challenges in diagnosis and therapy. Clin Microbiol Infect 10:2-4.

38. Chang, S. W., and T. E. King. 1986. Aspergillus terreus causing invasive pulmonary aspergillosis with air-crescent sign. $J$ Natl Med Assoc 78:248, 251-243.

39. Caillot, D., O. Casasnovas, A. Bernard, J. F. Couaillier, C. Durand, B. Cuisenier, E. Solary, F. Piard, T. Petrella, A. Bonnin, G. Couillault, M. Dumas, and H. Guy. 1997. Improved management of invasive pulmonary aspergillosis in neutropenic patients using early thoracic computed tomographic scan and surgery. J Clin Oncol 15:139-147.

40. Burgos, A., T. E. Zaoutis, C. C. Dvorak, J. A. Hoffman, K. M. Knapp, J. J. Nania, P. Prasad, and W. J. Steinbach. 2008. Pediatric invasive aspergillosis: a multicenter retrospective analysis of 139 contemporary cases. Pediatrics 121:e1286-1294.

41. Segal, B. H. 2009. Aspergillosis. N Engl J Med 360:1870-1884.

42. Kammer, R. B., and J. P. Utz. 1974. Aspergillus species endocarditis. The new face of a not so rare disease. Am J Med 56:506-521.

43. Holmberg, K., M. Berdischewsky, and L. S. Young. 1980. Serologic immunodiagnosis of of invasive aspergillosis. J Infect Dis 141:656-664.

44. Burnie, J. P., R. C. Matthews, I. Clark, and L. J. Milne. 1989. Immunoblot fingerprinting Aspergillus fumigatus. J Immunol Methods 118:179-186.

45. Young, R. C., and J. E. Bennett. 1971. Invasive aspergillosis. Absence of detectable antibody response. Am Rev Respir Dis 104:710-716.

46. Stynen, D., A. Goris, J. Sarfati, and J. P. Latge. 1995. A new sensitive sandwich enzymelinked immunosorbent assay to detect galactofuran in patients with invasive aspergillosis. J Clin Microbiol 33:497-500.

47. Segal, B. H., and T. J. Walsh. 2006. Current approaches to diagnosis and treatment of invasive aspergillosis. Am J Respir Crit Care Med 173:707-717.

48. Pfeiffer, C. D., J. P. Fine, and N. Safdar. 2006. Diagnosis of invasive aspergillosis using a galactomannan assay: a meta-analysis. Clin Infect Dis 42:1417-1427. 
49. Latge, J. P. 1999. Aspergillus fumigatus and aspergillosis. Clin Microbiol Rev 12:310350.

50. Haynes, K. A., J. P. Latge, and T. R. Rogers. 1990. Detection of Aspergillus antigens associated with invasive aspergillosis. J Clin Microbiol 28:2040-2044.

51. Latge, J. P., M. Moutaouakil, J. P. Debeaupuis, J. P. Bouchara, K. Haynes, and M. C. Prevost. 1991. The 18-kilodalton antigen secreted by Aspergillus fumigatus. Infect Immun 59:2586-2594.

52. Haynes, K. A., P. Tuinstra, T. A. Hughes, L. M. Wijnands, T. R. Rogers, and A. K. Allen. 1996. Purification and characterization of a $93 \mathrm{kDa}$ Aspergillus fumigatus antigen with diagnostic potential. J Med Vet Mycol 34:421-426.

53. Van Emon, J. M., A. W. Reed, I. Yike, and S. J. Vesper. 2003. ELISA measurement of stachylysin in serum to quantify human exposures to the indoor mold Stachybotrys chartarum. J Occup Environ Med 45:582-591.

54. McGinnis, M. R. 2004. Pathogenesis of indoor fungal diseases. Med Mycol 42:107-117.

55. Vesper, S. J., and M. J. Vesper. 2004. Possible role of fungal hemolysins in sick building syndrome. Adv Appl Microbiol 55:191-213.

56. Ebina, K., K. Yokota, and O. Sakaguchi. 1982. Studies on toxin of Aspergillus fumigatus XIV: Relationship between Asp-hemolysin and experimental infection in mice. Jpn J Med Mycol 23:246-252.

57. Bhakdi, S., F. Grimminger, N. Suttorp, D. Walmrath, and W. Seeger. 1994. Proteinaceous bacterial toxins and pathogenesis of sepsis syndrome and septic shock: the unknown connection. Med Microbiol Immunol 183:119-144.

58. Bhakdi, S., H. Bayley, A. Valeva, I. Walev, B. Walker, M. Kehoe, and M. Palmer. 1996. Staphylococcal alpha-toxin, streptolysin-O, and Escherichia coli hemolysin: prototypes of pore-forming bacterial cytolysins. Arch Microbiol 165:73-79.

59. Henrici, A. T. 1939. An endotoxin from Aspergillus fumigatus. J Immunology 36:319338.

60. Salvin, S. B. 1951. Hemolysin from the yeast-like phases of some pathogenic fungi. Proc Soc Exp Biol Med 76:852-854.

61. Berne, S., L. Lah, and K. Sepcic. 2009. Aegerolysins: structure, function, and putative biological role. Protein Sci 18:694-706.

62. Fedorova, N. D., N. Khaldi, V. S. Joardar, R. Maiti, P. Amedeo, M. J. Anderson, J. Crabtree, J. C. Silva, J. H. Badger, A. Albarraq, S. Angiuoli, H. Bussey, P. Bowyer, P. J. Cotty, P. S. Dyer, A. Egan, K. Galens, C. M. Fraser-Liggett, B. J. Haas, J. M. Inman, R. Kent, S. Lemieux, I. Malavazi, J. Orvis, T. Roemer, C. M. Ronning, J. P. Sundaram, G. Sutton, G. Turner, J. C. Venter, O. R. White, B. R. Whitty, P. Youngman, K. H. Wolfe, G. H. Goldman, J. R. Wortman, B. Jiang, D. W. Denning, and W. C. Nierman. 2008. Genomic islands in the pathogenic filamentous fungus Aspergillus fumigatus. PLoS Genet 4:e1000046.

63. Tilden, E. B., S. Freeman, and L. Lombard. 1963. Further Studies of the Aspergillus Endotoxins. Mycopathol Mycol Appl 20:253-271.

64. Payne, W. G. A., R. A. Dean, W. C. Nierman, P. Amedeo, E. G. A. Caler, N. D. Fedorova, R. Maiti, V. Joardar, J. Inman, K. J. Galinsky, J. Yu, and D. Bhatnagar. 2007. Genome sequence of Aspergillus flavus strain NRRL 3357. EMBL/GenBank/DDBJ databases. 
65. Yokota, K., H. Shimada, A. Kamaguchi, and O. Sakaguchi. 1977. Studies on the toxin of Aspergillus fumigatus VII. Purification and some properities of hemolytic toxin (asphemolysin) from culture filtrates and mycelia. Microbiol Immunol 21:11-22.

66. Ebina, K., S. Ichinowatari, and K. Yokota. 1984. Studies on toxin of Aspergillus fumigatus XIX: Biochemical alterations of sera after Asp-hemolysin inoculation or Aspergillus infection in mice. Jpn J Med Mycol 25.

67. Fukuchi, Y., T. Kumagai, K. Ebina, and K. Yokota. 1996b. Apolipoprotein B inhibits the hemolytic activity of asp-hemolysin from Aspergillus fumigatus. Biol Pharm Bull 19:547-550.

68. Fukuchi, Y., Y. Kudo, T. Kumagai, K. Ebina, and K. Yokota. 1998. Oxidized low density lipoprotein inhibits the hemolytic activity of Asp-hemolysin from Aspergillus fumigatus. FEMS Microbiol Lett 167:275-280.

69. Kudo, Y., Y. Fukuchi, T. Kumagai, K. Ebina, and K. Yokota. 2001. Oxidized lowdensity lipoprotein-binding specificity of Asp-hemolysin from Aspergillus fumigatus. Biochim Biophys Acta 1568:183-188.

70. Kudo, Y., T. Ootani, T. Kumagai, Y. Fukuchi, K. Ebina, and K. Yokota. 2002. A novel oxidized low-density lipoprotein-binding protein, Asp-hemolysin, recognizes lysophosphatidylcholine. Biol Pharm Bull 25:787-790.

71. Kumagai, T., Y. Kudo, Y. Fukuchi, K. Ebina, and K. Yokota. 2002. Expression of a synthetic gene encoding the Asp-hemolysin from Aspergillus fumigatus in Escherichia coli. Biol Pharm Bull 25:115-117.

72. Kumagai, T., H. Tsutsumi, N. Ogawa, S. Naito, K. Ebina, K. Yokota, and K. Nagata. 2006. Oxidized low-density lipoprotein-binding specificity of the Asp-hemolysin-related synthetic peptides from Aspergillus fumigatus. Biol Pharm Bull 29:2181-2186.

73. Tsutsumi, H., T. Kumagai, S. Naitoo, K. Ebina, and K. Yokota. 2006. Synthetic peptide (P-21) derived from Asp-hemolysin inhibits the induction of apoptosis on HUVECs by lysophosphatidylcholine. Biol Pharm Bull 29:907-910.

74. Wartenberg, D., K. Lapp, I. D. Jacobsen, H. M. Dahse, O. Kniemeyer, T. Heinekamp, and A. A. Brakhage. 2011. Secretome analysis of Aspergillus fumigatus reveals Asphemolysin as a major secreted protein. Int J Med Microbiol 301:602-611.

75. Nierman, W. C., A. Pain, M. J. Anderson, J. R. Wortman, H. S. Kim, J. Arroyo, M. Berriman, K. Abe, D. B. Archer, C. Bermejo, J. Bennett, P. Bowyer, D. Chen, M. Collins, R. Coulsen, R. Davies, P. S. Dyer, M. Farman, N. Fedorova, T. V. Feldblyum, R. Fischer, N. Fosker, A. Fraser, J. L. Garcia, M. J. Garcia, A. Goble, G. H. Goldman, K. Gomi, S. Griffith-Jones, R. Gwilliam, B. Haas, H. Haas, D. Harris, H. Horiuchi, J. Huang, S. Humphray, J. Jimenez, N. Keller, H. Khouri, K. Kitamoto, T. Kobayashi, S. Konzack, R. Kulkarni, T. Kumagai, A. Lafon, J. P. Latge, W. Li, A. Lord, C. Lu, W. H. Majoros, G. S. May, B. L. Miller, Y. Mohamoud, M. Molina, M. Monod, I. Mouyna, S. Mulligan, L. Murphy, S. O'Neil, I. Paulsen, M. A. Penalva, M. Pertea, C. Price, B. L. Pritchard, M. A. Quail, E. Rabbinowitsch, N. Rawlins, M. A. Rajandream, U. Reichard, H. Renauld, G. D. Robson, S. Rodriguez de Cordoba, J. M. Rodriguez-Pena, C. M. Ronning, S. Rutter, S. L. Salzberg, M. Sanchez, J. C. Sanchez-Ferrero, D. Saunders, K. Seeger, R. Squares, S. Squares, M. Takeuchi, F. Tekaia, G. Turner, C. R. Vazquez de Aldana, J. Weidman, O. White, J. Woodward, J. H. Yu, C. Fraser, J. E. Galagan, K. Asai, M. Machida, N. Hall, B. Barrell, and D. W. Denning. 2005. Genomic sequence of the 
pathogenic and allergenic filamentous fungus Aspergillus fumigatus. Nature 438:11511156.

76. Galagan, J. E., S. E. Calvo, C. Cuomo, L. J. Ma, J. R. Wortman, S. Batzoglou, S. I. Lee, M. Basturkmen, C. C. Spevak, J. Clutterbuck, V. Kapitonov, J. Jurka, C. Scazzocchio, M. Farman, J. Butler, S. Purcell, S. Harris, G. H. Braus, O. Draht, S. Busch, C. D'Enfert, C. Bouchier, G. H. Goldman, D. Bell-Pedersen, S. Griffiths-Jones, J. H. Doonan, J. Yu, K. Vienken, A. Pain, M. Freitag, E. U. Selker, D. B. Archer, M. A. Penalva, B. R. Oakley, M. Momany, T. Tanaka, T. Kumagai, K. Asai, M. Machida, W. C. Nierman, D. W. Denning, M. Caddick, M. Hynes, M. Paoletti, R. Fischer, B. Miller, P. Dyer, M. S. Sachs, S. A. Osmani, and B. W. Birren. 2005. Sequencing of Aspergillus nidulans and comparative analysis with A. fumigatus and A. oryzae. Nature 438:1105-1115.

77. Wortman, J. R., J. M. Gilsenan, V. Joardar, J. Deegan, J. Clutterbuck, M. R. Andersen, D. Archer, M. Bencina, G. Braus, P. Coutinho, H. von Dohren, J. Doonan, A. J. Driessen, P. Durek, E. Espeso, E. Fekete, M. Flipphi, C. G. Estrada, S. Geysens, G. Goldman, P. W. de Groot, K. Hansen, S. D. Harris, T. Heinekamp, K. Helmstaedt, B. Henrissat, G. Hofmann, T. Homan, T. Horio, H. Horiuchi, S. James, M. Jones, L. Karaffa, Z. Karanyi, M. Kato, N. Keller, D. E. Kelly, J. A. Kiel, J. M. Kim, I. J. van der Klei, F. M. Klis, A. Kovalchuk, N. Krasevec, C. P. Kubicek, B. Liu, A. Maccabe, V. Meyer, P. Mirabito, M. Miskei, M. Mos, J. Mullins, D. R. Nelson, J. Nielsen, B. R. Oakley, S. A. Osmani, T. Pakula, A. Paszewski, I. Paulsen, S. Pilsyk, I. Pocsi, P. J. Punt, A. F. Ram, Q. Ren, X. Robellet, G. Robson, B. Seiboth, P. van Solingen, T. Specht, J. Sun, N. Taheri-Talesh, N. Takeshita, D. Ussery, P. A. vanKuyk, H. Visser, P. J. van de Vondervoort, R. P. de Vries, J. Walton, X. Xiang, Y. Xiong, A. P. Zeng, B. W. Brandt, M. J. Cornell, C. A. van den Hondel, J. Visser, S. G. Oliver, and G. Turner. 2009. The 2008 update of the Aspergillus nidulans genome annotation: a community effort. Fungal Genet Biol 46 Suppl 1:S2-13.

78. Pel, H. J., J. H. de Winde, D. B. Archer, P. S. Dyer, G. Hofmann, P. J. Schaap, G. Turner, R. P. de Vries, R. Albang, K. Albermann, M. R. Andersen, J. D. Bendtsen, J. A. Benen, M. van den Berg, S. Breestraat, M. X. Caddick, R. Contreras, M. Cornell, P. M. Coutinho, E. G. Danchin, A. J. Debets, P. Dekker, P. W. van Dijck, A. van Dijk, L. Dijkhuizen, A. J. Driessen, C. d'Enfert, S. Geysens, C. Goosen, G. S. Groot, P. W. de Groot, T. Guillemette, B. Henrissat, M. Herweijer, J. P. van den Hombergh, C. A. van den Hondel, R. T. van der Heijden, R. M. van der Kaaij, F. M. Klis, H. J. Kools, C. P. Kubicek, P. A. van Kuyk, J. Lauber, X. Lu, M. J. van der Maarel, R. Meulenberg, H. Menke, M. A. Mortimer, J. Nielsen, S. G. Oliver, M. Olsthoorn, K. Pal, N. N. van Peij, A. F. Ram, U. Rinas, J. A. Roubos, C. M. Sagt, M. Schmoll, J. Sun, D. Ussery, J. Varga, W. Vervecken, P. J. van de Vondervoort, H. Wedler, H. A. Wosten, A. P. Zeng, A. J. van Ooyen, J. Visser, and H. Stam. 2007. Genome sequencing and analysis of the versatile cell factory Aspergillus niger CBS 513.88. Nat Biotechnol 25:221-231.

79. Braaksma, M., E. S. Uzunova-Martens, P. J. Punt, and P. J. Schaap. 2010. An inventory of the Aspergillus niger secretome by combining in silico predictions with shotgun proteomics data. BMC Genomics 11:584.

80. Andersen, M. R., M. P. Salazar, P. J. Schapp, P. J. van de Vondervoort, D. Culley, J. Thykaer, J. C. Frisvad, K. F. Nielsen, R. Albang, K. Albermann, R. M. Berka, G. H. Braus, S. A. Braus-Stromeyer, L. M. Corrochano, Z. Dai, P. W. van Dijck, G. Hofmann, L. L. Lasure, J. K. Magnuson, H. Menke, M. Meijer, S. L. Meijer, J. B. Nielsen, M. L. 
Nielsen, A. J. van Ooyen, H. J. Pel, L. Poulsen, R. A. Samson, H. Stam, A. Tsang, J. M. van den Brink, A. Atkins, A. Aerts, H. Shapiro, J. Pangilinan, A. Salamov, Y. Lou, E. Lindquist, S. Lucas, J. Grimwood, I. V. Grigoriev, C. P. Kubicek, D. Martinez, N. N. van Peij, J. A. Roubos, J. Nielsen, and S. E. Baker. 2011. Comparative genomics of citricacid-producing Aspergillus niger ATCC 1015 versus enzyme-producing CBS 513.88. Genome Res 21:885-897.

81. Donohue, M., W. Wei, J. Wu, N. H. Zawia, N. Hud, V. De Jesus, D. Schmechel, J. M. Hettick, D. H. Beezhold, and S. Vesper. 2006. Characterization of nigerlysin, hemolysin produced by Aspergillus niger, and effect on mouse neuronal cells in vitro. Toxicology 219:150-155.

82. Machida, M., K. Asai, M. Sano, T. Tanaka, T. Kumagai, G. Terai, K. Kusumoto, T. Arima, O. Akita, Y. Kashiwagi, K. Abe, K. Gomi, H. Horiuchi, K. Kitamoto, T. Kobayashi, M. Takeuchi, D. W. Denning, J. E. Galagan, W. C. Nierman, J. Yu, D. B. Archer, J. W. Bennett, D. Bhatnagar, T. E. Cleveland, N. D. Fedorova, O. Gotoh, H. Horikawa, A. Hosoyama, M. Ichinomiya, R. Igarashi, K. Iwashita, P. R. Juvvadi, M. Kato, Y. Kato, T. Kin, A. Kokubun, H. Maeda, N. Maeyama, J. Maruyama, H. Nagasaki, T. Nakajima, K. Oda, K. Okada, I. Paulsen, K. Sakamoto, T. Sawano, M. Takahashi, K. Takase, Y. Terabayashi, J. R. Wortman, O. Yamada, Y. Yamagata, H. Anazawa, Y. Hata, Y. Koide, T. Komori, Y. Koyama, T. Minetoki, S. Suharnan, A. Tanaka, K. Isono, S. Kuhara, N. Ogasawara, and H. Kikuchi. 2005. Genome sequencing and analysis of Aspergillus oryzae. Nature 438:1157-1161.

83. Bando, H., H. Hisada, H. Ishida, Y. Hata, Y. Katakura, and A. Kondo. 2011. Isolation of a novel promoter for efficient protein expression by Aspergillus oryzae in solid-state culture. Appl Microbiol Biotechnol 92:561-569.

84. Birren, B. W., E. S. Lander, J. E. Galagan, C. Nusbaum, K. Devon, M. Henn, L. J. Ma, D. B. Jaffe, J. Butler, P. Alvarez, S. Gnerre, M. Grabherr, M. Kleber, E. W. Mauceli, W. Brockman, S. Rounsley, S. K. Young, K. LaButti, and K. Madden. 2005. Annotation of the Aspergillus terreus NIH264 genome. EMBL/GenBank/DDBJ databases.

85. Bonilla-Soto, O., N. R. Rose, and C. E. Arbesman. 1961. Allergenic molds, antigenic and allergenic properties of Alternaria tenuis. J Allergy 32.

86. Champion, M., C. A. Cuomo, L. J. Ma, M. R. Henn, B. Klein, B. Goldman, S. K. Young, C. D. Kodira, Q. Zeng, M. Koehersen, L. Alvarado, A. M. Berlin, D. I. Heiman, T. A. Hepburn, S. Saif, T. D. Shea, N. Shenoy, S. Sykes, and B. W. Birren. 2009b. The genome sequence of Blastomyces dermatitidis strain ER-3. EMBL/GenBank/DDBJ databases.

87. Champion, M., C. A. Cuomo, L. J. Ma, M. R. Henn, B. Klein, B. Goldman, S. K. Young, C. D. Kodira, Q. Zeng, M. Koehersen, L. Alvarado, A. M. Berlin, D. I. Heiman, T. A. Hepburn, S. Saif, T. D. Shea, N. Shenoy, S. Sykes, and B. W. Birren. 2009c. The genome sequence of Blastomyces dermatitidis strain SLH14081. EMBL/GenBank/DDBJ databases.

88. Cuomo, C., B. Klein, T. Sullivan, J. Heitman, S. K. Young, Q. Zeng, S. Gargeya, L. Alvarado, A. M. Berlin, S. B. Chapman, Z. Chen, E. Freedman, M. Gellesch, J. Goldberg, A. Griggs, S. Gujja, E. Heilman, D. Heiman, and B. W. Birren. 2010. Annotation of Blastomyces dermatitidis strain ATCC 18188. EMBL/GenBank/DDBJ databases. 
89. Odds, F. C. 1997. Switch of phenotype as an escape mechanism of the intruder. Mycoses 40.

90. Manns, J. M., D. M. Mosser, and H. R. Buckley. 1994. Production of a hemolytic factor by Candida albicans. Infect Immun 62:5154-5156.

91. Lachke, S. A., T. Srikantha, L. K. Tsai, K. Daniels, and D. R. Soll. 2000. Phenotypic switching in Candida glabrata involves phase-specific regulation of the metallothionein gene MT-II and the newly discovered hemolysin gene HLP. Infect Immun 68:884-895.

92. Sharpton, T. J., J. E. Stajich, S. D. Rounsley, M. J. Gardner, J. R. Wortman, V. S. Jordar, R. Maiti, C. D. Kodira, D. E. Neafsey, Q. Zeng, C. Y. Hung, C. McMahan, A. Muszewska, M. Grynberg, M. A. Mandel, E. M. Kellner, B. M. Barker, J. N. Galgiani, M. J. Orbach, T. N. Kirkland, G. T. Cole, M. R. Henn, B. W. Birren, and J. W. Taylor. 2009. Comparative genomic analyses of the human fungal pathogens Coccidioides and their relatives. Genome Res 19:1722-1731.

93. Zheng, P., Y. Xia, G. Xiao, C. Xiong, S. Shi, W. Huang, Y. Shang, X. Hu, L. Li, Q. Gao, S. Zhang, Z. Duan, B. Wang, H. Zheng, Y. Huang, Y. Zhou, S. Wang, G. P. Zhao, and C. Wang. 2011. Cordyceps militaris genome sequencing Consortium. EMBL/GenBank/DDBJ databases.

94. Thatcher, L. F., D. M. Gardiner, K. Kazan, and J. M. Manners. 2012. A highly conserved effector in Fusarium oxysporum is required for full virulence on Arabidopsis. Mol Plant Microbe Interact 25:180-190.

95. Champion, M., C. A. Cuomo, L. J. Ma, M. R. Henn, A. Sil, B. Goldman, S. K. Young, C. D. Kodira, Q. Zeng, M. Koehersen, L. Alvardo, A. Berlin, D. Borenstein, Z. Chen, R. Engels, E. Freedman, M. Gellesch, J. Goldberg, and B. W. Birren. 2009a. The genome sequence of Ajellomyces capsulatus strain G186AR. EMBL/GenBank/DDJ databases.

96. Champion, M., C. A. Cuomo, L. J. Ma, M. R. Henn, A. Sil, B. Goldman, S. K. Young, C. D. Kodira, Q. Zeng, M. Koehersen, L. Alvarado, A. M. Berlin, D. Borenstein, Z. Chen, R. Engels, E. Freedman, M. Gellesch, J. Goldberg, and B. W. Birren. 2009d. The genome sequence of Ajellomyces capsulatus strain H143. EMBL/GenBank/DDBJ databases.

97. Champion, M., C. Cuomo, L. J. Ma, M. R. Henn, A. Sil, B. Goldman, S. K. Young, C. D. Kodira, Q. Zeng, M. Koehersen, L. Alvarado, A. Berlin, D. Borenstein, Z. Chen, R. Engels, E. Freedman, M. Gellesch, J. Goldberg, and B. W. Birren. 2008. Annotation of Ajellomyces capsulatus strain H88. EMBL/GenBank/DDBJ databases.

98. Gao, Q., K. Jin, S. H. Ying, Y. Zhang, G. Xiao, Y. Shang, Z. Duan, X. Hu, X. Q. Xie, G. Zhou, G. Peng, Z. Luo, W. Huang, B. Wang, W. Fang, S. Wang, Y. Zhong, L. J. Ma, R. J. St. Leger, G. P. Zhao, Y. Pei, M. G. Feng, Y. Xia, and C. Wang. 2011. Genome sequencing and comparative transcriptomics of the model entomopathogenic fungi Metarhizium anisopliae and M. acridum. PLoS Genet 7:e1001264.

99. Coleman, J. J., S. D. Rounsley, M. Rodriguez-Carres, A. Kuo, C. C. Wasmann, J. Grimwood, J. Schmutz, M. Taga, G. J. White, S. Zhou, D. C. Schwartz, M. Freitag, L. J. Ma, E. G. Danchin, B. Henrissat, P. M. Coutinho, D. R. Nelson, D. Straney, C. A. Napoli, B. M. Barker, M. Gribskov, M. Rep, S. Kroken, I. Molnar, C. Rensing, J. C. Kennell, J. Zamora, M. L. Farman, E. U. Selker, A. Salamov, H. Shapiro, J. Pangilinan, E. Lindquist, C. Lamers, I. V. Grigoriev, D. M. Geiser, S. M. Covert, E. Temporini, and H. D. Vanetten. 2009. The genome of Nectria haematococca: a contribution of supernumerary chromosomes to gene expansion. PLoS Genet 5:e1000618. 
100. Galagan, J. E., S. E. Calvo, K. A. Borkovich, E. U. Selker, N. D. Read, D. Jaffe, W. FitzHugh, L. J. Ma, S. Smirnov, S. Purcell, B. Rehman, T. Elkins, R. Engels, S. Wang, C. B. Nielsen, J. Butler, M. Endrizzi, D. Qui, P. Ianakiev, D. Bell-Pedersen, M. A. Nelson, M. Werner-Washburne, C. P. Selitrennikoff, J. A. Kinsey, E. L. Braun, A. Zelter, U. Schulte, G. O. Kothe, G. Jedd, W. Mewes, C. Staben, E. Marcotte, D. Greenberg, A. Roy, K. Foley, J. Naylor, N. Stange-Thomann, R. Barrett, S. Gnerre, M. Kamal, M. Kamvysselis, E. Mauceli, C. Bielke, S. Rudd, D. Frishman, S. Krystofova, C. Rasmussen, R. L. Metzenberg, D. D. Perkins, S. Kroken, C. Cogoni, G. Macino, D. Catcheside, W. Li, R. J. Pratt, S. A. Osmani, C. P. DeSouza, L. Glass, M. J. Orbach, J. A. Berglund, R. Voelker, O. Yarden, M. Plamann, S. Seiler, J. Dunlap, A. Radford, R. Aramayo, D. O. Natvig, L. A. Alex, G. Mannhaupt, D. J. Ebbole, M. Freitag, I. Paulsen, M. S. Sachs, E. S. Lander, C. Nusbaum, and B. Birren. 2003. The genome sequence of the filamentous fungus Neurospora crassa. Nature 422:859-868.

101. Ellison, C. E., J. E. Stajich, D. J. Jacobson, D. O. Natvig, A. Lapidus, B. Foster, A. Aerts, R. Riley, E. A. Lindquist, I. V. Grigoriev, and J. W. Taylor. 2011. Massive changes in genome architecture accompany the transition of self-fertility in the filamentous fungus Neurospora tetrasperma. Genetics 189:55-69.

102. McEwen, J. G., R. Puccia, G. H. Goldman, M. S. Felipe, L. J. Ma, M. R. Henn, D. B. Jaffe, S. K. Young, S. Gnerre, A. Berlin, D. Heiman, T. Hepburn, S. Sykes, C. Yandava, L. Alvarado, C. D. Kodira, R. Guigo, M. Borodovsky, and B. W. Birren. 2007. Annotation of Paracoccidioides brasiliensis Pb03. EMBL/GenBank/DDBJ databases.

103. McEwen, J. G., R. Puccia, G. H. Goldman, M. S. Felipe, L. J. Ma, M. R. Henn, M. Champion, C. Cuomo, D. B. Jaffe, S. K. Young, S. Gnerre, A. Berlin, D. Heiman, T. Hepburn, S. Sykes, C. Yandava, L. Alvarado, C. D. Kodira, and B. W. Birren. 2008a. Annotation of Paracoccidioides brasiliensis Pb18. EMBL/GenBank/DDBJ databases.

104. McEwen, J. G., R. Puccia, G. H. Goldman, M. S. Felipe, L. J. Ma, M. R. Henn, M. Champion, C. Cuomo, D. B. Jaffe, S. K. Young, S. Gnerre, A. Berlin, D. Heiman, T. Hepburn, S. Sykes, C. Yandava, L. Alvarado, C. D. Kodira, and B. W. Birren. 2008b. Annotation of Paracoccidioides brasiliensis Pb01. EMBL/GenBank/DDBJ databases.

105. van den Berg, M. A., R. Albang, K. Albermann, J. H. Badger, J. M. Daran, A. J. Driessen, C. Garcia-Estrada, N. D. Fedorova, D. M. Harris, W. H. Heijne, V. Joardar, J. A. Kiel, A. Kovalchuk, J. F. Martin, W. C. Nierman, J. G. Nijland, J. T. Pronk, J. A. Roubos, I. J. van der Klei, N. N. van Peij, M. Veenhuis, H. von Dohren, C. Wagner, J. Wortman, and R. A. Bovenberg. 2008. Genome sequencing and analysis of the filamentous fungus Penicillium chrysogenum. Nat Biotechnol 26:1161-1168.

106. Donohue, M., Y. Chung, M. L. Magnuson, M. Ward, M. J. Selgrade, and S. Vesper. 2005. Hemolysin chrysolysin from Penicillium chrysogenum promotes inflammatory response. Int J Hyg Environ Health 208:279-285.

107. Nowrousian, M., J. E. Stajich, M. Chu, I. Engh, E. Espagne, K. Halliday, J. Kamerewerd, F. Kempken, B. Knab, H. C. Kuo, H. D. Osiewacz, S. Poggler, N. D. Read, S. Seiler, K. M. Smith, D. Zickler, U. Kuck, and M. Freitag. 2010. De novo assembly of a $40 \mathrm{Mb}$ eukaryotic genome from short sequence reads: Sordaria macrospora, a model organism for fungal morphogenesis. PLoS Genet 6:e1000891. 
108. Vesper, S. J., D. G. Dearborn, I. Yike, W. G. Sorenson, and R. A. Haugland. 1999. Hemolysis, toxicity, and randomly amplified polymorphic DNA analysis of Stachybotrys chartarum strains. Appl Environ Microbiol 65:3175-3181.

109. Vesper, S. J., D. G. Dearborn, O. Elidemir, and R. A. Haugland. 2000b. Quantification of siderophore and hemolysin from Stachybotrys chartarum strains, including a strain isolated from the lung of a child with pulmonary hemorrhage and hemosiderosis. Appl Environ Microbiol 66:2678-2681.

110. Vesper, S. J., M. L. Magnuson, D. G. Dearborn, I. Yike, and R. A. Haugland. 2001. Initial characterization of the hemolysin stachylysin from Stachybotrys chartarum. Infect Immun 69:912-916.

111. Vesper, S. J., and M. J. Vesper. 2002. Stachylysin may be a cause of hemorrhaging in humans exposed to Stachybotrys chartarum. Infect Immun 70:2065-2069.

112. Gregory, L., T. G. Rand, D. Dearborn, I. Yike, and S. Vesper. 2003. Immunocytochemical localization of stachylysin in Stachybotrys chartarum spores and spore-impacted mouse and rat lung tissue. Mycopathologia 156:109-117.

113. Schaufuss, P., and U. Steller. 2003. Haemolytic activities of Trichophyton species. Med Mycol 41:511-516.

114. Mondego, J. M., M. F. Carazzolle, G. G. Costa, E. F. Formighieri, L. P. Parizzi, J. Rincones, C. Cotomacci, D. M. Carraro, A. F. Cunha, H. Carrer, R. O. Vidal, R. C. Estrela, O. Garcia, D. P. Thomazella, B. V. de Oliveira, A. B. Pires, M. C. Rio, M. R. Araujo, M. H. de Moraes, L. A. Castro, K. P. Gramacho, M. S. Goncalves, J. P. Neto, A. G. Neto, L. V. Barbosa, M. J. Guiltinan, B. A. Bailey, L. W. Meinhardt, J. C. Cascardo, and G. A. Pereira. 2008. A genome survey of Moniliophthora perniciosa gives new insights into Witches' Broom Disease of cacao. BMC Genomics 9:548.

115. Pires, A. B., K. P. Gramacho, D. C. Silva, A. Goes-Neto, M. M. Silva, J. S. MunizSobrinho, R. F. Porto, C. Villela-Dias, M. Brendel, J. C. Cascardo, and G. A. Pereira. 2009. Early development of Moniliophthora perniciosa basidiomata and developmentally regulated genes. BMC Microbiol 9:158.

116. Fernandez Espinar, M. T., and J. Labarere. 1997. Cloning and sequencing of the Aa-Pri1 gene specifically expressed during fruiting initiation in the edible mushroom Agrocybe aegerita, and analysis of the predicted amino-acid sequence. Curr Genet 32:420-424.

117. Berne, S., I. Krizaj, F. Pohleven, T. Turk, P. Macek, and K. Sepcic. 2002. Pleurotus and Agrocybe hemolysins, new proteins hypothetically involved in fungal fruiting. Biochim Biophys Acta 1570:153-159.

118. Shibata, T., M. Kudou, Y. Hoshi, A. Kudo, N. Nanashima, and K. Miyairi. 2010. Isolation and characterization of a novel two-component hemolysin, erylysin $\mathrm{A}$ and $\mathrm{B}$, from an edible mushroom, Pleurotus eryngii. Toxicon 56:1436-1442.

119. Ngai, P. H., and T. B. Ng. 2006. A hemolysin from the mushroom Pleurotus eryngii. Appl Microbiol Biotechnol 72:1185-1191.

120. Bernheimer, A. W., and L. S. Avigad. 1979. A cytolytic protein from the edible mushroom, Pleurotus ostreatus. Biochim Biophys Acta 585:451-461.

121. Sepcic, K., S. Berne, C. Potrich, T. Turk, P. Macek, and G. Menestrina. 2003. Interaction of ostreolysin, a cytolytic protein from the edible mushroom Pleurotus ostreatus, with lipid membranes and modulation by lysophospholipids. Eur J Biochem 270:1199-1210. 
122. Sepcic, K., S. Berne, K. Rebolj, U. Batista, A. Plemenitas, M. Sentjurc, and P. Macek. 2004. Ostreolysin, a pore-forming protein from the oyster mushroom, interacts specifically with membrane cholesterol-rich lipid domains. FEBS Lett 575:81-85.

123. Berne, S., K. Sepcic, G. Anderluh, T. Turk, P. Macek, and N. Poklar Ulrih. 2005. Effect of $\mathrm{pH}$ on the pore forming activity and conformational stability of ostreolysin, a lipid raft-binding protein from the edible mushroom Pleurotus ostreatus. Biochemistry 44:11137-11147.

124. Vidic, I., S. Berne, D. Drobne, P. Macek, R. Frangez, T. Turk, J. Strus, and K. Sepcic. 2005. Temporal and spatial expression of ostreolysin during development of the oyster mushroom (Pleurotus ostreatus). Mycol Res 109:377-382.

125. Zuzek, M. C., P. Macek, K. Sepcic, V. Cestnik, and R. Frangez. 2006. Toxic and lethal effects of ostreolysin, a cytolytic protein from edible oyster mushroom (Pleurotus ostreatus), in rodents. Toxicon 48:264-271.

126. Rebolj, K., N. P. Ulrih, P. Macek, and K. Sepcic. 2006. Steroid structural requirements for interaction of ostreolysin, a lipid-raft binding cytolysin, with lipid monolayers and bilayers. Biochim Biophys Acta 1758:1662-1670.

127. Berne, S., J. Pohleven, I. Vidic, K. Rebolj, F. Pohleven, T. Turk, P. Macek, A. Sonnenberg, and K. Sepcic. 2007. Ostreolysin enhances fruiting initiation in the oyster mushroom (Pleurotus ostreatus). Mycol Res 111:1431-1436.

128. Malicev, E., H. H. Chowdhury, P. Macek, and K. Sepcic. 2007. Effect of ostreolysin, an Asp-hemolysin isoform, on human chondrocytes and osteoblasts, and possible role of Asp-hemolysin in pathogenesis. Med Mycol 45:123-130.

129. Rebolj, K., U. Batista, K. Sepcic, V. Cestnik, P. Macek, and R. Frangez. 2007. Ostreolysin affects rat aorta ring tension and endothelial cell viability in vitro. Toxicon 49:1211-1213.

130. Juntes, P., K. Rebolj, K. Sepcic, P. Macek, M. C. Zuzek, V. Cestnik, and R. Frangez. 2009. Ostreolysin induces sustained contraction of porcine coronary arteries and endothelial dysfunction in middle- and large-sized vessels. Toxicon 54:784-792.

131. Sakurai, N., J. Kaneko, Y. Kamio, and T. Tomita. 2004. Cloning, expression, and poreforming properties of mature and precursor forms of pleurotolysin, a sphingomyelinspecific two-component cytolysin from the edible mushroom Pleurotus ostreatus. Biochim Biophys Acta 1679:65-73.

132. Tomita, T., K. Noguchi, H. Mimuro, F. Ukaji, K. Ito, N. Sugawara-Tomita, and Y. Hashimoto. 2004. Pleurotolysin, a novel sphingomyelin-specific two-component cytolysin from the edible mushroom Pleurotus ostreatus, assembles into a transmembrane pore complex. J Biol Chem 279:26975-26982.

133. Lv, H., Y. Kong, Q. Yao, B. Zhang, F. Leng, H. Bian, J. Balzarini, E. van Damme, and J. Bao. 2009. Nebrodeolysin, a novel hemolytic protein from mushroom Pleurotus nebrodensis with apoptosis-inducing and anti-HIV-1 effects. Phytomedicine 16:198-205.

134. Faulstich, H., S. Zobeley, and M. Weckauf-Bloching. 1974. Cytolytic properties of phallolysin. Hoppe Seylers Z Physiol Chem 355:1495-1498.

135. Seeger, R. 1975a. Demonstration and isolation of phallolysin, a haemolytic toxin from Amanita phalloides. Naunyn Schmiedebergs Arch Pharmacol 287:277-287.

136. Seeger, R. 1975b. Some physico-chemical properties of phallolysin obtained from Amanita phalloides. Naunyn Schmiedebergs Arch Pharmacol 288:155-162. 
137. Petzinger, E., and R. Seeger. 1976. Scanning electron microscopic studies on the cytolytic effect of phallolysin on isolated rat hepatocytes and AS-30 D hepatoma cells. Naunyn Schmiedebergs Arch Pharmacol 295:211-213.

138. Seeger, R., M. Burkhardt, M. Haupt, and L. Feulner. 1976. The haemolytic effect of phallolysin. Naunyn Schmiedebergs Arch Pharmacol 293:163-170.

139. Seeger, R., and E. Bunsen. 1980b. Degranulation of rat mast cells in vitro by the fungal cytolysins phallolysin, rubescenslysin and fascicularelysin. Naunyn Schmiedebergs Arch Pharmacol 315:163-166.

140. Seitz, J., G. Adler, E. Stofft, and H. Faulstich. 1981. The mechanism of cytolysis of erythrocytes by the mushroom toxin phallolysin. Morphological and biochemical evidence for sodium influx and swelling. Eur J Cell Biol 25:46-53.

141. Buhring, H. J., A. C. Vaisius, and H. Faulstich. 1983. Membrane damage of liposomes by the mushroom toxin phallolysin. Biochim Biophys Acta 733:117-123.

142. Lutsik-Kordovsky, M. D., T. V. Stasyk, and R. S. Stoika. 2001. Analysis of cytotoxicity of lectin and non-lectin proteins from Amanita mushrooms. Exp Oncol 23:43-45.

143. Seeger, R., H. Kraus, and R. Wiedmann. 1973. Presence of hemolysins in Amanita species. Arch Toxikol 30:215-226.

144. Seeger, R. 1980a. Studies on rubescenslysin haemolysis. Naunyn Schmiedebergs Arch Pharmacol 311:95-103.

145. Seeger, R., K. P. Odenthal, and U. Mengs. 1981. Toxic effects in mouse and rat of rubescenslysin from Amanita rubescens. Toxicon 19:409-417.

146. Odenthal, K. P., R. Seeger, R. Braatz, E. Petzinger, H. Moshaf, and C. Schmitz-Drager. 1982. Damage in vitro to various organs and tissues by rubescenslysin from the edible mushroom Amanita rubescens. Toxicon 20:765-781.

147. Tateno, H., and I. J. Goldstein. 2003. Molecular cloning, expression, and characterization of novel hemolytic lectins from the mushroom Laetiporus sulphureus, which show homology to bacterial toxins. J Biol Chem 278:40455-40463.

148. Mancheno, J. M., H. Tateno, I. J. Goldstein, and J. A. Hermoso. 2004. Crystallization and preliminary crystallographic analysis of a novel haemolytic lectin from the mushroom Laetiporus sulphureus. Acta Crystallogr D Biol Crystallogr 60:1139-1141.

149. Mancheno, J. M., H. Tateno, I. J. Goldstein, M. Martinez-Ripoll, and J. A. Hermoso. 2005. Structural analysis of the Laetiporus sulphureus hemolytic pore-forming lectin in complex with sugars. J Biol Chem 280:17251-17259.

150. Suzuki, K., T. Une, M. Yamazaki, and T. Takeda. 1990. Purification and some properties of a hemolysin from the poisonous mushroom Rhodophyllus rhodopolius. Toxicon 28:1019-1028.

151. Lin, J. Y., Y. J. Lin, C. C. Chen, H. L. Wu, G. Y. Shi, and T. W. Jeng. 1974. Cardiotoxic protein from edible mushrooms. Nature 252:235-237.

152. Lin, J. Y., H. L. Wu, and G. Y. Shi. 1975. Toxicity of the cardiotoxic protein flammutoxin, isolate from edible mushroom Flammulina velutipes. Toxicon 13:323-331.

153. Bernheimer, A. W., and J. D. Oppenheim. 1987. Some properties of flammutoxin from the edible mushroom Flammulina velutipes. Toxicon 25:1145-1162.

154. Tomita, T., D. Ishikawa, T. Noguchi, E. Katayama, and Y. Hashimoto. 1998. Assembly of flammutoxin, a cytolytic protein from the edible mushroom Flammulina velutipes, into a pore-forming ring-shaped oligomer on the target cell. Biochem J 333:129-137. 
155. Tadjibaeva, G., R. Sabirov, and T. Tomita. 2000. Flammutoxin, a cytolysin from the edible mushroom Flammulina velutipes, forms two different types of voltage-gated channels in lipid bilayer membranes. Biochim Biophys Acta 1467:431-443.

156. Tomita, T., Y. Mizumachi, K. Chong, K. Ogawa, N. Konishi, N. Sugawara-Tomita, N. Dohmae, Y. Hashimoto, and K. Takio. 2004. Protein sequence analysis, cloning, and expression of flammutoxin, a pore-forming cytolysin from Flammulina velutipes. Maturation of dimeric precursor to monomeric active form by carboxyl-terminal truncation. J Biol Chem 279:54161-54172.

157. Lin, J. Y., T. W. Jeng, C. C. Chen, G. Y. Shi, and T. C. Tung. 1973. Isolation of a new cardiotoxic protein from the edible mushroom Volvariella volvacea. Nature:524-525.

158. Khowala, S., P. C. Banerjee, A. K. Ghosh, and S. Sengupta. 1993. A hemolytic protein from cultured mycelia of mushroom, Termitomyces clypeatus. Indian J Exp Biol 31:4549.

159. Han, C. H., G. Q. Zhang, H. X. Wang, and T. B. Ng. 2010. Schizolysin, a hemolysin from the split gill mushroom Schizophyllum commune. FEMS Microbiol Lett 309:115121.

160. Botic, T., M. K. Kuncic, K. Specic, Z. Knez, and N. Gunde-Cimerman. 2012. Salt induces biosynthesis of hemolytically active compunds in the xerotolerant food-borne fungus Wallemia sebi. FEMS Microbiol Lett 326:40-46.

161. Fujiwara, A., J. W. Landau, and V. D. Newcomer. 1970a. Hemolytic activity of Rhizopus nigricans and Rhizopus arrhizus. Mycopathol Mycol Appl 40:131-138.

162. Fujiwara, A., J. W. Landau, and V. D. Newcomer. 1970b. Preliminary characterization of the hemolysin of Rhizopus nigricans. Mycopathol Mycol Appl 40:139-144.

163. Andersen, B., K. F. Nielsen, U. Thrane, T. Szaro, J. W. Taylor, and B. B. Jarvis. 2003. Molecular and phenotypic descriptions of Stachybotrys chlorohalonata sp. nov. and two chemotypes of Stachybotrys chartarum found in water-damaged buildings. Mycologia 95:1227-1238.

164. Finn, R. D., J. Tate, J. Mistry, P. C. Coggill, S. J. Sammut, H. R. Hotz, G. Ceric, K. Forslund, S. R. Eddy, E. L. Sonnhammer, and A. Bateman. 2008. The Pfam protein families database. Nucleic Acids Res 36:D281-288.

165. Ebina, K., H. Sakagami, K. Yokota, and H. Kondo. 1994. Cloning and nucleotide sequence of cDNA encoding Asp-hemolysin from Aspergillus fumigatus. Biochim Biophys Acta 1219:148-150.

166. Rau, E. M., E. B. Tilden, and V. L. Koenig. 1961. Partial purification and characterization of the endotoxin from Aspergillus fumigatus. Mycopathologia 14:347358.

167. Tilden, E. B., E. H. Hatton, S. Freeman, and W. M. Williamson. 1957. Studies of Aspergilli from captive birds. Bact Proc 144.

168. Tilden, E. B., E. H. Hatton, S. Freeman, W. M. Williamson, and V. L. Koenig. 1961. Preparation and properties of the endotoxins of Aspergillus fumigatus and Aspergillus flavus. Mycopathologia 14:325-346.

169. Sakaguchi, O., H. Shimada, and K. Yokota. 1975. Proceedings: Purification and characteristics of hemolytic toxin from Aspergillus fumigatus. Jpn J Med Sci Biol 28:328331. 
170. Ebina, K., S. Ichinowatari, and K. Yokota. 1985. Studies on toxin of Aspergillus fumigatus. XXII. Fashion of binding of Asp-hemolysin to human erythrocytes and Asphemolysin-binding proteins of erythrocyte membranes. Microbiol Immunol 29:91-101.

171. Rementeria, A., N. Lopez-Molina, A. Ludwig, A. B. Vivanco, J. Bikandi, J. Ponton, and J. Garaizar. 2005. Genes and molecules involved in Aspergillus fumigatus virulence. Rev Iberoam Micol 22:1-23.

172. Rutqvist, L. 1965. Studies on Aspergillus fumigatus; toxin production by different strains and serological comparison of the strains. Acta Vet Scand 6:224-233.

173. Giddings, K. S., A. E. Johnson, and R. K. Tweten. 2003. Redefining cholesterol's role in the mechanism of the cholesterol-dependent cytolysins. Proc Natl Acad Sci U S A 100:11315-11320.

174. Shimada, Y., M. Maruya, S. Iwashita, and Y. Ohno-Iwashita. 2002. The C-terminal domain of perfringolysin $\mathrm{O}$ is an essential cholesterol-binding unit targeting to cholesterol-rich microdomains. Eur J Biochem 269:6195-6203.

175. Ishitsuka, R., A. Yamaji-Hasegawa, A. Makino, Y. Hirabayashi, and T. Kobayashi. 2004. A lipid-specific toxin reveals heterogeneity of sphingomyelin-containing membranes. Biophys J 86:296-307.

176. Chowdhury, H. H., K. Rebolj, M. Kreft, R. Zorec, P. Macek, and K. Sepcic. 2008. Lysophospholipids prevent binding of a cytolytic protein ostreolysin to cholesterolenriched membrane domains. Toxicon 51:1345-1356.

177. Ebina, K., K. Yokota, and O. Sakaguchi. 1983. Studies on toxin of Aspergillus fumigatus XVI. Biological properties of Asp-hemolysin as a parasite factor. Jpn J Med Mycol 24:245-252.

178. CDC. 1994. Acute pulmonary hemorrhaging/hemosiderosis among infants: Cleveland, January 1993-November 1994. In Morbid Mortal Weekly Rep. Centers for Disease Control and Prevention. 881-883.

179. Dearborn, D. 1997. Pulmonary hemorrhage in infants and children. Curr Opin Pediatr 9:219-224.

180. Montana, E., R. A. Etzel, D. G. Dearborn, W. G. Sorenson, and R. Hill. 1995. Acute pulmonary hemorrhage in infancy associated with Stachybotrys atra Cleveland, Ohio, 1993-1995. Am J Epidemiol 141:S83.

181. Etzel, R. A., E. Montana, W. G. Sorenson, G. J. Kullman, and J. D. Miller. 1996. Pulmonary hemosiderosis associated with exposure to Stachybotrys atra. Epidemiology 7:S38.

182. Etzel, R. A., E. Montana, W. G. Sorenson, G. J. Kullman, T. M. Allan, D. G. Dearborn, D. R. Olson, B. B. Jarvis, and J. D. Miller. 1998. Acute pulmonary hemorrhage in infants associated with exposure to Stachybotrys atra and other fungi. Arch Pediatr Adolesc Med 152:757-762.

183. Pestka, J. J., I. Yike, D. Dearborn, M. D. W. Ward, and J. R. Harkema. 2008. Stachybotrys chartarum, trichothecene, mycotoxins, and damp building-related illness: New insights into a public health enigma. Toxicological Sciences 104:4-26.

184. Brasel, T. L., J. M. Martin, C. G. Carriker, S. C. Wilson, and D. C. Starus. 2005. Detection of airborne Stachybotrys chartarum macrocyclic trichothecene mycotoxins in the indoor environment. Appl Environ Microbiol 71:7376-7388. 
185. Vesper, S., D. G. Dearborn, I. Yike, T. Allan, J. Sobolewski, S. F. Hinkley, B. B. Jarvis, and R. A. Haugland. 2000a. Evaluation of Stachybotrys chartarum in the house of an infant with pulmonary hemorrhage: quantitative assessment before, during, and after remediation. J Urban Health 77:68-85.

186. Mims, C. A. 1987. The pathogensis of infectious disease. Academic Press, London, United Kingdom.

187. Bhakdi, S., and J. Tranum-Jensen. 1991. Alpha-toxin of Staphylococcus aureus. Microbiol Rev 55:733-751.

188. Jonsson, P., M. Lindberg, I. Haraldsson, and T. Wadstrom. 1985. Virulence of Staphylococcus aureus in a mouse mastitis model: studies of alpha hemolysin, coagulase, and protein A as possible virulence determinants with protoplast fusion and gene cloning. Infect Immun 49:765-769.

189. Ou Said, A. M., M. G. Contrepois, M. D. Vartanian, and J. Girardeau. 1988. Virulence factors and markers in Escherichia coli from calves with bacteremia. Am J Vet Res 49.

190. Welch, R. A., E. P. Dellinger, B. Minshew, and S. Falkow. 1981. Haemolysin contributes to virulence of extra-intestinal E. coli infections. Nature 294:665-667.

191. Elidemir, O., G. N. Colasurdo, S. N. Rossmann, and L. L. Fan. 1999. Isolation of Stachybotrys from the lung of a child with pulmonary hemosiderosis. Pediatrics 104:964966. 


\section{CHAPTER 2}

Characterization of monoclonal antibodies developed against a hemolytic preparation (stachylysin) from Stachybotrys 


\subsection{INTRODUCTION}

Filamentous fungi belonging to Stachybotrys species are occasionally isolated as contaminants of indoor and outdoor air. Stachybotrys are widely present and currently, 55 species of Stachybotrys including Memnoniella are known (1). Stachybotrys species produce trichothecene mycotoxins called as satratoxins, which bind to eukaryotic ribosomes and act as inhibitors of protein synthesis $(2,3)$. Stachybotrys species also produce proteinases that contribute to lung inflammation and injury through degradation of host collagen and can induce activation of a pro-inflammatory response (4).

S. chartarum exhibits hemolytic activity, which has been attributed to its hemolysin, stachylysin (5-8). Moreover, the detection of stachylysin in sera of experimental animals and patients with known exposure to $S$. chartarum in indoor environment provided an impetus for development of specific immunodiagnostic methodologies (9). However, polyclonal antibodies (pAbs) used in this study can lack specificity and are cross reactive as reported in previous studies in our laboratory (10-13). pAbs are also prone to batch-to-batch variability, which may influence the development of standardized assays. In order to overcome these limitations, we aimed to develop monoclonal antibodies $(\mathrm{mAb})$ to stachylysin that were species-specific. Compared to pAb-based methodologies, mAbs are mono-specific, can be generated as a constant resource, and therefore useful for development of standardized immunoassays. In our laboratory, we have previously successfully developed a species-specific mAb against $S$. chartarum that recognizes conidia but not the hyphae $(11,13,14)$.

To characterize stachylysin, we used S. chlorohalonata, a newly identified species that has the same phenotypic features as $S$. chartarum chemotype A, but morphologically is characterized by green extracellular pigmentation on Czapek yeast autolysate (CYA) medium (1, 
15). The strain of S. chlorohalonata (ATCC 201863; IBT 9825) was chosen because it was used in previous studies to produce the stachylysin (7). It was originally designated S. chartarum and isolated from the home of an infant diagnosed with IPH $(5,7)$. Nearly all strains of $S$. chlorohalonata produce S. chartarum chemotype A toxins, atranones and dolabellanes (15). Atranones also contribute to a variety of immunotoxic, inflammatory and pathological changes on exposure of animals to conidia from $S$. chartarum chemotype A (16). Dolabellanes are $\mathrm{C}_{24}$ atranones that also have been previously reported to be cytotoxic (17).

In this chapter, we report the generation of $\operatorname{IgM}$ mAbs to a stachylysin preparation and characterize their reactivity to purified stachylysin and extracts of S. chlorohalonata. In addition, we characterize the mAbs for cross-reactivity to other fungal species including multiple Stachybotrys species.

\subsection{METHODS AND MATERIALS}

\subsubsection{Semi-purified cytolytic Stachybotrys preparation- Stachylysin from Stachybotrys} chlorohalonata ATCC 201863 (American Type Culture Collection, Manassas, VA) was semipurified from tryptic soy broth (TSB, Becton Dickinson, Sparks, MD) CSN as previously described (7). Briefly, S. chlorohalonata conidia $\left(1 \times 10^{5}\right)$ were used to inoculate $500 \mathrm{ml}$ of TSB in a 1 liter flask placed on an incubator shaker for 7 days (7). Cellular debris was removed from the TSB CSN by centrifugation for 15 minutes at $5000 \mathrm{~g}$. The supernatant was then centrifuged in a Millipore Centricon plus 80 filter apparatus (Millipore, Bedford, MA) with a molecular mass cutoff of $50 \mathrm{kDa}$ at $4000 \mathrm{~g}$ for 15 minutes. The concentrate was then subjected to gel filtration and fractions were collected and plated onto sheep blood agar to determine hemolytic activity as previously described (7). The five most hemolytic fractions were pooled, desalted, and 
lyophilized as previously described (7). The lyophilized pellet was resuspended in sterile water and stored at $-20^{\circ} \mathrm{C}$ for further analysis and for immunization of animals for antibody production.

2.2.2 Preparation of fungal hyphal extracts- Fungi were grown in standard unsealed Petri plates containing $5 \mathrm{ml}$ of malt extract agar (MEA; $2 \%$ dextrose, $0.1 \%$ peptone, $2 \%$ malt extract, 2\% agar; Difco, Becton Dickinson, Sparks, MD). After 2 weeks of incubation at room temperature (RT), conidia were collected from sporulating cultures into TSB and $10 \mathrm{ml}$ of the conidial suspension $\left(1 \times 10^{6}\right)$ were transferred into a $125 \mathrm{ml}$ Corning flask containing $50 \mathrm{ml}$ of TSB. The flasks were rotated at $120 \mathrm{rpm}$ at $37^{\circ} \mathrm{C}$ for 3-4 days before the hyphae were harvested by filtration using a cell strainer (70 $\mu \mathrm{m}$, Becton Dickinson). The collected hyphae were washed two times in $50 \mathrm{ml}$ phosphate-buffered saline $\mathrm{pH} 7.4$ containing 0.05\% (v/v) Tween 20 (PBST) before being homogenized in the cell strainer using the plunger from a $10 \mathrm{ml}$ syringe. The homogenate was centrifuged at $4100 \mathrm{~g}$ for $5 \mathrm{~min}$ at $4^{\circ} \mathrm{C}$ and aliquots of the supernatants were stored at $-80^{\circ} \mathrm{C}$. The total protein concentration in the hyphal extracts was determined using a $\mathrm{BCA}^{\mathrm{TM}}$ protein assay kit (Pierce, Rockford, IL).

\subsubsection{Production of monoclonal and polyclonal antibodies against stachylysin- Five 10-14}

week old $\mathrm{BALB} / \mathrm{c}$ female mice were housed under controlled environmental conditions in HEPA-filtered ventilated polycarbonate cages on autoclaved hardwood Beta-chip bedding and were provided Teklad 7913 rodent chow (Harlan Laboratories, Madison, WI) and autoclaved tap water ad libitum. Sentinel mice were free of viral pathogens, parasites, mycoplasma, and Helicobacter spp. The National Institute for Occupational Safety and Health (NIOSH) animal 
facility is accredited by the Association for Assessment and Accreditation of Laboratory Animal Care International (AAALAC).

Mice were immunized intraperitoneally at bi-weekly intervals. Mice were primed with 50 $\mu \mathrm{g}$ of stachylysin emulsified in equal volumes of TiterMax ${ }^{\circledR}$ (TiterMax USA Inc., Norcross, GA). The antigen concentration was reduced by half for each of 5 subsequent booster immunizations. A final boost of $50 \mu \mathrm{g}$ was given three weeks after the sixth immunization and mice were sacrificed 3 days later for hybridoma production.

Hybridomas were produced by standard polyethylene glycol-based cell fusion techniques using SP2/0-AG14 myleoma cells (ATCC\# CRL-1581). Cell cultures were maintained in Dulbecco's Modified Eagle Medium (DMEM) (Life Technologies, Rockville, MD), supplemented with $1 \mathrm{mM}$ sodium pyruvate, 100 units $/ \mathrm{ml}$ penicillin, $100 \mu \mathrm{g} / \mathrm{ml}$ streptomycin, $0.292 \mathrm{mg} / \mathrm{ml} \mathrm{L-glutamine,} 100 \mathrm{mM}$ sodium hypoxanthine, $16 \mathrm{mM}$ thymidine, $10 \%$ fetal calf serum (HyClone, Logan, UT), and 100 units/ml IL-6 (Boerhinger, Mannheim, Germany). DMEM medium was also supplemented with azaserine for selective propagation of hybridomas. Positive clones were identified using $1 \mu \mathrm{g} / \mathrm{ml}$ of the stachylysin in an indirect ELISA (see below). Positive colonies were cloned twice by limiting dilution and the stable hybridomas were grown in bulk, aliquoted, and stored in liquid nitrogen. Hybridoma CSN containing anti-stachylysin mAbs were stored at $4{ }^{\circ} \mathrm{C}$ and used for various experimental analysis.

Rabbit pAbs against stachylysin were custom-produced and affinity-purified by Bethyl Laboratories (Montgomery, TX) using standard laboratory protocols. 


\subsubsection{Screening ELISA format for the analysis of hybridoma culture supernatants-}

Hybridoma CSN were screened using an indirect ELISA as previously described (11). In brief, ELISA plate wells were coated with $100 \mu \mathrm{l}$ of the stachylysin $(1 \mu \mathrm{g} / \mathrm{ml})$ in carbonate coating buffer $(\mathrm{CCB}, 60 \mathrm{mM}$ sodium carbonate, $140 \mathrm{mM}$ sodium bicarbonate, $\mathrm{pH}$ 9.6) and incubated at RT overnight. Wells were washed 3 times with $200 \mu \mathrm{l} /$ well of phosphate buffered-saline containing $0.5 \%$ Tween-20 (PBST) for $10 \mathrm{~min}$. The plates were then blocked for $1 \mathrm{hr}$ at RT with $200 \mu \mathrm{l} /$ well of PBST containing 1\% non-fat dry milk powder (PBSTM). Hybridoma CSN were incubated for $1 \mathrm{hr}$ at $37^{\circ} \mathrm{C}$ with $100 \mu \mathrm{l}$ of mAb CSN diluted 1/5 (v/v) in PBSTM. Bound antibodies were detected with $100 \mu \mathrm{l}$ of Biotin-SP-conjugated AffiPure goat anti-mouse IgG and IgM secondary antibody (Jackson ImmunoResearch Laboratories, Inc., West Grove, Pennsylvania) for $1 \mathrm{hr}$ at $37^{\circ} \mathrm{C}$ at a dilution of $1 / 5000(\mathrm{v} / \mathrm{v})$ in PBSTM. Bound biotin was detected with $100 \mu \mathrm{l}$ of alkaline phosphatase-conjugated streptavidin (Jackson ImmunoResearch Laboratories, Inc., West Grove, PA) by incubation for $1 \mathrm{hr}$ at $37^{\circ} \mathrm{C}$ at a dilution of 1/5000 (v/v) in PBSTM. The reaction product was produced by incubating $100 \mu$ per well of 4-nitrophenyl phosphate (Sigma, St. Louis, MO) in alkaline phosphatase substrate buffer (1 M diethanolamine, $\mathrm{pH} 9.5 ; 5 \mathrm{mM} \mathrm{MgCl}_{2}$ ) at RT and the optical density (OD) was determined at $405 \mathrm{~nm}$ after $30 \mathrm{~min}$ using an UltraMicroplate Reader, Model EL 800 (BIO-TEK Instruments, Inc., Winooski, Vermont). Negative control values were obtained by substituting plain culture supernatant for mAb culture. 
2.2.5 Capture ELISA format for the analysis of hyphal extracts- The specificity of mAbs was tested against hyphal extracts of $7 \mathrm{~S}$. chartarum isolates, 8 isolates of other Stachybotrys species including S. chlorohalonata as well as 39 related and non-related fungi commonly found in indoor environments. All extracts were tested in a capture ELISA using rabbit anti-stachylysin pAbs as solid-phase capture reagent. In brief, ELISA plate wells were coated with $100 \mu \mathrm{l}$ of rabbit anti-stachylysin pAbs $(1 \mu \mathrm{g} / \mathrm{ml})$ in CCB overnight at RT. The plates were washed and blocked as described above and $100 \mu \mathrm{l} /$ well of hyphal extract from each fungus $(50 \mu \mathrm{g} / \mathrm{ml})$ in PBST were added and allowed to react for $1 \mathrm{hr}$ at $37^{\circ} \mathrm{C}$. After washing the plates, mAb CSNs diluted 4 fold in PBST were incubated for $1 \mathrm{hr}$ at $37^{\circ} \mathrm{C}$ and the plates were processed as described for the screening ELISA. The ODs of supplemented DMEM that served as negative control ranged from 0 to 0.06 . An $\mathrm{OD} \geq 0.2$ (negative control +3 standard deviations) was considered to be a positive result. The sensitivity of the mAbs was measured with the same capture ELISA format except that the pAb was used at $2 \mu \mathrm{g} / \mathrm{ml}$ and the mAb CSN were diluted 5 fold.

2.2.6 Western Blot analysis of mAb reactivity- Stachylysin preparation was separated by SDS-PAGE on a 10\% acrylamide gel and transferred to nitrocellulose membranes (BioRad, Hercules, CA). The membranes were blocked with $3 \%$ bovine serum albumin (BSA) for $1 \mathrm{hr}$ at RT and incubated with mAbs (diluted 1/5 in PBST) for $1 \mathrm{hr}$ at RT. After incubation for $1 \mathrm{hr}$ with a 1/5000 (v/v) dilution of biotin-conjugated goat anti-mouse IgM antibodies (Jackson Immuno Research Laboratories Inc., West Grove, PA) the membranes were incubated with alkaline phosphatase-conjugated streptavidin (1/5000) (v/v) for $1 \mathrm{hr}$ at RT. Blots were developed 
with the nitroblue tetrazolium and bromo-chloro-indolyl phosphate substrate (NBT/BCIP) (Promega, Madison, WI).

2.2.7 Fluorescent halogen immunoassay- S. chartarum conidia, phialides, and hyphae were aerosolized by directing a jet of air across 2 -week old sporulating cultures grown on MEA medium. Aerosolized particles were collected by suction onto mixed cellulose ester (MCE) protein-binding membranes $(0.45 \mu \mathrm{m}$ pore size; Millipore Corporation, Bridgewater, MA) and immunostained using the fluorescent halogen immunoassay (FHIA) as previously described (13). Briefly, a clear adhesive and glass coverslip was used to laminate samples and the antigens were extracted in $0.2 \mathrm{M}$ borate buffer, $\mathrm{pH} 8.2$ at RT for $3 \mathrm{hrs}$. The samples were blocked with $5 \%$ BSA in PBS pH 7.4 for 90 mins and then incubated overnight at $4^{\circ} \mathrm{C}$ with the mAb 6D4 diluted 1/50 (v/v) in PBST containing 5\% BSA (PBSTB). Negative control treatments were processed in parallel by substituting the mAbs with supplemented DMEM medium diluted 1/50 (v/v) or isotype control mAb 1B9 (IgM) diluted 1:50. The membranes were rinsed 3 times in PBST and incubated for 90 mins with Alexa Fluor ${ }^{\circledR}$ 488-conjugated goat anti-mouse IgM (Molecular Probes Inc., Eugene OR) diluted 1/500 (v/v) in PBSTB. The membranes were rinsed 3 times in distilled $\mathrm{H}_{2} \mathrm{O}$ and mounted on a microscope slide in ProLong ${ }^{\circledR}$ Gold antifade reagent (Molecular Probes Inc.). Confocal laser scanning images were captured using a Zeiss LSM 510 laser scanning confocal system (Carl Zeiss Inc., Thornwood, NY). The images of mAb-labeled fungal particles were captured using 488-nm excitation and a narrow emission filter bandwidth (505$550 \mathrm{~nm}$ ). Fluorescent and differential interference contrast images (DIC) were captured using Zeiss software version 3.2 (Carl Zeiss Inc., Thornwood, NY). All settings on the confocal laser microscope remained constant in the analysis. 


\subsection{RESULTS}

2.3.1 mAb reactivity to $S$. chlorohalonata stachylysin and extracts- Immunization with stachylysin resulted in the production of eight murine IgM isotype antibodies (3C3, 6D4, 7D11, 9G6, 24D11, 27C10, 27E2, and 29E5). The mAbs 3C3, 6D4, 7D11, and 9G6 were selected based on preliminary studies of reactivity to $S$. chlorohalonata extracts. These antibodies showed varying degrees of reactivity towards stachylysin preparation (Fig. 2.1a). mAbs 7D11, 3C3, and 6D4 showed highest reactivity, while mAb 9G6 showed the lowest reactivity. The same pattern of $\mathrm{mAb}$ reactivity was also found against the hyphal extract of S. chlorohalonata when analyzed by capture ELISA (Fig 2.1.b). Reduced reactivity was observed to conidial extracts compared to hyphal extracts.

2.3.2 Localization of stachylysin in S. chlorohalonata- To determine the localization of stachylysin in morphological structures of $S$. chlorohalonata, we used the FHIA to ultrastructurally locate the antibody binding sites of mAb 6D4 in S. chlorohalonata conidia and hyphae (Fig. 2.2). mAb 6D4 immunostaining was primarily localized around phialides and sterigmata (Fig. 2.2b) with highest staining primarily localized around hyphal septal junctions and hyphal branch points (Fig. 2.2c). In contrast, the staining of S. chlorohalonata conidia was less intense and mostly restricted to the surface of the conidia (Fig 2.2a). We did not observe any specific staining with DMEM medium control or 1B9 $\operatorname{IgM}$ isotype control antibody staining (data not shown). 


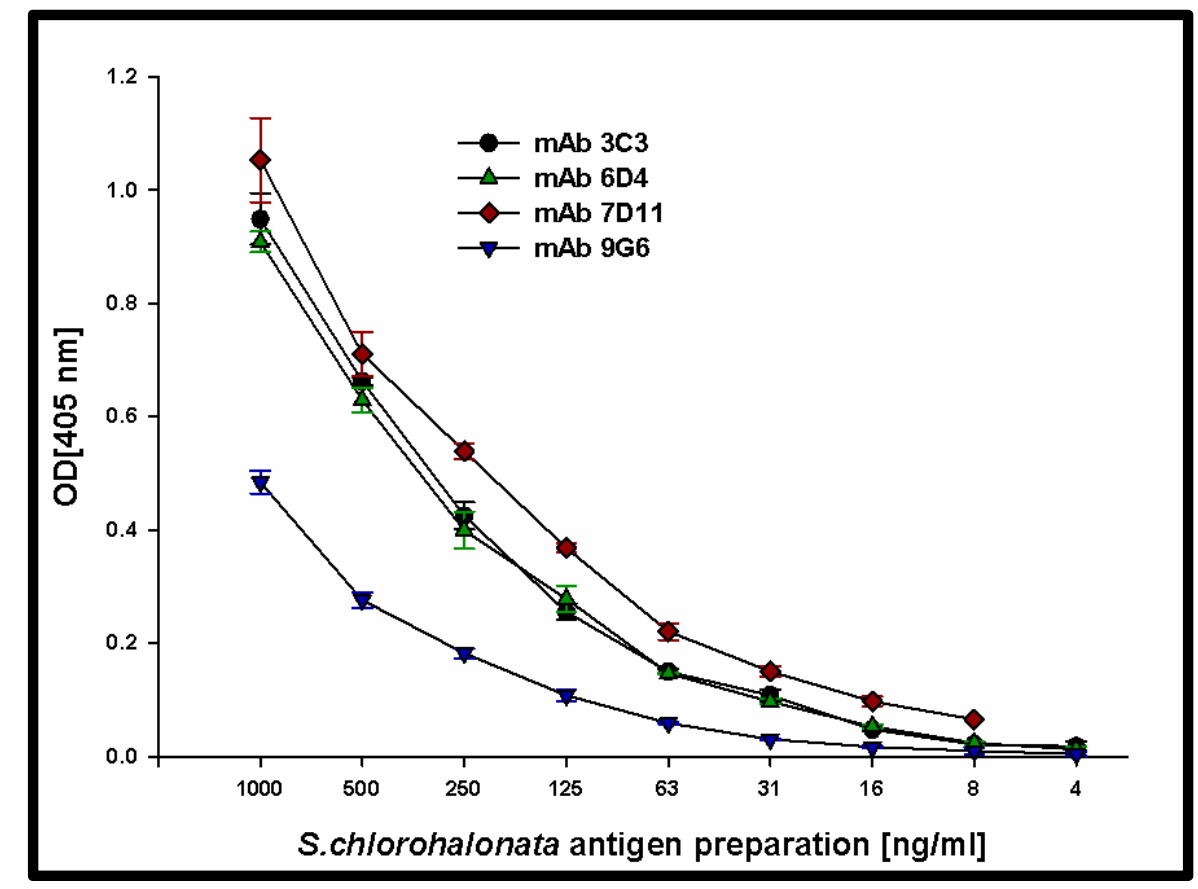

Fig. 2.1a. mAb reactivity against the stachylysin protein preparation. Stachylysin from S. chlorohalonata was diluted in PBSTM and the reactivity of $m A b s 3 C 3,6 D 4,7 D 11$ and $9 G 6$ were analyzed by capture ELISA. Optical densities (OD) were measured at $405 \mathrm{~nm}$ after 30 mins incubation with substrate. 


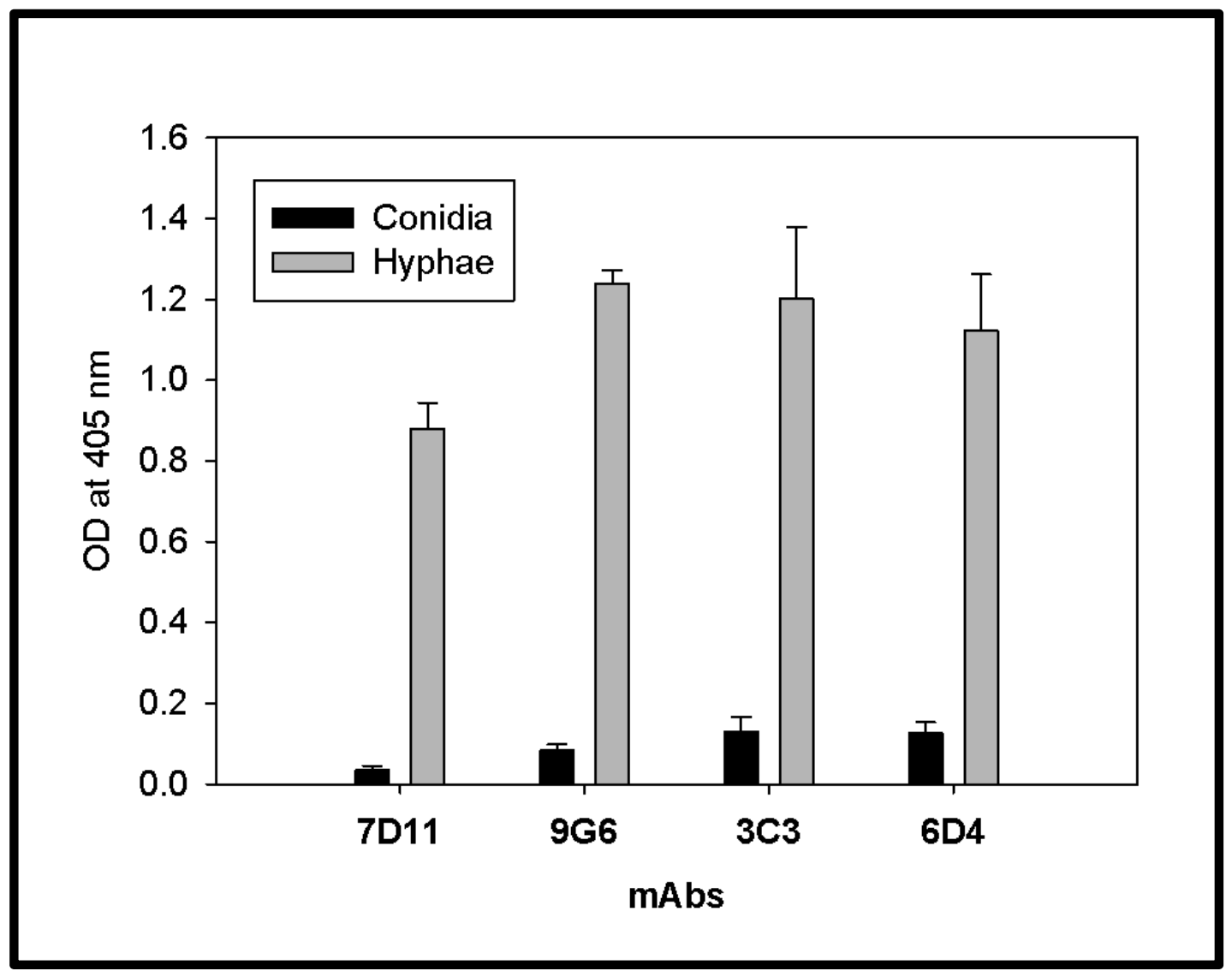

Fig. 2.1b. Reactivity of the 4 mAbs against S. chlorohalonata conidial and hyphal extracts. Extracts from conidia or hyphae of S. chlorohalonata were analyzed with mAbs 3C3, 6D4, 7D11 and $9 G 6$ using the capture ELISA. Optical densities $(O D)$ were measured at 405 nm after 30 mins incubation with substrate. 


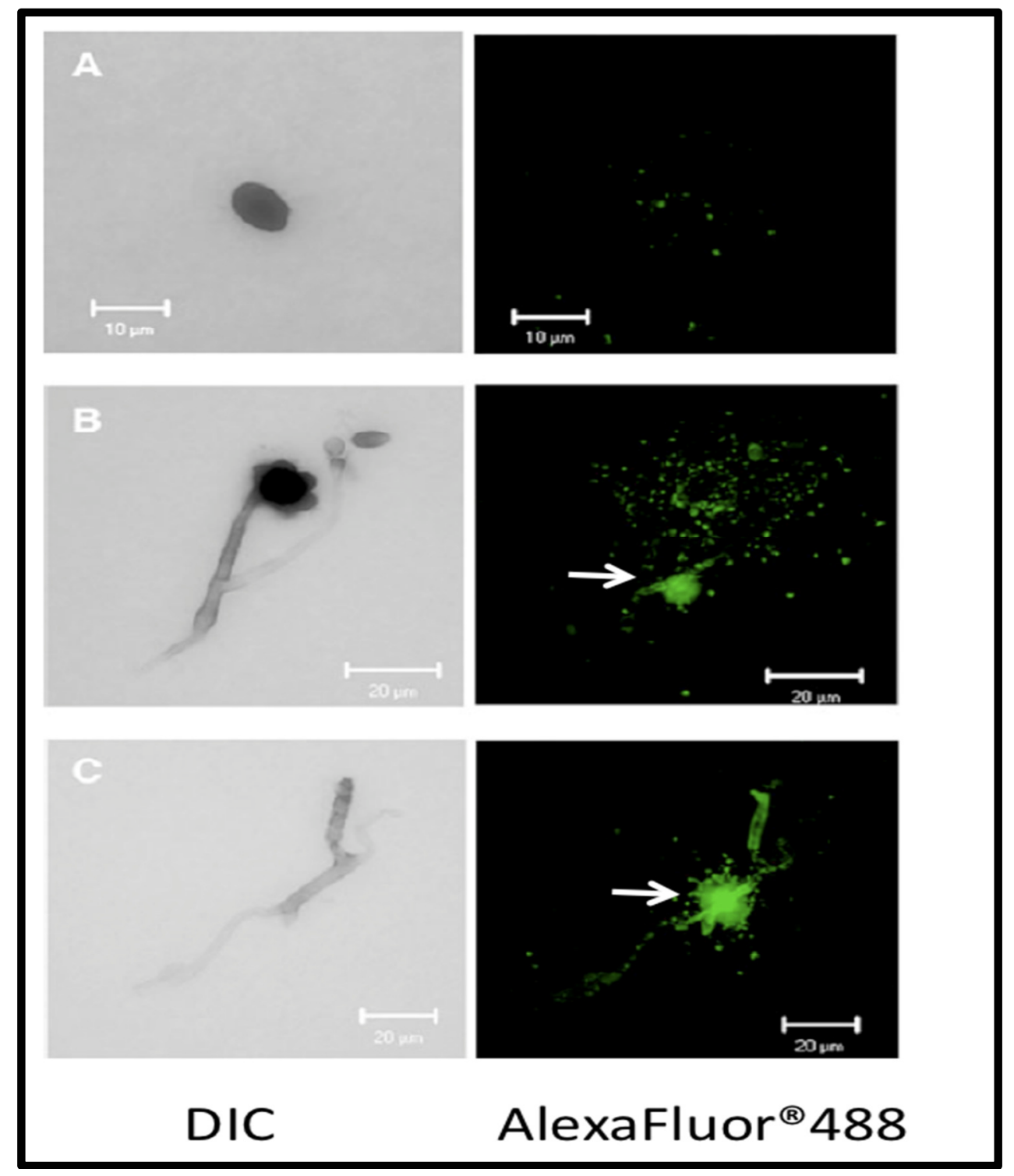

Fig. 2.2. Fluorescent halogen immunostaining of S. chlorohalonata. a) Conidia b) Phialides c) Hyphae. Green dots represent AlexaFluor ${ }^{\circledR} 488$ staining to identify the localization of $m A b 6 D 4$ specific antigens in the distinct morphological structures of S. chlorohalonata. White arrows highlight the regions of hyphal branch bifurcation where maximum staining was observed for stachylysin. Staining was also observed at septate junctions. 
2.3.3 Cross-reactivity- Hyphal extracts obtained from 48 different fungal species were tested in the capture ELISA for cross-reactivity with the 8 different mAbs. This included hyphal extracts from 7 different strains of $S$. chartarum as well (Table 2.1). All mAbs exhibited varying reactivity to most of the $S$. chartarum strains tested here. However, mAb 29E5 failed to react with 4 of the 7 (57\%) S. chartarum strains. All mAbs demonstrated limited cross-reactivity with different species of the genus Stachybotrys. The most frequent cross-reactivity was observed with S. chartarum, S. bisbyi and S. parvispora. However, none of the mAbs reacted with hyphal extracts of S. albipes, S. kampalensis or S. oenanthes. mAbs 27E2 and 29E5 did not react with hyphal extracts derived from $S$. chlorohalonata. mAb 7D11 strongly reacted to hyphal extract of S. cylindrospora while mAbs 27E2 and 6D4 exhibited cross-reactivity to $S$. nephrospora. mAbs 7D11, 9G6, and 27E2 also displayed minimal cross-reactivity with Memnoniella echinata; a species that is phylogenetically related to $S$. chartarum. mAbs 9G6 and 27E2 also cross-reacted with M. subsimplex. No cross-reactivity was observed with any of the other 39 tested fungal species.

2.3.4 Western blot- Western blot analysis following SDS-PAGE of S. chlorohalonata hyphal extracts indicated that the mAbs recognized multiple bands. mAbs 3C3, 7D11 and 6D4 recognized two doublet bands at $\sim 30 \mathrm{kDa}$ and single band at $\sim 48 \mathrm{kDa}$ (Fig 2.3), while $\mathrm{mAb}$ 9G6 recognized a streak of high molecular bands. Since, the antibodies were cloned by limiting dilution; the antigens identified by these antibodies may be highly processed proteins or possibly be components of protein complexes of varying molecular weight. 


\begin{tabular}{|c|c|c|c|c|c|c|c|c|c|}
\hline Fungal species & $\begin{array}{l}\text { Strain } \\
\text { I.D. }\end{array}$ & $\begin{array}{l}\mathrm{mAb} \\
3 \mathrm{C3}\end{array}$ & $\begin{array}{l}\text { mAb } \\
6 \mathrm{D} 4\end{array}$ & $\begin{array}{l}\text { mAb } \\
7 \mathrm{D11}\end{array}$ & $\begin{array}{l}\text { mAb } \\
9 G 6\end{array}$ & $\begin{array}{l}\mathrm{mAb} \\
24 \mathrm{D} 11\end{array}$ & $\begin{array}{l}\text { mAb } \\
27 C 10\end{array}$ & $\begin{array}{l}\mathrm{mAb} \\
27 \mathrm{E} 2\end{array}$ & $\begin{array}{l}\text { mAb } \\
29 E 5\end{array}$ \\
\hline $\begin{array}{l}\text { Stachybotrys } \\
\text { chartarum }\end{array}$ & IBT 7711 & 1.886 & 1.806 & 2.411 & 1.841 & 1.419 & 1.285 & 0.519 & 0.187 \\
\hline $\begin{array}{l}\text { Stachybotrys } \\
\text { chartarum }\end{array}$ & IBT 9460 & 1.888 & 1.636 & 2.185 & 1.717 & 1.302 & 1.511 & 0.437 & 0.241 \\
\hline $\begin{array}{l}\text { Stachybotrys } \\
\text { chartarum }\end{array}$ & IBT 9466 & 1.572 & 1.484 & 0.307 & 1.649 & 0.925 & 1.932 & 0.736 & 0.399 \\
\hline $\begin{array}{l}\text { Stachybotrys } \\
\text { chartarum }\end{array}$ & IBT 9631 & 1.307 & 1.149 & 1.537 & 1.499 & 0.598 & 1.241 & 0.591 & 0.356 \\
\hline $\begin{array}{l}\text { Stachybotrys } \\
\text { chartarum }\end{array}$ & IBT 9633 & 1.113 & 1.139 & 1.244 & 1.134 & 0.694 & 1.208 & 0.382 & 0.211 \\
\hline $\begin{array}{l}\text { Stachybotrys } \\
\text { chartarum }\end{array}$ & $\begin{array}{l}\text { IBT } \\
14915\end{array}$ & 2.305 & 2.244 & 0.930 & 1.993 & 1.541 & 1.736 & 0.862 & $\mathbf{0 . 3 3 5}$ \\
\hline $\begin{array}{l}\text { Stachybotrys } \\
\text { chartarum }\end{array}$ & $\begin{array}{l}\text { IBT } \\
14916\end{array}$ & 1.702 & 1.799 & 2.013 & 2.520 & 0.786 & 1.649 & 0.655 & 0.207 \\
\hline $\begin{array}{l}\text { Stachybotrys } \\
\text { chlorohalonata }\end{array}$ & $\begin{array}{l}\text { ATCC } \\
201863 \\
(\text { IBT } \\
9825)\end{array}$ & 1.856 & 1.761 & 1.951 & 0.795 & 1.333 & 1.565 & 0.043 & 0.017 \\
\hline $\begin{array}{l}\text { Stachybotrys } \\
\text { albipes }\end{array}$ & $\begin{array}{l}\text { ATCC } \\
18873\end{array}$ & 0.031 & 0.014 & 0.041 & 0.025 & 0.031 & 0.050 & 0.023 & 0.018 \\
\hline $\begin{array}{l}\text { Stachybotrys } \\
\text { bisbyi }\end{array}$ & $\begin{array}{l}\text { ATCC } \\
18825\end{array}$ & 2.790 & 2.575 & 0.320 & 2.618 & 1.783 & 2.052 & 0.938 & 0.578 \\
\hline $\begin{array}{l}\text { Stachybotrys } \\
\text { cylindrospora }\end{array}$ & $\begin{array}{l}\text { ATCC } \\
16276\end{array}$ & 0.010 & 0.009 & 1.039 & 0.068 & 0.026 & 0.410 & 0.012 & 0.003 \\
\hline $\begin{array}{l}\text { Stachybotrys } \\
\text { kampalensis }\end{array}$ & $\begin{array}{l}\text { ATCC } \\
22705\end{array}$ & 0.084 & 0.285 & 0.000 & 0.007 & 0.009 & 0.025 & 0.136 & 0.077 \\
\hline $\begin{array}{l}\text { Stachybotrys } \\
\text { nephrospora }\end{array}$ & $\begin{array}{l}\text { ATCC } \\
18839\end{array}$ & 0.027 & 0.952 & 0.047 & 0.042 & 0.033 & 0.064 & 0.455 & 0.022 \\
\hline $\begin{array}{l}\text { Stachybotrys } \\
\text { oenanthes }\end{array}$ & $\begin{array}{l}\text { CBS } \\
252.76\end{array}$ & 0.024 & 0.016 & 0.236 & 0.046 & 0.059 & 0.121 & 0.039 & 0.034 \\
\hline $\begin{array}{l}\text { Stachybotrys } \\
\text { parvispora }\end{array}$ & $\begin{array}{l}\text { CBS } \\
100155\end{array}$ & 2.156 & 2.332 & 3.355 & 0.017 & 1.528 & 2.768 & 0.008 & 0.004 \\
\hline Memnoniella & NRRL & 0.217 & 0.265 & 1.623 & 1.185 & 0.054 & 0.033 & 0.439 & 0.199 \\
\hline
\end{tabular}




\begin{tabular}{|c|c|c|c|c|c|c|c|c|c|}
\hline echinata & 2373 & & & & & & & & \\
\hline $\begin{array}{l}\text { Memnoniella } \\
\text { subsimplex }\end{array}$ & $\begin{array}{l}\text { ATCC } \\
32888\end{array}$ & 0.107 & 0.103 & 0.043 & 1.099 & 0.057 & 0.090 & 0.346 & 0.130 \\
\hline $\begin{array}{l}\text { Aspergillus } \\
\text { chevalieri }\end{array}$ & NRRL 78 & 0.130 & 0.052 & 0.091 & 0.126 & 0.094 & 0.132 & 0.069 & 0.062 \\
\hline $\begin{array}{l}\text { Asp42ergillus } \\
\text { clavatus }\end{array}$ & $\begin{array}{l}\text { NIOSH } \\
6-22-78\end{array}$ & 0.024 & 0.016 & 0.067 & 0.062 & 0.058 & 0.098 & 0.042 & 0.035 \\
\hline $\begin{array}{l}\text { Aspergillus } \\
\text { flavus }\end{array}$ & $\begin{array}{l}\text { ATCC } \\
24689\end{array}$ & 0.026 & 0.013 & 0.069 & 0.059 & 0.060 & 0.116 & 0.047 & 0.041 \\
\hline $\begin{array}{l}\text { Aspergillus } \\
\text { fumigatus }\end{array}$ & $\begin{array}{l}\text { FGSC } \\
\text { A1100 }\end{array}$ & 0.023 & 0.011 & 0.031 & 0.029 & 0.038 & 0.053 & 0.016 & 0.013 \\
\hline $\begin{array}{l}\text { Aspergillus } \\
\text { nidulans }\end{array}$ & $\begin{array}{l}\text { NIOSH } \\
15-22-08\end{array}$ & 0.016 & 0.013 & 0.029 & 0.042 & 0.057 & 0.018 & 0.031 & 0.021 \\
\hline $\begin{array}{l}\text { Aspergillus } \\
\text { niger }\end{array}$ & $\begin{array}{l}\text { FGSC } \\
\text { A1144 }\end{array}$ & 0.014 & 0.003 & 0.044 & 0.054 & 0.065 & 0.060 & 0.019 & 0.010 \\
\hline $\begin{array}{l}\text { Aspergillus } \\
\text { parasiticus }\end{array}$ & $\begin{array}{l}\text { ATCC } \\
26691\end{array}$ & 0.023 & 0.014 & 0.053 & 0.087 & 0.021 & 0.054 & 0.027 & 0.015 \\
\hline $\begin{array}{l}\text { Aspergillus } \\
\text { repens }\end{array}$ & NRRL 13 & 0.061 & 0.061 & 0.097 & 0.137 & 0.091 & 0.181 & 0.097 & 0.080 \\
\hline $\begin{array}{l}\text { Aspergillus } \\
\text { sydowii }\end{array}$ & $\begin{array}{l}\text { ATCC } \\
9507\end{array}$ & 0.102 & 0.053 & 0.098 & 0.120 & 0.094 & 0.109 & 0.073 & 0.067 \\
\hline $\begin{array}{l}\text { Aspergillus } \\
\text { terreus }\end{array}$ & $\begin{array}{l}\text { ATCC } \\
1012\end{array}$ & 0.019 & 0.016 & 0.056 & 0.058 & 0.041 & 0.095 & 0.028 & 0.025 \\
\hline Aspergillus ustus & $\begin{array}{l}\text { NRRL } \\
275\end{array}$ & 0.018 & 0.000 & 0.043 & 0.052 & 0.036 & 0.019 & 0.005 & 0.000 \\
\hline $\begin{array}{l}\text { Aspergillus } \\
\text { versicolor }\end{array}$ & $\begin{array}{l}\text { ATCC } \\
44408\end{array}$ & 0.023 & 0.017 & 0.037 & 0.054 & 0.067 & 0.106 & 0.043 & 0.034 \\
\hline $\begin{array}{l}\text { Penicillium } \\
\text { aurantiogriseum }\end{array}$ & $\begin{array}{l}\text { NRRL } \\
971\end{array}$ & 0.029 & 0.010 & 0.052 & 0.099 & 0.029 & 0.068 & 0.040 & 0.031 \\
\hline $\begin{array}{l}\text { Penicillium } \\
\text { expansum }\end{array}$ & $\begin{array}{l}\text { NRRL } \\
973\end{array}$ & 0.015 & 0.012 & 0.038 & 0.027 & 0.039 & 0.060 & 0.025 & 0.013 \\
\hline $\begin{array}{l}\text { Penicillium } \\
\text { fellutanum }\end{array}$ & $\begin{array}{l}\text { NRRL } \\
746\end{array}$ & 0.032 & 0.005 & 0.045 & 0.054 & 0.025 & 0.023 & 0.012 & 0.002 \\
\hline $\begin{array}{l}\text { Penicillium } \\
\text { purpurogenum }\end{array}$ & $\begin{array}{l}\text { NRRL } \\
1062\end{array}$ & 0.104 & 0.026 & 0.017 & 0.084 & 0.003 & 0.043 & 0.012 & 0.000 \\
\hline
\end{tabular}




\begin{tabular}{|c|c|c|c|c|c|c|c|c|c|}
\hline $\begin{array}{l}\text { Penicillium } \\
\text { roqueforti }\end{array}$ & $\begin{array}{l}\text { NRRL } \\
844\end{array}$ & 0.014 & 0.012 & 0.026 & 0.016 & 0.051 & 0.034 & 0.012 & 0.011 \\
\hline $\begin{array}{l}\text { Alternaria } \\
\text { alternata }\end{array}$ & $\begin{array}{l}\text { ATCC } \\
11612\end{array}$ & 0.065 & 0.044 & 0.097 & 0.095 & 0.070 & 0.156 & 0.084 & 0.085 \\
\hline $\begin{array}{l}\text { Alternaria } \\
\text { brassicicola }\end{array}$ & $\begin{array}{l}\text { ATCC } \\
96836\end{array}$ & 0.046 & 0.039 & 0.064 & 0.091 & 0.034 & 0.088 & 0.053 & 0.044 \\
\hline Wallemia sebi & $\begin{array}{l}\text { NIOSH } \\
26-41-01\end{array}$ & 0.015 & 0.017 & 0.040 & 0.027 & 0.026 & 0.049 & 0.027 & 0.023 \\
\hline $\begin{array}{l}\text { Acremonium } \\
\text { strictum }\end{array}$ & $\begin{array}{l}\text { ATCC } \\
46646\end{array}$ & 0.011 & 0.005 & 0.027 & 0.017 & 0.032 & 0.030 & 0.009 & 0.007 \\
\hline $\begin{array}{l}\text { Stemphylium } \\
\text { botryosum }\end{array}$ & $\begin{array}{l}\text { ATCC } \\
26881\end{array}$ & 0.014 & 0.028 & 0.069 & 0.052 & 0.056 & 0.093 & 0.060 & 0.050 \\
\hline $\begin{array}{l}\text { Trichoderma } \\
\text { viride }\end{array}$ & $\begin{array}{l}\text { ATCC } \\
16640\end{array}$ & 0.026 & 0.009 & 0.037 & 0.021 & 0.031 & 0.033 & 0.017 & 0.009 \\
\hline $\begin{array}{l}\text { Ulocladium } \\
\text { chartarum }\end{array}$ & $\begin{array}{l}\text { UAMH } \\
5703\end{array}$ & 0.016 & 0.007 & 0.039 & 0.031 & 0.031 & 0.053 & 0.019 & 0.009 \\
\hline $\begin{array}{l}\text { Cladosporium } \\
\text { herbarum }\end{array}$ & $\begin{array}{l}\text { ATCC } \\
6506\end{array}$ & 0.018 & 0.006 & 0.027 & 0.014 & 0.028 & 0.021 & 0.020 & 0.013 \\
\hline $\begin{array}{l}\text { Cladosporium } \\
\text { sphaerospermum }\end{array}$ & $\begin{array}{l}\text { ATCC } \\
11288\end{array}$ & 0.027 & 0.019 & 0.037 & 0.075 & 0.021 & 0.060 & 0.038 & 0.033 \\
\hline $\begin{array}{l}\text { Paecilomyces } \\
\text { variotii }\end{array}$ & $\begin{array}{l}\text { ATCC } \\
66705\end{array}$ & 0.104 & 0.064 & 0.102 & 0.093 & 0.081 & 0.141 & 0.082 & 0.073 \\
\hline $\begin{array}{l}\text { Chaetomium } \\
\text { globosum }\end{array}$ & $\begin{array}{l}\text { ATCC } \\
6205\end{array}$ & 0.009 & 0.025 & 0.015 & 0.035 & 0.003 & 0.036 & 0.018 & 0.007 \\
\hline Botrytis cinerea & $\begin{array}{l}\text { ATCC } \\
11542\end{array}$ & 0.026 & 0.022 & 0.042 & 0.031 & 0.032 & 0.048 & 0.017 & 0.010 \\
\hline $\begin{array}{l}\text { Geotrichum } \\
\text { candidum }\end{array}$ & $\begin{array}{l}\text { UAMH } \\
7863\end{array}$ & 0.018 & 0.012 & 0.041 & 0.031 & 0.036 & 0.085 & 0.035 & 0.017 \\
\hline $\begin{array}{l}\text { Epicoccum } \\
\text { nigrum }\end{array}$ & $\begin{array}{l}\text { ATCC } \\
34929\end{array}$ & 0.041 & 0.026 & 0.052 & 0.037 & 0.041 & 0.068 & 0.038 & 0.029 \\
\hline $\begin{array}{l}\text { Eurotium } \\
\text { amstelodami }\end{array}$ & $\begin{array}{l}\text { NIOSH } \\
19-23-3\end{array}$ & 0.004 & 0.003 & 0.013 & 0.000 & 0.000 & 0.002 & 0.010 & 0.013 \\
\hline $\begin{array}{l}\text { Exserohilum } \\
\text { rostratum }\end{array}$ & $\begin{array}{l}\text { ATCC } \\
26856\end{array}$ & 0.008 & 0.007 & 0.026 & 0.015 & 0.046 & 0.037 & 0.015 & 0.012 \\
\hline Fusarium & Penn State & 0.025 & 0.034 & 0.040 & 0.059 & 0.072 & 0.098 & 0.027 & 0.018 \\
\hline
\end{tabular}




\begin{tabular}{|l|l|l|l|l|l|l|l|l|l|}
\hline moniliforme & M6131 & & & & & & & & \\
\hline $\begin{array}{l}\text { Myrothecium } \\
\text { verrucaria }\end{array}$ & $\begin{array}{l}\text { NRRL } \\
2003\end{array}$ & 0.014 & 0.013 & 0.044 & 0.034 & 0.053 & 0.096 & 0.041 & 0.034 \\
\hline $\begin{array}{l}\text { Rhizopus } \\
\text { stolonifer }\end{array}$ & $\begin{array}{l}\text { NIOSH } \\
17-59-14\end{array}$ & 0.021 & 0.007 & 0.040 & 0.035 & 0.037 & 0.077 & 0.027 & 0.019 \\
\hline $\begin{array}{l}\text { Scopulariopsis } \\
\text { brumptii }\end{array}$ & $\begin{array}{l}\text { ATCC } \\
16278\end{array}$ & 0.083 & 0.047 & 0.087 & 0.057 & 0.102 & 0.131 & 0.076 & 0.060 \\
\hline
\end{tabular}

Table 2.1. Cross-reactivity profiles of the eight IgM anti-stachylysin mAbs analyzed by the capture ELISA. Optical densities (OD) were measured at 405 nm after 30 mins incubation with substrate. Bolded values identify reactivity of mAbs (columns) against a particular species (rows). ATCC-American Type Culture Collection, NRRL- Agricultural Research Service Culture Collection, NIOSH- National Institute for Occupational Safety and Health, FGSC-Fungal Genetics Stock Center, UAMH- University of Alberta Microfungus Collection and Herbarium, Penn State- Pennsylvania State University, IBT- Instituttet for Bioteknologi, Denmark, CBSCentraalbureau voor Schimmelcultures, Netherlands. 


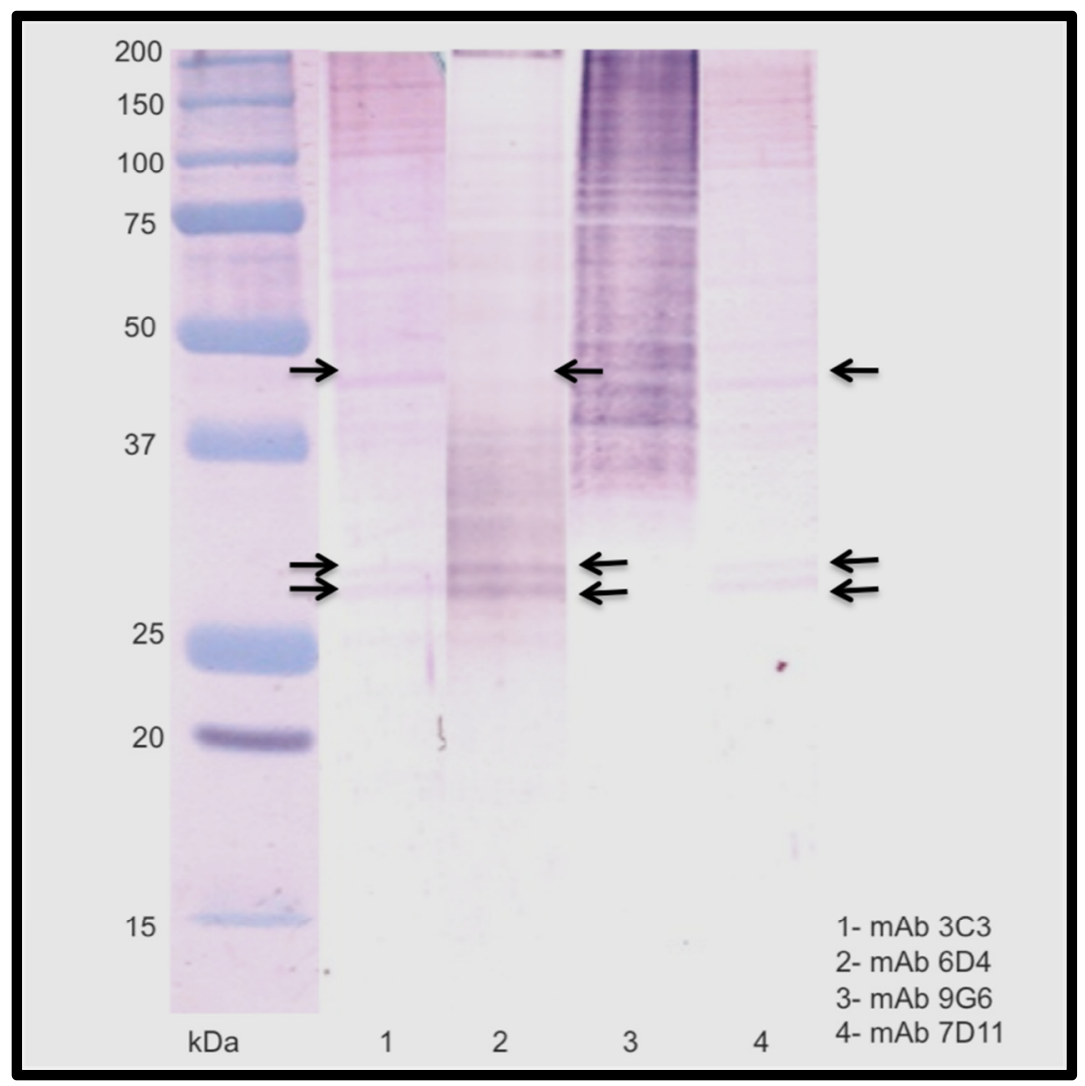

Fig 2.3. Western blot reactivity patterns: Mycelial extract from S. chlorohalonata were developed in Western blot analysis using Lane 1- $m A b 3 C 3$, Lane 2- $m A B$ 6D4, Lane 3- mAb 9G6 and Lane 4- mAb 7D10. Reactive bands are labeled with black arrows. 


\subsection{DISCUSSION}

The fungal genus, Stachybotrys, is a tertiary colonizer of moisture infiltrated cellulosebased building materials (18) and an indoor air contaminant (19). Personal exposure to Stachybotrys conidia has been associated with respiratory disease $(5,20-25)$; however, the scientific basis is not fully understood.

The identification of Stachybotrys in indoor environments requires macroscopic and microscopic identification of conidia by a certified indoor air quality professional. A few studies have developed strategies aimed at detection of Stachybotrys and associated biomarkers to determine exposure $(9,11,13,14,26-32)$. Often, mycological expertise is required to confirm the presence of Stachybotrys conidia in indoor environments, however, morphologically indiscernible hyphae and fragments that are equally important biomarkers of contamination, remain overlooked and are not quantified (33). Given the presence of Stachybotrys hyphae and hyphal fragments in indoor air samples and the potential health effects associated with personal exposure, the development of mAbs that recognize this overlooked fraction is an important step that will improve the quantification of these particulates. Fragments derived from hyphae and conidia also contain mycotoxins and other immunostimulatory antigens (34), however, the health effects associated with personal exposure remain uncharacterized. Recent developments in molecular and immunodiagnostic detection methodologies have improved the detection and quantification of $S$. chartarum. These studies have provided new insight into potential biomarkers of personal exposure $(11,20,26,27,29)$ including the cytolytic protein, stachylysin $(9,30,35,36)$.

Recently, several laboratories have developed mAbs towards $S$. chartarum $(32,37)$. The utility of antibody-based immunoassays for the quantification of personal exposure to $S$. 
chartarum has been explored elsewhere (9). A pAb has been utilized in an indirect ELISA for the quantification of stachylysin in environmental samples. Stachylysin has been detected in the serum of S. chartarum exposed animals. Similarly, stachylysin has also been detected in pooled serum derived from $S$. chartarum exposed workers but not in control subjects that had no $a$ priori S. chartarum exposure (9). Although polyclonal antibodies have been developed against other S. chartarum exoantigens for indoor environment exposure assessment studies, pAbs often lack specificity and cross-react with other fungal species (9). To the best of our knowledge, mAbs that recognize Stachybotrys hyphae have yet to be developed.

Though the protein sequence of stachylysin is currently unavailable, the amino acid composition was reported using an amino acid analysis service at Yale University (7). Amino acid composition similarity search using AACompIdent with 'hemolysis' as a key word identified amino acid composition similarities to hemolytic proteins from different species (APPENDIX A1).

In the present study, we immunized mice with stachylysin preparation purified from $S$. chlorohalonata hyphal CSN. Eight anti-stachylysin IgM isotype mAbs were produced that exhibited reactivity to the original stachylysin preparation used for immunization. Four mAbs, that consistently showed greater reactivity toward hyphal extracts derived from $S$. chlorohalonata and S. chartarum species, were selected for further characterization. Previously, it was shown that hyphae contain higher levels of this hemolytic protein than the conidia and this observation was consistent for all strains studied (9). We have experimentally confirmed this earlier observation in this study where we found high concentrations of stachylysin in hyphae compared to conidia. 
Immunolocalization studies utilizing the FHIA, confirmed that the greatest reactivity of the mAbs were toward antigens released from phialides and hyphae compared to conidia. Almost all reactivity in hyphae was observed at septal junctions and branch points of hyphal bifurcation. At this point in time it is difficult to suggest any possible role for stachylysin located at these points of growth. mAb 1B9, which served as an IgM isotype control in this study, was previously developed in our laboratory against particulate fraction of homogenized Aspergillus versicolor conidia (12).

Recent taxonomic studies have segregated $S$. chartarum into two separate chemotypes, based on the production of metabolites $(15,38)$. Chemotype A comprises atranone and dolabellane producing strains (IBT 9466, IBT 9633, IBT 14915) and chemotype S consists of satratoxin and other macrocyclic trichothecene producing strains (IBT 7711, IBT 9460, IBT 9631, IBT 14916). In the present study, all mAbs with the exception of mAb 29E5, reacted to antigens released from both chemotype A and S strains. mAbs 7D11, 9G6, and 27E2 that were developed in this study identified S. chlorohalonata and did cross-react with closely related species belonging to the genus Memnoniella. Also, our mAbs could not clearly differentiate between S. chartarum and S. chlorohalonata. Recent studies showed that other commercially available detection methodologies could also not differentiate between $S$. chartarum and $S$. chlorohalonata (39). Antibodies of IgM isotype can show high cross-reactivity due to the pentameric nature of the antibody, which contributes to increased avidity to the epitope. Development of $\operatorname{IgG}$ isotype antibodies to stachylysin may help overcome some of the crossreactivity problems. The reduced cross-reactivity observed for anti-stachylysin mAbs compared to the mAbs previously produced in our laboratory against Penicillium brevicompactum and A. versicolor could be due to the source of the antigen. $(10,12)$ Conidial antigens are fewer and 
may be shared between various fungal species and may show less antigenic variation compared to hyphal antigens, which are diverse and present in larger quantities. We have observed similar results in Aspergillus versicolor, where mAbs produced against conidia were cross-reactive (12).

The stachylysin preparation used in these studies was previously characterized as a homogenous protein preparation of $\sim 12 \mathrm{kDa}$ which migrates as $\sim 30 \mathrm{kDa}$ protein in SDS-PAGE (7). Interestingly, we observed immunoreactivity of the mAbs to multiple bands in Western blot including a doublet band at $\sim 30 \mathrm{kDa}$. This suggests that mAbs recognize the epitopes on oligomers or higher molecular weight protein complexes covalently bound to stachylysin. Since hemolysins conceptually aggregate after binding to their target and not in solution, it is possible that the mAbs may have been generated against higher molecular weight protein complexes present in S. chlorohalonata.

In this study, four IgM monoclonal antibodies have been developed directed against stachylysin derived from S. chlorohalonata and partially characterized. Although the mAbs showed limited reactivity with conidia, the results demonstrate the potential utility of these mAbs for the development of immunodetection methods for the quantification of Stachybotrys hyphae in indoor environments.

In this initial attempt to study fungal hemolysins as potential biomarkers we chose stachylysin due to its association to IPH and clinical disease exposure. Collectively, our data suggest the possibility of multiple proteins in the stachylysin preparation. This makes it difficult to develop mAbs to study the role of a single protein using these preparations. Additionally, the genome for Stachybotrys has not been sequenced, which would have aided in better characterization of stachylysin using recombinant techniques. Also, IgM antibodies are not ideal 
for developing immunoassays. Overall, the study was disappointing in that we were unable to identify the stachylysin protein with biochemical features of a hemolysin.

\subsection{REFERENCES}

1. Pinruan, U., E. H. C. McKenzie, E. B. G. Jones, and K. D. Hyde. 2004. Two new species of Stachybotrys, and a key to the genus. Fungal Diversity 17:145-157.

2. Pestka, J. J., I. Yike, D. Dearborn, M. D. W. Ward, and J. R. Harkema. 2008. Stachybotrys chartarum, trichothecene, mycotoxins, and damp building-related illness: New insights into a public health enigma. Toxicological Sciences 104:4-26.

3. Feinberg, B., and C. S. MacLaughlin. 1989. Biochemical mechanism of action of trichothecene mycotoxins. In Trichothecene Mycotoxins: Pathophysiologic effects. V. R. Beasley, ed. CRC Press, Boca Raton, FL. 27-36.

4. Yike, I., T. Rand, and D. G. Dearborn. 2007. The role of fungal proteinases in pathophysiology of Stachybotrys chartarum. Mycopathologia 164:171-181.

5. Vesper, S. J., D. G. Dearborn, I. Yike, W. G. Sorenson, and R. A. Haugland. 1999. Hemolysis, toxicity, and randomly amplified polymorphic DNA analysis of Stachybotrys chartarum strains. Appl Environ Microbiol 65:3175-3181.

6. Vesper, S. J., D. G. Dearborn, O. Elidemir, and R. A. Haugland. 2000b. Quantification of siderophore and hemolysin from Stachybotrys chartarum strains, including a strain isolated from the lung of a child with pulmonary hemorrhage and hemosiderosis. Appl Environ Microbiol 66:2678-2681.

7. Vesper, S. J., M. L. Magnuson, D. G. Dearborn, I. Yike, and R. A. Haugland. 2001. Initial characterization of the hemolysin stachylysin from Stachybotrys chartarum. Infect Immun 69:912-916.

8. Vesper, S. J., and M. J. Vesper. 2002. Stachylysin may be a cause of hemorrhaging in humans exposed to Stachybotrys chartarum. Infect Immun 70:2065-2069.

9. Van Emon, J. M., A. W. Reed, I. Yike, and S. J. Vesper. 2003. ELISA measurement of stachylysin in serum to quantify human exposures to the indoor mold Stachybotrys chartarum. J Occup Environ Med 45:582-591.

10. Schmechel, D., R. L. Gorny, J. P. Simpson, T. Reponen, S. A. Grinshpun, and D. M. Lewis. 2003. Limitations of monoclonal antibodies for monitoring of fungal aerosols using Penicillium brevicompactum as a model fungus. J Immunol Methods 283:235-245.

11. Schmechel, D., J. P. Simpson, D. Beezhold, and D. M. Lewis. 2006. The development of species-specific immunodiagnostics for Stachybotrys chartarum: the role of crossreactivity. J Immunol Methods 309:150-159.

12. Schmechel, D., J. P. Simpson, and D. M. Lewis. 2005. The production and characterization of monoclonal antibodies to the fungus Aspergillus versicolor. Indoor Air 15 Suppl 9:11-19.

13. Green, B. J., L. L. Millecchia, F. M. Blachere, E. R. Tovey, D. H. Beezhold, and D. Schmechel. 2006. Dual fluorescent halogen immunoassay for bioaerosols using confocal microscopy. Anal Biochem 354:151-153. 
14. Schmechel, D., and D. M. Lewis. 2001. The production of species-specific monoclonal antibodies (Mabs) against the allergenic and toxigenic fungus Stachybotrys chartarum. FASEB J 15:A662.

15. Andersen, B., K. F. Nielsen, U. Thrane, T. Szaro, J. W. Taylor, and B. B. Jarvis. 2003. Molecular and phenotypic descriptions of Stachybotrys chlorohalonata sp. nov. and two chemotypes of Stachybotrys chartarum found in water-damaged buildings. Mycologia 95:1227-1238.

16. Rand, T. G., J. Flemming, J. D. Miller, and T. O. Womiloju. 2006. Comparison of inflammatory responses in mouse lungs exposed to atranones A and C from Stachybotrys chartarum. J Toxicol Environ Health A 69:1239-1251.

17. Hiersemann, M., and H. Helmboldt. 2005. Recent progress in the total synthesis of dolabellane and dolastane diterpenes. In Natural product synthesis I-II: targets, methods, concepts (Topics in Current Chemistry). J. H. Mulzer, ed. Springer, New York, NY.

18. Kuhn, D. M., and M. A. Ghannoum. 2003. Indoor mold, toxigenic fungi, and Stachybotrys chartarum: infectious disease perspective. Clin Microbiol Rev 16:144-172.

19. Vesper, S., C. McKinstry, P. Ashley, R. Haugland, K. Yeatts, K. Bradham, and E. Svendsen. 2007. Quantitative PCR analysis of molds in the dust from homes of asthmatic children in North Carolina. J Environ Monit 9:826-830.

20. Vesper, S. J., and M. J. Vesper. 2004. Possible role of fungal hemolysins in sick building syndrome. Adv Appl Microbiol 55:191-213.

21. Mahmoudi, M., and M. E. Gershwin. 2000. Sick building syndrome. III. Stachybotrys chartarum. J Asthma 37:191-198.

22. Etzel, R. A., E. Montana, W. G. Sorenson, G. J. Kullman, T. M. Allan, D. G. Dearborn, D. R. Olson, B. B. Jarvis, and J. D. Miller. 1998. Acute pulmonary hemorrhage in infants associated with exposure to Stachybotrys atra and other fungi. Arch Pediatr Adolesc Med 152:757-762.

23. Hodgson, M. J., P. Morey, W. Y. Leung, L. Morrow, D. Miller, B. B. Jarvis, H. Robbins, J. F. Halsey, and E. Storey. 1998. Building-associated pulmonary disease from exposure to Stachybotrys chartarum and Aspergillus versicolor. J Occup Environ Med 40:241-249.

24. McGinnis, M. R. 2004. Pathogenesis of indoor fungal diseases. Med Mycol 42:107-117.

25. Vesper, S. J., C. McKinstry, C. Yang, R. A. Haugland, C. M. Kercsmar, I. Yike, M. D. Schluchter, H. L. Kirchner, J. Sobolewski, T. M. Allan, and D. G. Dearborn. 2006. Specific molds associated with asthma in water-damaged homes. J Occup Environ Med 48:852-858.

26. Haugland, R. A., and J. L. Heckman. 1998. Identification of putative sequence specific PCR primers for detection of the toxigenic fungal species Stachybotrys chartarum. Mol Cell Probes 12:387-396.

27. Haugland, R. A., S. J. Vesper, and L. J. Wymer. 1999. Quantitative measurement of Stachybotrys chartarum conidia using real time detection of PCR products with the TaqMan(TM)fluorogenic probe system. Mol Cell Probes 13:329-340.

28. Roe, J. D., R. A. Haugland, S. J. Vesper, and L. J. Wymer. 2001. Quantification of Stachybotrys chartarum conidia in indoor dust using real time, fluorescent probe-based detection of PCR products. J Expo Anal Environ Epidemiol 11:12-20. 
29. Cruz-Perez, P., M. P. Buttner, and L. D. Stetzenbach. 2001. Specific detection of Stachybotrys chartarum in pure culture using quantitative polymerase chain reaction. $\mathrm{Mol}$ Cell Probes 15:129-138.

30. Vojdani, A. 2005. Antibodies against Stachybotrys chartarum extract and its antigenic components, Stachyhemolysin and Stachyrase-A: a new clinical biomarker. Med Sci Monit 11:BR139-145.

31. Yike, I., A. M. Distler, A. G. Ziady, and D. G. Dearborn. 2006. Mycotoxin adducts on human serum albumin: Biomarkers of exposure to Stachybotrys chartarum. Env Health Pers 114:1221-1226.

32. Xu, J., Y. Liang, D. Belisle, and J. D. Miller. 2008. Characterization of monoclonal antibodies to an antigenic protein from Stachybotrys chartarum and its measurement in house dust. J Immunol Methods 332:121-128.

33. Yang, C. S., and P. A. Heinsohn. 2007. Sampling and analysis of indoor organisms. Wiley \& Sons Inc., Hoboken, NJ.

34. Brasel, T. L., D. R. Douglas, S. C. Wilson, and S. C. Straus. 2005. Detection of airborne Stachybotrys chartarum macrocyclic trichothecene mycotoxins on particulates smaller than conidia. Appl Environ Microbiol 71:114-122.

35. Gregory, L., T. G. Rand, D. Dearborn, I. Yike, and S. Vesper. 2003. Immunocytochemical localization of stachylysin in Stachybotrys chartarum spores and spore-impacted mouse and rat lung tissue. Mycopathologia 156:109-117.

36. Page, E., R. E. Biagini, and D. H. Beezhold. 2005. Methodologic issues concerning Stachyhemolysin and Stachyrase-A as clinical biomarkers. Med Sci Monit 11:LE7-8.

37. Xu, J., J. T. Jensen, Y. Liang, D. Belisle, and J. D. Miller. 2007. The biology and immunogenicity of a 34-kDa antigen of Stachybotrys chartarum sensu lato. Int Biodeterior Biodegradation 60:308-318.

38. Andersen, B., K. F. Nielsen, and B. B. Jarvis. 2002. Characterization of Stachbotrys from water-damaged buildings based on morphology, growth, and metabolite production. Mycologia 94:392-403.

39. Li, D. W., and C. S. Yang. 2005. Taxonomic history and current status of Stachybotrys chartarum and related species. Indoor Air 15 Suppl 9:5-10. 


\section{CHAPTER 3}

Aspergillus terreus and first approach at development of mAbs to putative hemolysin and its characterization 


\subsection{INTRODUCTION}

Aspergillus terreus was chosen because the genome was sequenced and a putative hemolysin was identified (1). A. terreus is one of the 4 major species including A. fumigatus, A. flavus and A. niger that are involved in invasive aspergillosis in humans. A. terreus-related invasive infections have been reported with highest mortality rates compared to other Aspergillus species. One of the contributing factors for high mortality is the resistance of A. terreus to the first line of treatment. Currently, there is a need for species-specific diagnostics for improved treatment strategies.

Previously, asp-hemolysin of A. fumigatus was detected in tissues of exposed experimental animals (2). This generated an interest in characterization of the hemolysin of $A$. terreus and developing it as a biomarker. Observations on hemolytic activity of 50 different fungal species cultivated on sheep blood agar (SBA) were reported in the former study. Thirtyfive of 50 different fungal species tested exhibited hemolytic activity between days 1-5 of growth. Interestingly, Aspergillus terreus was one of the only 2 fungi and the only member of genus Aspergillus to show hemolysis after 1 day of culture.

Our aim was to develop monoclonal antibodies (mAbs) to hemolytic protein of A. terreus by purifying it with methods described earlier for purification of stachylysin (3). Our goal was to develop species-specific mAbs recognizing A. terreus hemolysin for development of standardized rapid detection assays. This chapter describes A. terreus, its role in our environment, industrial uses and its emergence as a pathogen. Later we characterize the development of mAbs to purified hemolytic proteins from A. terreus. 


\subsection{ASPERGILLUS SPECIES}

Aspergillus species were first identified by a Roman Catholic clergyman and biologist Pier Antonio Micheli in the year 1729 (4). He identified microscopic structures bearing spores as being similar to 'asperges', which is a device used to sprinkle holy water. Aspergillus species are very common and pervasive. At present, over 600 species of Aspergillus have been identified however, with recent developments in molecular identification techniques, new species are routinely identified (5-8). Aspergillus species are divided into 8 different sub genera (Appendix A2).

Aspergillosis is the disease state identified by infection with members of Aspergillus species. Infections involving fungi have been reported more frequently and Aspergillus species are the most common fungi associated with invasive fungal diseases in immunocompromised patients (9-12). Though more than 40 species of Aspergillus have been identified as medically relevant; Aspergillus fumigatus, Aspergillus terreus, Aspergillus niger and Aspergillus flavus are most frequently isolated (13). Additional species including Aspergillus clavatus and Aspergillus nidulans are increasingly being identified in invasive infections (14). Although immunosuppression is a major prerequisite to invasive infection, some conditions in otherwise immunocompetent individuals may predispose them to Aspergillus infections (15). Recent reports have also emerged on pulmonary invasive aspergillosis after $\mathrm{H} 1 \mathrm{~N} 1$ infection $(16,17)$.

Aspergillus species cause diverse infections inversely associated to the status of host immune system (18). Pulmonary infection is often initiated by inhalation of metabolically dormant conidia. Owing to their small size, conidia can reach deep within the lungs in the alveoli. If the conidia germinate, the hyphae grow and demonstrate vasculotropic growth 
resulting in invasion of local blood vessels, causing obliteration of host tissue and leads to pulmonary hemorrhage (13).

\subsection{ASPERGILLUS TERREUS}

Aspergillus terreus was first described by Thom and Church in 1918 (19). A. terreus gets its name from the cinnamon brown (terrestrial) color of the colonies. Though colonies are predominantly brown, slight variations may occur between strains and may be attributed to differences in sporulation by individual strains (20). It plays an important role in nature in recycling of nutrients by decomposition of compost and plant material (21). In industry, it is used as a source of mevinolin (lovastatin) the first statin approved by FDA, which helps in lowering serum cholesterol (22-24). A. terreus is also a valuable source for various industrial chemicals and enzymes such as itaconic acid, gluconic acid, xylanases and proteases (25-29). A. terreus produces enzymes that are useful in biodegradation of lignocellulosic waste, plastics etc. (29-35).

A. terreus conidia are 1.5-2.4 $\mu \mathrm{m}$ in diameter and spherical in shape with striations on the surface (20). Conidiophores are smooth hyaline structures with vesicles at the apex bearing conidia on phialides. A. terreus produces accessory conidia that form laterally on hyphae. These accessory conidia, called aleurioconidia, are produced by the vegetative hyphae under submerged conditions and have been observed in vitro as well as in vivo (20). Some have speculated that aleurioconidia are involved in dissemination of the fungus during infection (3638). In comparison to phialidic conidia, aleurioconidia are larger in size, metabolically more active, possess enhanced adherence, and germinate very rapidly (37). All strains of $A$. terreus, clinical as well as environmental produce aleurioconidia, however variations in number and size exist (37). There is also a difference in the number of aleurioconidia borne at a single locus (37, 
39, 40). Other Aspergillus species that are closely related to A. terreus, such as A. flavipes, A. carneus and A. niveus have also been reported to also produce aleurioconidia $(36,38)$.

An increasing number of cases of aspergillosis involving A. terreus have been reported in recent years $(20,41-43)$. The same growth competences that make Aspergillus species excellent agents of decomposition of organic materials also make them formidable opportunistic pathogens. The ability of the pathogen to grow optimally at $35-37^{\circ} \mathrm{C}$ and its ability to tolerate higher temperatures $\left(40-42^{\circ} \mathrm{C}\right)$ allows it to grow at internal body temperature that is inhibitory to many fungi $(44,45)$.

A. terreus can cause wide range of diseases from superficial infections to invasive and disseminated aspergillosis. A. terreus has been identified as the causative agent in otomycosis (46-48), onychomycosis (49-51), endophthalmitis (52-54), cutaneous infection (55-57), peritonitis (58-60), osteomyelitis (61-63), allergic bronchopulmonary aspergillosis (64-66), aspergilloma $(67,68)$, and invasive aspergillosis (IA) $(41,42)$. A. terreus pathogenesis is poorly understood, however secondary metabolites that may have toxic effects on host cells have been reported (69-71).

Species-specific diagnosis of $A$. terreus opportunistic infections is clinically important due to the pathogen's resistance to the primary antifungal therapeutic amphotericin B (72-74). To date, the identification of A. terreus infections has challenged the most seasoned clinicians (75). Clinical diagnosis of A. terreus infection is subjective and has been restricted to macroscopic and microscopic characterization of tissue samples (76), computed tomography imaging (77), and detection of serum galactomannan or $(1,3)-\beta$-D-glucan $(78,79)$. These diagnostic methods are not specific and prevents the identification of the causative agent (79). Other more specific molecular methods such as PCR have been recently developed but are limited by a number of 
confounding factors such as problems with consistent DNA recovery and interference by inhibitors of PCR process $(79,80)$. Due to increasing A. terreus infections reported in the literature, its resistance to amphotericin $\mathrm{B}$, and the high mortality rate associated with infection, it is critical to develop sensitive and specific diagnostic tests (41).

In this chapter, we describe the production and characterization of species-specific mAbs to a partially purified cytolytic A. terreus preparation (cAtp). Using the mAbs, we characterized the cross-reactivity profiles, kinetics of antigen expression, and detection of antigens in presence of human serum proteins. Collectively, these results suggest that anti-cAtp mAbs may be useful for immunodiagnostic assays to detect invasive A. terreus disease.

\subsection{MATERIALS AND METHODS}

3.4.1 Preparation of cAtp and polyclonal antibodies- A. terreus ATCC 1012 (American Type Culture Collection, Manassas, VA) conidia were inoculated in Tryptic Soy Broth (TSB), grown in liquid culture for 7 days. cAtp was partially purified from TSB using molecular sieve and gel filtration steps to isolate the cytolytic fraction as previously described (3). Polyclonal antibodies (pAbs) to cAtp were generated in rabbits by Bethyl Laboratories (Montgomery, TX) and affinity purified using cAtp immobilized on activated sepharose columns.

\subsubsection{Production of monoclonal antibodies (mAbs) to cAtp- Four 10-14 week old BALB/c} mice (The Jackson Laboratory, Bar Harbor, ME) were housed under controlled environmental conditions in HEPA-filtered ventilated polycarbonate cages on autoclaved hardwood beta-chip bedding. Mice were provided Teklad 7913 rodent chow (Harlan Laboratories, Madison, WI) and autoclaved tap water ad libitum. Sentinel mice, housed in the animal quarters were free of viral 
pathogens, parasites, mycoplasma, and Helicobacter spp. The animal protocol was approved by the National Institute for Occupational Safety and Health (NIOSH) Animal Care and Use Committee (ACUC) and the NIOSH animal facility is accredited by the Association for Assessment and Accreditation of Laboratory Animal Care International (AAALAC).

Mice were immunized (6 times) intraperitoneally at bi-weekly intervals using $25 \mu \mathrm{g}$ of cAtp emulsified in TiterMax® ${ }^{\circledR}$ adjuvant (TiterMax USA, Norcross, GA). Mice received a final boost $\left(7^{\text {th }}\right.$ immunization) of $25 \mu \mathrm{g}$ of HEA without adjuvant 3 days before hybridoma production. Pre- and test-bleed mouse IgG-specific titers to HEA were tested using an indirect ELISA method. Briefly, 96-well Nunc Immuno MaxiSorp microplates (Thermo Fisher Scientific, Rochester, NY) were coated with $0.1 \mu \mathrm{g} /$ well cAtp in carbonate coating buffer (CCB, $60 \mathrm{mM}$ sodium carbonate, $140 \mathrm{mM}$ sodium bicarbonate, $\mathrm{pH}$ 9.6). Antibody binding from mouse sera was determined using biotin-SP goat anti-mouse $\operatorname{IgG} \mathrm{Fc} \gamma$ (Jackson ImmunoResearch Laboratories Inc., West Grove, PA) and alkaline phosphatase (AP)-conjugated Streptavidin (Jackson ImmunoResearch Laboratories Inc.). ELISA plates were developed with 4-nitrophenyl phosphate substrate (Sigma, St. Louis, MO) and read at $450 \mathrm{~nm}$ after 30 mins as previously described (81).

Three days following the final boost, the immunized mice were euthanized by $\mathrm{CO}_{2}$ asphyxiation, the spleens were surgically removed, and splenocytes were fused with SP2/0-Ag 14 ATCC myeloma cells (ATCC\# CRL-1581). Hybridomas were selected by growing the cells in Dulbecco's Modified Eagle Medium (DMEM) (Life Technologies, Rockville, MD) supplemented with $1 \mathrm{mM}$ sodium pyruvate, $100 \mathrm{U} / \mathrm{mL}$ penicillin, $100 \mathrm{mg} / \mathrm{mL}$ streptomycin, $0.292 \mathrm{mg} / \mathrm{mL}$ L-glutamine, $100 \mathrm{mM}$ sodium hypoxanthine, $16 \mathrm{mM}$ thymidine, $10 \%$ fetal calf serum (FCS) (HyClone, Logan, UT), and 100 U/mL IL-6 (Boehringer, Mannheim, Germany). 
DMEM medium was also supplemented with azaserine for selective propagation of hybridomas. After 10-14 days of hybridoma cell growth, the medium from individual wells was replenished with fresh medium. The tissue culture supernatant (CSN) fluid from individual hybridoma colonies was tested using a modification of a previously described sandwich ELISA. CSN from individual hybridoma clones was tested in duplicate to confirm the presence of cAtp-specific mAbs. Each positive hybridoma clone was further cloned twice by limiting dilution and single positive clones were screened and selected for bulk mAb production. Hybridoma cell lines of individual clones were frozen in FCS containing 10\% dimethyl sulfoxide (DMSO) and stored at $80^{\circ} \mathrm{C}$ for 2 weeks, and then transferred to a liquid nitrogen tank for long term storage.

3.4.3 cAtp capture ELISA- In brief, 96-well Nunc Immuno MaxiSorp microplates (Thermo Fisher Scientific, Rochester, NY) were coated with $100 \mu 1 /$ well rabbit anti-cAtp polyclonal antibody (pAb) $(1 \mu \mathrm{g} / \mathrm{ml})$ in CCB and incubated overnight at RT. Wells were washed three times by incubating with $200 \mu \mathrm{l} /$ well of PBS containing 0.05\% Tween 20 (PBST) for $10 \mathrm{~min}$. The plates were then blocked for $1 \mathrm{~h}$ at RT with $200 \mu \mathrm{l} /$ well of PBSTM (PBST containing $1 \%$ nonfat dry milk powder). Wells were then incubated for $1 \mathrm{~h}$ at $37^{\circ} \mathrm{C}$ with $100 \mu \mathrm{l} /$ well $\mathrm{cAtp}(1 \mu \mathrm{g} / \mathrm{ml})$ to bind cAtp. Plates were then processed with hybridoma CSN, followed by goat anti-mouse $\operatorname{IgG}$ antibody as described above. Negative control values were obtained by substituting hybridoma CSN with supplemented DMEM.

3.4.4 Isotyping and quantification of IgG antibodies- Isotyping of individual mAbs was determined by a direct ELISA. Plates were coated with CSN from A. terreus diluted in CCB (1 $\mu \mathrm{g} / \mathrm{ml})$ and incubated overnight. Next day plates were blocked with PBSTM and incubated with 
mAb solutions from individual hybridomas. mAbs bound to cAtp antigens were detected using Biotin SP-conjugated AffiniPure goat anti-mouse $\operatorname{IgG}_{1}, \operatorname{IgG}_{2 \mathrm{a}}, \operatorname{IgG}_{2 \mathrm{~b}}$ and $\operatorname{IgG}_{3}$ secondary antibodies (Jackson ImmunoResearch Laboratories Inc.) at a dilution of 1:5000 in PBSTM. ELISA plates were developed using methods described earlier.

For quantification, mAbs were serially diluted and captured on ELISA plates coated with AffiniPure goat anti-mouse IgG, Fc fragment of either subclass 1, 2a, 2b or 3 specificity at 1 $\mu \mathrm{g} / \mathrm{ml}$ concentration depending on the isotype of the mAb to be quantified (Jackson Immunoresearch Laboratories Inc.). $\operatorname{IgG}_{1}, \operatorname{IgG}_{2 \mathrm{a}}, \operatorname{IgG}_{2 \mathrm{~b}}$ and $\mathrm{IgG}_{3}$ standards (Sigma) were used to set up a standard curve for quantification purposes. AP-conjugated goat anti-mouse secondary antibodies (1:5000) diluted in PBSTM were used for quantification experiment.

\subsubsection{Preparation of $\boldsymbol{A}$. terreus extracts for characterization of mAbs- Conidial extracts.}

Conidia were collected from 10-14 days old A. terreus cultures grown on Malt Extract Agar (MEA) by rolling approximately $1 \mathrm{gm}$ of $0.5 \mathrm{~mm}$ glass beads (BioSpec Products Inc., Bartlesville, OK) over the plate. Glass beads with conidia were collected into a $2 \mathrm{~mL}$ screw cap microcentrifuge tube and processed in a mini bead beater (BioSpec Products Inc.). Mechanical bead beating was carried out for 2 mins to disrupt the outer cell wall of the conidia. Conidial proteins were collected in $50 \mathrm{mM}$ ammonium bicarbonate buffer $\mathrm{pH} 8.0$ containing $0.5 \mathrm{M}$ ethyldiaminetetraacetic acid, 0.1 M phenylmethylsulfonyl fluoride, and cOmplete Mini Protease Inhibitor Cocktail (Roche Diagnostics, Mannheim, Germany). The suspension was centrifuged at $4100 \mathrm{~g}$ for 10 mins and the supernatant fluid was collected and lyophilized overnight. Lyophilized conidial protein extract was resuspended in $\mathrm{PBS} \mathrm{pH} 7.4$ and stored at $-80^{\circ} \mathrm{C}$. 
Hyphal extracts and culture supernatants. Viable A. terreus conidia ( $2.5 \times 10^{7}$ conidia) were inoculated in $50 \mathrm{~mL}$ minimal medium consisting of $1 \%$ glucose, nitric salts and trace elements (82). Viability of conidia was determined by LIVE/DEAD® BacLight ${ }^{\mathrm{TM}}$ viability kit (Invitrogen, Carlsbad, CA) previously used for determination of viability of fungal conidia (83). Cultures were grown at $\mathrm{RT}$ or $37^{\circ} \mathrm{C}$ with shaking $(200 \mathrm{rpm})$ for varying intervals of time. For $\mathrm{mAb}$ reactivity assays, cultures were grown for a period of 6 days and for the kinetics of expression studies, cultures were grown for up to 12 days with samples collected every $24 \mathrm{hrs}$. Mycelial cultures were harvested by centrifugation at $4100 \mathrm{~g}$ for 5 mins and the hyphae (pellet) and CSN were collected and concentrated by lyophilization. The lyophilized CSN was reconstituted in $5 \mathrm{~mL}$ PBS pH 7.4 containing complete Mini Protease Inhibitor Cocktail and stored at $-80^{\circ} \mathrm{C}$ for further analysis. Lyophilized hyphae were macerated in a mortar containing liquid $\mathrm{N}_{2}$, suspended in cold PBS containing complete Mini Protease Inhibitor Cocktail, and incubated overnight on a rocker at $4^{\circ} \mathrm{C}$ to extract proteins. The mycelial extract (ME) was centrifuged at $4100 \mathrm{~g}$ for 5 mins and the supernatant fluid was collected, aliquoted and stored at $80^{\circ} \mathrm{C}$ for further analysis. Protein concentrations in all fungal extract preparations were determined using a NanoDrop ND-1000 Spectrophotometer (NanoDrop Technologies, Thermo Scientific, Wilmington, DE).

3.4.6 Characterization of cAtp expression in fungi- For cross-reactivity analyses, 56 fungal isolates representing 46 fungal species (Table 1.) were grown on MEA medium for 7-10 days. The conidia $\left(1.25 \times 10^{8}\right)$ were collected, and inoculated into $50 \mathrm{~mL}$ TSB medium. Cultures were grown for 4 days at RT and centrifuged at $4100 \mathrm{~g}$ for 5 mins to collect the mycelial pellet. The pellet was washed 3 times with cold PBS pH 7.4, macerated, and then centrifuged at $4100 \mathrm{~g}$ for 5 
mins as previously described. The supernatant fluid was collected, protein concentration determined by NanoDrop spectrophotometer, and mAb reactivity tested using the previously described capture ELISA. Positive reactivity was determined by an Optical Density (OD) of $\geq$ 0.2 (negative control value +3 standard deviations). The OD values of the negative controls ranged from 0 to 0.18 for different fungal extracts.

The kinetics of antigen expression during culture was also examined. Individual mAbs were tested against $A$. terreus conidial, hyphal, and CSN extracts used at $100 \mu \mathrm{g} / \mathrm{ml}$ of total protein to determine the level of antigen expression during different phases of A. terreus growth. The pAb-based capture ELISA was used for this analysis and all mAbs were normalized to 500 ng/ml in PBSTM. Plates were developed using secondary antibodies and reagents as previously described.

3.4.7 cAtp detection in spiked human serum- Detection of cAtp antigens by the mAbs in presence of human serum was studied using the ELISA methods described earlier. CSN was collected from a 6 day culture of $A$. terreus and was diluted to $100 \mu \mathrm{g} / \mathrm{ml}$. Pooled human serum (Sigma) was spiked with dilutions of A. terreus CSN and assayed in the capture ELISA at a final concentration of $50 \%$ total volume using $100 \mu \mathrm{l}$ of sample. Additionally, samples were also incubated in PBS and served as control for this experiment. All samples including controls were incubated at $37^{\circ} \mathrm{C}$ for $1 \mathrm{hr}$ before analysis in capture ELISA method.

3.4.8 Western blot assay- A. terreus CSN $(100 \mu \mathrm{g} / \mathrm{ml})$ obtained from a 6 day TSB culture was separated on a $12 \%$ polyacrylamide gel using SDS-PAGE under reducing conditions. Proteins were transferred overnight at $30 \mathrm{~V}$ to a $0.2 \mu \mathrm{m}$ nitrocellulose membrane. The membrane was 
blocked with containing 3\% bovine serum albumin (BSA) in PBST (PBSTB) for 2 hrs. The membrane was washed in PBST and then processed using a Mini-PROTEAN II Multiscreen Apparatus (Bio-Rad Laboratories, Hercules, CA). Each lane on the membrane was incubated with an individual $\mathrm{mAb}(500 \mathrm{ng} / \mathrm{ml})$ for $1 \mathrm{hr}$ with shaking. The membrane was washed with PBST and incubated with AP-conjugated goat anti-mouse IgG $(\mathrm{H}+\mathrm{L})$ (Promega, Madison, WI) diluted 1/5000 (v/v) in PBST for $1 \mathrm{hr}$ with shaking. The membrane was then washed with PBST and developed using 1-step NBT/BCIP substrate (Promega). The substrate reaction was developed for 15-20 mins and stopped by washing the membrane with distilled water.

\subsubsection{Immunoprecipitation of cAtp antigens using Protein G- Immunoprecipitation of} antigens recognized by mAbs 13E11, 12C4 and 19B2 was performed using Dynabeads ${ }^{\circledR}$ Protein G (Invitrogen Dynal AS, Oslo, Norway) per the manufacturer's instructions. Briefly, Protein G magnetic beads were washed twice with W\&B buffer (0.1M Na-phosphate, $0.01 \%$ Tween 20, pH 8.2) and incubated with $5 \mu \mathrm{g}$ of the individual mAbs diluted in $\mathrm{W} \& \mathrm{~B}$ buffer for 10 mins with rotation at RT. Antigen capture was performed after washing the Protein G magnetic beads with PBS and incubating with A. terreus hyphal extract overnight at $4^{\circ} \mathrm{C}$. The beads were washed thoroughly in PBS and the immunoprecipitate was eluted with Laemmli Sample Buffer (BioRad, Hercules, CA) containing 2-mercaptoethanol $(5 \% \mathrm{v} / \mathrm{v})$. Immunoprecipitate samples were analyzed by SDS-PAGE and stained with Imperial $^{\mathrm{TM}}$ Protein Stain (Thermo Scientific, Rockford, IL). Bands of interest as determined by a parallel Western blot analysis were excised from the SDS-PAGE gels and processed for proteomic analysis. 
3.4.10 Proteomic analysis- In gel reduction/alkylation/digestion. All reagents were obtained from Sigma Chemical (St. Louis, MO) unless otherwise noted. All incubations were performed at $37^{\circ} \mathrm{C}$ with shaking $(300 \mathrm{rpm})$. Protein bands of interest were excised, reduced, alkylated, and digested with porcine trypsin according to published methodologies $(84,85)$. Protein bands were transferred to low retention, siliconized $0.5 \mathrm{ml}$ microcentrifuge tubes and destained with two washes of $200 \mu \mathrm{l} 200 \mathrm{mM} \mathrm{NH}_{4} \mathrm{HCO}_{3}$ in $40 / 60$ acetonitrile/water for 30 mins and the supernatant removed. The gel bands were dehydrated 30 mins in a vacuum concentrator and rehydrated with $200 \mu \mathrm{l} 0.5 \mathrm{mM}$ tributylphosphine in $25 \mathrm{mM} \mathrm{NH}_{4} \mathrm{HCO}_{3}$, followed by 15 min incubation. The supernatant was removed and replaced with $200 \mu 10.4 \mathrm{mM}$ iodoacetamide, followed by $30 \mathrm{~min}$ incubation. The gel bands were washed twice with $200 \mu 125 \mathrm{mM} \mathrm{NH} \mathrm{NCO}_{3}$ for 15 mins followed by one wash with $200 \mu 1200 \mathrm{mM} \mathrm{NH} \mathrm{HCO}_{3}$ in 40/60 acetonitrile/water. Gel bands were dehydrated 30 mins in a vacuum concentrator and rehydrated with $1 \mu \mathrm{g}$ porcine trypsin in $100 \mu \mathrm{l}$ of $50 \mathrm{mM} \mathrm{NH} \mathrm{HCO}_{3}$. The samples were allowed to digest overnight and the supernatant was removed to a clean siliconized microcentrifuge tube. The gel bands were washed once with $0.1 \%$ trifluoroacetic acid in $50 \%$ acetonitrile for $15 \mathrm{~min}$. The wash and digest supernatants were combined and concentrated for $1 \mathrm{hr}$ in a vacuum concentrator and reconstituted in $20 \mu 10.1 \%$ trifluoroacetic acid prior to LC-MS/MS analysis.

Ultra-performance liquid chromatography/Tandem mass spectrometry. Enzymatic peptides were separated on a Waters (Milford, MA) nanoACQUITY ultra-performance liquid chromatography (UPLC) system. Aliquots $(3 \mu \mathrm{l})$ of the digest mixture were injected and trapped/desalted on a $5 \mu \mathrm{m}$ SymmetryC $_{18}(180 \mu \mathrm{m} \times 20 \mathrm{~mm})$ trapping column with 99.5/0.5 A/B (A:0.1\% formic acid; B:0.1\% formic acid in acetonitrile) at a flow rate of $15 \mu \mathrm{l} / \mathrm{min}$ for 1 minute. Separation was performed on a $1.7 \mu \mathrm{m}$ BEH130 $\mathrm{C}_{18}(75 \mu \mathrm{m} \times 100 \mathrm{~mm})$ analytical column 
utilizing gradient elution at a flow rate of $300 \mathrm{nl} / \mathrm{min}$ and a gradient of 99/1 to 60/40 $\mathrm{A} / \mathrm{B}$ over 60 min. The eluent from the UPLC system was directed to the nanoelectrospray source of a Waters SYNAPT MS quadrupole time-of-flight (qTOF) mass spectrometer. Positive ion nanoelectrospray was performed utilizing $10 \mu \mathrm{m}$ PicoTip (Waters) emitters held at a potential of $+3.5 \mathrm{kV}$. The cone voltage was held constant at $+40 \mathrm{~V}$ for all experiments. Dry $\mathrm{N}_{2}$ desolvation gas was supplied to the instrument via a nitrogen generator (NitroFlowLab, Parker Hannifin Corp., Haverhill, MA). [Glu] ${ }^{1}$-Fibrinopeptide B (100 fmol/ $\mu$ l in 75/25 A/B) was supplied to an orthogonal reference probe and the $[\mathrm{M}+2 \mathrm{H}]^{2+}$ ion $(\mathrm{m} / \mathrm{z}=785.84265 \mathrm{u})$ measured as an external calibrant at $30 \mathrm{sec}$ intervals. Ultra-high purity (UHP) argon was used as collision gas. Spectra were acquired in an "MS ${ }^{\mathrm{e}}$ " fashion (86). Alternating one-second mass spectra were acquired. The collision energy was set to $6 \mathrm{eV}$ ( $1 \mathrm{sec}$ low energy scan) and a 15-30 eV ramp (1 sec high energy scan).

Homology searching. Data were analyzed with ProteinLynx Global Server v. 2.4 (Waters) using the default PLGS search engine to query a custom Aspergillus terreus database downloaded from UniProtKB/Swiss-Prot and UniProtKB/TrEMBL (http://www.uniprot.org/uniprot/?query=terreus). A minimum of 2 peptides, with a minimum of three fragment ions each was required for identification. Trypsin was specified as the digestion enzyme and 1 missed cleavage was allowed. Carbamidomethyl cysteine was specified as a fixed modification and oxidized methionine and phosphoryl serine, threonine, and tyrosine were allowed as variable modifications. Protein assignments were confirmed via manual inspection of tandem mass spectra. 


\subsubsection{Confocal Scanning Laser Microscopy (CSLM) analysis for localization of putative}

leucine aminopeptidase and probable dipeptidyl-peptidase $\mathrm{V}$ of $A$. terreusImmunolocalization of A. terreus leucine aminopeptidase and dipeptidyl-peptidase $\mathrm{V}$ was studied using methods previously described with slight modifications $(87,88)$. Briefly, A. terreus FGSC 1156 cultures were grown on alcohol-sterilized cover slips in 6-well tissue culture plates containing minimal medium. Cultures were incubated at $37^{\circ} \mathrm{C}$ without shaking for $24 \mathrm{hrs}$. Cover slips were fixed with $8 \%$ formalin buffered saline containing $50 \mathrm{mM}$ PIPES (pH 6.7), $25 \mathrm{mM}$ EGTA, $1 \%$ dimethyl sulfoxide (DMSO) and $5 \mathrm{mM} \mathrm{MgSO}_{4}$. Cells were fixed for $1 \mathrm{hr}$ at RT and later rinsed with MTSB (50 mM PIPES (pH 6.7), $5 \mathrm{mM}$ EGTA and $5 \mathrm{mM} \mathrm{MgSO}$ ). Cell wall digestion was carried out for $1 \mathrm{hr}$ at RT with an enzyme solution containing $2.5 \%$ Driselase ${ }^{\circledR}$ (Sigma, St. Louis, MO), $1 \%$ lysozyme from chicken egg white (Sigma) and 2 mM EGTA. Cells were rinsed with $\mathrm{H}_{2} \mathrm{O}$ and were extracted with $0.1 \%$ Triton X-100 in Tris Buffered Saline (TBS) $\mathrm{pH} 7.4$ for 10 mins. Cells were quickly rinsed in MTSB and TBS once each. Cells were blocked with 3\% bovine serum albumin in TBS (TBSB) overnight at $4^{\circ} \mathrm{C}$ with gentle shaking. Next day, cover slips were incubated with mAb 9B4, 13E11 or $19 \mathrm{~B} 2$ at $3 \mu \mathrm{g} / \mathrm{ml}$ in TBSB for $3 \mathrm{hrs}$ with gentle shaking. mAb 9B4 was previously developed in our laboratory against an unidentified Stachybotrys chartarum conidial surface protein and is of $\operatorname{IgG}_{1}$ isotype (81). Cells were washed thoroughly in TBS containing 0.05\% Tween 20 (T-TBS) and stained with AlexaFluor ${ }^{\circledR} 594$ conjugated goat anti-mouse IgG (H+L) (Molecular Probes Inc., Eugene, OR) diluted 1:50 (v/v) in TBSB for $1 \mathrm{hr}$ at RT. Cells were washed thoroughly in T-TBS and cover slips were placed on clean slides with ProLong® Antifade Reagent with DAPI (Molecular Probes Inc.). Cells were observed with a Zeiss LSM-510 Meta Confocal Microscope System (Axioplan 2 Stand) (Carl Zeiss, Thornwood, NY). The images of AlexaFluor ${ }^{\circledR} 594$ labeled secondary antibodies bound to 
anti-HEA mAbs were acquired with Zeiss software version 3.2 (Carl Zeiss). All settings on the confocal laser microscope remained constant throughout the analysis.

\section{$3.5 \quad$ RESULTS}

3.5.1 Characterization of $\mathbf{m A b}$ reactivity to fungal extracts- All 4 mice immunized with cAtp, developed detectable IgG response to specific antigens after 3-4 immunizations, which mostly stabilized by the $4^{\text {th }}$ immunization. Twenty-three murine $\operatorname{IgG}_{1}$ isotype hybridomas were developed against cAtp (Table 3.2). Since the mAbs were developed against a partially purified cytolytic extract, reactivity of the mAbs to A. terreus culture extract antigen was tested. The $\mathrm{mAb}$ reactivity was the highest to mycelial extracts $(\mathrm{ME})$; however, weak reactivity to conidial extracts was also observed (Fig. 3.1a). As expected, the mAbs also showed significant reactivity to 6 day $\mathrm{CSN}$ from A. terreus cultures grown at RT and greater reactivity to $\mathrm{CSN}$ grown at $37^{\circ} \mathrm{C}$ (Fig. 3.1b). Collectively these results show that the mAbs react predominantly with hyphal antigens that are possibly actively secreted into the CSN.

3.5.2 Cross-reactivity of mAbs towards different fungi- Fifty-six different isolates of 46 fungal species representing 20 different genera were tested for cross-reactivity in the capture ELISA (Table 3.1). Positive reactivity was defined as a value $\geq 0.2 \mathrm{OD}_{405}$. All mAbs showed reactivity to ME tested from each A. terreus strain tested in this study (Table 3.1). Of the 23 mAbs that react with cAtp, $16(70 \%)$ did not cross-react with any of the fungal species tested here (Table 3.2). Seven mAbs cross-reacted with other fungi. Most of the cross-reactivity observed in these $7 \mathrm{mAbs}$ was limited within the genus Aspergillus except mAb 22D9 that also 
cross-reacted with ME derived from Acremonium strictum. Five mAbs (22D9, 38B6, 40C6, 52G7 and 64B3) cross-reacted with ME from at least 1 other fungus, while 24D7 cross-reacted with 2 different fungi (Table 3.2). The mAb 67G7 exhibited the greatest cross-reactivity, reacting to hyphal extracts derived from 4 different Aspergillus species (A. flavus, A. parasiticus, A. repens and A. sydowii). Of the fungal species tested, A. sydowii and A. repens ME showed highest cross-reactivity.

3.5.3 Western blot analysis of cAtp- Western blot analysis was performed with CSN from $A$. terreus culture using the 16 species-specific mAbs and the cross-reactive mAb 67G7 (Fig. 3.2). The results demonstrated differences within the mAbs in their reactivity to antigens in A. terreus CSN. The mAbs 13E11, 19B7, 24C8, 29C9 and 61E5 showed a similar pattern with strong reactivity to bands at $\sim 18 \mathrm{kDa}, 45 \mathrm{kDa}$, and $\sim 70 \mathrm{kDa}$ bands. The mAb $19 \mathrm{~B} 2$ identified unique high molecular weight bands at $\sim 100 \mathrm{kDa}$ and $\sim 150 \mathrm{kDa}$. It is possible that the immune reactivity to the $10 \mathrm{kDa}$ and the $45 \mathrm{kDa}$ antigens is due to binding of antibodies to shared epitopes or carbohydrate antigens. 


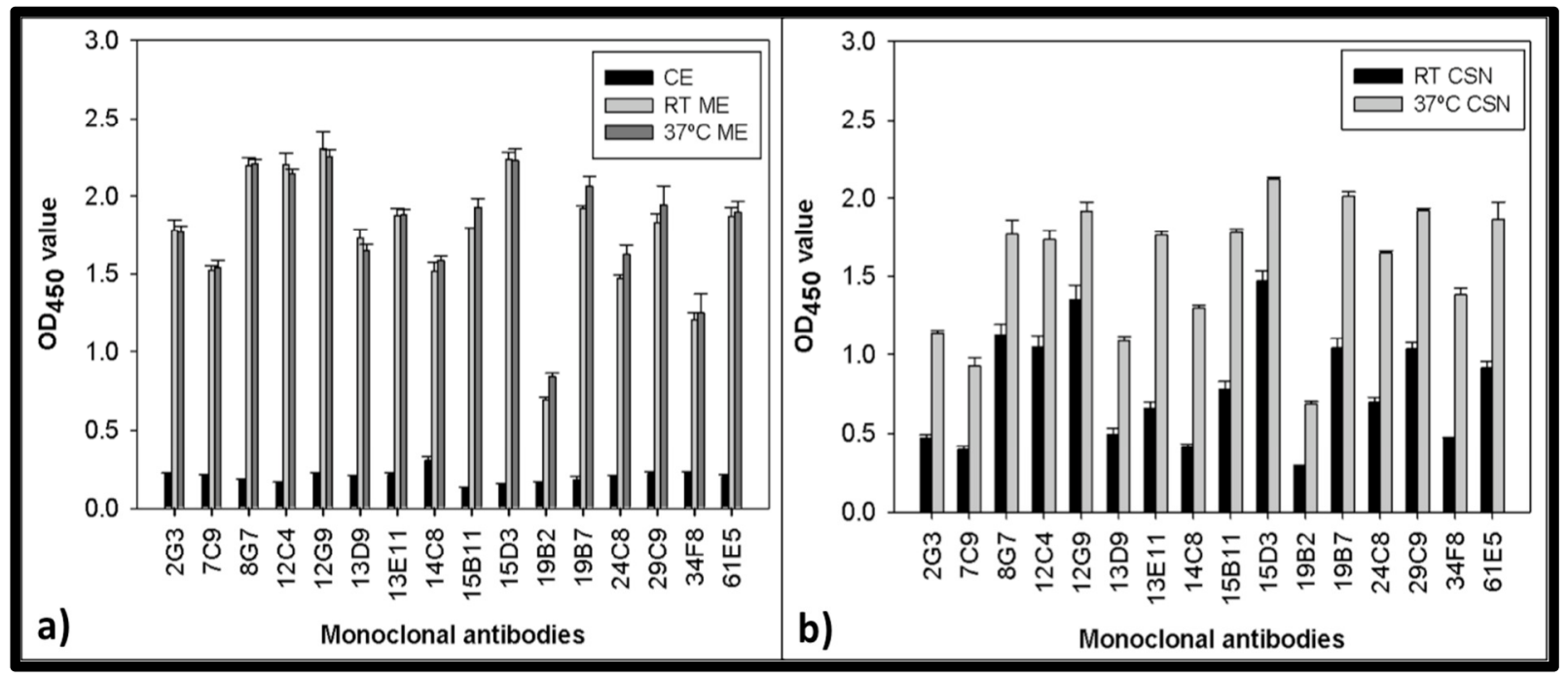

Fig. 3.1. $m A B$ reactivity to $A$. terreus extracts. a) $m A b$ reactivity to A. terreus conidial and hyphal extracts. Conidial and mycelial extracts of A. terreus were tested against 16 specific mAbs. CE-Spore extract, RT MEMycelial extract collected from an A. terreus culture grown at room temperature, $37^{\circ} \mathrm{C} \mathrm{ME}$ - Mycelial extract collected from an A. terreus culture grown at $37^{\circ} \mathrm{C}$. b) $\mathrm{mAb}$ reactivity to A. terreus culture supernatants. Culture

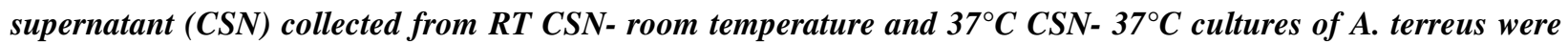
tested against 16 specific mAbs. Error bars represent the standard deviations of duplicate determinations from three independent experiments. 


\begin{tabular}{|c|c|c|c|}
\hline Fungal Species & $\begin{array}{l}\text { Culture } \\
\text { collection } \\
\text { I.D. }\end{array}$ & Fungal Species & $\begin{array}{l}\text { Culture } \\
\text { collection I.D. }\end{array}$ \\
\hline Aspergillus terreus & ATCC 1012 & Myrothecium verrucaria & NRRL 2003 \\
\hline Aspergillus terreus & FGSC A1156 & Paecilomyces variotii & ATCC 66705 \\
\hline Aspergillus terreus & ATCC 16794 & $\begin{array}{l}\text { Penicillium } \\
\text { aurantiogriseum }\end{array}$ & NRRL 971 \\
\hline Aspergillus terreus & SRC 2174 & Penicillium expansum & NRRL 973 \\
\hline Aspergillus chevalieri & NRRL 78 & Penicillium fellutanum & NRRL 746 \\
\hline Aspergillus clavatus & $\begin{array}{l}\text { NIOSH 6-22- } \\
78\end{array}$ & $\begin{array}{l}\text { Penicillium } \\
\text { purpurogenum }\end{array}$ & NRRL 1062 \\
\hline Aspergillus flavus & ATCC 24689 & Penicillium roqueforti & NRRL 844 \\
\hline Aspergillus fumigatus & FGSC A1100 & Rhizopus stolonifer & NIOSH 17-59-14 \\
\hline Aspergillus nidulans & $\begin{array}{ll}\text { NIOSH } & 15- \\
22-08 & \end{array}$ & \begin{tabular}{|l} 
Stachybotrys albipes \\
\end{tabular} & ATCC 18873 \\
\hline Aspergillus niger & FGSC A1144 & Stachybotrys bisbyi & ATCC 18825 \\
\hline Aspergillus parasiticus & ATCC 26691 & Stachybotrys chartarum & IBT 7711 \\
\hline Aspergillus repens & NRRL 13 & Stachybotrys chartarum & IBT 9290 \\
\hline Aspergillus sydowii & ATCC 9507 & Stachybotrys chartarum & IBT 9460 \\
\hline Aspergillus ustus & NRRL 275 & Stachybotrys chartarum & IBT 9466 \\
\hline Aspergillus versicolor & ATCC 44408 & Stachybotrys chartarum & IBT 9631 \\
\hline Acremonium strictum & ATCC 46646 & Stachybotrys chartarum & IBT 9633 \\
\hline Alternaria alternata & ATCC 11612 & Stachybotrys chartarum & IBT 14915 \\
\hline Alternaria brassicicola & ATCC 96836 & Stachybotrys chartarum & IBT 14916 \\
\hline Botrytis cinerea & ATCC 11542 & $\begin{array}{l}\text { Stachybotrys } \\
\text { chlorohalonata }\end{array}$ & ATCC 201863 \\
\hline
\end{tabular}




\begin{tabular}{|l|l|l|l|}
\hline Chaetomium globosum & ATCC 6205 & $\begin{array}{l}\text { Stachybotrys } \\
\text { cylindrospora }\end{array}$ & ATCC 16276 \\
\hline $\begin{array}{l}\text { Cladosporium } \\
\text { herbarum }\end{array}$ & ATCC 6506 & $\begin{array}{l}\text { Stachybotrys } \\
\text { kampalensis }\end{array}$ & ATCC 22705 \\
\hline $\begin{array}{l}\text { Cladosporium } \\
\text { cladosporioides }\end{array}$ & ATCC 11288 & $\begin{array}{l}\text { Stachybotrys } \\
\text { nephrospora }\end{array}$ & ATCC 18839 \\
\hline Epicoccum nigrum & ATCC 34929 & Stachybotrys oenanthes & CBS 252.76 \\
\hline Exserohilum rostratum & ATCC 26856 & Stachybotrys parvispora & CBS 100155 \\
\hline Fusarium moniliforme & PS M6131 & Scopulariopsis brumptii & ATCC 16278 \\
\hline Geotrichum candidum & UAMH 7863 & Stemphylium botryosum & ATCC 26881 \\
\hline Memnoniella echinata & NRRL 2373 & Trichoderma viride & ATCC 16640 \\
\hline $\begin{array}{l}\text { Memnoniella } \\
\text { subsimplex }\end{array}$ & ATCC 32888 & Wallemia sebi & NIOSH 26-41-01 \\
\hline
\end{tabular}

Table 3.1. Fungal species tested for cross-reactivity of cAtp-mAbs. Designation of sources for the 54 species representing 20 different genera of fungi. ATCC-American Type Culture Collection, NRRL-Agricultural Research Service Culture Collection, NIOSH- National Institute for Occupational Safety and Health, FGSCFungal Genetics Stock Center, UAMH- University of Alberta Microfungus Collection and Herbarium, Canada, PS- Pennsylvania State University, IBT- Instituttet for Bioteknologi, Denmark, CBS- Centraalbureau voor Schimmelcultures, The Netherlands. 


\begin{tabular}{|c|c|}
\hline cAtp-IgG 1 mAbs & Cross-reactivity \\
\hline 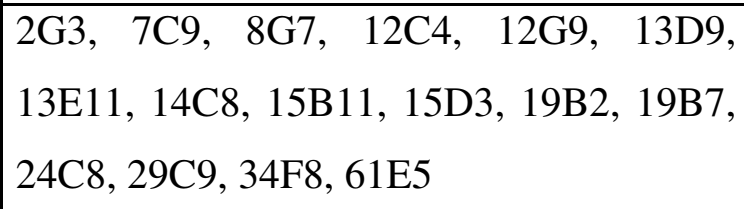 & $\begin{array}{l}\text { No cross-reactivity to any other species } \\
\text { tested. }\end{array}$ \\
\hline $22 \mathrm{D} 9$ & Acremonium strictum ATCC 46646 \\
\hline 24D7 & $\begin{array}{lcc}\text { Aspergillus sydowii } \text { ATCC } & 9507, \\
\text { Aspergillus repens NRRL } 13 & \end{array}$ \\
\hline 38B6, 40C6, 52G7, 64B3 & Aspergillus repens NRRL 13 \\
\hline 67G7 & $\begin{array}{lccc}\text { Aspergillus } & \text { flavus } & \text { ATCC } & 24689, \\
\text { Aspergillus } & \text { parasiticus } & \text { ATCC } & 26691, \\
\text { Aspergillus repens NRRL } & 13 \text {, Aspergillus } \\
\text { sydowii ATCC } 9507 & & \end{array}$ \\
\hline
\end{tabular}

Table 3.2. Cross-reactivity profiles of cAtp-mAbs analyzed by capture ELISA. 


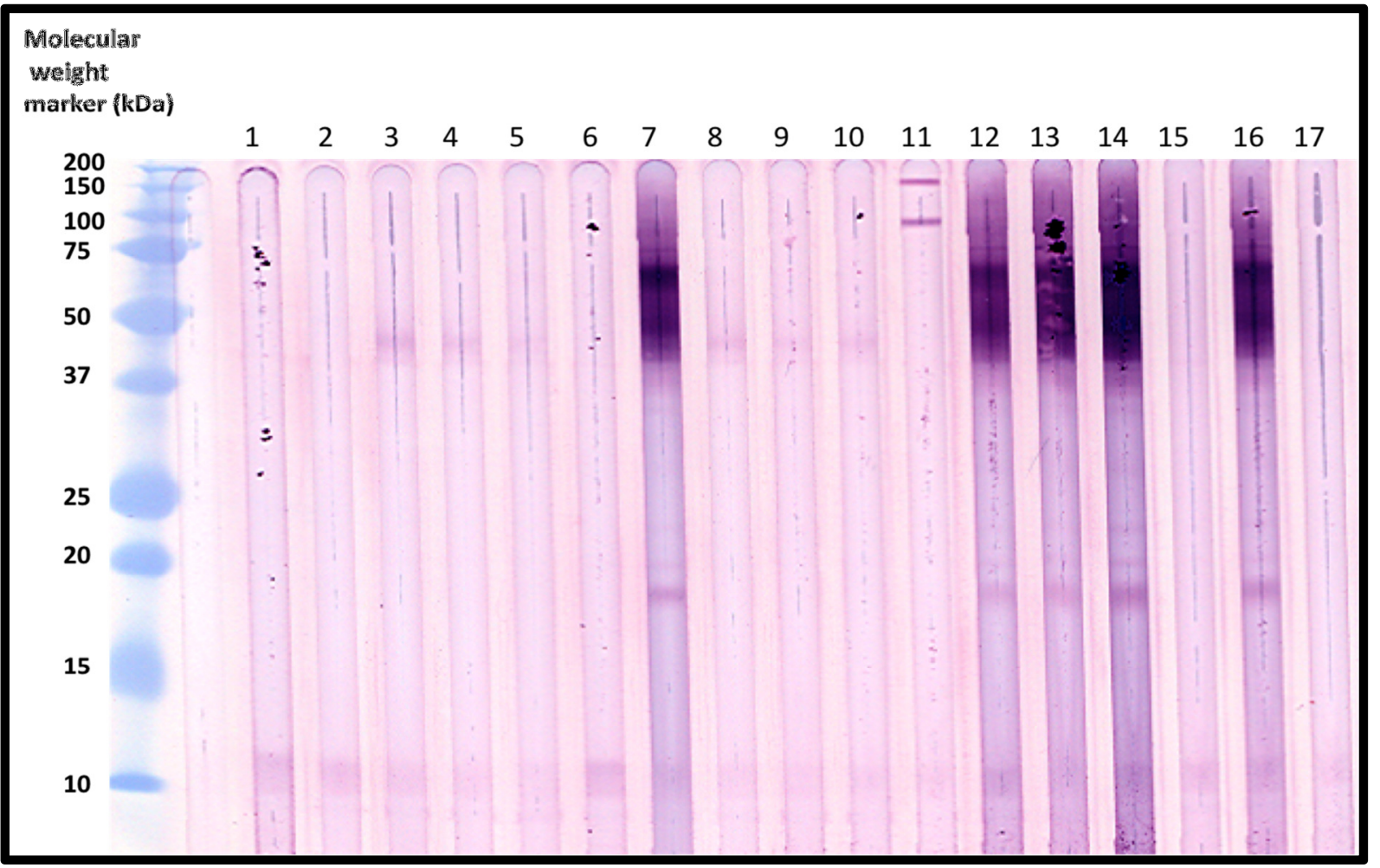

Fig. 3.2. Western blot reactivity of proteins in A. terreus culture supernatant extracts using anti-cAtp mAbs. 1$m A b$ 2G3, 2- $m A b$ 7C9, 3- $m A b$ 8G7, 4- $m A b$ 12C4, 5- $m A b$ 12G9, 6- $m A b$ 13D9, 7- $m A b$ 13E11, 8- $m A b$ 14C8, 9$m A b$ 15B11, 10- $m A b$ 15D3, 11- $m A b$ 19B2, 12- $m A b$ 19B7, 13- $m A b$ 24C8, 14- $m A b$ 29C9, 15- $m A b$ 34F8, 16$m A b$ 61E5, 17- $m A b 67 G 7$. 
3.5.4 Kinetics of A. terreus exoantigen expression- Four mAbs (13E11, 15D3, 19B2 and 19B7) were chosen for further study based on differences in patterns of reactivity in ELISA and Western blotting. Fig. 3.3 illustrates the time course of cAtp expression in A. terreus cultures. For mAbs 13E11, 15D3, and 19B7, the concentration of the cAtp rapidly increased in ME during days 3 to 5 and peaked at day 6 (Fig. 3.3a). Reactivity to cAtp in the CSN followed a similar pattern but appeared to lag behind ME by 24 hrs (Fig. 3.3b). At $37^{\circ} \mathrm{C}$, cAtp mAb reactivity was readily detectable by 24 hrs in both ME (Fig. 3.3c) and CSN (Fig. 3.3d) and peaked by days 3 and 4 , respectively. Interestingly, cAtp mAb reactivity could be detected in both ME and CSN beyond day 6 but appeared to decline in CSN after 10 days at $37^{\circ} \mathrm{C}$. The mAb $19 \mathrm{~B} 2$ antigen, while having a similar pattern as the other mAbs, appeared to lag in expression suggesting that this mAb may recognize a different antigen compared to other mAbs used in this study. Also, we observed a more rapid degradation of mAb 19B2 antigen after day 10 in CSN of A. terreus cultures grown at $37^{\circ} \mathrm{C}$. This could probably be due to proteolytic degradation of the antigen.

3.5.5 Human serum detection assay- To determine the ability of these mAbs to be used in immunodiagnostic assays, we tested $10 \mathrm{mAbs}$ for reactivity to A. terreus antigens spiked into human serum (Fig. 3.4). CSN grown at $37^{\circ} \mathrm{C}$ was mixed with human serum and assayed using a capture ELISA. Overall, there was a slight reduction in the detection of cAtp when spiked into human serum as compared to PBS alone for all mAbs tested, however, there did not seem to be any significant binding to serum components for any of the antibodies. 


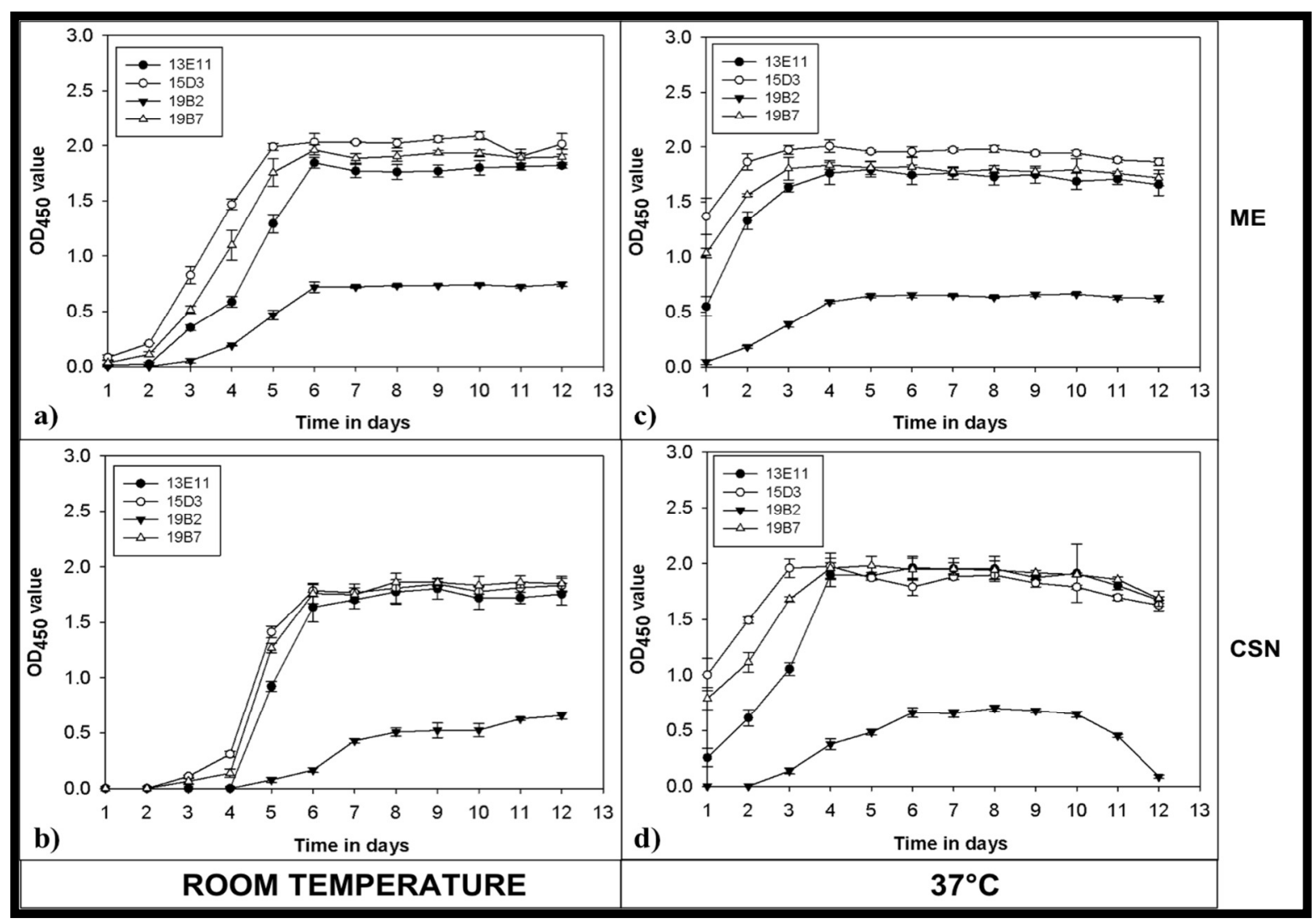

Fig. 3.3. Time point kinetic assay of cAtp in A. terreus hyphae and CSN. a) ME collected from A. terreus cultures grown at RT. b) CSN collected from A. terreus cultures grown at RT. c) ME collected from A. terreus cultures grown at $37^{\circ} \mathrm{C}$. d) $\mathrm{CSN}$ collected from A. terreus cultures grown at $37^{\circ} \mathrm{C}$. All samples were collected at $24 \mathrm{hr}$ intervals for 12 days and tested in capture ELISA. 


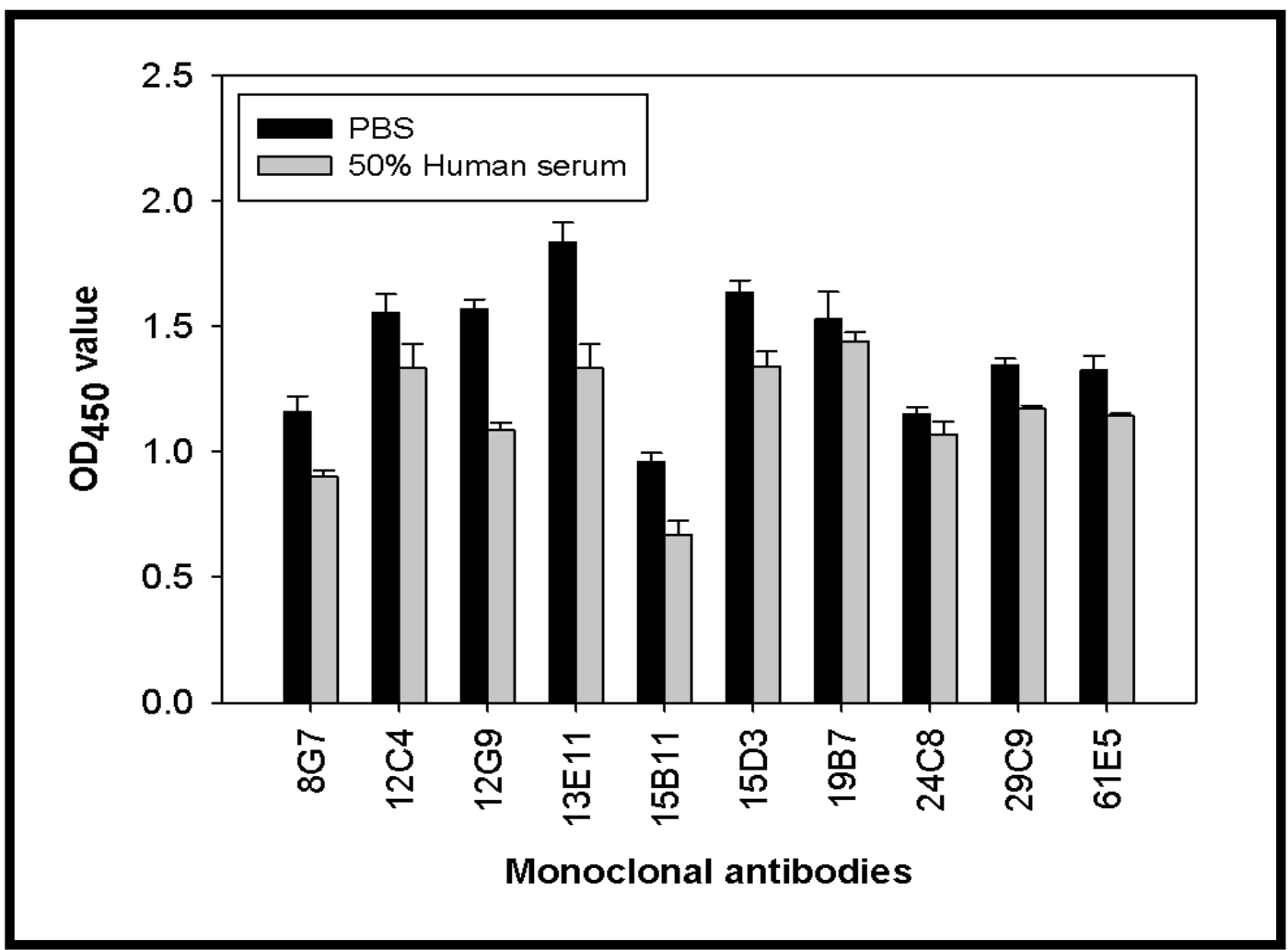

Fig 3.4. Lack of interference by serum proteins in the detection of cAtp by mAbs in presence of serum. A. terreus CSN was spiked into 50\% human serum or PBS and detected using capture ELISA. PBS served as a control in the experiment. 
3.5.6 Immunoprecipitation and determination of protein IDs- Three mAbs (13E11, 19B2 and 12C4) were selected for further analysis based on exhibition of differential patterns of reactivity to A. terreus extract (Fig. 3.2). The mAbs were incubated with the A. terreus hyphal extract, and protein-antibody complexes bound to the protein $\mathrm{G}$ magnetic beads were eluted and separated using SDS-PAGE. Using mAb 13E11 to stain the immunoblot showed immunoprecipitation of an $\sim 65 \mathrm{kDa}$ band, slightly higher than the antibody heavy chain band. Interestingly, mAb 13E11 also showed similar reactivity to immunoprecipitate of mAb $12 \mathrm{C} 4$ but not to that of mAb $19 \mathrm{~B} 2$ (Fig. 3.5). This suggests that mAb $13 \mathrm{E} 11$ and mAb $12 \mathrm{C} 4$ recognized similar antigens. In contrast, mAb 19B2 demonstrated immunoreactivity to an antigen localized at $\sim 100 \mathrm{kDa}$. While mAb $12 \mathrm{C} 4$ precipitated a $66 \mathrm{kDa}$ band that was recognized by mAb 13E11, this $\mathrm{mAb}$ does not recognize this band when used to stain the Western blot, indicating that it may recognize a conformational epitope.

Specific bands were excised from a parallel SDS-PAGE gel on which immunoprecipitated samples from each mAb were separated. Samples were subjected to UPLC tandem (MS/MS) analysis to determine the identity of the proteins. By comparing peptide masses of recovered peptides in silico to the generated database for A. terreus, we identified peptides for a putative uncharacterized protein (Q0CAZ7) in immunoprecipitates from both mAbs 13E11 and 12C4. The protein Q0CAZ7 has (> 60\%) sequence homology to a leucine aminopeptidase found in other Aspergillus species such as A. fumigatus, A. nidulans, A. oryzae and A. flavus. Peptides for a probable dipeptidyl peptidase V (Q0C8V9) were also identified following UPLC MS/MS analysis of mAb 19B2 immunoprecipitates (Table 3.3.). Both of these proteolytic enzymes consist of putative $N$-glycosylation sites and are secreted after processing of a signal peptide. 


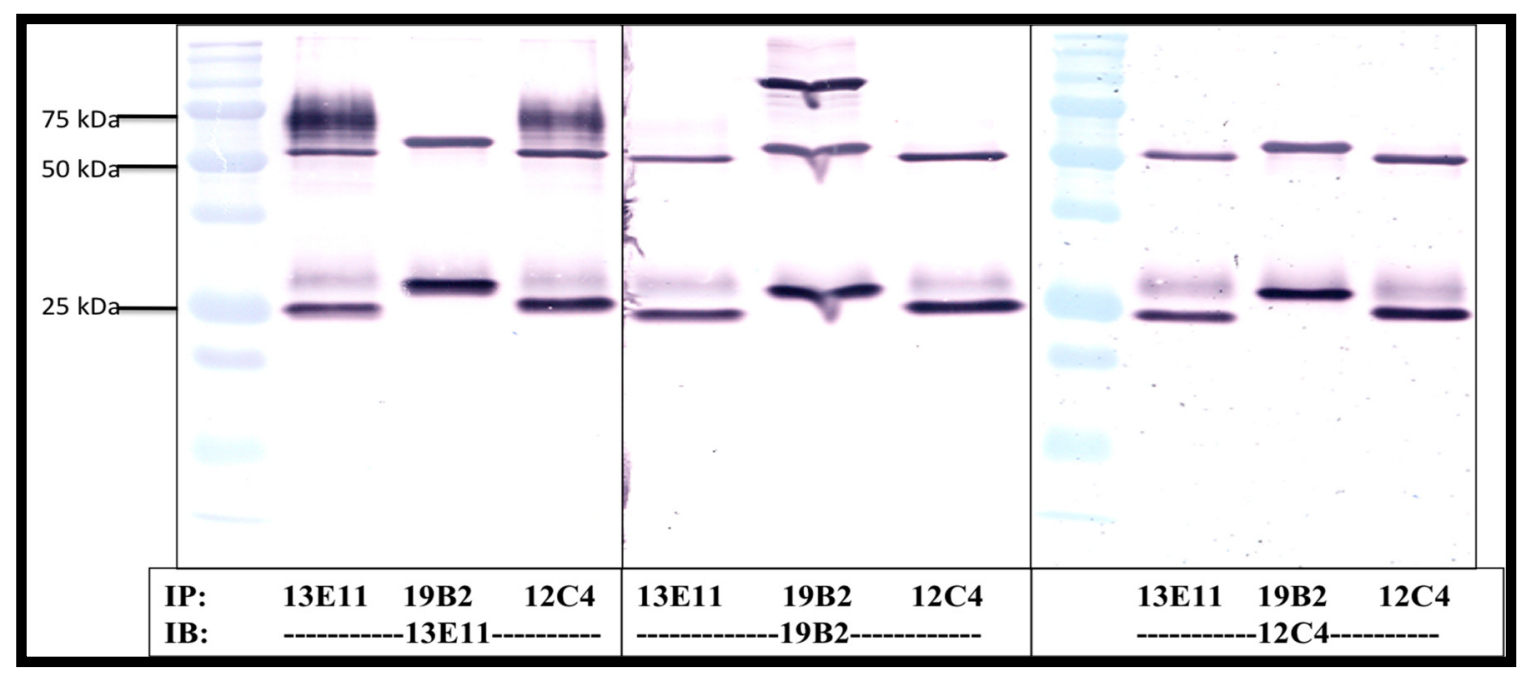

Fig. 3.5. Immunoprecipitation of cAtp antigens. mAbs 13E11, $19 B 2$ and $12 C 4$ were used for immunoprecipitation of their respective antigens from A. terreus CSN. Immunoprecipitates were analyzed using individual mAbs to identify cross-identification of antigens between mAbs. IP: Immunoprecipitate and IB: Immunoblot. 
3.5.7 Immunolocalization of cAtp antigens- The immunolocalizations of A. terreus leucine aminopeptidase (mAb 13E11) and dipeptidyl peptidase $\mathrm{V}(\mathrm{mAb}$ 19B2) in the hyphae were determined using confocal scanning laser microscopy. Interestingly, the leucine aminopeptidase was localized in extracellular matrix (ECM) structures (Fig 3.6). Immunostaining was also observed within the hyphae. mAb 19B2 immunostaining for a probable dipeptidyl peptidase $\mathrm{V}$ was diffuse but uniform over the entire hypha, suggesting that this protein might be present in the cytoplasm of A. terreus hyphae. No staining was observed in the extracellular matrix for mAb 19B2. The mAb 9B4 served as a isotype control for these studies and did not stain any structures. 


\begin{tabular}{|c|c|c|c|c|}
\hline $\begin{array}{l}\text { Monoclonal } \\
\text { Antibody }\end{array}$ & cAtp antigen ID & $\begin{array}{l}\text { Sequence } \\
\text { coverage }\end{array}$ & $\begin{array}{l}N \text {-glycosylation } \\
\text { sites }\end{array}$ & $\begin{array}{l}\text { Signal } \\
\text { Peptides } \\
\text { prediction }\end{array}$ \\
\hline $\begin{array}{l}13 \mathrm{E} 11 \text { and } \\
12 \mathrm{C} 4\end{array}$ & $\begin{array}{l}\text { Putative } \\
\text { uncharacterized } \\
\text { leucine } \\
\text { aminopeptidase } \\
\text { (Q0CAZ7) }\end{array}$ & $10 \%$ & $\begin{array}{l}232, \quad 349,432, \\
435,466\end{array}$ & 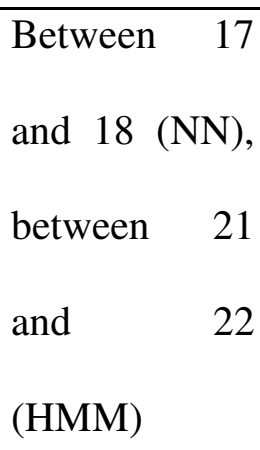 \\
\hline 19B2 & $\begin{array}{l}\text { Probable } \\
\text { dipeptidyl- } \\
\text { peptidase } \\
\text { (Q0C8V9) }\end{array}$ & $52 \%$ & $\begin{array}{l}37,79,97,154, \\
255,339,381, \\
451,509,608\end{array}$ & $\begin{array}{l}\text { Between } 19 \\
\text { and 20. (NN } \\
\text { and HMM) }\end{array}$ \\
\hline
\end{tabular}

Table 3.3 Proteomic analysis of cAtp antigens. Numbers for $\mathrm{N}$-Glycosylation and signal peptides sites are amino acid sites on pre-protein. NN- Neural Networks, HMM- Hidden Markov Models. 


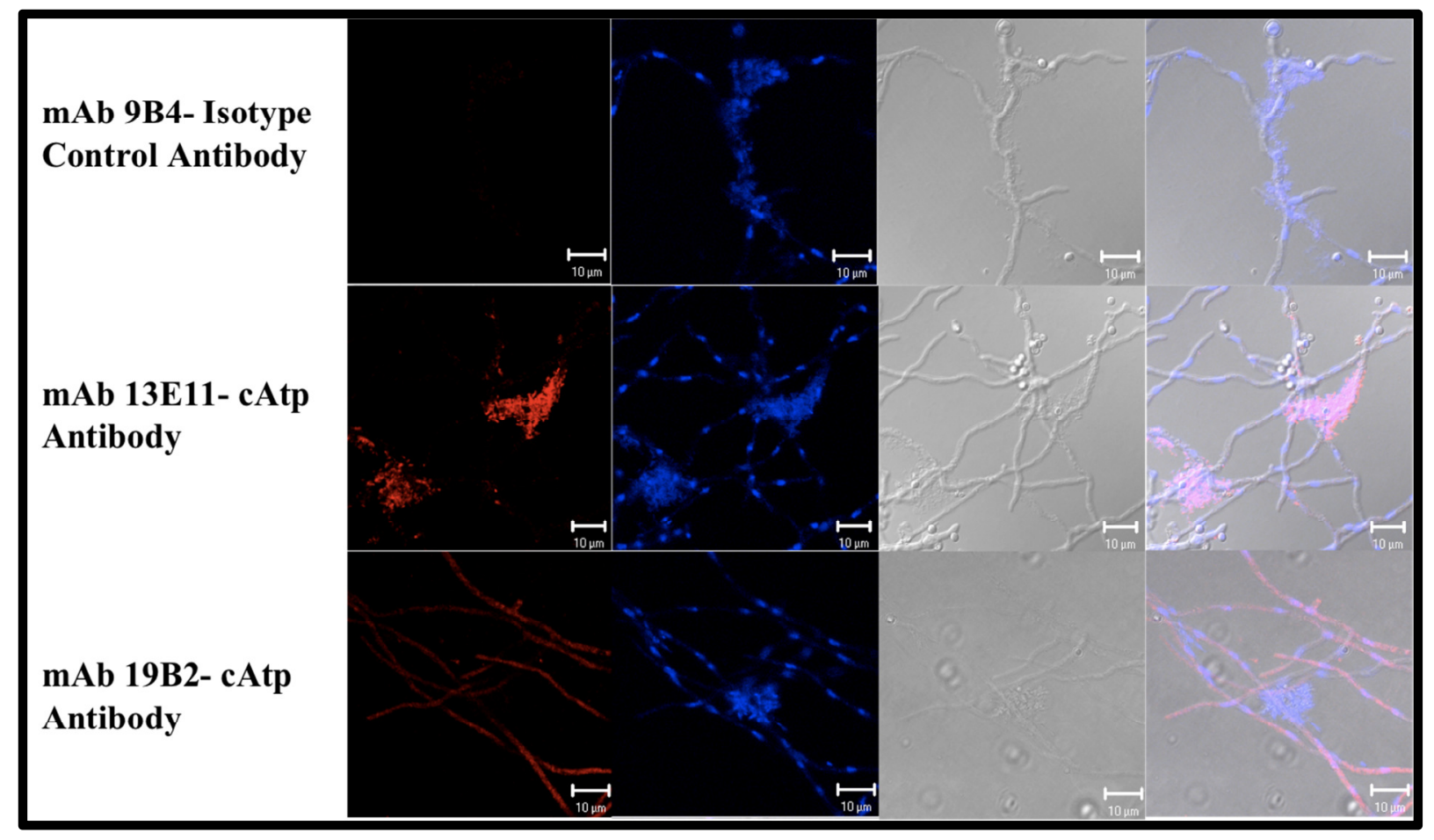

Fig. 3.6. Immunolocalization of cAtp antigens. Immunolocalization of HEA antigens was determined by AlexaFluor ${ }^{\circledR} 594$-labeled goat anti-mouse IgG secondary antibodies (Red) and nuclear staining was identified by DAPI (Blue). mAb $9 B 4$ acted as an IgG $\mathrm{G}_{1}$ isotype control antibody in this study. 


\subsection{DISCUSSION}

Invasive aspergillosis develops in the lungs of immunocompromised patients following the inhalation of viable Aspergillus conidia from the environment (13,41, 89). Upon germination, the conidia differentiate into a vegetative hyphal form that can cause damage to the host tissue and may allow the fungus to disseminate to other parts of the body (15). To date, the diagnostic methods have been limited to identifying macroscopic and microscopic characteristics in lung biopsies $(18,79)$. Serological diagnostics have also been developed but are limited to the detection of galactomannan and $(1,3)-\beta$-D-glucan $(18,79)$. Although this methodology may confirm a fungal infection, it does not identify the specific pathogenic species involved. Previous studies have detected Aspergillus antigens in the sera and urine of patients diagnosed with invasive aspergillosis (90-93). These results suggest that during infection, Aspergillus species secrete proteins into the blood stream that could be detected serologically. Therefore it is critical to identify biomarkers that could be used serologically for the identification of individual pathogenic Aspergillus species.

Although A. fumigatus is the most widely known etiological agent of invasive aspergillosis, A. terreus has emerged as a pathogen and can cause a variety of infections including fatal disseminated aspergillosis (20). To our knowledge, no immunodiagnostics have been developed for the specific detection of A. terreus in clinical samples. In this study, $23 \operatorname{IgG}_{1}$ mAbs were produced using a partially purified cytolytic cAtp preparation using a methodology previously used to purify stachylysin from Stachybotrys chartarum (3). The mAbs developed in the present study specifically detect antigens localized in conidia and hyphae, but more importantly, these antigens were detected in the CSN fluid. These findings demonstrate that these hemolytic antigens may be actively secreted during hyphal differentiation and growth and 
may function as candidate biomarkers for immunodiagnostic assays similarly to stachylysin. Detection of hemolytic antigen in higher concentrations in hyphae is consistent with our previous studies of stachylysin described in the previous chapter and in other studies as well (3, 94-96). Sixteen mAbs were found to be species-specific, while seven cross-reacted with other species. The species-specific mAbs did not cross-react with ME from other important Aspergillus pathogens including A. fumigatus, A. flavus, A. niger and A. nidulans. No cross-reactivity was observed with other fungal species belonging to the genera Penicillium and Fusarium. Most cross-reactivity was minimal with $\mathrm{OD}_{450}$ values $\leq 0.5$.

Previously, differences were reported in metabolic activities, growth rate and virulence capabilities of different A. terreus strains depending on their environmental source (44). We were curious to see if any of these differences reflected in altered expression of cAtp antigens. All mAbs reacted with the mycelial extracts from the 4 A. terreus strains used in this study, however, comprehensive testing with additional clinical strains of $A$. terreus strains will be critical prior to the development of diagnostic methods for use in the clinical setting. Moreover, other species that are closely related to A. terreus such as A. carneus, A. niveus and the newly identified A. alabamensis (5) as well as other unrelated species including Scedosporium and Rhizopus stolonifer (11) should be tested for cross-reactivity.

A. terreus growth is accompanied by conidial germination during favorable nutrient and environmental conditions. This process involves the swelling of conidia, initiation of primary metabolism, and eventually hyphal extension and aggregation. In this study, we observed that the antigens were detected earlier in hyphal growth than in CSN suggesting an active secretion of these proteins. The concentration of these antigens appeared to correlate with an increase in the total biomass of the fungus as measured by the mycelial pellet size and protein concentration 
(data not shown) during cAtp kinetic experiments. mAb reactivity to cAtp was also observed to increase progressively with increases in pellet size. Most importantly, cAtp was continuously detected in $\mathrm{CSN}$ at $37^{\circ} \mathrm{C}$, emphasizing the relative stability of these antigens to proteolytic degradation for longer period of time.

Detection of antigens in CSN may not fully reflect antigen production during invasive disease. Furthermore, secreted antigens may bind to serum proteins or other factors that alter the conformation of the protein and subsequently reduce the availability of the epitope for $\mathrm{mAb}$ detection. Certain fungal proteins are known to bind serum components in vitro (97). In tests with pooled human serum, there was only a slight reduction in detection of the epitopes using our mAbs. This suggests that the epitopes detected by our mAbs do not interact with serum components and this may have potential use for serodetection of invasive A. terreus disease.

Leucine aminopeptidase and dipeptidyl-peptidase $\mathrm{V}$ are both predicted to possess putative $\mathrm{N}$-glycosylation sites as determined by N-Glycosite (98). These proteins are secreted with putative signal peptides as determined by SignalP, version 3.0, in silico analysis (99-101). This has been confirmed experimentally by us in this study and previously by others for $A$. terreus and other fungal species $(102,103)$. Homologous dipeptidyl-peptidase $\mathrm{V}$ in other fungal species have been reported as a potential virulence factor or allergen and as important for tissue invasion and modulation of host immune responses (103-109).

Immunolocalization studies demonstrated that the putative leucine aminopeptidase identified by mAb 13E11 was localized to extracellular structures containing DNA. Similar structures containing extracellular DNA have been very recently reported in vitro and in vivo and have been identified as the extracellular matrix of fungi (110-112). ECMs have been only recently identified and there is little information on their role in pathogenesis of fungal 
infections. mAb 13E11 may be a useful tool in studying ECM and more importantly, the putative leucine aminopeptidase may function as a biomarker of invasive A. terreus disease. In contrast, mAb 19B2 recognized a probable dipeptidyl peptidase $\mathrm{V}$ and immunostaining was primarily localized within the cytoplasm. These mAbs also have the potential to be used for the immunofluorescent detection of A. terreus in bronchoalveolar lavage samples.

In conclusion, we observed that cAtp antigens were released from vegetative hyphae and into CSN in a time-dependent manner. The mAbs developed in this study recognized these antigens and the binding was not inhibited by human serum components in spiking experiments. Collectively, the data suggest that mAbs developed to cAtp may have potential diagnostic value in cases of A. terreus invasive aspergillosis. Serological detection of A.terreus-specific antigens in patient serum would obviate the need to obtain clinical specimens by invasive methods to identify the causal agent. Previously, dipeptidyl-peptidase $\mathrm{V}$ has been reported as one of the two major antigens with the greatest serodiagnostic potential for detecting aspergillosis due to $A$. fumigatus $(107,108,113,114)$. These methodological developments may aid in the development of standardized immunoassays for rapid identification of pathogenic species in clinical samples.

Our goal in these experiments was to develop mAbs to the hemolysin of A. terreus (terrelysin) as a potential biomarker of $A$. terreus infection. In characterizing these mAbs, we identified these antigens to be other proteolytic proteins, which appear to be major constituents of the cAtp preparation. These proteins may have 'hemolytic' activity owing to their general proteolytic activity. The mAbs we developed to HEA recognize secreted proteins and have potential diagnostic value. Our interest in developing mAbs to the terrelysin to study its expression and potential as a biomarker were not achieved and required a different approach. We propose to develop terrelysin using recombinant techniques in order to develop highly purified 
form of the hemolysin. This will also assist in developing standardized reagents for development of consistent methodologies.

\subsection{REFERENCES}

1. Birren, B. W., E. S. Lander, J. E. Galagan, C. Nusbaum, K. Devon, M. Henn, L. J. Ma, D. B. Jaffe, J. Butler, P. Alvarez, S. Gnerre, M. Grabherr, M. Kleber, E. W. Mauceli, W. Brockman, S. Rounsley, S. K. Young, K. LaButti, and K. Madden. 2005. Annotation of the Aspergillus terreus NIH264 genome. EMBL/GenBank/DDBJ databases.

2. Ebina, K., K. Yokota, and O. Sakaguchi. 1982. Studies on toxin of Aspergillus fumigatus XIV: Relationship between Asp-hemolysin and experimental infection in mice. Jpn J Med Mycol 23:246-252.

3. Vesper, S. J., M. L. Magnuson, D. G. Dearborn, I. Yike, and R. A. Haugland. 2001. Initial characterization of the hemolysin stachylysin from Stachybotrys chartarum. Infect Immun 69:912-916.

4. Ainsworth, G. C. 1976. Introduction to the history of mycology. Cambridge University Press, Cambridge.

5. Balajee, S. A., J. W. Baddley, S. W. Peterson, D. Nickle, J. Varga, A. Boey, C. LassFlorl, J. C. Frisvad, and R. A. Samson. 2009b. Aspergillus alabamensis, a new clinically relevant species in the section Terrei. Eukaryot Cell 8:713-722.

6. Samson, R. A., S. B. Hong, and J. C. Frisvad. 2006. Old and new concepts of species differentiation in Aspergillus. Med Mycol 44:S133-S148.

7. Geiser, D. M., M. A. Klich, J. C. Frisvad, S. W. Peterson, J. Varga, and R. A. Samson. 2007. The current status of species recognition and identification in Aspergillus. Stud Mycol 59:1-10.

8. Samson, R. A., J. Varga, S. M. Witiak, and D. M. Geiser. 2007. The species concept in Aspergillus: recommendations of an international panel. Stud Mycol 59:71-73.

9. Pagano, L., M. Caira, A. Candoni, M. Offidani, L. Fianchi, B. Martino, D. Pastore, M. Picardi, A. Bonini, A. Chierichini, R. Fanci, C. Caramatti, R. Invernizzi, D. Mattei, M. E. Mitra, L. Melillo, F. Aversa, M. T. Van Lint, P. Falcucci, C. G. Valentini, C. Girmenia, and A. Nosari. 2006. The epidemiology of fungal infections in patients with hematologic malignancies: the SEIFEM-2004 study. Haematologica 91:1068-1075.

10. Chamilos, G., M. Luna, R. E. Lewis, G. P. Bodey, R. Chemaly, J. J. Tarrand, A. Safdar, Raad, II, and D. P. Kontoyiannis. 2006. Invasive fungal infections in patients with hematologic malignancies in a tertiary care cancer center: an autopsy study over a 15year period (1989-2003). Haematologica 91:986-989.

11. Marr, K. A., R. A. Carter, F. Crippa, A. Wald, and L. Corey. 2002. Epidemiology and outcome of mould infections in hematopoietic stem cell transplant recipients. Clin Infect Dis 34:909-917.

12. Latge, J. P., and W. J. Steinbach. 2009. Aspergillus fumigatus and aspergillosis. ASM Press. 
13. Zaas, A. K., and B. D. Alexander. 2009. Invasive Pulmonary Aspergillosis. In Aspergillus fumigatus and Aspergillosis. J. P. Latge, and W. J. Steinbach, eds. ASM Press, Washington, DC.

14. Marr, K. A., T. Patterson, and D. Denning. 2002. Aspergillosis. Pathogenesis, clinical manifestations, and therapy. Infect Dis Clin North Am 16:875-894, vi.

15. Segal, B. H. 2009. Aspergillosis. N Engl J Med 360:1870-1884.

16. Lat, A., N. Bhadelia, B. Miko, E. Y. Furuya, and G. R. Thompson, 3rd. 2010. Invasive aspergillosis after pandemic (H1N1) 2009. Emerg Infect Dis 16:971-973.

17. Chen, T. K., C. J. Babbitt, C. Maggi, A. Abbosaida, I. Randhawa, and T. J. Walsh. 2010. Pulmonary aspergillosis following $\mathrm{H} 1 \mathrm{~N} 1$ influenza A infection in pediatric patients. In 20th Annual Focus on Fungal Infections, New Orleans, LA.

18. Segal, B. H., and T. J. Walsh. 2006. Current approaches to diagnosis and treatment of invasive aspergillosis. Am J Respir Crit Care Med 173:707-717.

19. Thom, C., and M. B. Church. 1918. A. fumigatus, A. nidulans, A. terreus n.sp., and their allies. Am J Botany 5:84-104.

20. Balajee, S. A. 2009a. Aspergillus terreus complex. Med Mycol 47 Suppl 1:S42-46.

21. Bennett, J. W. 2010. An overview of the genus Aspergillus. In Aspergillus: Molecular Biology and Genomics. M. Machida, and K. Gomi, eds. Caister Academic Press, Norwich. $\mathrm{x}+238$.

22. Alberts, A. W., J. Chen, G. Kuron, V. Hunt, J. Huff, C. Hoffman, J. Rothrock, M. Lopez, H. Joshua, E. Harris, A. Patchett, R. Monaghan, S. Currie, E. Stapley, G. AlbersSchonberg, O. Hensens, J. Hirshfield, K. Hoogsteen, J. Liesch, and J. Springer. 1980. Mevinolin: a highly potent competitive inhibitor of hydroxymethylglutaryl-coenzyme A reductase and a cholesterol-lowering agent. Proc Natl Acad Sci U S A 77:3957-3961.

23. Barrios-Gonzalez, J., and R. U. Miranda. 2010. Biotechnological production and applications of statins. Appl Microbiol Biotechnol 85:869-883.

24. Akiro, E. 2004. The origin of statins. Atherosclerosis Supp 5:125-130.

25. Berry, D., A. Chmiel, and Z. Al Obaidi, eds. 1977. Citric acid production by Aspergillus niger. Academic Press, London.

26. Dowdells, C., R. L. Jones, M. Mattey, M. Bencina, M. Legisa, and D. M. Mousdale. 2010. Gluconic acid production by Aspergillus terreus. Lett Appl Microbiol 51:252-257.

27. Singh, O. V., and R. Kumar. 2007. Biotechnological production of gluconic acid: future implications. Appl Microbiol Biotechnol 75:713.

28. Chantasingh, D., K. Pootanakit, V. Champreda, P. Kanokratana, and L. Eurwilaichitr. 2006. Cloning, expression, and characterization of a xylanase 10 from Aspergillus terreus (BCC129) in Pichia pastoris. Protein Expr Purif 46:143-149.

29. Hughes, R. L. 1968. Microbiological degradation of paper. In Biodeterioration of materials. A. H. Walters, and J. J. Elphick, eds. Elsevier Publishing Co.Ltd., Amsterdam, London, New York. 281-290.

30. Emitazi, G., N. Naghavi, and A. Bordbar. 2001. Biodegradation of lignocellulosic waste by Aspergillus terreus. Biodegradation 12:259-263.

31. Cripps, R. E., and T. R. Roberts. 1978. Microbial degradation of herbicides. In Pesticide microbiology: microbiological aspects of pesticide behavior in the environment. I. R. Hill, and S. J. L. Wright, eds. Academic Press, London. 
32. Subramaniam, C. V. 1983. Hyphomycetes, taxonomy and biology. Academic Press, London.

33. Woodcock, D. 1978. Microbial degradation of fungicides. In Pesticide microbiology: microbiological aspects of pesticide behavior in the environment. I. R. Hill, and S. J. L. Wright, eds.

34. Turner, J. N. 1967. The microbiology of fabricated materials. J. \& A. Churchill Ltd., London.

35. Thomas, A. R., ed. 1977. The genus Aspergillus and biodeterioration. Academic Press, London.

36. Raper, B. K., and D. I. Fennell. 1965. The Genus Aspergillus. Williams and Wilkins Co., Baltimore.

37. Deak, E., S. D. Wilson, E. White, J. H. Carr, and S. A. Balajee. 2009. Aspergillus terreus accessory conidia are unique in surface architecture, cell wall composition and germination kinetics. PLoS One 4:e7673.

38. Pore, R. S., and H. W. Larsh. 1967. Aleuriospore formation in four related Aspergillus species. Mycologia 59:318-325.

39. Ornvold, K., and J. Paepke. 1992. Aspergillus terreus as a cause of septic olecranon bursitis. Am J Clin Pathol 97:114-116.

40. Tracy, S. L., M. R. McGinnis, J. E. Peacock, Jr., M. S. Cohen, and D. H. Walker. 1983. Disseminated infection by Aspergillus terreus. Am J Clin Pathol 80:728-733.

41. Iwen, P. C., M. E. Rupp, A. N. Langnas, E. C. Reed, and S. H. Hinrichs. 1998. Invasive pulmonary aspergillosis due to Aspergillus terreus: 12-year experience and review of the literature. Clin Infect Dis 26:1092-1097.

42. Hachem, R. Y., D. P. Kontoyiannis, M. R. Boktour, C. Afif, C. Cooksley, G. P. Bodey, I. Chatzinikolaou, C. Perego, H. M. Kantarjian, and Raad, II. 2004. Aspergillus terreus: an emerging amphotericin B-resistant opportunistic mold in patients with hematologic malignancies. Cancer 101:1594-1600.

43. Baddley, J. W., P. G. Pappas, A. C. Smith, and S. A. Moser. 2003. Epidemiology of Aspergillus terreus at a university hospital. J Clin Microbiol 41:5525-5529.

44. Rippon, J. W., D. N. Anderson, and M. Soo Hoo. 1971. Aspergillosis, comparative virulence, metabolic rate, growth rate and ubiquinone content of soil and human isolates of Aspergillus terreus. Sabouraudia 12:157-161.

45. Abdel-Hafez, S. I. I. 1982. Thermophilic and thermotolerant fungi in the desert soils of Saudi Arabia. Mycopathologia 80:15-20.

46. Tiwari, S., S. M. Singh, and S. Jain. 1995. Chronic bilateral suppurative otitis media caused by Aspergillus terreus. Mycoses 38:297-300.

47. English, M. P. 1962. An outbreak of fungal infections of postoperative aural cavities. $J$ Laryngol Otol 76:1-11.

48. Powell, D. E., and M. P. English. 1962. Clinical, bacteriological and mycological findings in post-operative ear cavities. J Laryngol Otol 76:12-21.

49. Hilmioglu-Polat, S., D. Y. Metin, R. Inci, T. Dereli, I. Kilinc, and E. Tumbay. 2005. Nondermatophytic molds as agents of onychomycosis in Izmir, Turkey - a prospective study. Mycopathologia 160:125-128.

50. Gupta, A. K., and B. E. Elewski. 1996. Nondermatophyte causes of onychomycosis and superficial mycoses. Curr Top Med Mycol 7:87-97. 
51. Onsberg, P., D. Stahl, and N. K. Veien. 1978. Onychomycosis caused by Aspergillus terreus. Sabouraudia 16:39-46.

52. Moinfar, N., W. E. Smiddy, D. Miller, D. Miller, and K. Herschel. 2006. Posttraumatic Aspergillus terreus endophthalmitis masquerading as dispersed lens fragments. $J$ Cataract Refract Surg 33:739-740.

53. Garg, P., S. Mahesh, A. K. Bansal, U. Gopinathan, and G. N. Rao. 2003. Fungal infection of sutureless self-sealing incision for cataract surgery. Ophthalmology 110:2173-2177.

54. Das, T., P. Vyas, and S. Sharma. 1993. Aspergillus terreus postoperative endophthalmitis. Br J Ophthalmol 77:386-387.

55. Welsch, M. J., C. M. Moon, D. M. Elston, and P. Vogel. 2002. Invasive synergistic fungal infection after motor vehicle collision. Cutis 71:201-204.

56. Cooke, F. J., E. Terpos, J. Boyle, A. Rahemtulla, and T. R. Rogers. 2003. Disseminated Aspergillus terreus infection arising from cutaneous inoculation treated with caspofungin. Clin Microbiol Infect 9:1238-1241.

57. Ozer, B., A. Kalaci, N. Duran, Y. Dogramaci, and A. N. Yanat. 2009. Cutaneous infection caused by Aspergillus terreus. J Med Microbiol 58:968-970.

58. E Silva, A., C. M. Takiya, M. G. Lima, C. Ribeiro, A. Kaufman, L. C. Pereira, and L. R. Andrade. 2006. Early Detection of Aspergillus terreus in a Tenckhoff Catheter. Perit Dial Int 26:723-724.

59. Verghese, S., R. Palani, N. Thirunavakarasu, T. Chellamma, and P. Pathipata. 2007. Peritonitis due to Aspergillus terreus in a patient undergoing continuous ambulatory peritoneal dialysis. Mycoses 51:174-176.

60. Kalishian, Y., E. B. Miller, A. Kagan, and Z. Landau. 2004. Aspergillus terreus peritonitis in a CAPD patient: report of a case. Perit Dial Int 24:93.

61. Natesan, S., G. Abraham, M. Mathew, M. K. Lalitha, and C. N. Srinivasan. 2007. Secondary sternal Aspergillus osteomyelitis in a diabetic hemodialysis patient with previous allograft rejection. Hemodial Int 11:403-405.

62. Steinfeld, S., P. Durez, J. P. Hauzeur, S. Motte, and T. Appelboom. 1997. Articular aspergillosis: two case reports and review of the literature. Br J Rheumatol 36:1331-1334.

63. Grandiere-Perez, L., P. Asfar, C. Foussard, J. M. Chennebault, P. Penn, and I. Degasne. 2000. Spondylodiscitis due to Aspergillus terreus during an efficient treatment against invasive pulmonary aspergillosis. Intensive Care Med 26:1010-1011.

64. Laham, M. N., and J. L. Carpenter. 1982. Aspergillus terreus, a pathogen capable of causing infective endocarditis, Pulmonary mycetoma, and allergic bronchopulmonary aspergillosis. Am Rev Respir Dis 125:769-772.

65. Nakahara, Y., O. Katoh, H. Yamada, I. Sumida, and M. Hanada. 1992. Allergic bronchopulmonary aspergillosis caused by Aspergillus terreus presenting lobar collapse. Intern Med 31:140-142.

66. Cimon, B., R. Zouhair, F. Symoens, J. Carrere, D. Chabasse, and J. P. Bouchara. 2003. Aspergillus terreus in a cystic fibrosis clinic: environmental distribution and patient colonization pattern. J Hosp Infect 53:81-82.

67. Khan, Z. U., M. Kortom, R. Marouf, R. Chandy, M. G. Rinaldi, and D. A. Sutton. 2000. Bilateral pulmonary aspergilloma caused by an atypical isolate of Aspergillus terreus. $J$ Clin Microbiol 38:2010-2014. 
68. Judson, M. A., and D. A. Stevens. 2001. The treatment of pulmonary aspergilloma. Curr Opin Investig Drugs 2:1375-1377.

69. Moss, M. O., ed. 1977. Aspergillus mycotoxins. Academic Press, London.

70. Miller, P. A., P. W. Trown, W. Fulmor, G. O. Morton, and J. Karliner. 1968. An epidithiapiperazinedione antiviral agent from Aspergillus terreus. Biochem Biophys Res Commun 33:219-221.

71. Chung, C. H., K. H. Ling, S. S. Tung, and T. C. Tung. 1971. Study on fungi of the stored unhulled rice of Taiwan. (2) Aflatoxin B-like compounds from the culture of Aspergillus genus. J Formosan Med Assoc 70:258-266.

72. Walsh, T. J., V. Petraitis, R. Petraitiene, A. Field-Ridley, D. Sutton, M. Ghannoum, T. Sein, R. Schaufele, J. Peter, J. Bacher, H. Casler, D. Armstrong, A. Espinel-Ingroff, M. G. Rinaldi, and C. A. Lyman. 2003. Experimental pulmonary aspergillosis due to Aspergillus terreus: pathogenesis and treatment of an emerging fungal pathogen resistant to amphotericin B. J Infect Dis 188:305-319.

73. Blum, G., S. Perkhofer, H. Haas, M. Schrettl, R. Wurzner, M. P. Dierich, and C. LassFlorl. 2008. Potential basis for amphotericin B resistance in Aspergillus terreus. Antimicrob Agents Chemother 52:1553-1555.

74. Steinbach, W. J., D. K. Benjamin, Jr., D. P. Kontoyiannis, J. R. Perfect, I. Lutsar, K. A. Marr, M. S. Lionakis, H. A. Torres, H. Jafri, and T. J. Walsh. 2004. Infections due to Aspergillus terreus: a multicenter retrospective analysis of 83 cases. Clin Infect Dis 39:192-198.

75. Hope, W. W., and D. W. Denning. 2004. Invasive aspergillosis: current and future challenges in diagnosis and therapy. Clin Microbiol Infect 10:2-4.

76. Yuanjie, Z., D. Jingxia, W. Hai, C. Jianghan, and G. Julin. 2009. Primary cutaneous aspergillosis in a patient with cutaneous T-cell lymphoma. Mycoses 52:462-464.

77. Caillot, D., J. F. Couaillier, A. Bernard, O. Casasnovas, D. W. Denning, L. Mannone, J. Lopez, G. Couillault, F. Piard, O. Vagner, and H. Guy. 2001. Increasing volume and changing characteristics of invasive pulmonary aspergillosis on sequential thoracic computed tomography scans in patients with neutropenia. J Clin Oncol 19:253-259.

78. Stynen, D., A. Goris, J. Sarfati, and J. P. Latge. 1995. A new sensitive sandwich enzymelinked immunosorbent assay to detect galactofuran in patients with invasive aspergillosis. J Clin Microbiol 33:497-500.

79. Hope, W. W., T. J. Walsh, and D. W. Denning. 2005. Laboratory diagnosis of invasive aspergillosis. Lancet Infect Dis 5:609-622.

80. Balajee, S. A., R. Kano, J. W. Baddley, S. A. Moser, K. A. Marr, B. D. Alexander, D. Andes, D. P. Kontoyiannis, G. Perrone, S. Peterson, M. E. Brandt, P. G. Pappas, and T. Chiller. 2009c. Molecular identification of Aspergillus species: Transplant Associated Infection Surveillance Network (TRANSNET). J Clin Microbiol 47:3138-3141.

81. Schmechel, D., J. P. Simpson, D. Beezhold, and D. M. Lewis. 2006. The development of species-specific immunodiagnostics for Stachybotrys chartarum: the role of crossreactivity. J Immunol Methods 309:150-159.

82. Hill, T. W., and E. Kafer. 2001. Improved protocols for Aspergillus minimal medium: Trace element and minimal medium stock solutions. Fungal Genet Newsletter 48:20-21.

83. Chen, C. Y., and G. Seguin-Swartz. 2002. A rapid method for assessing the viability of fungal spores. Can J Plant Pathol 24:230-232. 
84. Speicher, K. D., O. Kolbas, S. Harper, and D. W. Speicher. 2000. Systematic analysis of peptide recoveries from in-gel digestions for protein identifications in proteome studies. $J$ Biomol Tech 11:74-86.

85. Stone, K. L., and K. R. Williams. 2002. Enzymatic digestion of proteins in solution and in SDS Polyacrylaminde gels. In The Protein Protocols Handbook, 2 ed. J. M. Walker, ed. Humana Press, Totowa, NJ. 511-521.

86. Chakraborty, A. B., S. J. Berger, and J. C. Gebler. 2007. Use of an integrated MSmultiplexed MS/MS data acquisition strategy for high-coverage peptide mapping studies. Rapid Commun Mass Spectrom 21:730-744.

87. Osmani, S. A., D. B. Engle, J. H. Doonan, and N. R. Morris. 1988. Spindle formation and chromatin condensation in cells blocked at interphase by mutation of a negative cell cycle control gene. Cell 52:241-251.

88. Xiang, X., C. Roghi, and N. R. Morris. 1995. Characterization and localization of the cytoplasmic dynein heavy chain in Aspergillus nidulans. Proc Natl Acad Sci USA 92:9890-9894.

89. Yano, S., S. Shishido, K. Kobayashi, H. Nakano, and Y. Kawasaki. 1999. Bronchocentric granulomatosis due to Aspergillus terreus in an immunocompetent and non-asthmatic woman. Respir Med 93:672-674.

90. Chumpitazi, B. F. F., C. Pinel, B. Lebeau, P. Ambroise-Thomas, and R. Grillot. 2000. Aspergillus fumigatus antigen detection in sera from patients at risk for invasive aspergillosis. J Clin Microbiol 38:438-443.

91. Haynes, K. A., J. P. Latge, and T. R. Rogers. 1990. Detection of Aspergillus antigens associated with invasive aspergillosis. J Clin Microbiol 28:2040-2044.

92. Haynes, K. A., P. Tuinstra, T. A. Hughes, L. M. Wijnands, T. R. Rogers, and A. K. Allen. 1996. Purification and characterization of a $93 \mathrm{kDa}$ Aspergillus fumigatus antigen with diagnostic potential. J Med Vet Mycol 34:421-426.

93. Latge, J. P., M. Moutaouakil, J. P. Debeaupuis, J. P. Bouchara, K. Haynes, and M. C. Prevost. 1991. The 18-kilodalton antigen secreted by Aspergillus fumigatus. Infect Immun 59:2586-2594.

94. Van Emon, J. M., A. W. Reed, I. Yike, and S. J. Vesper. 2003. ELISA measurement of stachylysin in serum to quantify human exposures to the indoor mold Stachybotrys chartarum. J Occup Environ Med 45:582-591.

95. Sakaguchi, O., H. Shimada, and K. Yokota. 1975. Proceedings: Purification and characteristics of hemolytic toxin from Aspergillus fumigatus. Jpn J Med Sci Biol 28:328331.

96. Yokota, K., H. Shimada, A. Kamaguchi, and O. Sakaguchi. 1977. Studies on the toxin of Aspergillus fumigatus VII. Purification and some properities of hemolytic toxin (asphemolysin) from culture filtrates and mycelia. Microbiol Immunol 21:11-22.

97. Fukuchi, Y. 2001. [Interactions between Asp-hemolysin from Aspergillus fumigatus and blood plasma components]. Yakugaku Zasshi 121:423-432.

98. Zhang, M., B. Gaschen, W. Blay, B. Foley, N. Haigwood, C. Kuiken, and B. Korber. 2004. Tracking global patterns of N-linked glycosylation site variation in highly variable viral glycoproteins: HIV, SIV and HCV envelopes and influenza hemagglutinin. Glycobiology 14:1229-1246. 
99. Bendtsen, J. D., H. Nielsen, G. von Heijne, and S. Brunak. 2004. Improved prediction of signal peptides: SignalP 3.0. J Mol Biol 340:783-795.

100. Gasteiger, E., C. Hoogland, A. Gattiker, S. Duvaud, M. R. Wilkins, R. D. Appel, and A. Bairoch. 2005. Protein identification and analysis tools on the ExPASy server. In The Proteomics Protocols Handbook. J. M. Walker, ed. Humana Press, New York, NY. 571607.

101. Nielsen, H., and A. Krogh. 1998. Prediction of signal peptides and signal anchors by a Hidden Markov model. In Proceedings of the Sixth International Conference on Intelligent Systems for Molecular Biology (ISMB 6). AAAI Press, Menlo Park, CA. 122130.

102. Han, M. J., N. J. Kim, S. Y. Lee, and H. N. Chang. 2010. Extracellular proteome of Aspergillus terreus grown on different carbon sources. Curr Genet 56:369-382.

103. Vermout, S., A. Baldo, J. Tabart, B. Losson, and B. Mignon. 2008. Secreted dipeptidyl peptidases as potential virulence factors for Microsporum canis. FEMS Immunol Med Microbiol 54:299-308.

104. Slunt, J. B., E. A. Taketomi, J. A. Woodfolk, M. L. Hayden, and T. A. Platts-Mills. 1996. The immune response to Trichophyton tonsurans: distinct $\mathrm{T}$ cell cytokine profiles to a single protein among subjects with immediate and delayed hypersensitivity. J Immunol 157:5192-5197.

105. Woodfolk, J. A., J. B. Slunt, B. Deuell, M. L. Hayden, and T. A. Platts-Mills. 1996. Definition of a Trichophyton protein associated with delayed hypersensitivity in humans. Evidence for immediate (IgE and $\mathrm{IgG} 4$ ) and delayed hypersensitivity to a single protein. J Immunol 156:1695-1701.

106. Woodfolk, J. A., L. M. Wheatley, R. V. Piyasena, D. C. Benjamin, and T. A. Platts-Mills. 1998. Trichophyton antigens associated with IgE antibodies and delayed type hypersensitivity. Sequence homology to two families of serine proteinases. J Biol Chem 273:29489-29496.

107. Beauvais, A., M. Monod, J. P. Debeaupuis, M. Diaquin, H. Kobayashi, and J. P. Latge. 1997. Biochemical and antigenic characterization of a new dipeptidyl-peptidase isolated from Aspergillus fumigatus. J Biol Chem 272:6238-6244.

108. Kobayashi, H., J. P. Debeaupuis, J. P. Bouchara, and J. P. Latge. 1993. An 88-kilodalton antigen secreted by Aspergillus fumigatus. Infect Immun 61:4767-4771.

109. Latge, J. P. 1999. Aspergillus fumigatus and aspergillosis. Clin Microbiol Rev 12:310350.

110. Muller, F. M. C., M. Seidler, and A. Beauvais. 2011. Aspergillus fumigatus biofilms in the clinical setting. Med Mycol 49:S96-S100.

111. Loussert, C., C. Schmitt, M. C. Prevost, V. Balloy, E. Fadel, B. Philippe, C. KauffmanLacroix, J. P. Latge, and A. Beauvais. 2010. In vivo biofilm composition of Aspergillus fumigatus. Cell Microbiol 12:405-410.

112. Al-Fattani, M. A., and L. J. Douglas. 2006. Biofilm matrix of Candida albicans and Candida tropicalis: chemical composition and role in drug resistance. J Med Microbiol 55:999-1008.

113. Biguet, J., P. Tran van Ky, and S. Andrieu. 1967. Identification d'une activité chymotrypsique au niveau de fractions remarquables d'Aspergillus fumigatus. 
Répercussions sur le diagnostic immunologique de l'aspergillose. Rev Immunol Ther Antimicrob 31:317-328.

114. Monod, M., O. Jousson, and U. Reichard. 2009. Aspergillus fumigatus secreted proteases. In Aspergillus fumigatus and Aspergillosis. J. P. Latge, and W. J. Steinbach, eds. ASM Press, Washington, D.C. 


\section{CHAPTER 4}

Cloning, Expression and purification of recombinant terrelysin 


\subsection{INTRODUCTION}

The aegerolysin family (Pfam: PF06355; InterPro: IPR009413) consists of low molecular weight, acidic cytolytic proteins from both prokaryotes and eukaryotes. The fungal hemolysins, aegerolysin (Agrocybe aegerita), ostreolysin (Pleurotus ostreatus), asp-hemolysin (Aspergillus fumigatus) and more recently the hemolysin from the basidiomycete Moniliophthora perniciosa have been characterized (1-6). The role of bacterial hemolysins as virulence factors has been well established $(7,8)$ and a similar putative role for the fungal hemolysins has been suggested $(9,10)$. In vitro studies have shown that asp-hemolysin causes lysis of erythrocytes and is cytotoxic to macrophages, fibroblasts, leukocytes, and endothelial cells in vitro (11-13). Ostreolysin and aegerolysin have been suggested to play an important role in the development of fruiting bodies in the basidiomycete fungi $(2,5)$.

As noted previously, rapid identification of fungi at the species level could aid in early and improved treatment of fungal infections. Fungal hemolysins have been hypothesized as candidates for use as biomarkers for species identification thus aiding in their early detection (10, $14,15)$.

In characterization of hemolytic preparations from A. terreus culture, we identified the presence of multiple proteins. However, we could not detect any mAbs to proteins in the expected size range of the specific hemolytic protein, terrelysin. Also, proteomic analysis of the hemolytic preparations did not yield any peptides belonging to terrelysin.

Recently, the genomes of a number of fungi including A. terreus were completed and the sequences of aegerolysin-like proteins were reported (16-21). Using homology search, we identified the sequence of a putative terrelysin, based on homology to asp-hemolysin ( $A$. fumigatus), as a prototype of the aegerolysin family. This chapter describes the development of a 
recombinant terrelysin by expressing it in Escherichia coli, its purification and the development of mAbs to terrelysin.

\subsection{MATERIALS AND METHODS}

4.2.1 Culture of A. terreus and cloning of rTerrelysin- Conidia of A. terreus ATCC 1012 (1 $\left.\mathrm{x} 10^{6}\right)$ were inoculated in TSB medium $(50 \mathrm{ml})$. Cultures were grown for 3 days at RT after which the mycelium was harvested and washed thoroughly in phosphate buffered-saline (PBS) pH 7.4. Total RNA was extracted from mycelium with RNAqueous kit (Ambion Inc. Austin, TX). cDNA was synthesized using a High Capacity RNA-to-cDNA Master Mix (Applied Biosystems Foster City, CA) according to the manufacturer's instructions. Terrelysin encoding open reading frame was amplified by PCR using cDNA as the template and a PCR SuperMix High Fidelity kit (Invitrogen Carlsbad, CA). The following primers were used: forward primer (F1) 5'_ATGGTAGGTCTCAGCGCATGGACGACTCTCAATGGGTTTC_3' and reverse primer (R1) 5'_ATGGTAGGTCTCATATCAGGCAGCAGAAATATCAATGAA AACA_3' (BsaI restriction sites are indicated in bold). PCR was performed with initialization at $94^{\circ} \mathrm{C}$ for 30 secs followed by 32 cycles of denaturation at $94^{\circ} \mathrm{C}$ for 30 secs, annealing at $68^{\circ} \mathrm{C}$ for 30 secs and extension at $72^{\circ} \mathrm{C}$ for $1 \mathrm{~min}$; with final holding at $68^{\circ} \mathrm{C}$ for $1 \mathrm{~min}$. The PCR product was ligated into the BsaI-digested pASK-IBA6 vector (IBA-GmbH, Göttingen, Germany), transferred into One Shot ${ }^{\circledR}$ TOP 10 chemically competent Escherichia coli cells (Invitrogen). Clones were screened by PCR and analyzed on 1.2\% agarose gel stained with ethidium bromide $(200 \mu \mathrm{g} / \mathrm{ml})$. Bands were observed using a MultiImage ${ }^{\mathrm{TM}}$ Light Cabinet (Alpha Innotech Corporation, San Leandro, CA). Clones were verified for orientation of the insert by DNA sequencing with primers (designated F2 and R2) recommended by IBA. 
4.2.2 Expression and purification of rTerrelysin- The terrelysin construct was introduced into One Shot ${ }^{\circledR}$ BL21 Star ${ }^{\mathrm{TM}}$ (DE3) chemically competent $E$. coli cells (Invitrogen) for protein expression. Transformed E. coli were grown in LB medium $(50 \mathrm{ml})$ supplemented with 100 $\mu \mathrm{g} / \mathrm{ml}$ ampicillin overnight at $37^{\circ} \mathrm{C}$. The overnight culture was inoculated into flasks containing LB medium $(500 \mathrm{ml})$ supplemented with ampicillin. Cultures were incubated at $37^{\circ} \mathrm{C}$ until they reached an $\mathrm{OD}_{600}$ of $0.5-0.7$. rTerrelysin expression was induced by the addition of $100 \mu \mathrm{g}$ anhydrotetracycline (AHTC) per $500 \mathrm{ml}$ culture, and growth was continued at $30^{\circ} \mathrm{C}$ for $3 \mathrm{hrs} . E$. coli were harvested by centrifugation at $12,000 \mathrm{~g}$ for 15 mins at $4^{\circ} \mathrm{C}$ and the pellet was resuspended in $10 \mathrm{ml}$ CelLytic B solution (Sigma, St. Louis, MO). Phenylmethylsulfonyl fluoride (PMSF) $(100 \mu \mathrm{l})$ was added to inhibit endogenous protease activity. Avidin $(100 \mu \mathrm{l}, 2 \mathrm{mg} / \mathrm{ml})$ was added to sequester endogenous biotin carboxyl carrier protein (BCCP) from E.coli that would otherwise bind to the Strep-Tactin column (IBA) and thus interfere with the purification of rTerrelysin. The suspension was centrifuged at $12,000 \mathrm{~g}\left(4^{\circ} \mathrm{C}\right.$ for $\left.15 \mathrm{mins}\right)$ to remove lysed $E$. coli and cellular debris. The supernatant was applied to an affinity column packed with $10 \mathrm{ml}$ Strep-Tactin-sepharose (IBA) and unbound proteins were removed with washing buffer (100 mM TRIS, $150 \mathrm{mM} \mathrm{NaCl}, 1 \mathrm{mM}$ EDTA, pH 8) (IBA). rTerrelysin was then eluted with washing buffer containing $2.5 \mathrm{mM}$ desthiobiotin, $\mathrm{pH} 8$ (IBA) and the concentration of the purified rTerrelysin was determined using a NanoDrop ND1000 Spectrophotometer (Thermo Scientific, Wilmington, DE). Recombinant protein was then dialyzed in PBS pH 7.4 and was stored at $-20^{\circ}$ C. 


\subsubsection{Matrix-assisted laser desorption/ionization time-of-flight mass spectrometry}

(MALDI-TOF MS)- Samples were prepared for MALDI-TOF MS analysis by mixing equal volumes of rTerrelysin $(500 \mu \mathrm{g} / \mathrm{ml})$ and $\alpha$-cyano-4-hydroxycinnamic acid $(10 \mathrm{mg} / \mathrm{ml})$. Aliquots of $1 \mu \mathrm{l}$ were air-dried on the gold sample stage (Bio-Rad, Hercules, CA) and MALDI-TOF mass spectra were acquired using a Ciphergen PBS-IIc linear TOF mass spectrometer (Bio-Rad, Hercules, CA) with a flight path of $0.8 \mathrm{~m}$. Spectra were acquired over the $\mathrm{m} / \mathrm{z}$ range of 0 to 30 $\mathrm{kDa}$, with the delayed extraction parameters set to optimally focus the 15 to $20 \mathrm{kDa}$ range. Protein calibrants between 1 to $66 \mathrm{kDa}$ were used for external calibration.

4.2.4 Circular Dichroism Spectroscopy- Circular Dichroism (CD) spectra were recorded using a JASCO J-810 spectro-polarimeter (JASCO Inc., Easton, MD) under the following conditions: Temperature $20^{\circ} \mathrm{C}$; pathlength $0.1 \mathrm{~cm}$; protein concentration $0.2-0.35 \mathrm{mg} / \mathrm{ml}$; scanning range between 300-180 nm (Far-UV). For pH effect studies, rTerrelysin was dialyzed into the following buffers: $\mathrm{pH}$ 3: $20 \mathrm{mM}$ citrate buffer; $\mathrm{pH}$ 6-8: $20 \mathrm{mM}$ phosphate buffer; $\mathrm{pH}$ 910: $20 \mathrm{mM}$ borate buffer. CD spectra were recorded for rTerrelysin ( $\mathrm{pH} 8$ ) between temperature $20^{\circ} \mathrm{C}-90^{\circ} \mathrm{C}$ with a $5^{\circ} \mathrm{C}$ interval to study the thermal denaturation of rTerrelysin. Baseline correction was performed with respective buffers without protein and an average spectrum was obtained from 3 scans. Spectra were fit using CDPro over the range of 260-185 nm. The fitting procedure can be used to predict the tertiary class of the protein assuming it is all $\alpha$-helix, all $\beta$ sheet, a mixture of $\alpha$-helix and $\beta$-sheet, or a denatured protein (22). 
4.2.5 SDS-PAGE and protein blot analysis- SDS-PAGE electrophoresis was performed using $12 \%$ acrylamide separating gel and $4 \%$ stacking gels. SDS-PAGE was carried out using constant voltage of $100 \mathrm{~V}$ for 90 mins and the separated proteins were stained with Imperial ${ }^{\mathrm{TM}}$ protein staining solution (Pierce, Rockford, IL). For protein blots, gels were transferred to a nitrocellulose membrane at a constant voltage of $15 \mathrm{~V}$ overnight at $4^{\circ} \mathrm{C}$ and the membranes blocked for $1 \mathrm{hr}$ in $3 \%$ bovine serum albumin (BSA) in PBST (PBSTB). After washing with PBST, the membrane was incubated for $1 \mathrm{hr}$ with horseradish peroxidase-conjugated StrepTactin diluted 1/100,000 (v/v) (IBA). The blots were subsequently developed with tetramethylbenzidine solution (TMB) (KPL Inc., Gaithersburg, MD).

4.2.6 Hemolysis assay- Hemolysis assay was performed by incubating serial dilutions of rTerrelysin $(5 \mathrm{mg} / \mathrm{ml}-0.02 \mathrm{mg} / \mathrm{ml})$ in PBS pH 7.4 containing sodium citrate $(0.57 \%)$. Each rTerrelysin dilution $(100 \mu \mathrm{l})$ was incubated with $100 \mu \mathrm{l}$ of sheep red blood cells (SRBC) at several concentrations ranging from 2 to $5 \%$ in PBS pH 7.4 containing $0.57 \%$ sodium citrate in a 96-well microtiter plate. Samples were incubated for 30 mins at RT. SRBC incubated with Tween (1\%) acted as a positive control and SRBC incubated with PBS acted as a negative control. After incubation, plates were centrifuged at $4100 \mathrm{~g}$ for 5 mins. The supernatant was collected and measured at $\mathrm{OD}_{540} \mathrm{~nm}$. 


\subsection{RESULTS}

4.3.1 Sequence alignment of aegerolysin-like proteins- The putative sequence for terrelysin was obtained by performing a BLAST search with asp-hemolysin (ASPH_ASPFU) as a search query. The search yielded results for homologues present in different Ascomycetes, Basidiomycetes, bacteria and plants. A putative uncharacterized protein sequence from Aspergillus terreus ( $\underline{\mathrm{Q} 0 \mathrm{CRX} 8}$ ) with $26 \%$ identity to Asp-hemolysin was identified. Sequences of putative uncharacterized proteins from A. fumigatus, A. terreus, A. flavus, A. clavatus, A. oryzae, Penicillium chrysogenum, Agrocybe aegerita, and Pleurotus ostreatus were analyzed using Clustal W multiple sequence alignment software (23) (Fig. 4.1). Significant homology was observed in the C-terminal region of aegerolysin-like proteins. Terrelysin (Q0CRX8) shares > 50\% identity with putative hemolysins from A. niger (A2RBK6-55\%) and A. nidulans (Q5BD27$69 \%)$ and $\geq 30 \%$ identity with 13 other aegerolysin-like proteins. Terrelysin Q0CRX8 contained a unique sequence DCSRSGLPLLFR at AA 29-40 that was not found in the other aegerolysins.

4.3.2 Cloning and expression of rTerrelysin- Total RNA was isolated from A. terreus and reverse transcribed to cDNA. The open reading frame encoding the putative terrelysin (Fig. 4.1) was amplified using specific primers F1 and R1, which amplified a 390 bp PCR product that was cloned into the pASK-IBA6 vector (Fig. 4.2). The open reading frame did not contain the sequence for the peptide AA29-40 found in Q0CRX8, which instead was replace by a glutamic acid (AA29). 
cDNA

rTerrelysin

ASPH ASPFU

A4DA $\overline{6} 5$ ASPFU

B8NXA7-ASPFL

B8N7M1_ASPFL

A1CGD5 ASPCL

A2QA29 ASPNG

A2RBK6_ASPNG

Q2U8X3 ASPOR

B6GXR4 PENCH

B6HE31_PENCH

AAPR1_AGRAE

Q56QW9'PLEOS

CDNA

rTerrelysin

ASPH ASPFU

A4DA 65 ASPFU

B8NXA7-ASPFL

B8N7M1 ASPFL

A1CGD5 ASPCL

A2QA29_ASPNG

A2RBK6_ASPNG

Q2U8X3_ASPOR

B6GXR4_PENCH

B6HE31_PENCH

AAPR1_AGRAE

Q56QW9'PLEOS

cDNA

rTerrelysin

ASPH_ASPFU

A4DA 65 ASPFU

B8NXA7-ASPFL

B8N7M1_ASPFL

A1CGD5_ASPCL

A2QA29 ASPNG

A2RBK6_ASPNG

Q2U8X3_ASPOR

B6GXR4 PENCH

B6HE31_PENCH

AAPR1 AGRAE

Q56QW9_PLEOS
---------MDDSQWVS IH IRDRLAQGNITIRES F LYEGQFHS PEDKKKALTEDDIDQLI-51 ---------MDD SQWVS IH IRDRLAQGNIT IRES FLYEGQFHSPEDKKKALTEDDIDQLI- 51 -----MASVQAYAQWVTVHLINSMSSETLSIQNASLSWGKWYKDGDKDAEITSEDVQQKT - 55 -----MASTTGQQFLDIEIKDDMKYD-IRIENAHIESGEFYREGDQNDTLTTDDIEDMI- 53 ---MDTDLNKYNSKWVEFHIRDHLKDGEISVRHTVIEDGEFQDPNNRRKS IHEDVIDEIV- 57 IHRQVDMPADAYGQYVDIKIEDGMKYD-LRIENAHLDSGQFYRQGDQGDIMTADDIDDMI-119 ------MAPTSAHQYLDMEIKDDMQYD-IRIENARIDSGEFHSASDENDTLTTDDVEDLM- 53 ------MAERAEAQWVHIRVVNSLSFDTLSVRNTWLGWGKFHKENNKSAEI PVSDINALR- 54 ----MPAAGPMDDQWVSFHIRDHLEKGEITVRHTVIEGGEFHDPNNRRQSLTEDEIDEIT-56 MALCLCQQSKISGAQELIRLLFDIDLLHLIID-LNIRSRKI PKGNMKRTKKYASQVNGKE- 59 ----MDNMDKYNSQWVSFHIRDHIKDGEILVQNTVIEGGEFAD PNNRRRSLTEEEIDEIK- 56 -----MASSLSQKSLQIQIQDDLKYD-IRIENAKLESGKFYNEDDQSDILTSEDVDDMV- 53 --MDSNKDERAYAQWVI I ILHN-VGSSPFKIANLGLSWGKLYADGNKDKEVYPSDYNGKT- 57 -------AYAQWVI ILIHN-VGQQNVKI KNLNA.SWGKLYADGDKDTEVPASKYEGMV-49

IPS-EGIGEVCARGR----RGSEGWMDLFD---GEKKICELHWDNR-TKRPSNEFEVIDG-102 IPS-EGIGEVCARGR----RGSEGWMDLFD---GEKKICELHWDNR-TKRPSNEFEVIDG-102 APP-GGSVNVNSCGRSDASSGTTGGFDLYD---GNTKIGRVHWDCP-WGSKTNDFDVGER-110 IRHNGGLRHVCSCGEEKGFKGLQGTIDLID-DVKDAKICTLEWNAPMEPGKRNTFMLRDQ-112 IPS-DGIGEICAHGR----RGSEGRLDLFH---GNDKICELHWDDR-DGRRENLVEMLDE-108 IRHNGGIREVCSCGETDSMSGTQGTIDLID-DVKDTRICTLAWSAPMQSGRKNRFSMLNH- 178 IRHNGGTRHVCSSGEEEGFKGLQGTIDLVD-DVRDARICTLAWNAPMEPGKRNLLMMHHH-112 A_AP-GGSFNVFACGRAHSPSGTEGSFDVYN---GDVRVAYIYWDCP-WGSKRNQFRVDRI-109 IPS-YGIGEICARGR----RGSEGRLDLFH---DEEKICELHWDNR-QGNPVNIVEMIDS-107 IIP-GTSQLLETCGRSSA_ASGTEGTLELWD---KTQRICKLYWDCP-WGSKVNKFKVQEK-114 ISP-DGVGEIGASSR----RGSEGRLDLFH---DNDKICELHWENR-GGEHANLVEVLDK-107 IRHNGGIRSVCS------MDGSEGS IDLVD-DVRDAKICNLTWRAS PEGGERNE IKKLNE-106 VGP-DEKIQINSCGRENASSGTEGSFDIVDPNDGNKTIRHFYWECP-WGSKRNTWTPSGS-115 IAP-GDQVQINACGREDA_AEGTTGTFDLVDPNDSDKQVRHISWDCP-WGTKANSWVVGGS-107

$$
\text { : : } \quad * \quad *:: \text {. } \quad \text { : * }{ }^{*} \text { sdentities sSimilarities }
$$

DKDYKIECSGWSPQAG-PLGHVFIDISA_AKKKA_A_A_A_AK--141 DKDYKIECSGWSPQAG-PLGHVFIDISAA-------------130

NKNYWVEIGTWNKYGG-AIGTVDVEVGRKR------------139

DPRYHIDIGQWN-ESG-ILGKVPVTISDE-----------139

SDKYRIEHGGWSPEANGPLGHVYVDVWAKDKSK---------141

DPRYKVDIGKWQ-ESG-TMGTVNVAIKDE-------------205

DPQYNVEIGKWN-ESG-VMGTVPITISNQ------------139

ADDYWVETGYWNQSGG-AIGSVTVEIGRRDRAIRSSL-----145

NSKYRVEHGGWSPEAG-PLGHVYIDILEQQKKKNSK------142

YKTYRVEVGPWNSYGG-ALGNVDVEISRKRA-----------144

SDKYTIEHGGWSSEAG-PLGHVFVDVAEKKK----------137

DTRYMVDIGSWN-ESG-TVGSVLVTVKDQE------------134

NTKWMVEWSGQNLDSG-ALGTITVDVLRKGN-----------145

NSKWMIEYTGQNLDSG-ALGTITVNTLKIGN-----------137

$--$

100

$--$

29

100

34

55

53

53

33

32

28

60

31

48

31

24

N.A.

52

51

51

78

57

69

54

41

: : : . . $:^{\star}:$ :

Fig 4.1. Sequence alignment of putative aegerolysin family proteins produced by various fungi. Alignment was

performed using Clustal W. Proteins were identified by their database accession numbers. Abbreviations of organisms from which the proteins were identified. PENCH: Penicillium chrysogenum, ASPOR: Aspergillus oryzae, ASPFL: Aspergillus flavus, ASPFU: Aspergillus fumigatus, ASPCL: Aspergillus clavatus, ASPNG: 
Aspergillus niger, AGRAE: Agrocybe aegerita, PLEOS: Pleurotus ostreatus. The full-length sequence of terrelysin identified by translation of the cDNA sequence is identified as cDNA, while the recombinant sequence without the Strep-tag II is identified as rTerrelysin. The \% identities and \% similarities were reported from BLAST results on EBI website. '*' Fully conserved residues, ':’ strongly conserved residues, ‘’ weakly conserved residues. N.A. is defined as "not determined" using the BLAST tool on EBI website with terrelysin (QOCRX8) as a query. The query did not yield results for identities and similarities for ostreolysin (Q56QW9). Sequence analysis was performed on August 12, 2009. 
Using the primers F2 and R2 the ligation of the insert in the pASK-IBA6 vector was verified. The terrelysin insert was not present in unligated pASK-IBA vector (Lane 2) but was present after ligation into the vector (Lane 3) as observed by an approximately 390bp difference in bands on the gel. After transferring the plasmid into competent E. coli by heat-shock transformation, positive clones were selected on the basis of ampicillin resistance and the correct orientation of the insert was confirmed by sequencing primers F2 and R2. Clones expressing the terrelysin sequence in the proper reading frame were identified and chosen for further study. The presence of terrelysin cDNA was demonstrated in the TOP 10 cloning strain (Lane 5) and the BL21 (DE3) expression strain (Lane 6) of E. coli, but not in the original E. coli DH5a strain bearing the plasmid with no insert (Lane 4) (Fig. 4.3). 


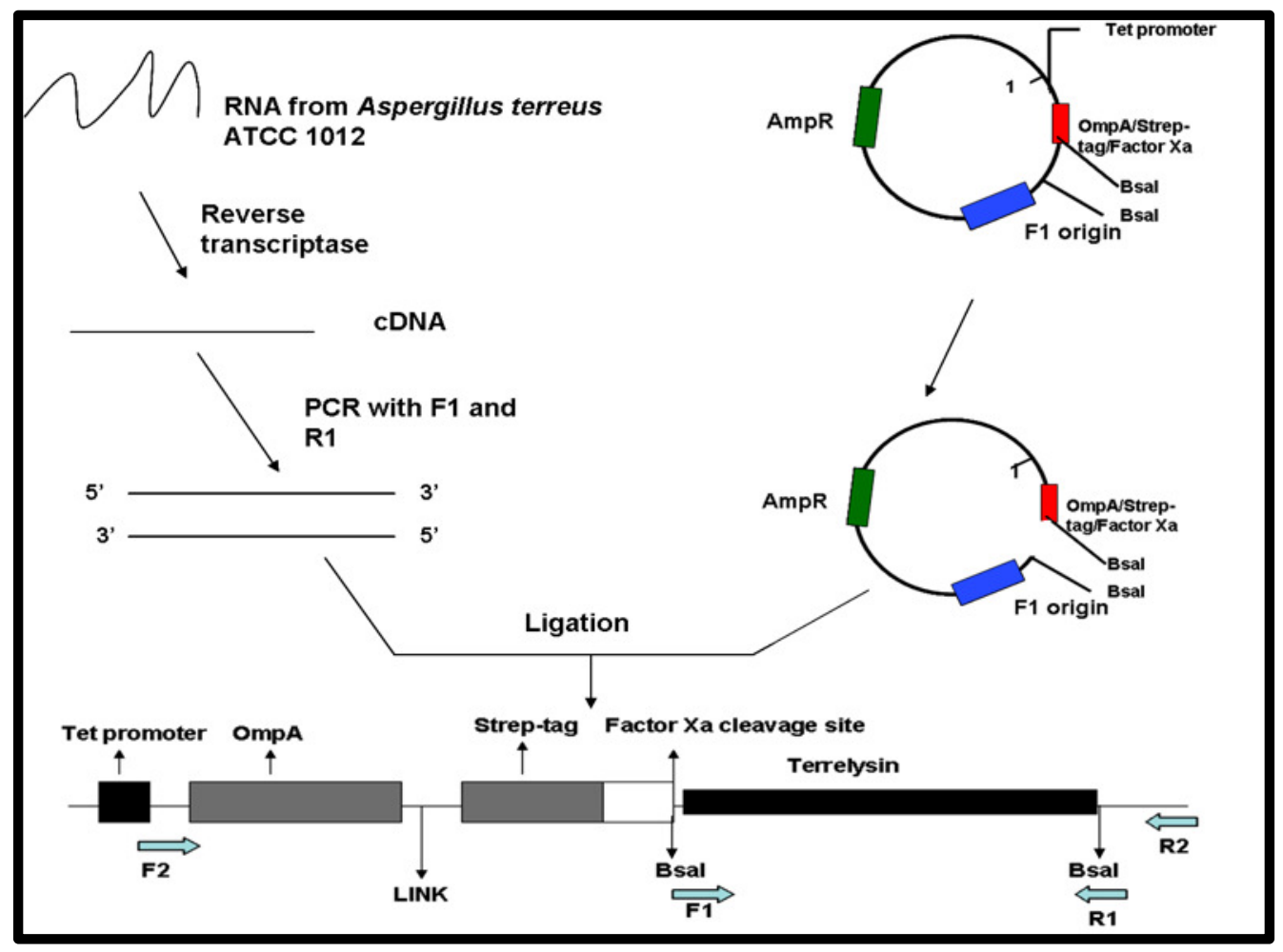

Fig 4.2. Cloning strategy for recombinant terrelysin in PASK-IBA6 vector and expression in Escherichia coli. 
4.3.3 Characterization of rTerrelysin- The pASK-IBA6 vector is designed for expression of the recombinant protein into the periplasmic space through a signal peptide OmpA inserted at the $\mathrm{N}$-terminal of the recombinant protein. The signal is cleaved by endogenous signal peptidase during the protein translocation resulting in the release of the protein into the periplasmic space. Immediately downstream of the OmpA signal the pASK-IBA6 vector contains a Strep-tag II and Factor Xa recognition sequence at the N-terminus that is a part of the rTerrelysin polypeptide.

Protein preparations from uninduced E. coli, AHTC induced E. coli, and Strep-Tactin column purified rTerrelysin were analyzed by SDS-PAGE (Fig. 4.4a). An $\sim 17 \mathrm{kDa}$ band representing rTerrelysin was observed only in induced cultures (Lane 3) and the purified fraction (Lane 4), but was absent in the uninduced cultures (Lane 2).

Protein blots were performed and rTerrelysin was identified using HRP-conjugated StrepTactin and TMB as a substrate (Fig. 4.4b). A band corresponding to rTerrelysin was present in AHTC induced cultures (Lane 5) and in the Step-Tactin column-purified fraction (Lane 6), but absent in uninduced (Lane 4) or induced E. coli cultures without the insert (Lane 3). The bands observed in Lanes 4 and 5 at $\sim 17 \mathrm{kDa}$ just above the rTerrelysin band could possibly be BCCP from E. coli. This band is absent in purified preparation (Lane 6) suggesting the removal of BCCP after addition of avidin prior to purification on the Strep-Tactin column.

The mass of rTerrelysin was determined using MALDI-TOF MS (Fig. 4.5). The single charged $[\mathrm{M}+\mathrm{H}]^{+}$ion of rTerrelysin was observed at $\mathrm{m} / \mathrm{z} 16428$, in good agreement with SDSPAGE results (Fig. 4.4). The peak observed at $m / z 8197$ represents the doubly charged $[\mathrm{M}+2 \mathrm{H}]^{2+}$ ions of rTerrelysin, respectively. 


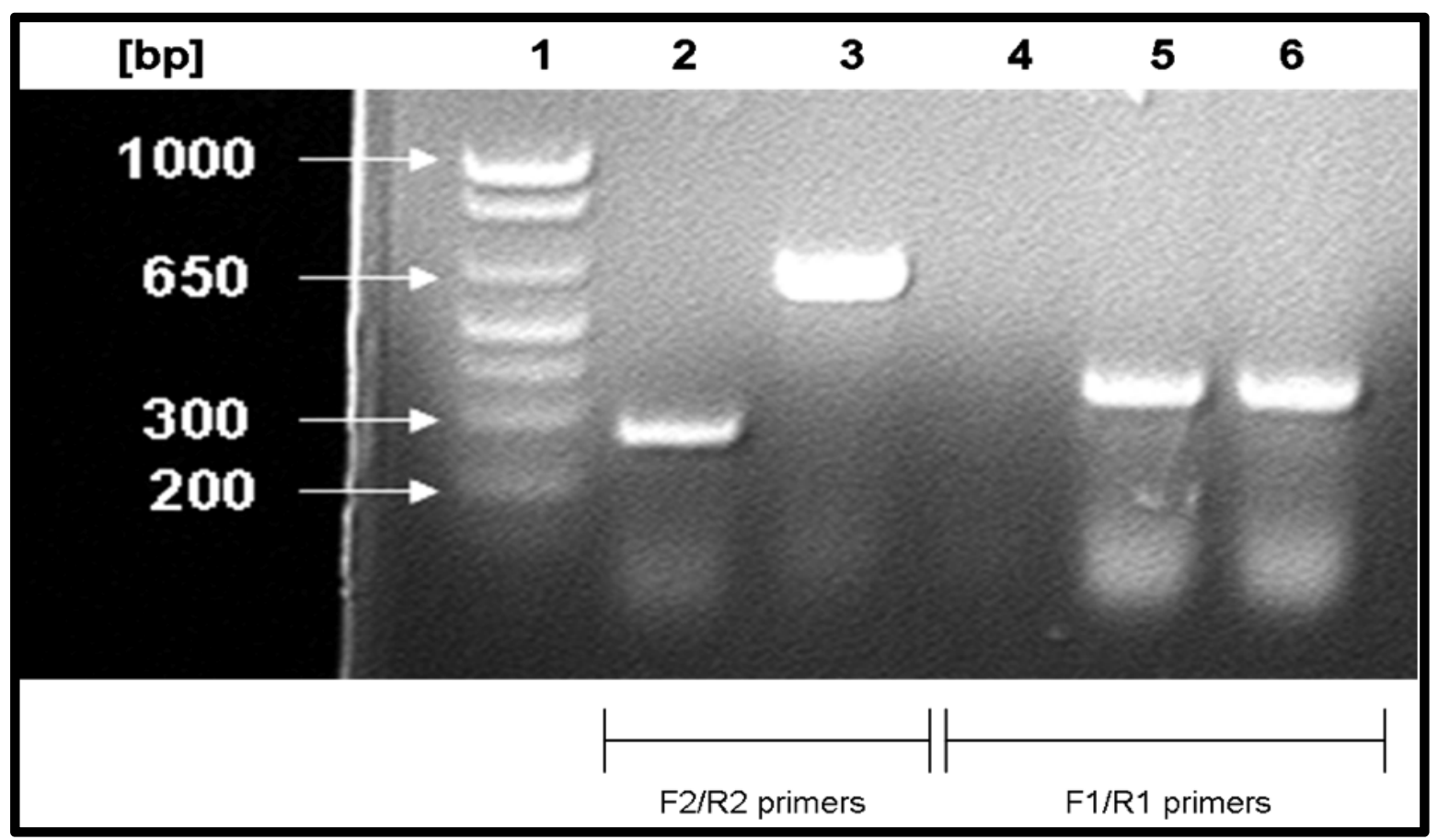

Fig 4.3. Agarose gel electrophoresis. Lane 1: DNA ladder, Lanes 2, 4: pASK-IBA6 vector with no insert (PCR products of primers $F 2$ and R2), Lanes 3, 5, 6: pASK-IBA6 vector with terrelysin gene insert (PCR products of primers F1 and R1). Lane 5: Cloning strain (OneShot Top10) and Lane 6: expression strain (DE3). 


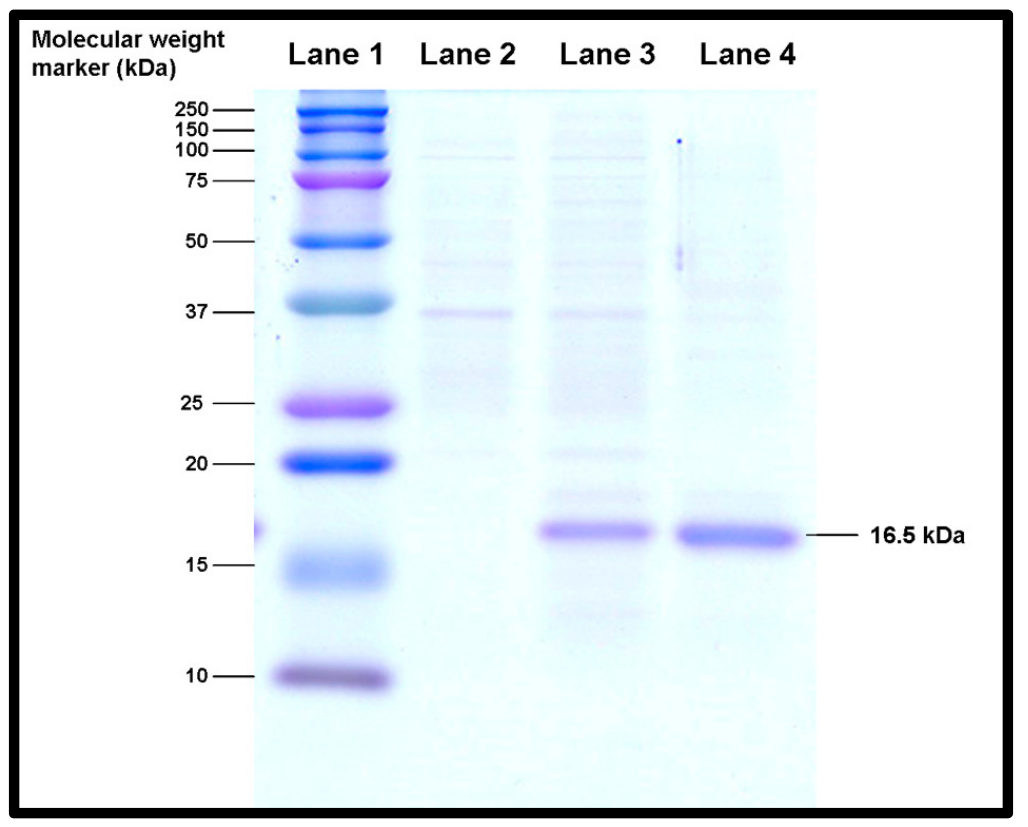

Fig 4.4a. SDS-PAGE for terrelysin. Lane 1: Molecular weight marker, Lane 2: Uninduced pASK-IBA6 vector (with terrelysin insert), Lane 3: Induced pASK-IBA6 vector (with terrelysin insert), Lane 4: Recombinant terrelysin purified on Strep-Tactin column. 


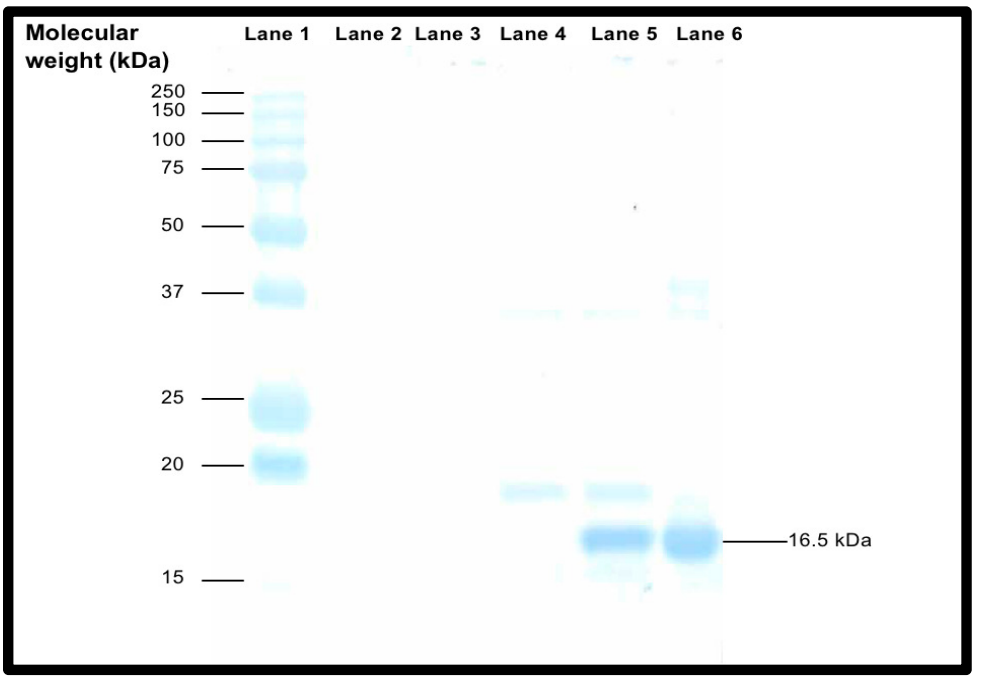

Fig 4.4b. Protein blot for rTerrelysin. Lane 1: Molecular weight marker, Lane 2: Uninduced pASK-IBA6 vector (no insert), Lane 3: Induced pASK-IBA6 vector (no insert), Lane 4: Uninduced pASK-IBA6 vector (with terrelysin insert), Lane 5: Induced pASK-IBA6 vector (with terrelysin insert), Lane 6: Recombinant terrelysin purified on Strep-Tactin column. 


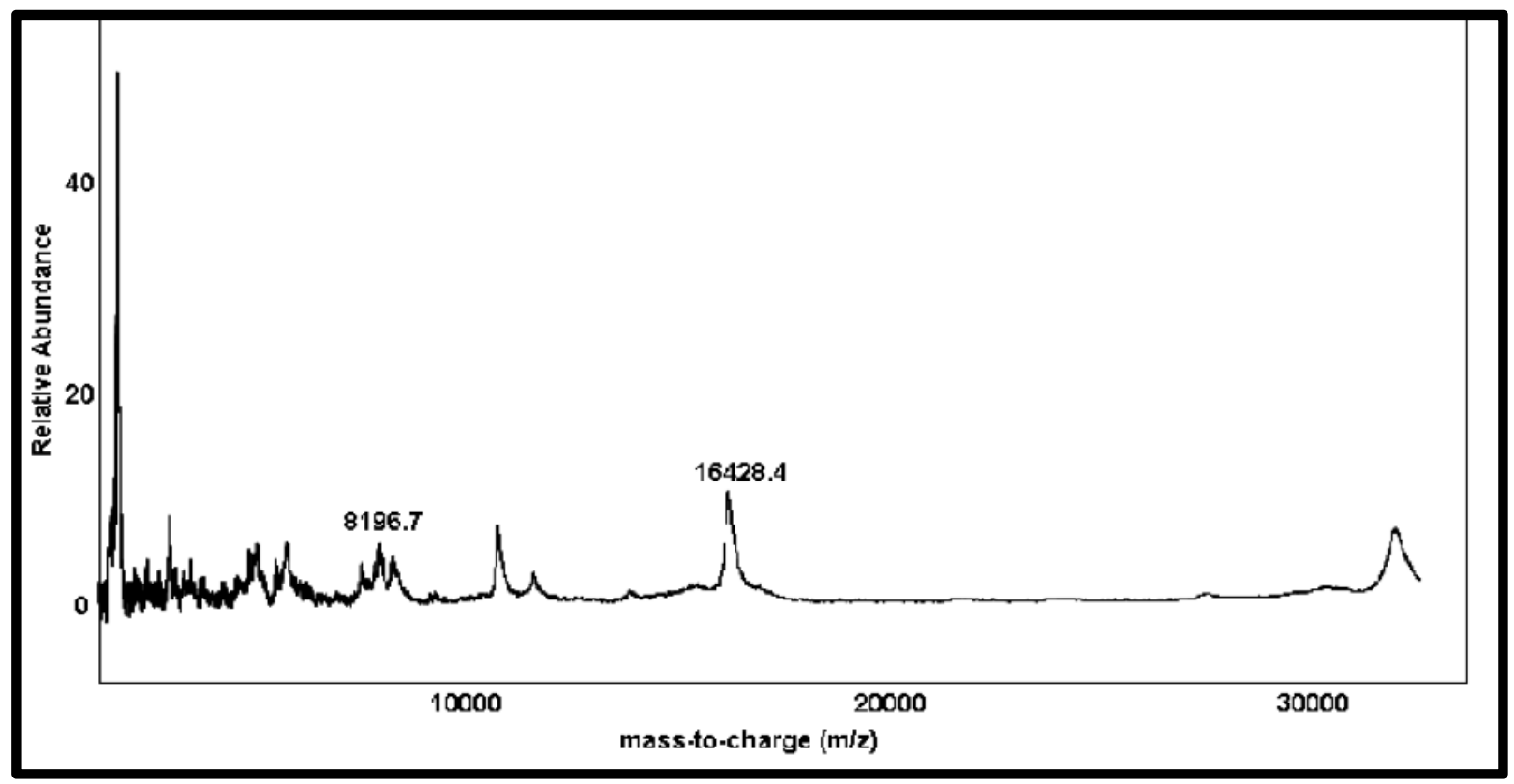

Fig 4.5. MALDI-TOF MS of rTerrelysin. $[M+H]^{+}: 16428.4 \mathrm{Da} .[\mathrm{M}+2 \mathrm{H}]^{2+}: 8196.7 \mathrm{Da}$. 
4.3.4 Secondary structure of rTerrelysin- The secondary structure of rTerrelysin was determined using far-UV (185-240) CD spectroscopy analysis (Fig. 4.6). The lowest ellipticity at $216 \mathrm{~nm}$ combined with the highest ellipticity at $195 \mathrm{~nm}$, identified rTerrelysin as a predominantly $\beta$-sheet protein (Fig. 4.6a). This result was further supported by fitting the data with the prediction that the protein was completely in the $\beta$-sheet conformation. The effect of different $\mathrm{pH}$ (3-10) on rTerrelysin unfolding was studied. The optimum $\beta$-sheet conformation was observed at $\mathrm{pH} 8$. With decreasing $\mathrm{pH}$, a decrease in $\beta$-sheet conformation population was observed, with the loss of almost all of the $\beta$-sheet conformation at pH 3 (Fig. 4.6b). A similar effect was observed with the change in $\mathrm{pH}$ from 8-10 (data not shown). With the increase in alkalinity a gradual decrease in $\beta$-sheet conformation was observed.

Thermal denaturation studies with rTerrelysin and its effect on its secondary structure was studied using $\mathrm{CD}$ spectroscopy with monitoring the spectra of rTerrelysin from $20^{\circ} \mathrm{C}-90^{\circ} \mathrm{C}$ with a $5^{\circ} \mathrm{C}$ interval. The spectra revealed a gradual shift from a predominantly $\beta$-sheet conformation to a $\alpha$-helical structure with the increasing temperature (Fig. 4.6c). Spectrum measurement in the far UV range identified three different states of secondary structure conformation for rTerrelysin. Between $20^{\circ} \mathrm{C}-65^{\circ} \mathrm{C}$, the $\mathrm{CD}$ spectrum revealed predominantly $\beta$ sheet structure. Between $65^{\circ} \mathrm{C}-75^{\circ} \mathrm{C}$, the spectrum showed a possible intermediate structure with $\beta$-sheet as well as $\alpha$-helix elements in the secondary structure. Above $75^{\circ} \mathrm{C}$, the structure was predominantly $\alpha$-helix. 
4.3.5 Hemolysis assay- The rTerrelysin preparation showed hemolytic activity when tested on agar plates containing SRBC with a zone of clearance around the site of inoculation (data not shown). Dose-dependent hemolysis was analyzed by incubating dilutions of rTerrelysin with varying concentrations of SRBC. Hemolysis was measured spectrophotometrically as release of hemoglobin at $540 \mathrm{~nm}$ (Fig. 4.7). Hemolysis, with a steep dose-response curve was observed at relatively high concentrations of rTerrelysin higher than $313 \mu \mathrm{g} / \mathrm{ml}$. 


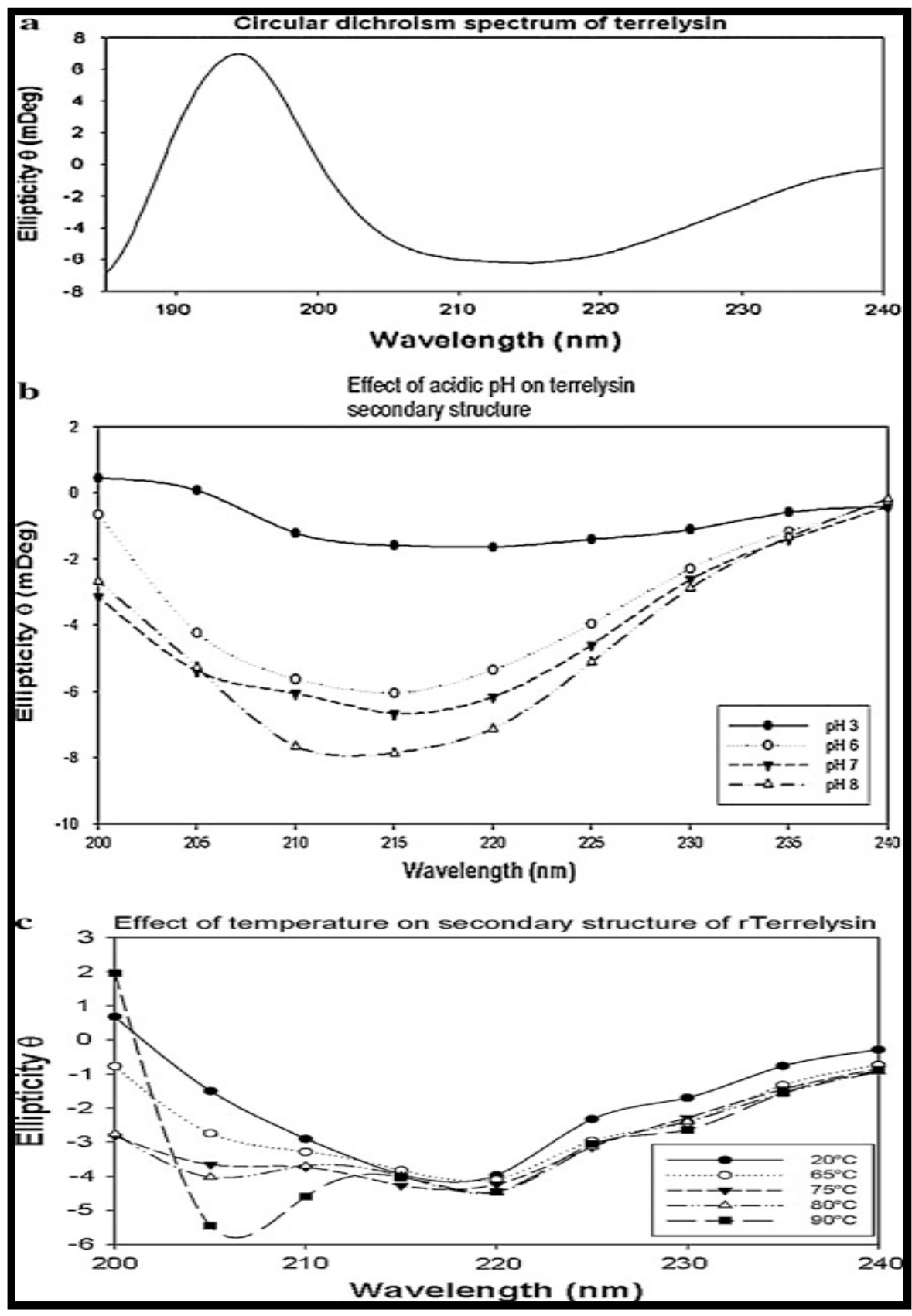

Fig 4.6. Secondary structure analysis of rTerrelysin. a) CD analysis of rTerrelysin. Negative signal at $216 \mathrm{~nm}$ and a positive signal of similar magnitude at $195 \mathrm{~nm}$ identify the protein as a predominantly $\beta$-sheet protein.

b) rTerrelysin was dialyzed into various buffers of differing pH. Optimum $\beta$-sheet conformation was observed at pH 8 with a reduction in $\beta$-sheet conformation with decreasing $p H$. A disordered secondary structure is observed at $\mathrm{pH}$ 3. c) Thermal denaturation of rTerrelysin was studied between temperatures $20^{\circ} \mathrm{C}-90^{\circ} \mathrm{C}$. rTerrelysin 
retained $\beta$-sheet structure up to $65^{\circ} \mathrm{C}$ and beyond that the structure included $\alpha$-helix elements. Above $75^{\circ} \mathrm{C}$, the structure was predominantly a-helix. 


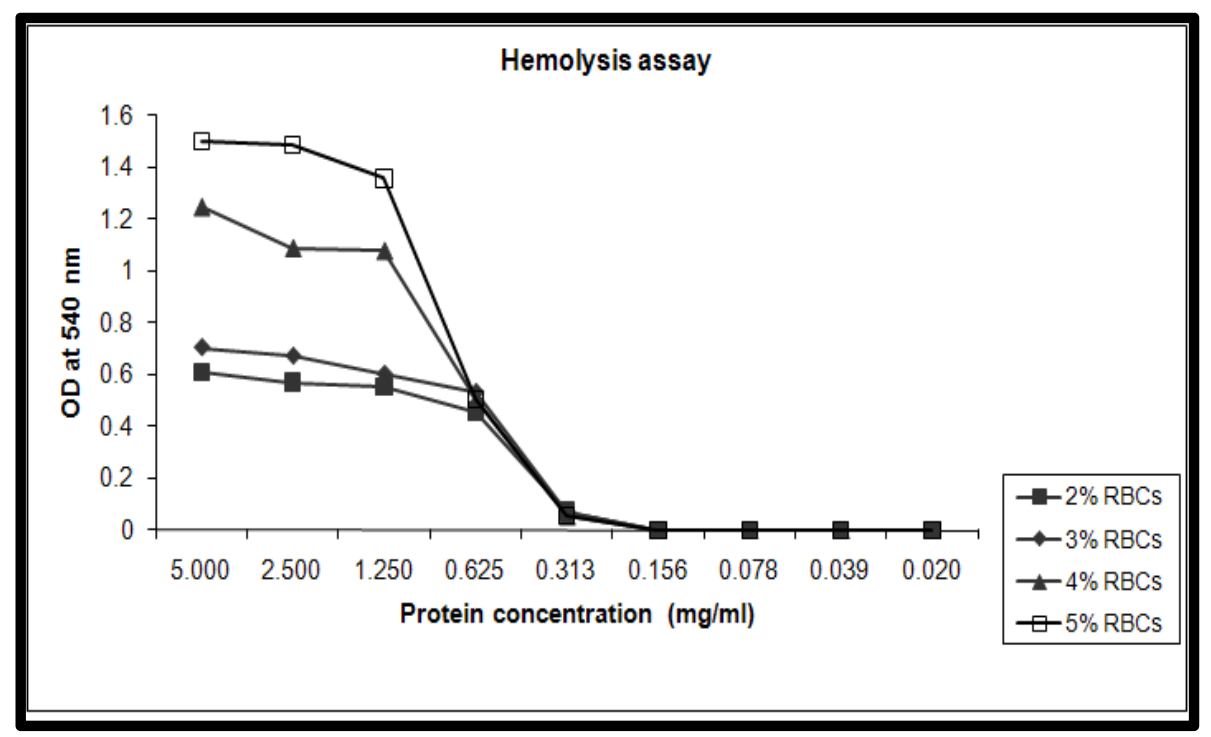

Fig 4.7. Hemolysis assay. Hemolysis was observed at high concentrations of purified rTerrelysin. Increased hemolysis was observed on increasing the concentration of SRBC. Hemolysis was measured at OD540 nm. 


\subsection{DISCUSSION}

Hemolysins are proteins that lyse red blood cells as well as various other eukaryotic cells. Here we report the cloning, expression and purification of a recombinant fusion protein of a putative hemolysin produced by A. terreus called terrelysin. Terrelysin belongs to the aegerolysin family of proteins that consists of cytolysins produced by other filamentous fungi, bacteria, and plants (9). A search using the terrelysin sequence as a template in the NCBIBLAST2 - Protein Database Query yielded sequence similarities to 40 other proteins from different fungi, bacteria and certain members of kingdom Animalia such as Schistosoma japonicum and Ciona intestinalis. Terrelysin is a 141 AA protein with a predominantly $\beta$-sheet structure and a predicted molecular weight of 15,805 Da and a pI of 5.23.

Recombinant terrelysin was expressed as a Strep-tag II fusion protein in the pASK-IBA6 vector. An apparent intron sequence (DCSRSGLPLLFR) found in the genomic sequence Q0CRX8 was not found in the cDNA transcribed from A. terreus mRNA. In addition, we truncated the recombinant protein at AA 130 to better correspond with other aegerolysins. The recombinant also contained the linker, Strep-tag II and Factor Xa recognition sequences (ASWSHPQFEKIEGR) at the N-terminus giving the fusion protein a predicted MW of 16,290 Da and pI of 4.91.

The benefit of using the Strep-tag II system rather than other, more common systems such as histidine tag $\left(\mathrm{His}_{6}\right)$, is that it is less likely to interfere with protein folding or function (24-28). For example, asp-hemolysin has been cloned and expressed as a Maltose Binding Protein (MBP) fusion construct, however, this protein was not functionally active $(3,4)$. Other proteins from the aegerolysin family (Cbm 17.1 and $\mathrm{Cbm} 17.2$ produced by Clostridium bifermentans) were produced as $\mathrm{His}_{6}$-tag fusion proteins (29) that failed to be hemolytic. 
Similarly, His 6 -tagged PA0122 protein from Pseudomonas aeruginosa was also successfully expressed in E. coli but found to be non-hemolytic (30). His 6 -tag constructs of terrelysin were also made in our lab and we did not observe any hemolytic activity with them. With the MBPtagged protein, the large size of MBP (42.7 kDa) may affect the conformation and function of asp-hemolysin (14.2 kDa) (4), but to date recombinant hemolysins have been functionally inactive.

In preliminary experiments, we observed the rTerrelysin Strep-tag II fusion protein preparation to have hemolytic activity against SRBC. However, given the rather steep dose response and the significant doses required, the possibility of surfactants or detergents being present in rTerrelysin preparation could not be ruled out. The CelLytic B solution used for lysing E. coli cells contains a proprietary formulation with detergents, which could not be completely removed by dialysis. Recent research has identified the requirement of a co-factor for the functional activity of pleurotolysin $(31,32)$. Whether a co-factor is required for terrelysin activity will require further work but this helps to further explain the lack of functional activity of recombinant hemolysins.

Sequence alignment of multiple aegerolysin family proteins demonstrated that most conserved residues were present in the C-terminal region of the protein sequences. The hemolysins of A. oryzae and A. flavus in the genomic database were observed to share the exact same sequence. These two species belong to the Aspergillus section Flavi, and are phylogenetically closely related $(20,33,34)$. Interestingly, it was also observed that members of the aegerolysin family share some structural homology with a family of proteins that contain an E-set domain (Conserved Domain Database: c109101) for sugar utilizing enzymes $(35,36)$. 
Although aegerolysins are typically characterized as hemolysins, they may have other enzymatic functions not yet identified.

Differences in mass of fungal hemolysins have been reported (1, 2, 37-39). Aegerolysin family proteins are typically low molecular weight ( $14-17 \mathrm{kDa})$ proteins. Our experimentally determined rTerrelysin mass is in good agreement with those of other members of the aegerolysin family $(2,4,29,30)$. The secondary structure is very important for functionality of native hemolysins since they undergo conformational changes once inserted into the target membrane, to induce pore formation (40). We expressed rTerrelysin in the periplasmic space of E. coli to allow for proper folding of the protein.

The secondary structure of aegerolysin family proteins has been predicted to be predominantly $\beta$-sheet $(41,42)$. The secondary structures of nigerlysin and ostreolysin have been reported $(38,41)$. While nigerlysin was reported as $\alpha$-helical structure, ostreolysin was identified as a $\beta$-sheet protein. $\beta$-sheet structures have also been identified in bacterial hemolysins such as alpha toxin of Staphylococcus aureus and perfringolysin-O of Clostridium perfringens $(43,44)$. We have identified rTerrelysin as a predominantly $\beta$-sheet protein and it may be similar in function to some of the bacterial hemolysins that play a role in pathogenesis.

Our findings on terrelysin unfolding as a result of $\mathrm{pH}$ changes confirm the observations of Berne et al. on ostreolysin (41). These authors suggested that ostreolysin might exist in conformationally distinct states as a function of $\mathrm{pH}$. The authors identified the optimum $\beta$-sheet conformation at $\sim \mathrm{pH} 8$, an observation that has been confirmed for several hemolysins $(45,46)$. Berne et al. also reported that as the $\mathrm{pH}$ is shifted to the acidic or alkaline range, the conformation of the protein changes. The disordered conformation of rTerrelysin at $\mathrm{pH} 3$ may 
provide the protein flexibility that it lacked in the $\beta$-sheet conformation. This flexibility may increase the formation of oligomers and in pore formation.

A. terreus is a thermotolerant organism capable of growing at elevated temperatures of up to $50^{\circ} \mathrm{C}$. Our thermal denaturation studies on the secondary structure of rTerrelysin indicate that the $\beta$-sheet conformation of the recombinant protein is stable up to $65^{\circ} \mathrm{C}$. Presence of a thermostable protein may provide the fungus an advantage in colonizing in elevated soil temperatures or within human body.

The aegerolysin family of proteins is an interesting new group of proteins that may have multiple functions. In basidiomycetes (mushrooms), they have been found to accelerate fruiting body formation $(2,47)$ and may be critical during germination of spores of filamentous fungi. Their role in pathogenesis appears to be related to their cytolytic activities $(12,13,48)$. Interestingly, ostreolysin and other aegerolysins may bind microhetereogeneic domains within the membrane that are rich in cholesterol (49). Some have also characterized the binding of asphemolysin to low density lipoproteins (50-52). Preliminary studies have suggested the possibility of the use of fungal hemolysins as diagnostic markers $(10,53)$.

Future studies will be aimed at generating monoclonal antibodies to rTerrelysin and developing inhibition ELISA methods using rTerrelysin as reference standard to quantify terrelysin in human serum samples or environmental samples. These experiments will help to further understand the biological significance of terrelysin, its expression, localization and potential use as a biomarker for exposure to A. terreus. 


\subsection{REFERENCES}

1. Sakaguchi, O., H. Shimada, and K. Yokota. 1975. Proceedings: Purification and characteristics of hemolytic toxin from Aspergillus fumigatus. Jpn J Med Sci Biol 28:328331.

2. Berne, S., I. Krizaj, F. Pohleven, T. Turk, P. Macek, and K. Sepcic. 2002. Pleurotus and Agrocybe hemolysins, new proteins hypothetically involved in fungal fruiting. Biochim Biophys Acta 1570:153-159.

3. Ebina, K., H. Sakagami, K. Yokota, and H. Kondo. 1994. Cloning and nucleotide sequence of cDNA encoding Asp-hemolysin from Aspergillus fumigatus. Biochim Biophys Acta 1219:148-150.

4. Kumagai, T., Y. Kudo, Y. Fukuchi, K. Ebina, and K. Yokota. 2002. Expression of a synthetic gene encoding the Asp-hemolysin from Aspergillus fumigatus in Escherichia coli. Biol Pharm Bull 25:115-117.

5. Fernandez Espinar, M. T., and J. Labarere. 1997. Cloning and sequencing of the Aa-Pri1 gene specifically expressed during fruiting initiation in the edible mushroom Agrocybe aegerita, and analysis of the predicted amino-acid sequence. Curr Genet 32:420-424.

6. Pires, A. B., K. P. Gramacho, D. C. Silva, A. Goes-Neto, M. M. Silva, J. S. MunizSobrinho, R. F. Porto, C. Villela-Dias, M. Brendel, J. C. Cascardo, and G. A. Pereira. 2009. Early development of Moniliophthora perniciosa basidiomata and developmentally regulated genes. BMC Microbiol 9:158.

7. Bhakdi, S., H. Bayley, A. Valeva, I. Walev, B. Walker, M. Kehoe, and M. Palmer. 1996. Staphylococcal alpha-toxin, streptolysin-O, and Escherichia coli hemolysin: prototypes of pore-forming bacterial cytolysins. Arch Microbiol 165:73-79.

8. Bhakdi, S., F. Grimminger, N. Suttorp, D. Walmrath, and W. Seeger. 1994. Proteinaceous bacterial toxins and pathogenesis of sepsis syndrome and septic shock: the unknown connection. Med Microbiol Immunol 183:119-144.

9. Berne, S., L. Lah, and K. Sepcic. 2009. Aegerolysins: structure, function, and putative biological role. Protein Sci 18:694-706.

10. Vesper, S. J., and M. J. Vesper. 2004. Possible role of fungal hemolysins in sick building syndrome. Adv Appl Microbiol 55:191-213.

11. Ebina, K., S. Ichinowatari, and K. Yokota. 1985. Studies on toxin of Aspergillus fumigatus. XXII. Fashion of binding of Asp-hemolysin to human erythrocytes and Asphemolysin-binding proteins of erythrocyte membranes. Microbiol Immunol 29:91-101.

12. Kumagai, T., T. Nagata, Y. Kudo, Y. Fukuchi, K. Ebina, and K. Yokota. 1999. Cytotoxic activity and cytokine gene induction of Asp-hemolysin to murine macrophages. Nippon Ishinkin Gakkai Zasshi 40:217-222.

13. Kumagai, T., T. Nagata, Y. Kudo, Y. Fukuchi, K. Ebina, and K. Yokota. 2001. [Cytotoxic activity and cytokine gene induction of Asp-hemolysin to vascular endothelial cells]. Yakugaku Zasshi 121:271-275.

14. Ebina, K., K. Yokota, and O. Sakaguchi. 1982. Studies on toxin of Aspergillus fumigatus XIV: Relationship between Asp-hemolysin and experimental infection in mice. Jpn $J$ Med Mycol 23:246-252.

15. Van Emon, J. M., A. W. Reed, I. Yike, and S. J. Vesper. 2003. ELISA measurement of stachylysin in serum to quantify human exposures to the indoor mold Stachybotrys chartarum. J Occup Environ Med 45:582-591. 
16. Nierman, W. C., A. Pain, M. J. Anderson, J. R. Wortman, H. S. Kim, J. Arroyo, M. Berriman, K. Abe, D. B. Archer, C. Bermejo, J. Bennett, P. Bowyer, D. Chen, M. Collins, R. Coulsen, R. Davies, P. S. Dyer, M. Farman, N. Fedorova, T. V. Feldblyum, R. Fischer, N. Fosker, A. Fraser, J. L. Garcia, M. J. Garcia, A. Goble, G. H. Goldman, K. Gomi, S. Griffith-Jones, R. Gwilliam, B. Haas, H. Haas, D. Harris, H. Horiuchi, J. Huang, S. Humphray, J. Jimenez, N. Keller, H. Khouri, K. Kitamoto, T. Kobayashi, S. Konzack, R. Kulkarni, T. Kumagai, A. Lafon, J. P. Latge, W. Li, A. Lord, C. Lu, W. H. Majoros, G. S. May, B. L. Miller, Y. Mohamoud, M. Molina, M. Monod, I. Mouyna, S. Mulligan, L. Murphy, S. O'Neil, I. Paulsen, M. A. Penalva, M. Pertea, C. Price, B. L. Pritchard, M. A. Quail, E. Rabbinowitsch, N. Rawlins, M. A. Rajandream, U. Reichard, H. Renauld, G. D. Robson, S. Rodriguez de Cordoba, J. M. Rodriguez-Pena, C. M. Ronning, S. Rutter, S. L. Salzberg, M. Sanchez, J. C. Sanchez-Ferrero, D. Saunders, K. Seeger, R. Squares, S. Squares, M. Takeuchi, F. Tekaia, G. Turner, C. R. Vazquez de Aldana, J. Weidman, O. White, J. Woodward, J. H. Yu, C. Fraser, J. E. Galagan, K. Asai, M. Machida, N. Hall, B. Barrell, and D. W. Denning. 2005. Genomic sequence of the pathogenic and allergenic filamentous fungus Aspergillus fumigatus. Nature 438:11511156.

17. Galagan, J. E., S. E. Calvo, C. Cuomo, L. J. Ma, J. R. Wortman, S. Batzoglou, S. I. Lee, M. Basturkmen, C. C. Spevak, J. Clutterbuck, V. Kapitonov, J. Jurka, C. Scazzocchio, M. Farman, J. Butler, S. Purcell, S. Harris, G. H. Braus, O. Draht, S. Busch, C. D'Enfert, C. Bouchier, G. H. Goldman, D. Bell-Pedersen, S. Griffiths-Jones, J. H. Doonan, J. Yu, K. Vienken, A. Pain, M. Freitag, E. U. Selker, D. B. Archer, M. A. Penalva, B. R. Oakley, M. Momany, T. Tanaka, T. Kumagai, K. Asai, M. Machida, W. C. Nierman, D. W. Denning, M. Caddick, M. Hynes, M. Paoletti, R. Fischer, B. Miller, P. Dyer, M. S. Sachs, S. A. Osmani, and B. W. Birren. 2005. Sequencing of Aspergillus nidulans and comparative analysis with A. fumigatus and A. oryzae. Nature 438:1105-1115.

18. Birren, B. W., E. S. Lander, J. E. Galagan, C. Nusbaum, K. Devon, M. Henn, L. J. Ma, D. B. Jaffe, J. Butler, P. Alvarez, S. Gnerre, M. Grabherr, M. Kleber, E. W. Mauceli, W. Brockman, S. Rounsley, S. K. Young, K. LaButti, and K. Madden. 2005. Annotation of the Aspergillus terreus NIH264 genome. EMBL/GenBank/DDBJ databases.

19. Fedorova, N. D., N. Khaldi, V. S. Joardar, R. Maiti, P. Amedeo, M. J. Anderson, J. Crabtree, J. C. Silva, J. H. Badger, A. Albarraq, S. Angiuoli, H. Bussey, P. Bowyer, P. J. Cotty, P. S. Dyer, A. Egan, K. Galens, C. M. Fraser-Liggett, B. J. Haas, J. M. Inman, R. Kent, S. Lemieux, I. Malavazi, J. Orvis, T. Roemer, C. M. Ronning, J. P. Sundaram, G. Sutton, G. Turner, J. C. Venter, O. R. White, B. R. Whitty, P. Youngman, K. H. Wolfe, G. H. Goldman, J. R. Wortman, B. Jiang, D. W. Denning, and W. C. Nierman. 2008. Genomic islands in the pathogenic filamentous fungus Aspergillus fumigatus. PLoS Genet 4:e1000046.

20. Machida, M., K. Asai, M. Sano, T. Tanaka, T. Kumagai, G. Terai, K. Kusumoto, T. Arima, O. Akita, Y. Kashiwagi, K. Abe, K. Gomi, H. Horiuchi, K. Kitamoto, T. Kobayashi, M. Takeuchi, D. W. Denning, J. E. Galagan, W. C. Nierman, J. Yu, D. B. Archer, J. W. Bennett, D. Bhatnagar, T. E. Cleveland, N. D. Fedorova, O. Gotoh, H. Horikawa, A. Hosoyama, M. Ichinomiya, R. Igarashi, K. Iwashita, P. R. Juvvadi, M. Kato, Y. Kato, T. Kin, A. Kokubun, H. Maeda, N. Maeyama, J. Maruyama, H. Nagasaki, T. Nakajima, K. Oda, K. Okada, I. Paulsen, K. Sakamoto, T. Sawano, M. Takahashi, K. 
Takase, Y. Terabayashi, J. R. Wortman, O. Yamada, Y. Yamagata, H. Anazawa, Y. Hata, Y. Koide, T. Komori, Y. Koyama, T. Minetoki, S. Suharnan, A. Tanaka, K. Isono, S. Kuhara, N. Ogasawara, and H. Kikuchi. 2005. Genome sequencing and analysis of Aspergillus oryzae. Nature 438:1157-1161.

21. van den Berg, M. A., R. Albang, K. Albermann, J. H. Badger, J. M. Daran, A. J. Driessen, C. Garcia-Estrada, N. D. Fedorova, D. M. Harris, W. H. Heijne, V. Joardar, J. A. Kiel, A. Kovalchuk, J. F. Martin, W. C. Nierman, J. G. Nijland, J. T. Pronk, J. A. Roubos, I. J. van der Klei, N. N. van Peij, M. Veenhuis, H. von Dohren, C. Wagner, J. Wortman, and R. A. Bovenberg. 2008. Genome sequencing and analysis of the filamentous fungus Penicillium chrysogenum. Nat Biotechnol 26:1161-1168.

22. Venyaminov, S. Y., and K. S. Vassilenko. 1994. Determination of protein tertiary structure class from circular dichroism spectra. Anal Biochem 222:176-184.

23. Thompson, J. D., D. G. Higgins, and T. J. Gibson. 1994. CLUSTAL W: improving the sensitivity of progressive multiple sequence alignment through sequence weighting, position-specific gap penalties and weight matrix choice. Nucleic Acids Res 22:46734680.

24. Schmidt, T. G., J. Koepke, R. Frank, and A. Skerra. 1996. Molecular interaction between the Strep-tag affinity peptide and its cognate target, streptavidin. J Mol Biol 255:753-766.

25. Schmidt, T. G., and A. Skerra. 1994. One-step affinity purification of bacterially produced proteins by means of the "Strep tag" and immobilized recombinant core streptavidin. J Chromatogr A 676:337-345.

26. Schmidt, T. G., and A. Skerra. 2007. The Strep-tag system for one-step purification and high-affinity detection or capturing of proteins. Nat Protoc 2:1528-1535.

27. Skerra, A., and T. G. Schmidt. 1999. Applications of a peptide ligand for streptavidin: the Strep-tag. Biomol Eng 16:79-86.

28. Skerra, A., and T. G. Schmidt. 2000. Use of the Strep-Tag and streptavidin for detection and purification of recombinant proteins. Methods Enzymol 326:271-304.

29. Barloy, F., M. M. Lecadet, and A. Delecluse. 1998. Cloning and sequencing of three new putative toxin genes from Clostridium bifermentans CH18. Gene 211:293-299.

30. Rao, J., A. DiGiandomenico, J. Unger, Y. Bao, R. K. Polanowska-Grabowska, and J. B. Goldberg. 2008. A novel oxidized low-density lipoprotein-binding protein from Pseudomonas aeruginosa. Microbiology 154:654-665.

31. Sakurai, N., J. Kaneko, Y. Kamio, and T. Tomita. 2004. Cloning, expression, and poreforming properties of mature and precursor forms of pleurotolysin, a sphingomyelinspecific two-component cytolysin from the edible mushroom Pleurotus ostreatus. Biochim Biophys Acta 1679:65-73.

32. Tomita, T., K. Noguchi, H. Mimuro, F. Ukaji, K. Ito, N. Sugawara-Tomita, and Y. Hashimoto. 2004. Pleurotolysin, a novel sphingomyelin-specific two-component cytolysin from the edible mushroom Pleurotus ostreatus, assembles into a transmembrane pore complex. J Biol Chem 279:26975-26982.

33. Geiser, D. M., M. A. Klich, J. C. Frisvad, S. W. Peterson, J. Varga, and R. A. Samson. 2007. The current status of species recognition and identification in Aspergillus. Stud Mycol 59:1-10.

34. Rokas, A., G. Payne, N. D. Fedorova, S. E. Baker, M. Machida, J. Yu, D. R. Georgianna, R. A. Dean, D. Bhatnagar, T. E. Cleveland, J. R. Wortman, R. Maiti, V. Joardar, P. 
Amedeo, D. W. Denning, and W. C. Nierman. 2007. What can comparative genomics tell us about species concepts in the genus Aspergillus? Stud Mycol 59:11-17.

35. Kelley, L. A., and M. J. Sternberg. 2009. Protein structure prediction on the Web: a case study using the Phyre server. Nat Protoc 4:363-371.

36. Marchler-Bauer, A., J. B. Anderson, M. K. Derbyshire, C. DeWeese-Scott, N. R. Gonzales, M. Gwadz, L. Hao, S. He, D. I. Hurwitz, J. D. Jackson, Z. Ke, D. Krylov, C. J. Lanczycki, C. A. Liebert, C. Liu, F. Lu, S. Lu, G. H. Marchler, M. Mullokandov, J. S. Song, N. Thanki, R. A. Yamashita, J. J. Yin, D. Zhang, and S. H. Bryant. 2007. CDD: a conserved domain database for interactive domain family analysis. Nucleic Acids Res 35:D237-240.

37. Vesper, S. J., M. L. Magnuson, D. G. Dearborn, I. Yike, and R. A. Haugland. 2001. Initial characterization of the hemolysin stachylysin from Stachybotrys chartarum. Infect Immun 69:912-916.

38. Donohue, M., W. Wei, J. Wu, N. H. Zawia, N. Hud, V. De Jesus, D. Schmechel, J. M. Hettick, D. H. Beezhold, and S. Vesper. 2006. Characterization of nigerlysin, hemolysin produced by Aspergillus niger, and effect on mouse neuronal cells in vitro. Toxicology 219:150-155.

39. Donohue, M., Y. Chung, M. L. Magnuson, M. Ward, M. J. Selgrade, and S. Vesper. 2005. Hemolysin chrysolysin from Penicillium chrysogenum promotes inflammatory response. Int J Hyg Environ Health 208:279-285.

40. Gonzalez, M. R., M. Bischofberger, L. Pernot, F. G. van der Goot, and B. Freche. 2008. Bacterial pore-forming toxins: the (w)hole story? Cell Mol Life Sci 65:493-507.

41. Berne, S., K. Sepcic, G. Anderluh, T. Turk, P. Macek, and N. Poklar Ulrih. 2005. Effect of $\mathrm{pH}$ on the pore forming activity and conformational stability of ostreolysin, a lipid raft-binding protein from the edible mushroom Pleurotus ostreatus. Biochemistry 44:11137-11147.

42. Kelley, L. A., R. M. MacCallum, and M. J. Sternberg. 2000. Enhanced genome annotation using structural profiles in the program 3D-PSSM. J Mol Biol 299:499-520.

43. Shimada, Y., M. Nakamura, Y. Naito, K. Nomura, and Y. Ohno-Iwashita. 1999. Cterminal amino acid residues are required for the folding and cholesterol binding property of perfringolysin O, a pore-forming cytolysin. J Biol Chem 274:18536-18542.

44. Tobkes, N., B. A. Wallace, and H. Bayley. 1985. Secondary structure and assembly mechanism of an oligomeric channel protein. Biochemistry 24:1915-1920.

45. Poklar, N., J. Volker, G. Anderluh, P. Macek, and T. V. Chalikia. 2001. Acid- and baseinduced conformational transitions of equinatoxin II. Biophys Chem 90:103-121.

46. Ulrih, N. P., G. Anderluh, P. Macek, and T. V. Chalikian. 2004. Salt-induced oligomerization of partially folded intermediates of equinatoxin II. Biochemistry 43:9536-9545.

47. Berne, S., J. Pohleven, I. Vidic, K. Rebolj, F. Pohleven, T. Turk, P. Macek, A. Sonnenberg, and K. Sepcic. 2007. Ostreolysin enhances fruiting initiation in the oyster mushroom (Pleurotus ostreatus). Mycol Res 111:1431-1436.

48. Sakaguchi, O., K. Yokota, and A. Kamaguchi. 1977. [Studies on the toxin of Aspergillus fumigatus. VIII. Biological properties of Asp-hemolysin (author's transl)]. Nippon Saikingaku Zasshi 32:821-828. 
49. Chowdhury, H. H., K. Rebolj, M. Kreft, R. Zorec, P. Macek, and K. Sepcic. 2008. Lysophospholipids prevent binding of a cytolytic protein ostreolysin to cholesterolenriched membrane domains. Toxicon 51:1345-1356.

50. Kudo, Y., T. Ootani, T. Kumagai, Y. Fukuchi, K. Ebin, and K. Yokota. 2002. A novel oxidized low-density lipoprotein-binding protein, Asp-hemolysin, recognizes lysophosphatidylcholine. Biol Pharm Bull 25:787-790.

51. Kumagai, T. 2006. [Biological activity of Asp-hemolysin as a regulation factor to atherogenic effect by oxidized low-density lipoprotein]. Yakugaku Zasshi 126:955-964.

52. Kumagai, T., N. Ogawa, H. Tsutsumi, K. Ebina, and K. Yokota. 2005. A synthetic peptide (P-21) derived from asp-hemolysin inhibits the induction of macrophage proliferation by oxidized low-density lipoprotein. Biol Pharm Bull 28:1381-1384.

53. Vojdani, A. 2005. Antibodies against Stachybotrys chartarum extract and its antigenic components, Stachyhemolysin and Stachyrase-A: a new clinical biomarker. Med Sci Monit 11:BR139-145. 


\section{CHAPTER 5}

Development of monoclonal antibodies to recombinant terrelysin and characterization of terrelysin expression in Aspergillus terreus 


\subsection{INTRODUCTION}

Hemolysins have been suggested to play a key role in pathogenesis by lysing host cell membranes, which assists in causing infection (1-3). However, less is understood about the biological relevance of these hemolytic proteins in fungi. Fungal hemolysins have been studied for a few decades for their role as virulence factors (4-7), their lipoprotein-binding properties (8, 9) and utility as unique markers of micro-domains on eukaryotic cell membranes $(10,11)$. Plants, animals and humans are opportunistic hosts of the fungus and these hemolytic proteins may have distinct functions in fungal biology in nature. Their hemolytic activity and other cytotoxic properties associated with host factors may only be coincidental. Some studies have earlier reported involvement of these hemolysins in the morphology and development of fungi especially mushrooms $(12,13)$. However, limited information is currently available on expression and localization of these hemolysins in filamentous fungi, which may be essential in ascertaining a role for these proteins in fungal biology.

In our previous work we attempted to develop mAbs to fungal hemolysins using partially purified hemolytic preparations. This lead to identification of multiple proteins in the preparation and we identified some of these proteins to be proteolytic enzymes. In our effort to study the specific hemolysin of A. terreus, terrelysin, we cloned the gene for terrelysin and expressed the protein in E. coli. The recombinant rTerrelysin was purified and used in production of monoclonal antibodies (mAbs) for characterization of expression of terrelysin by A. terreus and development of immunoassays for detection of terrelysin as a surrogate biomarker for exposure to A. terreus.

In this report we describe the generation of monoclonal antibodies (mAbs) to terrelysin, their purification and characterization of kinetics of native terrelysin expression by A. terreus. 
We will also use these tools to study the localization of terrelysin within the fungal hyphae and conidia. This will help in suggesting putative functions for these proteins in fungi.

\subsection{METHODS AND MATERIALS}

5.2.1 Production of monoclonal antibodies against rTerrelysin- Three 8-10 week old BALB/c mice (The Jackson Laboratory, Bar Harbor, ME) were housed in the animal facility at the National Institute for Occupational Safety and Health (NIOSH), Morgantown, WV. The facility is accredited by the Association for Assessment and Accreditation of Laboratory Animal Care International (AAALAC) and animals were free of viral pathogens, parasites, mycoplasma, and Helicobacter spp. Animals were housed together in a HEPA-filtered ventilated polycarbonate cages on autoclaved hardwood Beta-chip bedding with cotton fiber nesting material. The animals were provided with Teklad 7913 rodent chow (Harlan Laboratories, Madison, WI) and autoclaved tap water ad libitum. All animal procedures and immunizations were reviewed and approved by the NIOSH Animal Care and Use Committee (ACUC).

Prior to immunization, blood samples were collected from the tail vein and the serum was stored at $-20^{\circ} \mathrm{C}$. Each animal was immunized 3 times, every other week with $25 \mu \mathrm{g}$ of purified rTerrelysin emulsified (50\% v/v) in TiterMax® (TiterMax USA, Norcross, GA) adjuvant. The mice were monitored for adverse health effects post immunizations. Between immunizations, serum was collected from the tail vein to monitor for rTerrelysin-specific IgG antibody response.

Following the development of sufficient IgG titers, the animals were euthanized by $\mathrm{CO}_{2}$ asphyxiation. The spleen was aseptically removed from each mouse and single cell suspensions of the splenocytes produced. Fusion of splenocytes with SP2/0-Ag 14 myeloma cells (ATCC\# CRL-1581) was performed as previously described (14). Hybridomas were selected by growing 
cells in Dulbecco's Modified Eagle Medium (DMEM) (Life Technologies, Rockville, MD) supplemented with $1 \mathrm{mM}$ sodium pyruvate, $100 \mathrm{U} / \mathrm{ml}$ penicillin, $100 \mathrm{mg} / \mathrm{ml}$ streptomycin, 0.292 $\mathrm{mg} / \mathrm{ml} \mathrm{L}$-glutamine, $100 \mathrm{mM}$ sodium hypoxanthine, $16 \mathrm{mM}$ thymidine, $10 \%$ fetal calf serum (FCS) (HyClone, Logan, UT), and 100 U/ml IL-6 (Boerhinger, Mannheim, Germany). DMEM was also supplemented with azaserine for selective propagation of hybridomas. After 10-14 days of growth, medium from individual wells with growth of hybridoma cells was replenished with fresh DMEM medium. The supernatants from individual hybridoma colonies were tested in ELISA to detect presence of antibodies specific to rTerrelysin.

Supernatants of individual clones were tested twice to confirm reactivity of antibodies. Hybridomas from each positive well was further cloned, twice by limiting dilution analysis and single positive clones were screened and selected for production of large quantities of mAbs. Positive clones were frozen in $10 \%$ dimethyl sulfonic acid (DMSO) and stored at $-80^{\circ} \mathrm{C}$ for 2 weeks and later transferred to liquid nitrogen facility for long-term storage.

\subsubsection{Production, isotyping and quantification of rTerrelysin mAbs- All rTerrelysin mAbs} were concentrated and partially purified by ammonium sulfate precipitation as described previously (15). Briefly, mAb supernatant collected from individual hybridomas was centrifuged at $20,000 \mathrm{~g}$ for $30 \mathrm{~min}$ at $4^{\circ} \mathrm{C}$. The supernatant was collected and saturated ammonium sulfate was slowly added to the supernatant to $45 \%(\mathrm{v} / \mathrm{v})$ and incubated for $8-10 \mathrm{hrs}$ at $4{ }^{\circ} \mathrm{C}$. The tubes were centrifuged for 45 mins at $20,000 \mathrm{~g}$ at $4^{\circ} \mathrm{C}$ and the precipitate was collected and resuspended in PBS, pH 7.4. Concentration of purified antibodies and their isotype were determined using methods described earlier. 
5.2.3 Fungal cultures and extracts- For time point assay, fungal cultures were grown by inoculating $50 \mathrm{ml}$ minimal medium containing glucose, nitric salts and trace elements with $2.5 \mathrm{x}$ $10^{7}$ A. terreus viable conidia. Viability was determined using LIVE/DEAD® BacLight ${ }^{\mathrm{TM}}$ Viability kit (Molecular Probes, Inc., Eugene, OR) as described previously (16). Following inoculation, flasks were incubated at either $\mathrm{RT}$ or at $37^{\circ} \mathrm{C}$ depending on the specific experimental design. A. terreus cultures were grown for 12 days with an individual flask representing a $24 \mathrm{hr}$ time point were collected each day. A. terreus culture and mycelial pellets were collected in $50 \mathrm{ml}$ tubes and centrifuged at $4100 \mathrm{~g}$ for 10 mins. The culture supernatant (CSN) and mycelial pellets were collected and stored at $-80^{\circ} \mathrm{C}$ and the lyophilized CSN residue was resuspended in PBS, and mycelial pellets were processed using a mortar and pestle with PBS containing Complete Mini Protease Inhibitor Cocktail (Roche Diagnostics, Indianapolis, IN). Mycelial slurry was then collected into $15 \mathrm{ml}$ polypropylene tubes and incubated at $4^{\circ} \mathrm{C}$ overnight on a shaker to facilitate the release of intracellular proteins into the lysis solution. The next day, mycelial extracts (ME) were centrifuged at $4100 \mathrm{~g}$ for 10 mins and the supernatant collected and stored at $-20^{\circ} \mathrm{C}$ until analysis.

For cross-reactivity studies, ME were prepared from 29 different fungal species including 12 different Aspergillus species using the same method (Table 1.) Fungi were grown till mycelial pellets had formed (3-4) days. Protein concentrations of CSN and ME were estimated using NanoDrop ND-1000 Spectrophotometer (NanoDrop Technologies, Thermo Scientific, Wilmington, DE). 
5.2.4 ELISA methods- Screening $m A b s$. Hybridomas producing anti-rTerrelysin mAbs were identified by indirect ELISA. In brief, 96-well Immuno MaxiSorp microplates (Nunc, Rochester, $\mathrm{NY})$ were coated with rTerrelysin $(1 \mu \mathrm{g} / \mathrm{ml})$ in $0.05 \mathrm{M}$ carbonate coating buffer $\mathrm{pH} 9.6(\mathrm{CCB})$, and blocked with phosphate buffered saline (PBS) containing 0.5\% Tween-20 and 5\% nonfat dry milk (PBSTM) for $1 \mathrm{hr}$. CSN from each hybridoma was incubated in duplicate wells for $1 \mathrm{hr}$ at $37^{\circ} \mathrm{C}$, washed with PBS containing 0.5\% Tween-20 (PBST), and detected using alkaline phosphatase conjugated goat-anti mouse IgG antibody $(\mathrm{H}+\mathrm{L})$ (Promega, Madison, WI) diluted 1:5000 in PBSTM for $1 \mathrm{hr}$ at $37^{\circ} \mathrm{C}$. The wells were then washed in PBST and developed for 30 min using 4-paranitrophenyl phosphate substrate (Sigma). Reactivity was determined by measuring the optical density (OD) at $405 \mathrm{~nm}$. TO compare the reactivity of identified mAbs, each $\mathrm{mAb}$ was purified and used at a concentration of $1 \mu \mathrm{g} / \mathrm{ml}$ and assayed with various dilutions of rTerrelysin bound to the assay plate. The plates were washed 3 times between individual steps of incubation with PBST.

Inhibition ELISA for analysis of kinetics of terrelysin expression. An inhibition ELISA was performed over a period of 2 days. On day 1 , the 'assay plate' was coated with $0.1 \mu \mathrm{g} / \mathrm{ml}$ of rTerrelysin and a second plate 'inhibition plate' was blocked overnight with PBSTM to prevent protein binding. On day 2 , both plates were washed with PBST and the 'assay plate' was blocked with PBSTM at RT for 2 hrs. In the inhibition plate, serial dilutions of ME and CSN samples (protein concentration range $5 \mathrm{mg} / \mathrm{ml}-0.078 \mathrm{mg} / \mathrm{ml}$ ) and serially diluted rTerrelysin standard time points (days 1-12). Standards were set up by serial dilution of rTerrelysin (protein concentration range $1 \mathrm{mg} / \mathrm{ml}-78 \mu \mathrm{g} / \mathrm{ml}$ ) were incubated with $40 \mathrm{ng} / \mathrm{ml}$ of anti-terrelysin mAb 10G4. Negative control wells were incubated with PBS and positive control wells were incubated with mAb 10G4 alone. The inhibition plate was incubated on a shaker at RT for $1 \mathrm{hr}$ at $200 \mathrm{rpm}$ and for 30 
min without shaking. Next, the assay plates were washed and incubated with $100 \mu$ of reaction mixture from the inhibition plate at $37^{\circ} \mathrm{C}$ for $1 \mathrm{hr}$. Plates were washed and incubated with alkaline phosphatase conjugated goat anti-mouse IgG antibody $(\mathrm{H}+\mathrm{L})$ diluted 1:5000 in PBSTM for $1 \mathrm{hr}$ at $37^{\circ} \mathrm{C}$. Plates were washed and developed using 4-paranitrophenyl phosphate substrate. Reactivity was measured at OD at $405 \mathrm{~nm}$ and terrelysin concentrations were determined for each sample by comparing to the standard curve using regression analysis.

\subsubsection{Western blot analysis of rTerrelysin and fungal ME- Reactivity to rTerrelysin and} native terrelysin. Pooled polyclonal sera collected each immunized mouse was tested using Western blot with rTerrelysin and A. terreus ME. A. terreus ME was collected from 3 days old cultures grown in TSB for $72 \mathrm{hrs}$ at RT. rTerrelysin (50 ng) and A. terreus ME (25 $\mu \mathrm{g})$ were separated using a $12 \%$ acrylamide gel and transferred to a nitrocellulose membrane. The membrane was blocked for $1 \mathrm{hr}$ in PBST containing 3\% bovine serum albumin (BSA) (PBSTB) and incubated with anti-rTerrelysin pooled polyclonal sera (1/2000 v/v) in PBSTB for $1 \mathrm{hr}$ at RT. The membrane was washed 3 times with PBST and then incubated with alkaline phosphatase conjugated goat anti-mouse IgG. The membrane was washed again and immunoreactive proteins were detected using the chromogenic substrate NBT/BCIP (Promega, Madison, WI).

Western blot analysis was performed for screening individual mAbs reactivity to rTerrelysin, native terrelysin (A. terreus CSN and ME extracts), and for cross-reactivity analysis. rTerrelysin $(500 \mathrm{ng} / \mathrm{ml})$ and $\mathrm{ME}(2.5 \mathrm{mg} / \mathrm{ml})$ collected from day 4 culture of A. terreus were individually separated by performing SDS-PAGE on a $12 \%$ polyacrylamide gel. For crossreactivity testing, $\mathrm{ME}(2.5 \mathrm{mg} / \mathrm{ml})$ from 29 different fungal species were separated on $12 \%$ polyacrylamide gels. Proteins were transferred overnight to nitrocellulose membranes $(0.22 \mu \mathrm{m}$, 
BioRad) and the membranes were blocked using Tris-buffered saline (TBS) containing $0.1 \%$ Tween-20 (TBST) and 3\% bovine serum albumin (blocking buffer). Membranes were washed with TBST and transferred to a BIO-RAD Multi Screen apparatus (BioRad, Hercules, CA). Individual lanes were incubated with $1 \mu \mathrm{g} / \mathrm{ml}$ of mAbs diluted in blocking buffer and incubated on a rocker for $1 \mathrm{hr}$. Membranes were washed 3X with TBST, and incubated with alkaline phosphatase-conjugated goat anti-mouse $\operatorname{IgG}$ antibody $(\mathrm{H}+\mathrm{L})$ diluted 1:5000 in blocking buffer for $1 \mathrm{hr}$ on a rocker. Membranes were then washed with TBST and developed for 15-20 mins using 1-Step NBT/BCIP (Promega, Madison, WI) substrate solution. The reaction was stopped by washing the membranes with distilled water.

5.2.6 Epitope mapping- Epitope mapping was performed using synthetic peptides synthesized by Sigma Genosys (JPT Peptide Technologies GmbH, Berlin, Germany) using methods previously described (17). For peptide scans, 68 peptides spanning the entire rTerrelysin (including the Strep-tag II sequence) were synthesized as linear decapeptides overlapping by 2 amino acids. Peptides were covalently bound to a Whatman 50 cellulose support (PepSpots membrane) at the $\mathrm{C}$-terminus and $\mathrm{N}$-terminus of peptides was acetylated for higher stability. The membranes were processed for epitope mapping per the manufacturer's instructions.

In brief, the PepSpots membrane was rinsed in methanol for 5 mins, washed $3 \mathrm{X}$ with TBS for 10 mins, blocked overnight at $4^{\circ} \mathrm{C}$ on a shaker with TBS containing 3\% BSA. The membrane was incubated with $5 \mu \mathrm{g} / \mathrm{ml}$ of rTerrelysin mAbs for $3 \mathrm{hrs}$ at RT on a shaker. The $\mathrm{mAb} 9 \mathrm{~B} 4$, an $\mathrm{IgG}_{1}$ isotype, which recognizes a Stachybotrys chartarum conidial surface protein served as a negative control. The membrane was washed in TBST $3 \mathrm{X}$ for 5 min each and then incubated with goat anti-mouse $\operatorname{IgG}$ horseradish peroxidase (HRP) conjugated antibody 
(Promega, Madison, WI) diluted 1:50,000 in blocking buffer for $1 \mathrm{hr}$ at RT on shaker. The membrane was washed thoroughly in TBST $3 \mathrm{X}$ for 5 mins each and developed with ECL Western blotting substrate (Promega) as per manufacturer's instructions. After a brief incubation, excess substrate was discarded and the membrane was exposed to CL-XPosure ${ }^{\mathrm{TM}}$ clear blue XRay film (Thermo Scientific, Rockford, IL) and developed using a SRX-101A tabletop processor (Konica Minolta, Ramsey, New Jersey). For regeneration, the PepSpots membrane was washed twice with water for 10 mins each and then incubated with regeneration buffer I (62.5 mM TRIS containing 2\% SDS, $\mathrm{pH} 6.7 ; 100 \mathrm{mM}$ 2-mercaptoethanol) at $50^{\circ} \mathrm{C}$ using four $30 \mathrm{mins}$ incubations. The membranes were washed 3X for 20 mins with PBS (10X), 3X with TBST for 20 mins and $3 \mathrm{X}$ with TBS for 10 mins at RT. The membrane was analyzed to ensure efficient removal of bound primary and secondary antibodies prior to analysis of new mAbs.

\subsubsection{Microscopic examination of A. terreus morphological changes- In order to correlate} the expression of terrelysin to associated growth changes in A. terreus, we cultivated A. terreus in 24-well plates containing $2 \mathrm{ml}$ of minimal medium. Wells were incubated with 1 x $10^{6}$ viable A. terreus conidia and incubated on a shaker at either RT or $37^{\circ} \mathrm{C}$. Growth of $A$. terreus was monitored at various time points using Olympus IX70 microscope (Olympus Corporation, Tokyo, Japan) and images were captured using a QImaging Retiga 2000R Fast camera (QImaging, Surrey, Canada) and processed using the SimplePCI6 software (Hamamatsu Corporation, Sewickley, PA). 


\subsubsection{Confocal Scanning Laser Microscopy (CSLM) analysis for localization of native}

terrelysin in A. terreus- Immunolocalization of terrelysin was studied using a slight modification of previously described methods $(18,19)$. Briefly, A. terreus FGSC 1156 cultures were grown on alcohol-sterilized cover slips in 6-well tissue culture plates that contained minimal medium. Cultures were incubated at $37^{\circ} \mathrm{C}$ under static conditions for $24 \mathrm{hrs}$. Cover slips were fixed with $8 \%$ formalin buffered saline containing $50 \mathrm{mM}$ PIPES (pH 6.7), $25 \mathrm{mM}$ EGTA, $1 \%$ dimethyl sulfoxide (DMSO) and $5 \mathrm{mM} \mathrm{MgSO}_{4}$ for $1 \mathrm{hr}$ at $\mathrm{RT}$ and the cover slips were then rinsed with MTSB (50 mM PIPES (pH 6.7), $5 \mathrm{mM}$ EGTA and $5 \mathrm{mM} \mathrm{MgSO}_{4}$ ). Cell wall digestion was carried out for $1 \mathrm{hr}$ at RT with an enzyme solution containing $2.5 \%$ Driselase ${ }^{\circledR}$ (Sigma, St. Louis, MO), 1\% lysozyme from chicken egg white (Sigma) and 2 mM EGTA. Cells were rinsed with $\mathrm{H}_{2} \mathrm{O}$ and then treated with $0.1 \%$ Triton X-100 in TBS pH 7.4 for 10 mins. Cells were then rinsed in MTSB and TBS once each. Cells were blocked with 3\% bovine serum albumin in TBS (TBSB) overnight at $4^{\circ} \mathrm{C}$ with gentle shaking. Next, the cover slips were incubated with mAb 15B5 at $3 \mu \mathrm{g} / \mathrm{ml}$ in TBSB for $3 \mathrm{hrs}$ with gentle shaking. mAb 9B4 (S. chartarum conidial surface protein) served as a negative control (20). mAb 13E11 described earlier in chapter 3 , and reacts with hyphal exoantigen leucine aminopeptidase from A. terreus served as a positive control. Cells were washed thoroughly in TBS containing $0.05 \%$ Tween 20 (TBST) and stained with AlexaFluor ${ }^{\circledR} 594$ conjugated goat anti-mouse $\operatorname{IgG}(\mathrm{H}+\mathrm{L})$ (Molecular Probes Inc., Eugene, OR) diluted 1:50 in TBSB for $1 \mathrm{hr}$ at RT. Cells were washed in TBST and cover slips were placed on clean slides with ProLong® Antifade Reagent with DAPI (Molecular Probes Inc.). Cells were observed with a Zeiss LSM-510 Meta Confocal Microscope System (Axioplan 2 Stand) (Carl Zeiss, Thornwood, NY) and the images were acquired with Zeiss 
software version 3.2 (Carl Zeiss). All settings on the confocal laser microscope remained constant throughout the analysis.

\subsection{RESULTS}

5.3.1 Isotyping and sensitivity screening of rTerrelysin mAbs- Mice immunized with rTerrelysin developed detectable specific IgG after the first immunization that increased with subsequent immunizations. Thirty-two hybridomas recognized rTerrelysin during the initial screening. Sixteen clones survived the multiple cloning steps and were further analyzed in screening, cross-reactivity, and immunolocalization experiments. Nine clones (2G4, 3B2, 6D2, 7D8, 13G10, 15B5, 16C7, 9F4, 19E3) produced $\mathrm{IgG}_{1}$ isotype mAbs, 4 (3B7, 10G4, 15C5, 15E4) produced $\mathrm{IgG}_{2 \mathrm{a}}$ isotype $\mathrm{mAbs}$ and $3(6 \mathrm{E} 4,10 \mathrm{G} 7,2 \mathrm{D} 3)$ produced $\mathrm{IgG}_{2 \mathrm{~b}}$ isotype $\mathrm{mAbs}$. The $\mathrm{mAbs}$ exhibited variable reactivity to immobilized rTerrelysin in ELISA (Fig. 5.1). mAbs 2G4, 9F4, $19 \mathrm{E} 3,6 \mathrm{E} 4$ and $15 \mathrm{E} 4$ showed least reactivity $\left(\leq 0.25 \mathrm{OD}_{405}\right.$ value) to rTerrelysin (data not shown). mAbs 3B2, 6D2, 7D8 and 16C7 showed moderate reactivity (Fig. 5.1a), while mAbs 13G10, 15B5, 3B7, 10G4, 15C5, 10G7 and 2D3 showed highest reactivity to rTerrelysin (Fig. 5.1b). 


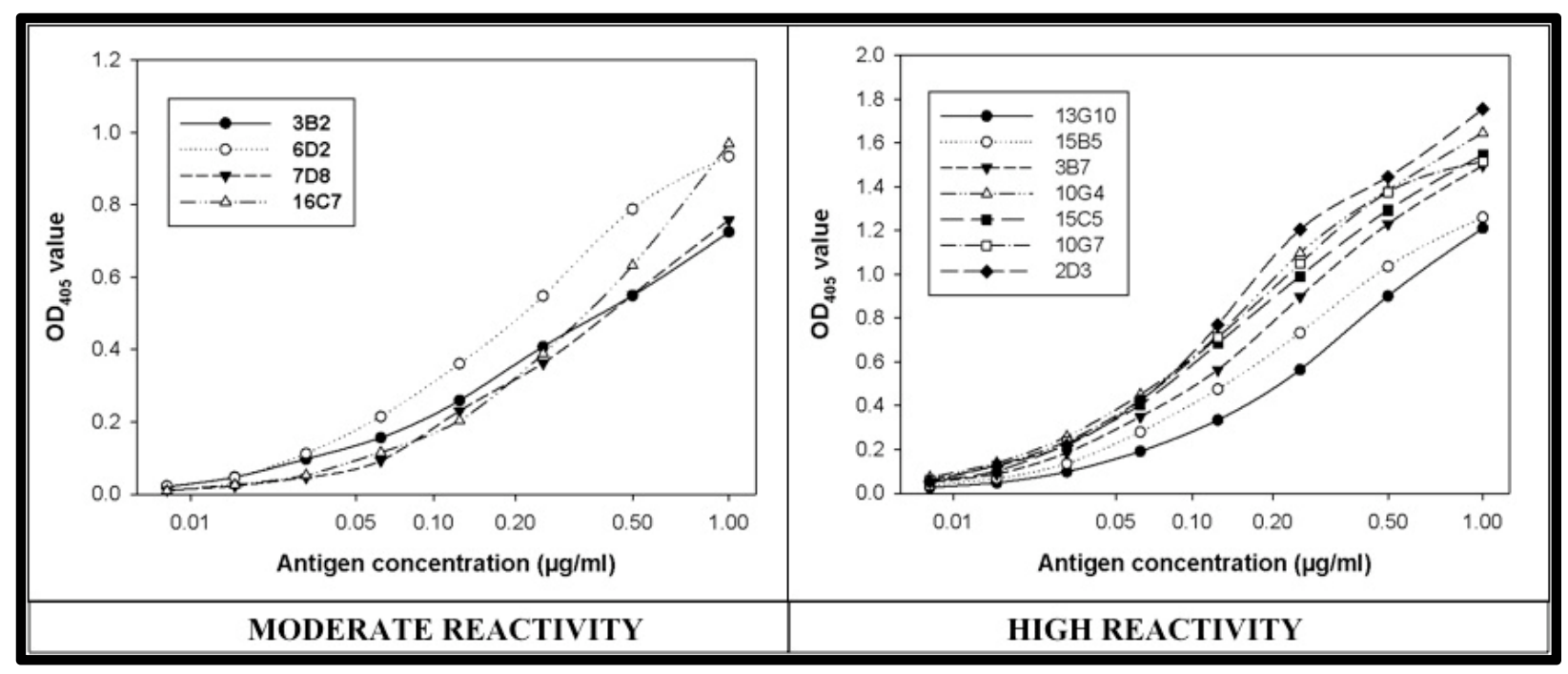

Fig 5.1. Reactivity of mAbs to rTerrelysin. Moderate reactivity is defined as $\leq 1.0\left(O D_{405}\right.$ value $)$ in assay with 1 $\mu \mathrm{g} / \mathrm{ml}$ of $\mathrm{mAb}$ concentration. High reactivity is defined as $\geq 1.0\left(O D_{405}\right.$ value $)$ in assay with $1 \mu \mathrm{g} / \mathrm{ml}$ of $\mathrm{mAb}$ concentration. 


\subsubsection{Western blot reactivity of pooled sera and mAbs to rTerrelysin and native}

terrelysin- Pooled sera from mice immunized with rTerrelysin was used to confirm the presence of immunoreactive terrelysin in extracts from the mycelia of A. terreus (Fig. 5.2). Western blot analysis revealed reactivity to denatured rTerrelysin $(16.5 \mathrm{kDa})$ for 11 of the $16 \mathrm{mAbs}$ (Fig. 5.3a). The higher molecular weight bands observed in the lanes with purified rTerrelysin are likely to be aggregates formed during the storage of the protein at $-20^{\circ} \mathrm{C}$. For native terrelysin, 4 of the $11 \mathrm{mAbs}(3 \mathrm{~B} 2,6 \mathrm{D} 2,16 \mathrm{C} 7$ and 2D3) did not show any reactivity with A. terreus ME (Fig. 5.3b). Seven mAbs (7D8, 13G10, 15B5, 3B7, 10G4, 15C5, and 10G7) reacted to a putative native terrelysin in ME and were chosen for further study. 


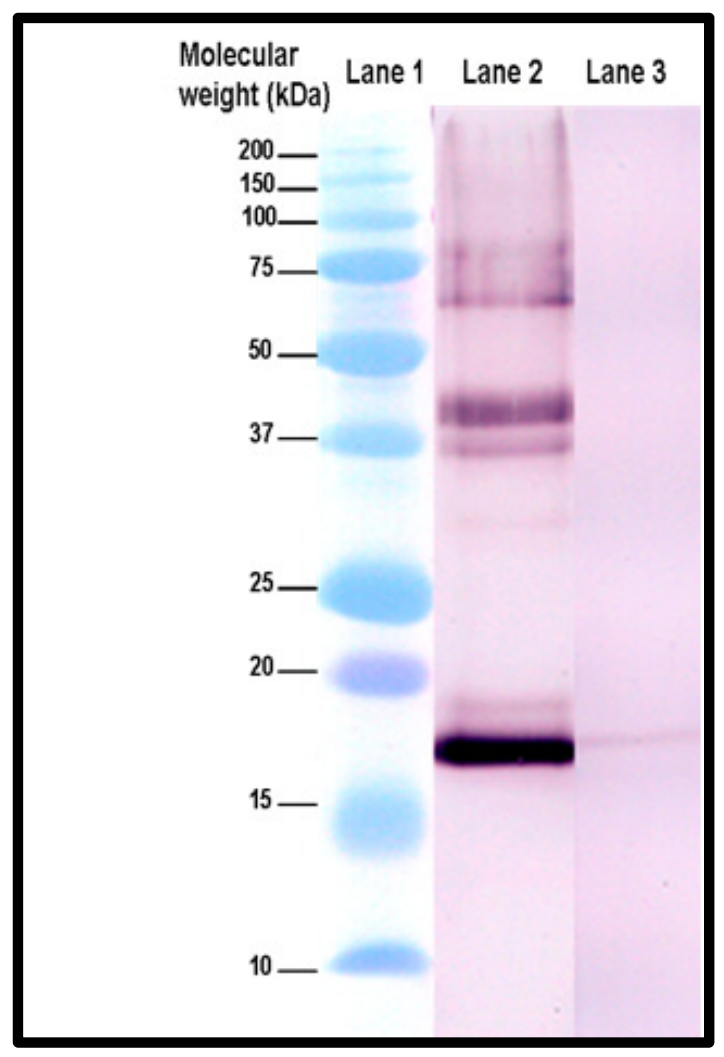

Fig 5.2. Western blot analysis with pooled sera. Lane 1: Molecular weight marker, Lane 2: rTerrelysin and Lane 3: mycelial extract from $72 \mathrm{hr}$ old culture of A. terreus. 
5.3.3 Cross-reactivity and strain variations- Five strains of A. terreus including the pathogenic strain FGSC 1156 and the commonly used environmental strain ATCC 1012 were analyzed with each mAb by Western blot. All mAbs, except 7D8, exhibited reactivity to a protein of the same molecular weight in ME derived from all strains (Table 5.1). Interestingly, the mAb 7D8 reacted to ME from 3 strains but 2 strains (NIOSH 17-30-31 and NIOSH 35-0806) did not react.

ME from 11 other Aspergillus species including the pathogens A. fumigatus, A. flavus, A. nidulans and A. niger were also tested. mAb 15C5 showed maximum cross-reactivity among the mAbs tested, exhibiting cross-reactivity to ME from 6 different fungi, including A. nidulans and A. parasiticus. mAb $10 \mathrm{G} 7$ did not cross-react with any tested Aspergillus species tested here, but it did react to $\mathrm{ME}$ from E. rostratum, P. variotii and T. harzianum. mAb 3B7 cross-reacted to ME from C. cladosporioides. No cross-reactivity was observed with any mAbs against ME from 4 different Penicillium species. 4 mAbs (7D8, 13G10, 15B5 and 10G4) did cross-react with any of the tested fungal species. 


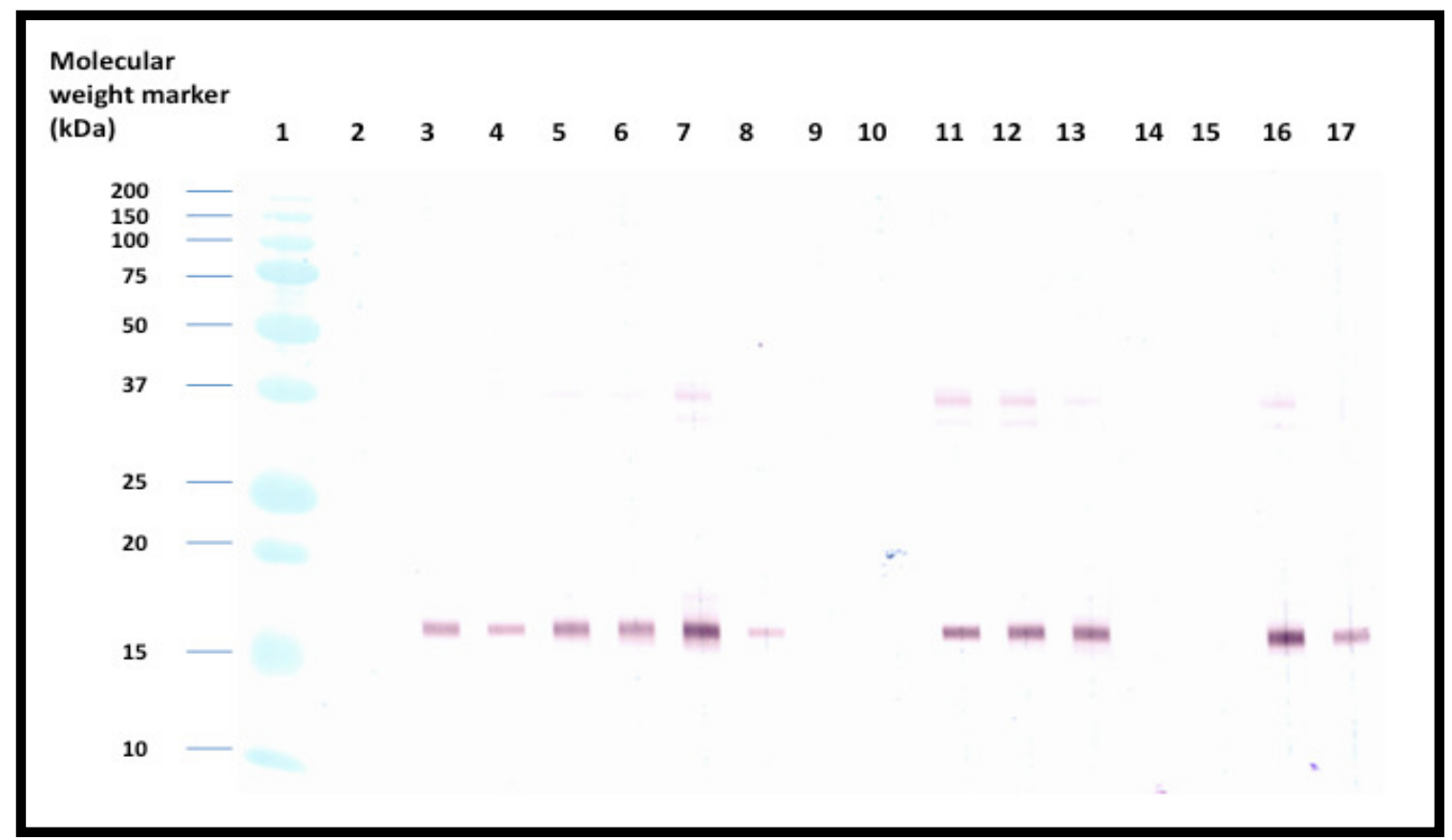

Fig. 5.3a. Western blot reactivity of rTerrelysin-mAbs with rTerrelysin. Lane 1: Molecular weight marker, 2: $m A b$ 2G4, 3: $m A b$ 3B2, 4: 6D2, 5: $m A b$ 7D8, 6: $m A b$ 13G10, 7: $m A b$ 15B5, 8: $m A b$ 16C7, 9: $m A b$ 9F4, 10: $m A b$ 19E3, 11: $m A b$ 3B7, 12: $m A b$ 10G4, 13: $m A b$ 15C5, 14: $m A b$ 15E4, 15: $m A b$ 6E4, 16: $m A b$ 10G7, 17: $m A b 2 D 3$. Positive reactivity is identified by presence of an immunoreactive band at $\sim 17 \mathrm{kDa}$. 
Molecular

weight marker

(kDa)

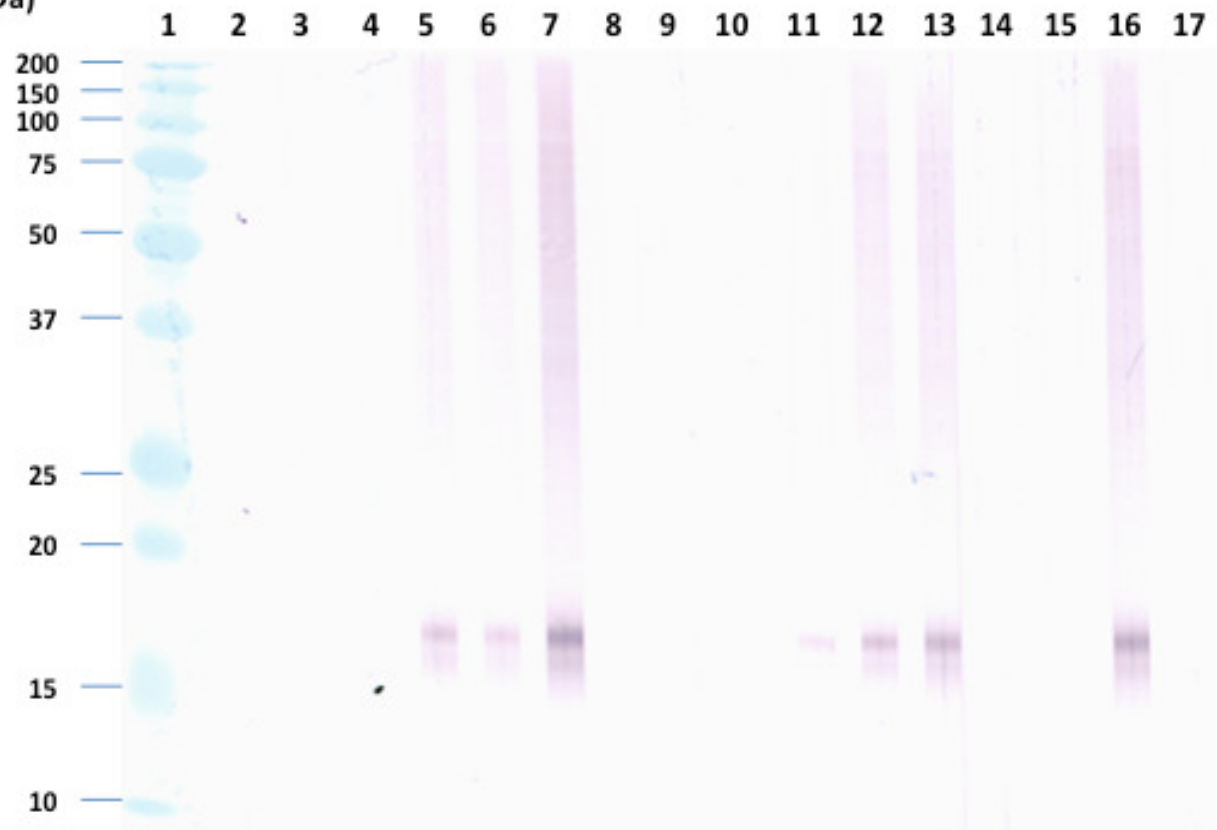

Fig. 5.3b. Western blot analysis of A. terreus mycelial extract with terrelysin mAbs. Lane 1: Molecular weight marker, 2: $m A b$ 2G4, 3: $m A b$ 3B2, 4: 6D2, 5: $m A b$ 7D8, 6: $m A b$ 13G10, 7: $m A b$ 15B5, 8: $m A b$ 16C7, 9: $m A b$ 9F4, 10: $m A b$ 19E3, 11: $m A b$ 3B7, 12: $m A b$ 10G4, 13: $m A b$ 15C5, 14: $m A b$ 15E4, 15: $m A b$ 6E4, 16: $m A b$ 10G7, 17: $\mathrm{mAb}$ 2D3. Positive reactivity is identified by presence of an immunoreactive band at $\sim 17 \mathrm{kDa}$. 


\begin{tabular}{|c|c|c|c|c|c|c|c|}
\hline FUNGI & 7D8 & 13G10 & $15 B 5$ & 3B7 & 10G4 & $15 \mathrm{C5}$ & 10G7 \\
\hline As. terreus FGSC 1156 & + & + & + & + & + & + & + \\
\hline A. terreus ATCC 1012 & + & + & + & + & + & + & + \\
\hline A. terreus NIOSH 17-30-31 & - & + & + & + & + & + & + \\
\hline A. terreus NIOSH 35-08-05 & + & + & + & + & + & + & + \\
\hline A. terreus NIOSH 35-08-06 & - & + & + & + & + & + & + \\
\hline A. candidus NIOSH 17-28-24 & - & - & - & - & - & - & - \\
\hline A. chevalieri NRRL 78 & - & - & - & - & - & - & - \\
\hline A. clavatus NIOSH 6-22-78 & - & - & - & - & - & - & - \\
\hline A. flavus NIOSH 15-41-07 & - & - & - & - & - & - & - \\
\hline A. fumigatus FGSC A1100 & - & - & - & - & - & - & - \\
\hline A. nidulans NIOSH 15-22-08 & - & - & - & - & - & + & - \\
\hline A. niger FGSC A1143 & - & - & - & - & - & - & - \\
\hline A. parasiticus ATCC 26690 & - & - & - & - & - & + & - \\
\hline A. penicilloides ATCC 16910 & - & - & - & - & - & - & - \\
\hline A. repens NRRL 13 & - & - & - & - & - & - & - \\
\hline A. ustus NRRL 275 & - & - & - & - & - & - & - \\
\hline Ac. strictum ATCC 46646 & - & - & - & - & - & - & - \\
\hline Al. alternata ATCC 11612 & - & - & - & - & - & + & - \\
\hline Ch. globosum NRRL 1870 & - & - & - & - & - & - & - \\
\hline Cl. cladosporioides NIOSH 17-28-17 & - & - & - & + & - & - & - \\
\hline Cl. sphaerospermum ATCC 11288 & - & - & - & - & - & - & - \\
\hline Ex. rostratum ATCC 26856 & - & - & - & - & - & + & + \\
\hline Fu. moniliforme NIOSH 32-40-16 & - & - & - & - & - & - & - \\
\hline Fu. oxysporum NIOSH 32-40-14 & - & - & - & - & - & - & - \\
\hline Ne. fischeri NIOSH 29-53-20 & - & - & - & - & - & - & - \\
\hline Pa. variotii ATCC 66705 & - & - & - & - & - & + & + \\
\hline
\end{tabular}




\begin{tabular}{|l|c|c|c|c|c|c|c|}
\hline Pe. chrysogenum NRRL 1951 & - & - & - & - & - & - & - \\
\hline Pe. expansum NRRL 973 & - & - & - & - & - & - & - \\
\hline Pe. melinii NIOSH 32-46-01 & - & - & - & - & - & - & - \\
\hline Pe. purpurogenum NRRL 1062 & - & - & - & - & - & - & - \\
\hline Sc. brumptii ATCC 16278 & - & - & - & - & - & - & - \\
\hline Tr. harzianum NIOSH 29-32-13 & - & - & - & - & - & + & + \\
\hline Tr. viride ATCC 16640 & - & - & - & - & - & - & - \\
\hline
\end{tabular}

Table 5.1- Cross-reactivity profiles of terrelysin-mAbs analyzed by Western blot. As: Aspergillus, Ac: Acremonium, Al: Alternaria, Ch: Chaetomium, Cl: Cladosporium, Ex: Exserohilum, Fu: Fusarium, Ne: Nesosartorya, Pa: Paecilomyces, Pe: Penicillium, Sc: Scopulariopsis, Tr: Trichoderma. \$ : Positive reactivity. 
5.3.4 Epitopes for rTerrelysin-mAbs- Owing to the high specificity determined in crossreactivity studies, $3 \mathrm{mAbs}(15 \mathrm{~B} 5,13 \mathrm{G} 10$ and 10G4) were tested to determine their epitopes using overlapping decapeptides that span the entire sequence of rTerrelysin. For mAb 15B5, 2 spots were recognized at positions 20-21 (Fig. 5.4). The sequence of spots 20 and 21 correspond to 'SFLYEGQFHS' and 'LYEGQFHSPE' respectively. These data suggest that the epitope recognized by mAb $15 B 5$ is 'LYEGQFHS'.

After ensuring complete removal of bound mAb 15B5 and regeneration of the SPOTs membrane, the membrane was then scanned using mAb 13G10. Four consecutive spots (52-55) reacted with mAb 13G10 and the resultant epitope was 'PSNEFE'. Subsequently, mAb 10G4 was found to recognize the same epitope as mAb 13G10 based on SPOTscan data. SPOTscan of membrane using control mAb 9B4 and secondary antibodies did not result in reactivity to any spots (data not shown). 


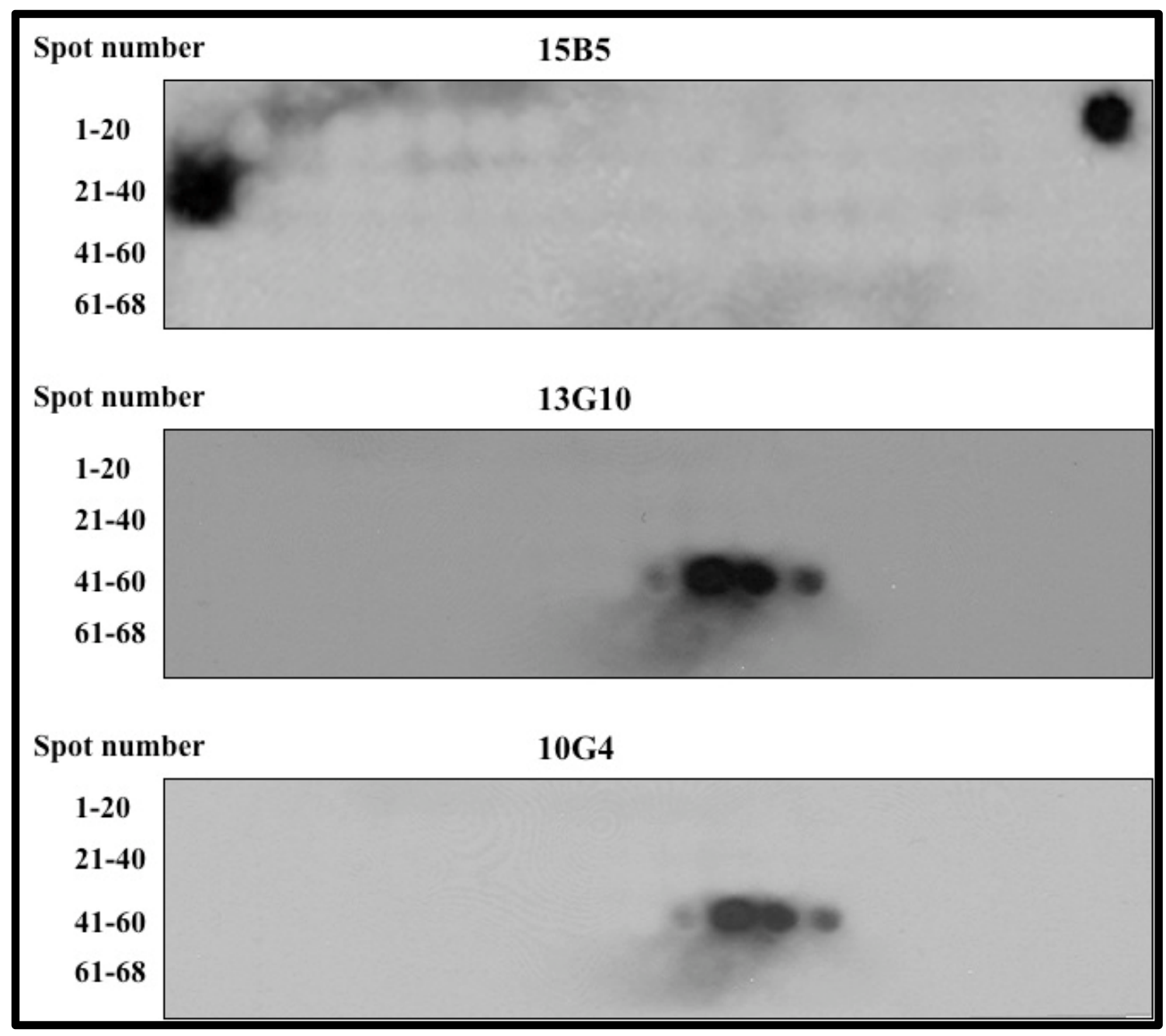

Fig. 5.4 Epitope mapping of anti-rTerrelysin mAbs. SPOTs membrane scans for mAbs 15B5, $13 G 10$ and $10 G 4$. Each spot represents a decapeptide of rTerrelysin sequence. Decapeptides were sequential with an overlap of 2 amino acids and spanned the entire sequence of rTerrelysin including the N-terminal purification Strep-tag II and the Factor Xa cleavage site. $m A b 15 B 5$ recognizes the epitope 'LYEGQFHS', while mAbs $13 G 10$ and $10 G 4$ recognize the epitope 'PSNEFE'. 
5.3.5 Time-point kinetics of expression of terrelysin- The expression of native terrelysin was examined using an inhibition ELISA to quantify the amount of terrelysin in CSN and ME at 24 hr intervals (Fig. 5.5a). In ME, the highest relative concentrations of terrelysin were observed during the first few days of growth ranging between $10-12 \mu \mathrm{g} / \mathrm{mg}$ of total fungal protein. A 10fold reduction was observed by day 4-5 ( $1 \mu \mathrm{g} / \mathrm{mg}$ of total protein) and after day 6 , very little terrelysin was quantified in ME. Lower levels of terrelysin were detected in the CSN with a maximum at day 6 and then declining to nearly baseline by day 12 .

The morphological features that were observed at the same time intervals are depicted in Fig. 5.5b. The early time points when expression of terrelysin was the highest, involved the initial stages of conidial germination and hyphal extension (12 hrs to $24 \mathrm{hrs}$ ). Hyphal aggregation was observed up to 96-120 hrs, when quantities of terrelysin were observed to decline. Beyond this time interval, the morphological changes could not be differentiated. Collectively, these results suggest that terrelysin expression occurs during initial stages of fungal growth between days $0-4$. When hyphal aggregation is complete, a concurrent reduction in the production of terrelysin was observed. Terrelysin was detected in the CSN at each measured time interval with peak concentrations observed on day 6 .

As A. terreus is thermotolerant, this experiment was repeated at $37^{\circ} \mathrm{C}$ to further compare morphological stages with terrelysin production. Again, cultures were grown for 12 days and ME and CSN was collected at $24 \mathrm{~h}$ intervals. Overall the growth of A. terreus was accelerated and the morphological stages of conidial germination and hyphal extension occurred earlier compared to RT treatments (Fig. 5.6b). Terrelysin expression was highest on day 1 (12 $\mu \mathrm{g} / \mathrm{mg}$ of total protein) and decreased 3-fold by day $2(4 \mu \mathrm{g} / \mathrm{mg}$ of total protein) (Fig. 5.6a). The concentration of terrelysin was further reduced 8 -fold by day $(0.5 \mu \mathrm{g} / \mathrm{mg}$ of total protein). In 
$\mathrm{CSN}$, comparatively higher proportion of terrelysin was detected during initial growth at $37^{\circ} \mathrm{C}$ compared to RT; however, there was a decline in the concentration of terrelysin in the CSN at $37^{\circ} \mathrm{C}$.

In summary, we observed that terrelysin expression is concurrent with conidial germination, hyphal extension and aggregation. Terrelysin concentration declined on formation of the mycelial pellets. Lower levels of terrelysin were detected in the CSN. 


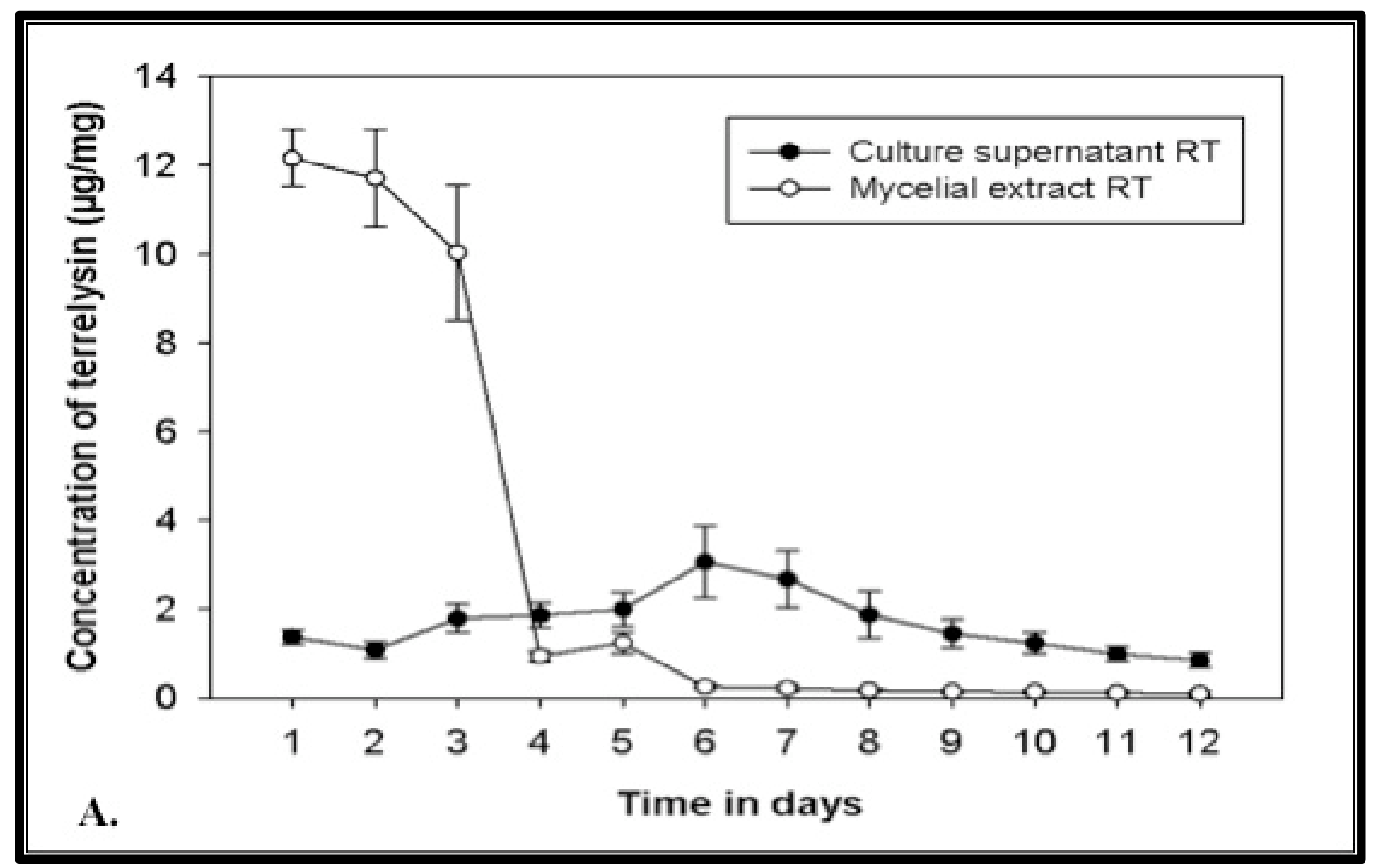

Fig. 5.5a. Time point kinetics of expression of terrelysin at RT. Analysis performed using mAb $10 G 4$. 


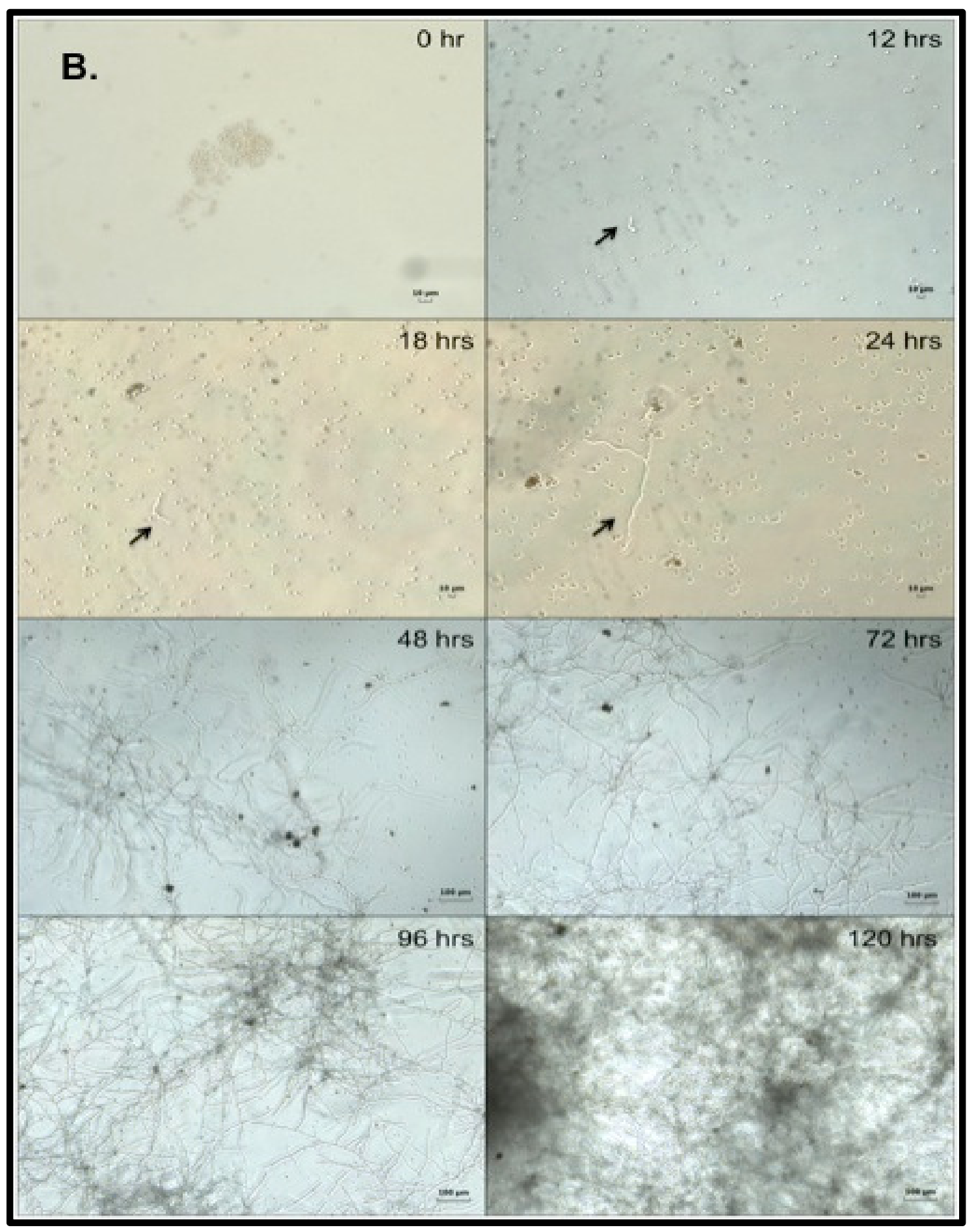

Fig. 5.5b. Morphological changes and progression of A. terreus culture growth at RT. Black arrows point to germinating conidia and hyphal extension in early cultures. Bar sizes correspond to 10 um for 0-24 hrs and 100 um for 48-120 hrs. 


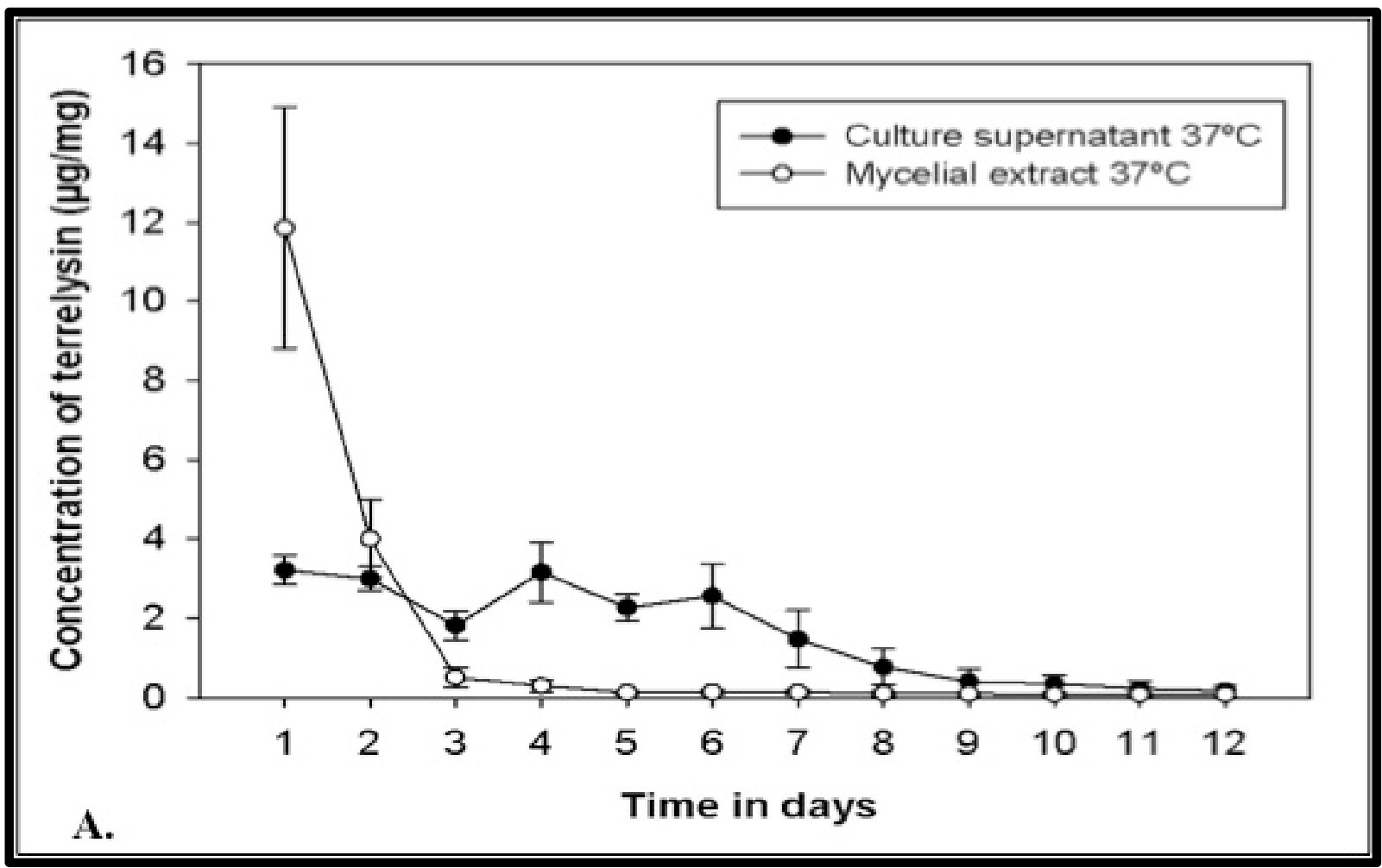

Fig. 5.6a. Time point kinetics of expression of terrelysin at $37^{\circ} \mathrm{C}$. Analysis performed using $\mathrm{mAb} 10 \mathrm{G4}$. 


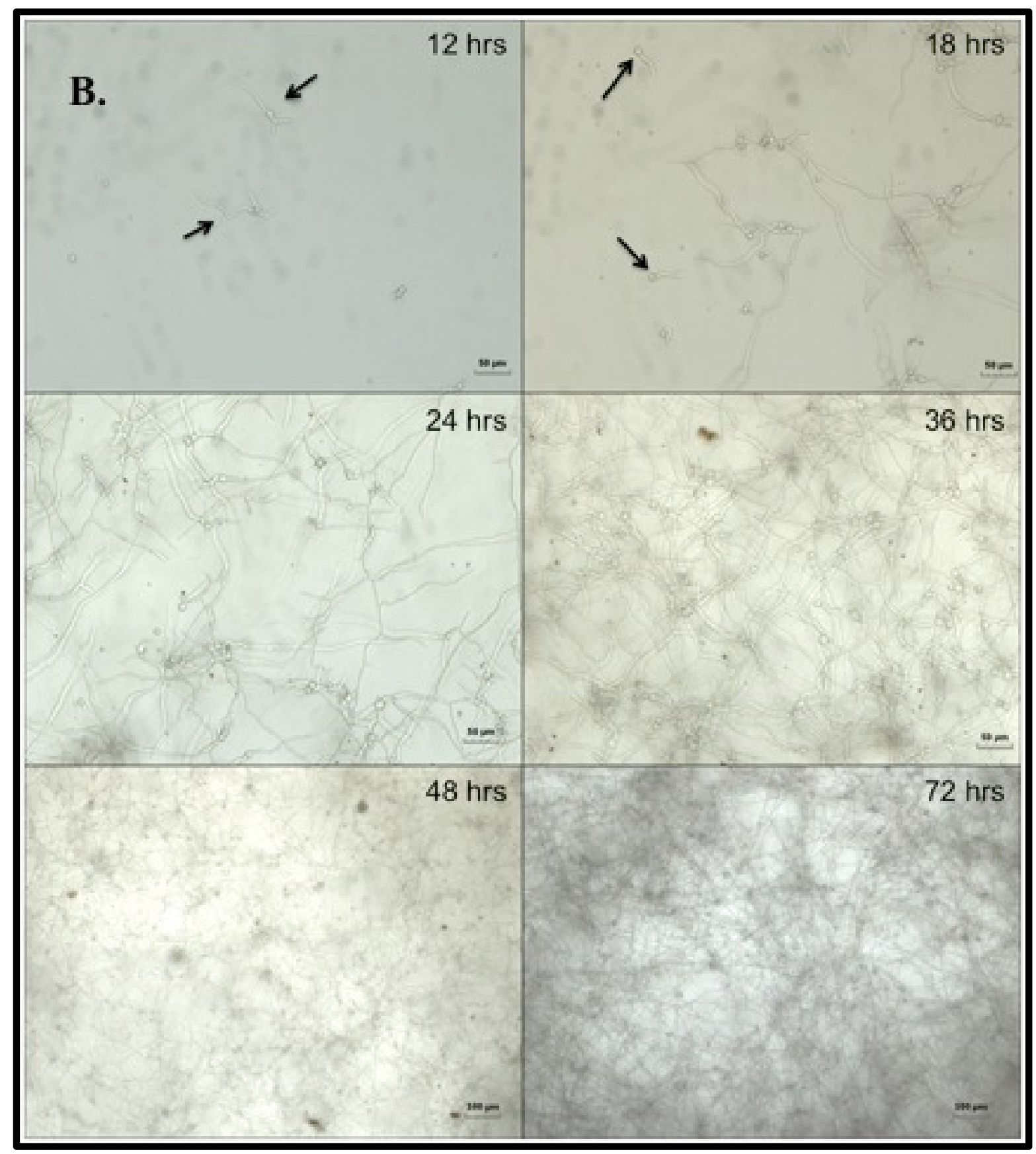

Fig. 5.6b. Morphological changes and progression of A. terreus culture growth at $37^{\circ} \mathrm{C}$. Black arrows point to germinating conidia and hyphal extension in early cultures. Bar sizes correspond to $10 \mu \mathrm{m}$ for 12-24 hrs and 100 um for 36-72 hrs. 
5.3.6 Immunolocalization of terrelysin- The cellular localization of terrelysin was examined by immunohistochemical staining methods using the terrelysin-specific mAb 15B5. Terrelysin was widely distributed within the hyphae (Fig. 5.7), with staining often of greater intensity near the hyphal tips. This pattern was distinctly different than the positive control (mAb 13E11) that stained a leucine aminopeptidase, a secreted protease within the extracellular matrix of the hyphae. No staining was observed in the extracellular matrix with mAb 15B5. 


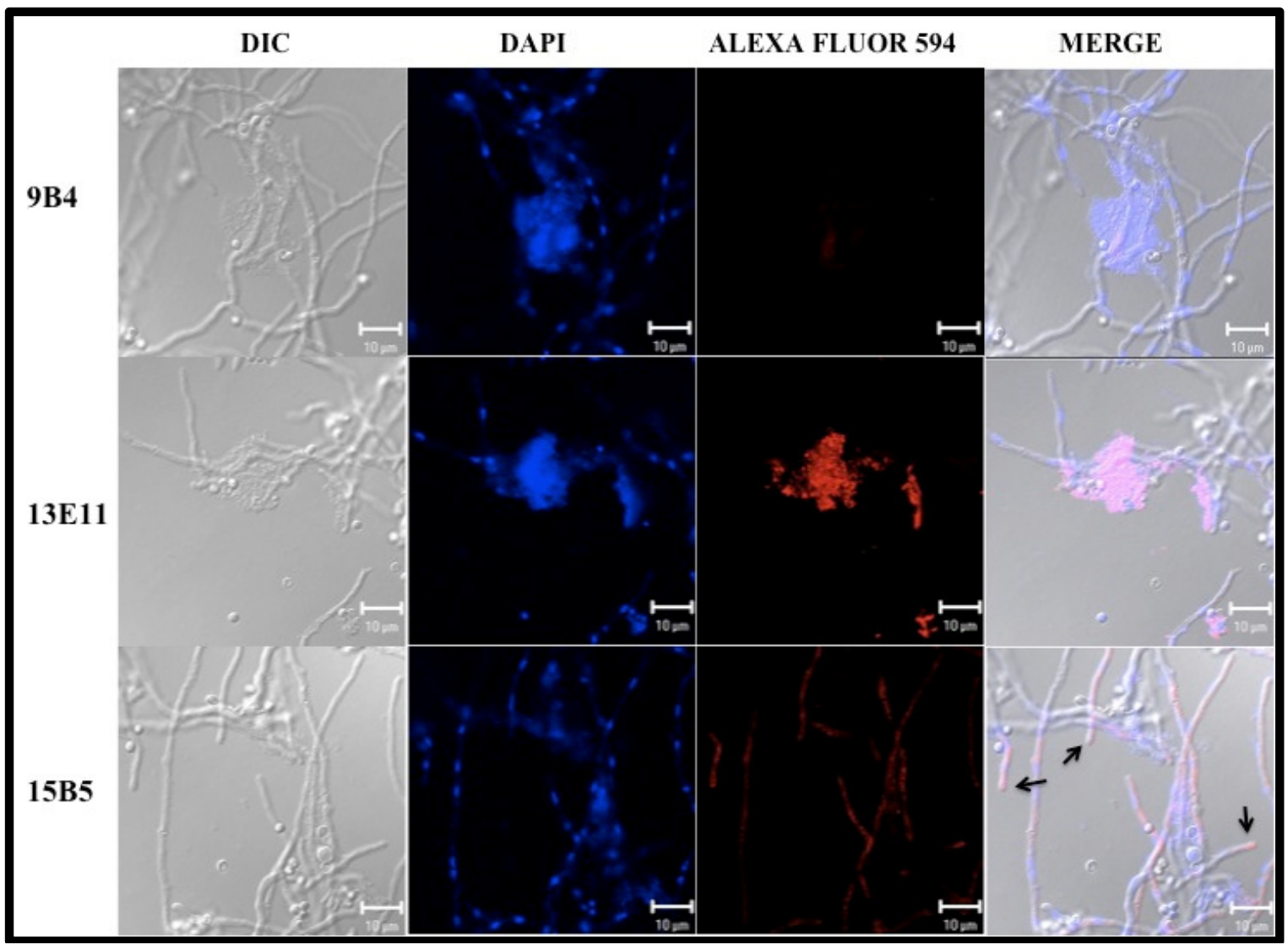

Fig. 5.7. Immunolocalization of terrelysin in A. terreus hyphae. Immunolocalization of the antigens was determined AlexaFluor ${ }^{\circledR}$ 594-labeled goat anti-mouse IgG secondary antibodies (Red) and nuclear staining was identified through DAPI staining (Blue). mAb $13 E 11$ served as a positive control and stains specifically for A. terreus leucine aminopeptidase while $\mathrm{mAb} 9 \mathrm{9B} 4$ served as a negative control. 


\subsection{DISCUSSION}

Aspergillus terreus is an emerging opportunistic pathogen reported to be an etiological agent of fatal disseminated infections in immunocompromised populations (21-23). Due to the ability of this species to grow optimally at internal body temperature and produce accessory conidia, this filamentous fungus is capable of initiating an infection and disseminating within the body. Resistance to antibiotic treatment such as amphotericin B allows for a longer infection time until effective treatment. A combination of these factors facilitates rapid dissemination of the fungus and can result in mortality. To date, very little is known about the overall pathogenesis and involvement of specific virulence factors of $A$. terreus during infection.

In A. fumigatus infections, asp-hemolysin was reported in tissues of experimental animals in an infection model and a role for hemolysin as potential virulence factors had been previously suggested $(4,7,24,25)$.

Previously, the gene for terrelysin was cloned and used to produce a recombinant protein as described in chapter 4. In this study, rTerrelysin was used as the antigen for the development of terrelysin-specific mAbs, which were then utilized to characterize terrelysin expression during A. terreus growth. Four of the $11 \mathrm{mAbs}(3 \mathrm{~B} 2,6 \mathrm{D} 2,16 \mathrm{C} 7$ and $2 \mathrm{D} 3)$ did not react to native terrelysin in A. terreus ME. Two possibilities for this include; a) the mAbs recognized the Nterminal tag associated with rTerrelysin or b) their epitopes may be modified by posttranslational processes under natural conditions as there is putative $N$-glycosylation $(\mathrm{N}-\mathrm{X}-\mathrm{S} / \mathrm{T})$ sites in the terrelysin sequence. One antibody (mAb 2D3) reacted with purified recombinant proteins (rEnolase from Chaetomium globosum and $\mathrm{rHev}$ b 5 an allergen from Hevea brasiliensis) expressed in the same pASK-IBA6 vector (data not shown). It was concluded that $\mathrm{mAb} 2 \mathrm{D} 3$ recognizes an epitope in the $\mathrm{N}$-terminal tag expressed by this vector. Epitope mapping 
showed that mAb 2D3 recognizes the Strep-tag II sequence 'WSHPQFEK' (data not shown). The other 3 mAbs did not show reactivity to the other recombinant proteins, thus it is possible that their epitopes are conformational or blocked by post-translationally modifications to the native protein.

In order to be useful as a diagnostic tool for the serological detection of terrelysin, it is essential that the mAb be species-specific. We tested 5 A. terreus strains, including the strain used for genome sequencing (NIH 2624/FGSC A1156). All mAbs tested detected terrelysin expressed in this strain. Interestingly, 7D8 showed reactivity towards $3 / 5$ strains of $A$. terreus tested and while low affinity might explain this inconsistent detection, genetic diversity within the epitope for this mAb is also a possibility. Although additional strains from different clinical and environmental isolates were not tested, the data suggests consistent expression of terrelysin across strains. Recently, a new species, A. alabamensis, which is phenotypically homologous but genetically different to A. terreus was isolated from immunocompetent patient populations (26). It will be important to test the reactivity of these mAbs to A. alabamensis as well as other fungal species within Section Terrei such as A. carneus and A. niveus, which can also cause infections under rare circumstances $(27,28)$.

The terrelysin mAbs did not cross-react to ME from other clinically relevant Aspergillus species such as A. fumigatus, A. flavus and A. niger. Weak reactivity was observed for mAb 15C5 with A. nidulans and A. parasiticus in Western blots. This reactivity was restricted to high molecular weight proteins of $\sim 50$ and $\sim 60 \mathrm{kDa}$ and probably represents non-specific staining. Using cross-reactivity data, we identified 3 mAbs (13G10, 15B5 and 10G4) that did not crossreact with any of the tested species. These 3 highly specific mAbs are important candidates for immunodiagnostic detection of A. terreus in clinical samples. Based on epitope mapping studies, 
we identified 2 different epitopes recognized by these antibodies. mAb 15B5 $\left(\operatorname{IgG}_{1}\right)$ recognized the epitope 'LYEGQFHS' while both mAbs $13 \mathrm{G} 10\left(\mathrm{IgG}_{1}\right)$ and $10 \mathrm{G} 4\left(\mathrm{IgG}_{2 \mathrm{a}}\right)$ recognized the epitope 'PSNEFE'. These epitope sequences were not identified in homologous hemolysins derived from other fungal species with known aegerolysin sequences (Fig. 4.1).

Expression of hemolysin in relation to growth has been studied previously for Pleurotus ostreatus and Pseudomonas aeruginosa $(12,13,29)$. For P. ostreatus, a basidiomycete, the greatest expression of ostreolysin was observed during the initial stages of fungal fruiting. For the bacteria $P$. aeruginosa, it was observed that the expression of its hemolysin, PA0122 is highest in the stationary phase of growth (29). In contrast, limited information is available for the expression of aegerolysins in ascomycetes. Recent studies have reported high asp-hemolysin transcript levels in developing hyphae of A. fumigatus (30). In the present study, the expression of terrelysin was associated with morphological stages of A. terreus growth. The presence of terrelysin was highest during initial growth stages that encompassed conidial germination, hyphal extension and hyphal aggregation ('log phase'). During stationary growth phases, (lack of increase in mycelial pellet size) detection of terrelysin was significantly reduced. This was observed at earlier time points when cultures were grown at $37^{\circ} \mathrm{C}$ and the presence of terrelysin consistently correlated with the morphological changes. These findings are consistent with studies by Swedish mycologist Lars Rutqvist which showed that the hemolytic principle could be purified from A. fumigatus mycelia only during a limited period of incubation at room temperature and that this period was earlier and shorter at $37^{\circ} \mathrm{C}(31)$.

Using an inhibition ELISA, terrelysin was detected in CSN even though we did not identify a signal peptide on the terrelysin sequence using SignalP 3.0 (32). This is in contrast to an earlier report where terrelysin was not identified in the secretome of A. terreus. Whether the 
detection of terrelysin in CSN a result of active secretion, hyphal degradation, fragmentation or due to involvement of unique secretory processes is currently not known and is the focus of future research. Recently, asp-hemolysin was identified as one of the most abundant protein in the A. fumigatus secretome even though the protein does not possess a signal peptide as noted earlier (33). Other studies have highlighted secretion of proteins with no predicted signal sequence and have proposed non-conventional secretory mechanisms (34-36). At day 6 in RT cultures and day 4 at $37^{\circ} \mathrm{C}$, small increases in levels of terrelysin were observed in CSN. Hyphal fragmentation was observed at these time points and this could, in part, explain the presence of terrelysin in CSN. Our immunolocalization studies demonstrate a uniform distribution of terrelysin within A. terreus hyphal cytoplasm with greater reactivity localized at the hyphal tips. The hyphal tips are a region of extensive metabolic activity and consist of higher concentrations of proteins compared to regions trailing the hyphal tip. Based on these morphological and immunohistochemical observations, it appears that terrelysin is expressed during early stages of growth, probably during the emergence of hyphae from conidia and active hyphal growth.

In summary, 7 terrelysin mAbs were characterized and 3 were identified to be highly specific for A. terreus. These mAbs were used to show that terrelysin is expressed during conidial germination and early growth of A. terreus hyphae. Since terrelysin was detected in CSN, it is possible that it could be detected in the serum of infected patients; however, this aspect has not been confirmed and remains the focus of future research. Serologic detection of terrelysin would make terrelysin useful as a biomarker, however the early expression of terrelysin in A. terreus growth may limit its usefulness for detecting infection. The kinetics of terrelysin production in vivo is unknown and more studies are required. 


\subsection{REFERENCES}

1. Bhakdi, S., F. Grimminger, N. Suttorp, D. Walmrath, and W. Seeger. 1994. Proteinaceous bacterial toxins and pathogenesis of sepsis syndrome and septic shock: the unknown connection. Med Microbiol Immunol 183:119-144.

2. Chu, L., T. E. Bramanti, J. L. Ebersole, and S. C. Holt. 1991. Hemolytic activity in the periodontopathogen Porphyromonas gingivalis: kinetics of enzyme release and localization. Infect Immun 59:1932-1940.

3. Seeger, W., R. Obernitz, M. Thomas, D. Walmrath, N. Suttorn, I. B. Holland, F. Grimminger, B. Eberspacher, F. Hugo, and S. Bhakdi. 1991. Lung vascular injury after administration of viable hemolysin-forming Escherichia coli in isolated rabbit lungs. Am Rev Respir Dis 143:797-805.

4. Kumagai, T., T. Nagata, Y. Kudo, Y. Fukuchi, K. Ebina, and K. Yokota. 1999. Cytotoxic activity and cytokine gene induction of Asp-hemolysin to murine macrophages. Nippon Ishinkin Gakkai Zasshi 40:217-222.

5. Malicev, E., H. H. Chowdhury, P. Macek, and K. Sepcic. 2007. Effect of ostreolysin, an Asp-hemolysin isoform, on human chondrocytes and osteoblasts, and possible role of Asp-hemolysin in pathogenesis. Med Mycol 45:123-130.

6. Rebolj, K., U. Batista, K. Sepcic, V. Cestnik, P. Macek, and R. Frangez. 2007. Ostreolysin affects rat aorta ring tension and endothelial cell viability in vitro. Toxicon 49:1211-1213.

7. Zuzek, M. C., P. Macek, K. Sepcic, V. Cestnik, and R. Frangez. 2006. Toxic and lethal effects of ostreolysin, a cytolytic protein from edible oyster mushroom (Pleurotus ostreatus), in rodents. Toxicon 48:264-271.

8. Kudo, Y., Y. Fukuchi, T. Kumagai, K. Ebina, and K. Yokota. 2001. Oxidized lowdensity lipoprotein-binding specificity of Asp-hemolysin from Aspergillus fumigatus. Biochim Biophys Acta 1568:183-188.

9. Kudo, Y., T. Ootani, T. Kumagai, Y. Fukuchi, K. Ebina, and K. Yokota. 2002. A novel oxidized low-density lipoprotein-binding protein, Asp-hemolysin, recognizes lysophosphatidylcholine. Biol Pharm Bull 25:787-790.

10. Rebolj, K., N. P. Ulrih, P. Macek, and K. Sepcic. 2006. Steroid structural requirements for interaction of ostreolysin, a lipid-raft binding cytolysin, with lipid monolayers and bilayers. Biochim Biophys Acta 1758:1662-1670.

11. Chowdhury, H. H., K. Rebolj, M. Kreft, R. Zorec, P. Macek, and K. Sepcic. 2008. Lysophospholipids prevent binding of a cytolytic protein ostreolysin to cholesterolenriched membrane domains. Toxicon 51:1345-1356.

12. Berne, S., I. Krizaj, F. Pohleven, T. Turk, P. Macek, and K. Sepcic. 2002. Pleurotus and Agrocybe hemolysins, new proteins hypothetically involved in fungal fruiting. Biochim Biophys Acta 1570:153-159.

13. Berne, S., J. Pohleven, I. Vidic, K. Rebolj, F. Pohleven, T. Turk, P. Macek, A. Sonnenberg, and K. Sepcic. 2007. Ostreolysin enhances fruiting initiation in the oyster mushroom (Pleurotus ostreatus). Mycol Res 111:1431-1436.

14. Köhler, G., and C. Milstein. 1975. Continuous cultures of fused cells secreting antibody of predefined specificity. Nature (Lond.) 256:495-497.

15. Andrew, S. M., and J. A. Titus. 1997. Purification and fragmentation of antibodies. In Current Protocols in Immunology. John Wiley \& Sons, Inc., Somerset, NJ. 2.7.1-2.7.12. 
16. Chen, C. Y., and G. Seguin-Swartz. 2002. A rapid method for assessing the viability of fungal spores. Can J Plant Pathol 24:230-232.

17. Beezhold, D. H., V. L. Hickey, M. F. Sutherland, and R. E. O'Hehir. 2004. The latex allergen Hev b 5 is an antigen with repetitive murine B-cell epitopes. Int Arch Allergy Immunol 134:334-340.

18. Osmani, S. A., D. B. Engle, J. H. Doonan, and N. R. Morris. 1988. Spindle formation and chromatin condensation in cells blocked at interphase by mutation of a negative cell cycle control gene. Cell 52:241-251.

19. Xiang, X., C. Roghi, and N. R. Morris. 1995. Characterization and localization of the cytoplasmic dynein heavy chain in Aspergillus nidulans. Proc Natl Acad Sci USA 92:9890-9894.

20. Schmechel, D., J. P. Simpson, D. H. Beezhold, and D. M. Lewis. 2006. The development of species-specific immunodiagnostics for Stachybotrys chartarum: the role of crossreactivity. J Immunol Methods 309:150-159.

21. Balajee, S. A. 2009a. Aspergillus terreus complex. Med Mycol 47 Suppl 1:S42-46.

22. Iwen, P. C., M. E. Rupp, A. N. Langnas, E. C. Reed, and S. H. Hinrichs. 1998. Invasive pulmonary aspergillosis due to Aspergillus terreus: 12-year experience and review of the literature. Clin Infect Dis 26:1092-1097.

23. Hachem, R. Y., D. P. Kontoyiannis, M. R. Boktour, C. Afif, C. Cooksley, G. P. Bodey, I. Chatzinikolaou, C. Perego, H. M. Kantarjian, and I. I. Raad. 2004. Aspergillus terreus: an emerging amphotericin B-resistant opportunistic mold in patients with hematologic malignancies. Cancer 101:1594-1600.

24. Berne, S., L. Lah, and K. Sepcic. 2009. Aegerolysins: structure, function, and putative biological role. Protein Sci 18:694-706.

25. Ebina, K., K. Yokota, and O. Sakaguchi. 1982. Studies on toxin of Aspergillus fumigatus XIV: Relationship between Asp-hemolysin and experimental infection in mice. Jpn $J$ Med Mycol 23:246-252.

26. Balajee, S. A., J. W. Baddley, S. W. Peterson, D. Nickle, J. Varga, A. Boey, C. LassFlorl, J. C. Frisvad, and R. A. Samson. 2009b. Aspergillus alabamensis, a new clinically relevant species in the section Terrei. Eukaryot Cell 8:713-722.

27. Crissy, J. T., H. Lang, and L. C. Parish. 1995. Manual of Medical Mycology. Blackwell Sciences, Cambridge, MA.

28. Wadhwani, K., and A. K. Srivastava. 1984. Fungi from otitis media of agricultural field workers. Mycopathologia 88:155-159.

29. Rao, J., A. DiGiandomenico, J. Unger, Y. Bao, R. K. Polanowska-Grabowska, and J. B. Goldberg. 2008. A novel oxidized low-density lipoprotein-binding protein from Pseudomonas aeruginosa. Microbiology 154:654-665.

30. Gravelat, F. N., T. Doedt, L. Y. Chiang, H. Liu, S. G. Filler, T. F. Patterson, and D. C. Sheppard. 2008. In vivo analysis of Aspergillus fumigatus developmental gene expression determined by real-time reverse transcription-PCR. Infect Immun 76:3632-3639.

31. Rutqvist, L. 1965. Studies on Aspergillus fumigatus; toxin production by different strains and serological comparison of the strains. Acta Vet Scand 6:224-233.

32. Bendtsen, J. D., H. Nielsen, G. von Heijne, and S. Brunak. 2004. Improved prediction of signal peptides: SignalP 3.0. J Mol Biol 340:783-795. 
33. Wartenberg, D., K. Lapp, I. D. Jacobsen, H. M. Dahse, O. Kniemeyer, T. Heinekamp, and A. A. Brakhage. 2011. Secretome analysis of Aspergillus fumigatus reveals Asphemolysin as a major secreted protein. Int J Med Microbiol 301:602-611.

34. Medina, M. L., P. A. Haynes, L. Breci, and W. A. Francisco. 2005. Analysis of secreted proteins from Aspergillus flavus. Proteomics 5:3153-3161.

35. Rubartelli, A., and R. Sitia. 1997. Secretion of mammalian proteins that lack a signal sequence. In Unusual secretory pathways: From bacteria to man. K. Kuchler, A. Rubartelli, and B. I. Holland, eds. RG Landes, Austin, TX. 87-104.

36. Nickel, W. 2010. Pathways of unconventional protein secretion. Curr Opin Biotechnol 21:621-626. 


\section{CHAPTER 6}

\section{GENERAL DISCUSSION}




\subsection{INTRODUCTION}

Recent interest in fungal hemolysins was stimulated by an association of Stachybotrys chartarum with an outbreak of idiopathic pulmonary hemorrhage (IPH) in Cleveland (1). Stachybotrys chartarum in particular was isolated from the homes of infants with IPH. Fungal proteins capable of hemolysis (hemolysins) were postulated as the causative agent and stachylysin was proposed as a potential biomarker for exposure to Stachybotrys chartarum (2-4). Detection of hemolysins in sera and tissues of experimentally exposed animals and in some humans working in chronic exposure environments further fueled an interest in utilizing fungal hemolysins as biomarkers for fungal exposure $(4,5)$. Thus methods of detecting and quantifying stachylysin were necessary to better understand this association.

Stachylysin was first proposed as a potential biomarker for detection of exposure to Stachybotrys chartarum based on immunoassays using a poorly characterized polyclonal antiserum (4). In order to verify stachylysin as a biomarker, we developed mAbs to stachylysin preparation in collaboration with Dr. Steve Vesper at the Environment Protection Agency in Cincinnati, $\mathrm{OH}$. The initial goal of this project was to develop $S$. chartarum-specific mAbs and the development of rapid detection assays for stachylysin from environmental and clinical samples. However, the hemolytic antigen preparation contained multiple proteins making a monoclonal antibody to stachylysin difficult to obtain. Since, the genome of S. chartarum has not been sequenced, we then shifted the focus to studying similar Aegerolysins from a well characterized fungal species where the genome has been sequenced. We chose to study the hemolysin from A. terreus, an emerging pathogen, especially for immunocompromised patients $(6,7)$. As the first step of this strategy, we developed mAbs to a similar hemolytic preparation purified from A. terreus culture medium. We successfully obtained $\operatorname{IgG}_{1} \mathrm{mAbs}_{\mathrm{a}}$ that were highly 
specific for A. terreus, however, on initial characterization of the mAbs; we again identified reactivity to multiple proteins with little evidence of reactivity to a hemolysin. On further characterization, we elucidated that the mAbs recognized proteolytic enzymes secreted by $A$. terreus.

Since, the genome of A. terreus had been sequenced, our next approach involved identifying terrelysin, using homology to the sequence information available for asp-hemolysin, the Aegerolysin of A. fumigatus. We subsequently produced a recombinant terrelysin using the pASK-IBA6 vector in an E. coli host. The recombinant protein then served as the antigen and murine $\mathrm{mAbs}$ of $\operatorname{IgG}_{1}, \operatorname{IgG}_{2 \mathrm{a}}$ and $\mathrm{IgG}_{2 \mathrm{~b}}$ isotypes were generated against rTerrelysin. These $\mathrm{mAbs}$ are highly specific to A. terreus and have the potential for developing diagnostic assays for detection of A. terreus in environmental and clinical samples.

\subsection{STACHYLYSIN}

As noted above, a goal of this project was to develop mAbs to stachylysin, a molecule that had been previously characterized in multiple studies using a polyclonal antiserum $(2-4,8)$. The data published using this polyclonal reported there were very high levels of stachylysin in the lungs and sera of exposed animals $(10.9 \mathrm{ng} / \mathrm{ml}$ and human $(371 \mathrm{ng} / \mathrm{ml})$ suggesting the assay was subject to interferences or inaccuracy. It was reasoned that a mAb would produce a more accurate and reproducible assay and also improve the specificity of the assay. Using the hemolytic preparation developed by Dr. Vesper's group. (2), we developed murine mAbs to this partially purified hemolytic fraction. Although the extract was purified from S. chartarum, the specific strain was later identified and characterized as a related species called S. chlorohalonata

(9). The obtained mAbs showed consistent reactivity to hyphal extracts from multiple strains of 
both $S$. chartarum and S. chlorohalonata and the reactivity were notably weaker to conidial extracts. This also confirmed an earlier report that stachylysin was expressed in higher concentrations in the hyphae (4). We also observed significant reactivity of the mAbs to hyphae in immunohistochemical localization studies using the halogen immunoassay. Interestingly, most reactivity to hyphal structures was concentrated at septal junctions and hyphal branch points. Repeated attempts to confirm that stachylysin was the antigen recognized by the mAbs were not successful undoubtedly due to the fact that these hemolytic preparations used as an antigen source, do not appear to contain the Aegerolysins.

One of the goals was to develop IgG mAbs for better utility in immunoassays; however, we only identified IgM mAbs to the S. chlorohalonata hemolytic preparation. The screening procedure used antibodies to $\operatorname{IgG}$ and $\operatorname{IgM}$ isotypes to ensure identification of the greatest number of clones. This enabled us to detect IgM mAbs, but the nature of the immune response appears to have been primarily IgM after 6 immunizations with the hemolytic preparation. This is likely due to the presence of glycoproteins in the hemolytic preparation. Previously in our lab, we have reported difficulty in generation of detectable $\mathrm{IgG}$ titers in animals immunized with conidial, hyphal or secreted antigens, with similar issues (10).

The mAbs were developed to the hemolytic preparation with the primary purpose of identifying S. chartarum stachylysin. While we could not confirm the presence of stachylysin, the mAbs are species specific and react to hyphal extracts from both atranone as well as satratoxin producing chemotypes of S. chartarum. Although some cross-reactivity was observed with other closely related fungal species such as Memnoniella species, overall the IgM mAbs showed good specificity to Stachybotrys species. Reactivity to conidia was minimal but detectable using assays developed here. Since no mAbs are available for detection of 
Stachybotrys hyphal antigens and these antigens are expressed in high concentrations in hyphae, these mAbs may be useful for the specific identification of Stachybotrys hyphae using ELISA or microscopic techniques.

\subsection{TERRELYSIN}

The genome of Stachybotrys species has not been sequenced which hampered our efforts to identify stachylysin and hence we focused on characterization of a hemolysin in a fungus whose genome had been sequenced. The genome of A. terreus was recently sequenced (11) and we identified the sequence for the hemolysin based on the homology to asp-hemolysin of $A$. fumigatus. In our first approach, Dr. Vesper's group at EPA, Cincinnati, $\mathrm{OH}$, purified terrelysin using the previously used biochemical methods $(2,12)$. With the knowledge that this preparation was only partially purified, the preparation was identified as a cytolytic A. terreus preparation (cAtp) in our studies.

Using this preparation, we successfully developed highly specific $\mathrm{IgG}_{1} \mathrm{mAbs}$ to cAtp in mice. Initial analysis of the anti-cAtp mAbs using Western blot analysis showed multiple bands suggesting that the mAbs might react to different proteins that co-purified with the hemolysin. No mAbs exhibited reactivity to an $18 \mathrm{kDa}$ protein, the expected molecular weight of terrelysin. However, we did observe reactivity to multiple high molecular weight bands, suggesting that the epitopes might be shared between different proteins or the high molecular weight proteins might be aggregates of terrelysin.

Using immunoprecipitation and subsequent proteomic analysis of the immunoreactive bands, we identified leucine aminopeptidase (LAP) and dipeptidyl peptidase V (DPP 5) as two antigens of cAtp. We did not identify any peptides with the terrelysin sequence in the cAtp 
preparation. As previously noted for stachylysin, higher concentrations of LAP and DPP 5 were detected in the hyphae than the conidia. Also, we detected high levels of these proteins in $A$. terreus CSN, suggesting that these proteins might be secreted. Indeed, we identified putative signal peptides in the N-terminal domain of the sequences of these proteins. Also, on investigation of the kinetics of expression of these proteins, we observed a lag period between expression of the antigens within the hyphae and in the growth medium, suggesting involvement of active secretion processes.

In immunolocalization studies, we observed that LAP staining was predominantly outside the growing hyphae in extracellular structures. These extracellular structures also stained with DAPI for DNA, and genetic material has been reported as part of the extracellular matrix of the fungi $(13,14)$. Presumably, fungi use these structures to anchor to the substrate on which they colonize. Little is known about the clinical significance of fungal ECM and LAP. Interestingly, these proteins were detected in the fungal growth medium throughout the course of the expression studies. In previously reported studies, DPP 5 has been reported as an important serodiagnostic marker for $A$. fumigatus $(15,16)$ and recently identified as the $3^{\text {rd }}$ most abundant protein among the secreted proteins of A. fumigatus (17). These results highlight the potential of mAbs developed in this study for serodiagnostic assays for detection of A. terreus.

\subsection{RECOMBINANT TERRELYSIN}

Our goal of identifying terrelysin using previously described biochemical methods was not achieved and required a different strategy. We utilized the A. terreus genome sequence information available in the database to identify a homologue to asp-hemolysin of $A$. fumigatus and used molecular techniques for cloning and expression of terrelysin. In our first attempt to 
produce recombinant terrelysin, we expressed the clone in E. coli, and purified the protein using the $\mathrm{His}_{6}$-tag at the N-terminus of the expressed protein. We did not observe any hemolytic activity with this construct and also encountered problems of impurities after purification on $\mathrm{Ni}$ column. One of the reasons for the lack of hemolytic activity could be that the protein expressed using this system was localized within E. coli cytoplasm where reducing conditions may not permit proper folding of the protein. Folding of the hemolytic proteins and the associated conformational changes play a vital role in the mechanism of hemolysis (18).

To address this issue, we expressed the protein in the pASK-IBA6 vector, which utilizes a signal peptide at the $\mathrm{N}$-terminus of the vector sequence that enables efficient expression of the protein in the periplasmic space. Here, the conditions are more favorable for the proper folding of the expressed recombinant protein. Also, the high affinity Strep-tag II allows for purification of the expressed recombinant protein under physiological conditions. Using recombinant protein produced in this system, we confirmed the secondary structure of terrelysin using CD techniques and also assessed the conformational changes resulting from changes in $\mathrm{pH}$ and temperature. The observations were similar to those previously reported for native ostreolysin, an Aegerolysin purified from the mushroom P. ostreatus (19).

Murine mAbs were raised to the rTerrelysin and characterized for reactivity to native terrelysin and also for cross-reactivity towards other fungal species. Except for one, all of the mAbs to recombinant terrelysin also recognized the native terrelysin in extracts from different strains of A. terreus including the pathogenic FGSC A1156 strain. Three of the mAbs reacted to hyphal extracts from other fungal species, while $3 \mathrm{mAbs}$ did not show any cross-reactivity. These 3 A. terreus-specific mAbs, 13G10, 15B5, and 10G4 were used for further characterization of terrelysin. Epitope mapping results showed that mAb $15 \mathrm{~B} 5$ recognizes a 
different epitope than mAbs 13G10 and 10G4. The epitopes recognized by these mAbs were also absent in fungal species in which homologous Aegerolysin family hemolysins have been identified. Overall, these mAbs have the potential for use in developing double monoclonal antibody-based diagnostic assays for highly specific and sensitive assays for the early detection of terrelysin in clinical and environmental samples.

We also studied the kinetics of terrelysin expression and correlated it with the morphological changes during growth of A. terreus. We observed that terrelysin expression was high during the initial 3 days of growth but its concentration diminished with the increasing fungal biomass, and was essentially non-detectable in mycelium from the 7-day old cultures that were used by Dr. Vesper to make isolate the hemolytic antigen preparations. Also, we detected some terrelysin in the A. terreus growth CSN. Although terrelysin does not possess a putative signal peptide; it has been reported that fungi possess non-classical strategies for protein secretion (20-22). Interestingly, terrelysin was not identified in the A. terreus secretome (23), however, a recent study identified that although asp-hemolysin does not have a signal peptide, it was the $4^{\text {th }}$ most abundant protein in the A. fumigatus secretome (17). These discrepancies suggest that although hemolysins may be secreted proteins they are differentially expressed and regulated in filamentous fungal species.

Our studies demonstrate the difficulties of using a biochemical approach for isolation and characterization of hemolytic proteins from fungi. Previously asp-hemolysin and ostreolysin were purified from A. fumigatus and P. ostreatus respectively, using similar biochemical methods (hemolytic fractions of separated proteins) $(12,24)$. This resulted in the purification of homologous Aegerolysins with similar biochemical and pathogenic properties. However, using similar methods for the purification of stachylysin and terrelysin did not result in purification of 
Aegerolysin proteins. For A. terreus at least, we were able to determine that our mAbs detected the proteases, LAP and DPP 5. It is now apparent that the hemolytic activity that was followed during the purification of the "hemolysin" was likely contributed by these proteases. Proteases have been previously shown to have hemolytic activity $(25,26)$. To further corroborate this point, in a recently published report on asp-hemolysin, hemolysis and cytotoxicity was not altered using deletion mutants for asp-hemolysin (17). This work together with ours, demonstrates that Aegerolysin family proteins are not the major hemolytic factors in fungal extracts.

\subsection{OTHER CONCLUSIONS}

In our studies with Stachybotrys, Western blot staining with our mAbs identified a 30 $\mathrm{kDa}$ protein as a putative Aegerolysin using a monoclonal antibody developed after immunization with the hemolytic protein preparation. Previously, stachylysin was reported as a $12 \mathrm{kDa}$ protein that migrates in SDS-PAGE as a $30 \mathrm{kDa}$ protein (2). It was suggested that stachylysin may be a highly acidic protein and such proteins have been previously reported to demonstrate anomalous behavior in SDS-PAGE (27). However, based on our findings with $A$. terreus, we should reinterpret that data as it likely represents a protease from Stachybotrys.

In this study for the first time we have cloned and expressed terrelysin and to date it is the only Aegerolysins from A. terreus that has been identified and cloned. Although we did observe hemolytic activity with the purified recombinant protein, because of the possibility of contamination of the purified rTerrelysin preparation with surfactants, we could not be sure the hemolytic activity was due to rTerrelysin. Although we did not examine the role of terrelysin in pathogenesis, recent studies using asp-hemolysin mutants show that asp-hemolysin may not be 
important for virulence and may be dispensable for pathogenesis (17). This challenges earlier observations regarding the role of asp-hemolysin in pathogenesis of A. fumigatus $(5,12,28-30)$. The concentration of asp-hemolysin used in these studies may not necessarily be at levels achieved during an in vivo infection.

Reagents developed in these studies will be beneficial in developing standardized and rapid diagnostic tests for diagnosis of environmental and clinical exposure to Stachybotrys species and A. terreus. For A. terreus, mAbs developed to hyphal exoantigens such as LAP and DPP 5 used in combination with mAbs developed to terrelysin may be helpful in developing surveillance assays for A. terreus. Since terrelysin is expressed early during growth, its detection may suggest early infection, while detection of LAP and DPP 5 and reduced levels of terrelysin may suggest late infection. On treatment, levels of LAP and DPP 5 may be monitored to assess efficacy of treatment and clearance of $A$. terreus infection.

However, we have limited information regarding the expression and the stability of these proteins in vivo during infection. Studies utilizing animal models for invasive aspergillosis in immunocompromised mice will help in determining the presence of these proteins in various clinical samples. Some studies have reported presence of these proteins in urine samples collected from patients (31). Development of dip-stick based assay kits may also introduce portability.

Collectively these mAbs have tremendous potential in development of diagnostic assays for Stachybotrys species and A. terreus exposures. The improved methodologies described in these studies will help in better and consistent characterization of fungal growth and protein expression. Tools and methodologies developed in these studies will also be useful in developing highly specific double monoclonal antibody based assays. 


\subsection{REFERENCES}

1. CDC. 1994. Acute pulmonary hemorrhaging/hemosiderosis among infants: Cleveland, January 1993-November 1994. In Morbid Mortal Weekly Rep. Centers for Disease Control and Prevention. 881-883.

2. Vesper, S. J., M. L. Magnuson, D. G. Dearborn, I. Yike, and R. A. Haugland. 2001. Initial characterization of the hemolysin stachylysin from Stachybotrys chartarum. Infect Immun 69:912-916.

3. Vesper, S. J., and M. J. Vesper. 2002. Stachylysin may be a cause of hemorrhaging in humans exposed to Stachybotrys chartarum. Infect Immun 70:2065-2069.

4. Van Emon, J. M., A. W. Reed, I. Yike, and S. J. Vesper. 2003. ELISA measurement of stachylysin in serum to quantify human exposures to the indoor mold Stachybotrys chartarum. J Occup Environ Med 45:582-591.

5. Ebina, K., K. Yokota, and O. Sakaguchi. 1982. Studies on toxin of Aspergillus fumigatus XIV: Relationship between Asp-hemolysin and experimental infection in mice. Jpn J Med Mycol 23:246-252.

6. Iwen, P. C., M. E. Rupp, A. N. Langnas, E. C. Reed, and S. H. Hinrichs. 1998. Invasive pulmonary aspergillosis due to Aspergillus terreus: 12-year experience and review of the literature. Clin Infect Dis 26:1092-1097.

7. Hachem, R. Y., D. P. Kontoyiannis, M. R. Boktour, C. Afif, C. Cooksley, G. P. Bodey, I. Chatzinikolaou, C. Perego, H. M. Kantarjian, and Raad, II. 2004. Aspergillus terreus: an emerging amphotericin B-resistant opportunistic mold in patients with hematologic malignancies. Cancer 101:1594-1600.

8. Vesper, S. J., and M. J. Vesper. 2004. Possible role of fungal hemolysins in sick building syndrome. Adv Appl Microbiol 55:191-213.

9. Andersen, B., K. F. Nielsen, U. Thrane, T. Szaro, J. W. Taylor, and B. B. Jarvis. 2003. Molecular and phenotypic descriptions of Stachybotrys chlorohalonata sp. nov. and two chemotypes of Stachybotrys chartarum found in water-damaged buildings. Mycologia 95:1227-1238.

10. Schmechel, D., J. P. Simpson, and D. M. Lewis. 2005. The production and characterization of monoclonal antibodies to the fungus Aspergillus versicolor. Indoor Air 15 Suppl 9:11-19.

11. Birren, B. W., E. S. Lander, J. E. Galagan, C. Nusbaum, K. Devon, M. Henn, L. J. Ma, D. B. Jaffe, J. Butler, P. Alvarez, S. Gnerre, M. Grabherr, M. Kleber, E. W. Mauceli, W. Brockman, S. Rounsley, S. K. Young, K. LaButti, and K. Madden. 2005. Annotation of the Aspergillus terreus NIH264 genome. EMBL/GenBank/DDBJ databases.

12. Sakaguchi, O., H. Shimada, and K. Yokota. 1975. Proceedings: Purification and characteristics of hemolytic toxin from Aspergillus fumigatus. Jpn J Med Sci Biol 28:328331.

13. Loussert, C., C. Schmitt, M. C. Prevost, V. Balloy, E. Fadel, B. Philippe, C. KauffmanLacroix, J. P. Latge, and A. Beauvais. 2010. In vivo biofilm composition of Aspergillus fumigatus. Cell Microbiol 12:405-410.

14. Mowat, E., C. Williams, B. Jones, S. McChlery, and G. Ramage. 2009. The characteristics of Aspergillus fumigatus mycetoma development: is this a biofilm? Med Mycol 47:S120-126. 
15. Beauvais, A., M. Monod, J. P. Debeaupuis, M. Diaquin, H. Kobayashi, and J. P. Latge. 1997. Biochemical and antigenic characterization of a new dipeptidyl-peptidase isolated from Aspergillus fumigatus. J Biol Chem 272:6238-6244.

16. Biguet, J., P. Tran van Ky, and S. Andrieu. 1967. Identification d'une activité chymotrypsique au niveau de fractions remarquables d'Aspergillus fumigatus. Répercussions sur le diagnostic immunologique de l'aspergillose. Rev Immunol Ther Antimicrob 31:317-328.

17. Wartenberg, D., K. Lapp, I. D. Jacobsen, H. M. Dahse, O. Kniemeyer, T. Heinekamp, and A. A. Brakhage. 2011. Secretome analysis of Aspergillus fumigatus reveals Asphemolysin as a major secreted protein. Int J Med Microbiol.

18. Gonzalez, M. R., M. Bischofberger, L. Pernot, F. G. van der Goot, and B. Freche. 2008. Bacterial pore-forming toxins: the (w)hole story? Cell Mol Life Sci 65:493-507.

19. Berne, S., K. Sepcic, G. Anderluh, T. Turk, P. Macek, and N. Poklar Ulrih. 2005. Effect of $\mathrm{pH}$ on the pore forming activity and conformational stability of ostreolysin, a lipid raft-binding protein from the edible mushroom Pleurotus ostreatus. Biochemistry 44:11137-11147.

20. Rubartelli, A., and R. Sitia. 1997. Secretion of mammalian proteins that lack a signal sequence. In Unusual secretory pathways: From bacteria to man. K. Kuchler, A. Rubartelli, and B. I. Holland, eds. RG Landes, Austin, TX. 87-104.

21. Nickel, W. 2010. Pathways of unconventional protein secretion. Curr Opin Biotechnol 21:621-626.

22. Lu, X., J. Sun, M. Nimtz, J. Wissing, A. P. Zeng, and U. Rinas. 2010. The intra- and extracellular proteome of Aspergillus niger growing on defined medium with xylose or maltose as carbon substrate. Microb Cell Fact 9:1-13.

23. Han, M. J., N. J. Kim, S. Y. Lee, and H. N. Chang. 2010. Extracellular proteome of Aspergillus terreus grown on different carbon sources. Curr Genet 56:369-382.

24. Berne, S., I. Krizaj, F. Pohleven, T. Turk, P. Macek, and K. Sepcic. 2002. Pleurotus and Agrocybe hemolysins, new proteins hypothetically involved in fungal fruiting. Biochim Biophys Acta 1570:153-159.

25. Keen, M. G., and P. S. Hoffman. 1989. Characterization of a Legionella pneumophila extracellular protease exhibiting hemolytic and cytotoxic activities. Infect Immun 57:732738.

26. Lee, C. Y., M. F. Cheng, M. S. Yu, and M. J. Pan. 2002. Purification and characterization of a putative virulence factor, serine protease, from Vibrio parahemolyticus. FEMS Microbiol Lett 209:31-37.

27. Garcia-Ortega, L., V. De los Rios, A. Martinez-Ruiz, M. Onaderra, J. Lacadena, A. Martinez del Pozo, and J. G. Gavilanes. 2005. Anomalous electrophoretic behavior of a very acidic protein: ribonuclease U2. Electrophoresis 26:3407-3413.

28. Sakaguchi, O., K. Yokota, and A. Kamaguchi. 1977. [Studies on the toxin of Aspergillus fumigatus. VIII. Biological properties of Asp-hemolysin (author's transl)]. Nippon Saikingaku Zasshi 32:821-828.

29. Yokota, K., H. Shimada, A. Kamaguchi, and O. Sakaguchi. 1977. Studies on the toxin of Aspergillus fumigatus VII. Purification and some properities of hemolytic toxin (asphemolysin) from culture filtrates and mycelia. Microbiol Immunol 21:11-22. 
30. Ebina, K., K. Yokota, and O. Sakaguchi. 1983. Studies on toxin of Aspergillus fumigatus XVI. Biological properties of Asp-hemolysin as a parasite factor. Jpn J Med Mycol 24:245-252.

31. Latge, J. P., M. Moutaouakil, J. P. Debeaupuis, J. P. Bouchara, K. Haynes, and M. C. Prevost. 1991. The 18-kilodalton antigen secreted by Aspergillus fumigatus. Infect Immun 59:2586-2594. 


\section{APPENDIX}


A1. Amino acid composition similarity search. Search was performed using keyword 'hemolysis' and input of \% amino acid composition of stachylysin. Swiss-Prot and TrEMBL constellation 0 was chosen for analysis.

\begin{tabular}{|l|l|l|}
\hline Protein & Species & Accession \# \\
\hline Hydralysin-2 & Burkholderia glumae & HLYS2_CHLVR \\
\hline Hydralysin-1 & Burkholderia glumae & HLYS1_CHLVR \\
\hline Aerolysin & Aeromonas sobria & AERA_AERSO \\
\hline Aerolysin & Aeromonas salmonicida & AERA_AERSA \\
\hline Aerolysin & Aeromonas trota & AERA_AERTR \\
\hline Aerolysin-4 & Aeromonas hydrophila & AER4_AERHY \\
\hline Aerolysin-5 & Aeromonas hydrophila & AER5_AERHY \\
\hline Aerolysin-3 & Aeromonas hydrophila & AER3_AERHY \\
\hline Alveolysin & Bacillus alvei & TACY_PAEAL \\
\hline Hemolysin & Vibrio cholerae & HLYA_VIBCH \\
\hline Thermostable direct hemolysin 1 & Vibrio parahemolyticus & HLY1_VIBPA \\
\hline Echotoxin-2 & Cymatium echo & ACTP2_CYMEC \\
\hline Verrucotoxin subunit beta & Synanceia verrucosa & VTXB_SYNVE \\
\hline Pneumolysin & Streptococcus pneumoniae & TACY_STRPN \\
\hline Pneumolysin & Streptococcus pneumoniae & TACY_STRR6 \\
\hline Pneumolysin & Streptococcus pneumoniae & TACY_STRP2 \\
\hline Stonustoxin subunit alpha & Synanceia horrida & STXA_SYNHO \\
\hline Toxin A & Carybdea alata & CTXA_CARAL \\
\hline Thermostable direct hemolysin 2 & Vibrio parahemolyticus & HLY2_VIBPA \\
\hline Cytolysin & Vibrio vulnificus & VVHA_VIBVU \\
\hline
\end{tabular}


A2. Sub divisions of Aspergillus species

\begin{tabular}{|c|c|}
\hline Sub genus & Section (e.g. of representative species) \\
\hline 1. Aspergillus & $\begin{array}{l}\text { a. Aspergillus- Aspergillus glaucus } \\
\text { b. Restricti-Aspergillus penicilloides }\end{array}$ \\
\hline 2. Fumigati & $\begin{array}{l}\text { a. Fumigati- Aspergillus fumigatus } \\
\text { b. Clavati-Aspergillus clavatus }\end{array}$ \\
\hline 3. Circumdati & $\begin{array}{l}\text { a. Circumdati- Aspergillus ochraceus } \\
\text { b. Nigri-Aspergillus niger } \\
\text { c. Flavi-Aspergillus flavus } \\
\text { d. Cremei-Aspergillus wentii }\end{array}$ \\
\hline 4. Terrei & $\begin{array}{ll}\text { a. } & \text { Terrei-Aspergillus terreus } \\
\text { b. } & \text { Flavipedes-Aspergillus flavipes }\end{array}$ \\
\hline 5. Nidulantes & $\begin{array}{l}\text { a. Nidulantes- Aspergillus nidulans } \\
\text { b. Usti-Aspergillus ustus } \\
\text { c. Sparsi- Aspergillus sparsus } \\
\text { d. Raperi-Aspergillus raperi } \\
\text { e. Silvati- Aspergillus silvaticus } \\
\text { f. Ochraceorosei- Aspergillus } \\
\text { ochraceoroseus } \\
\text { g. Bispori-Aspergillus bisporus }\end{array}$ \\
\hline 6. Ornati & a. Ornati- Sclerocleista ornata \\
\hline 7. Warcupi & $\begin{array}{l}\text { a. Warcupi- Warcupiella spinulosa } \\
\text { b. Zonati-Aspergillus zonatus }\end{array}$ \\
\hline 8. Candidi & a. Candidi-Aspergillus candidus \\
\hline
\end{tabular}


A3. List of species in which Aegerolysins have been identified

\begin{tabular}{|l|l|}
\hline Aspergillus terreus & Histoplasma capsulatum \\
\hline Aspergillus fumigatus & Neurospora crassa \\
\hline Aspergillus oryzae & Pleurotus ostreatus \\
\hline Aspergillus clavatus & Agrocybe aegerita \\
\hline Aspergillus niger & Spirosoma linguale \\
\hline Aspergillus flavus & Pseudomonas aeruginosa \\
\hline Aspergillus nidulans & Burkholderia glumae \\
\hline Penicillium chrysogenum & Clostridium bifermentans \\
\hline Paracoccidioides brasiliensis & Bacillus thuringiensis \\
\hline Coccidioides immitis & Trichoplusia ni ascovirus $2 c(T n A V-2 c)$ \\
\hline
\end{tabular}


A4. Cytotoxicity of Aegerolysin proteins on different cell lines. Modified from (1)

\begin{tabular}{|c|c|c|c|}
\hline Protein & Cell Line (Source) & $\mathrm{ED}_{50}(\mu \mathrm{g} / \mathrm{ml})$ & References \\
\hline \multirow[t]{4}{*}{ Asp-hemolysin } & Leukocytes (Human) & 500 & (2) \\
\hline & $\begin{array}{ll}\text { Alveolar macrophages } \\
\text { (Guinea pig) }\end{array}$ & 60 & (2) \\
\hline & $\begin{array}{l}\text { Peritoneal macrophages } \\
\text { (Mouse) }\end{array}$ & 25 & (3) \\
\hline & $\begin{array}{l}\text { Umbilical vein endothelial } \\
\text { cells (Human) }\end{array}$ & 100 & (4) \\
\hline \multirow[t]{6}{*}{ Ostreolysin } & $\begin{array}{lll}\begin{array}{l}\text { Fibrosarcoma } \\
\text { (Human) }\end{array} & \text { HT } & 1080 \\
\end{array}$ & 10 & (5) \\
\hline & $\begin{array}{l}\text { Mammalian tumor MCF } 7 \\
\text { (Human) }\end{array}$ & 10 & (5) \\
\hline & $\begin{array}{lll}\text { Ovary } & \text { cells } & \text { (Chinese } \\
\text { hamster) } & & \\
\end{array}$ & 1 & (6) \\
\hline & $\begin{array}{l}\text { Articular chondrocytes } \\
\text { (Human) }\end{array}$ & 1 & (7) \\
\hline & $\begin{array}{l}\text { Lung fibroblasts V-79- } \\
\text { 379A (Chinese hamster) }\end{array}$ & 1.3 & (8) \\
\hline & $\begin{array}{l}\text { Umbilical vein endothelial } \\
\text { cells (Human) }\end{array}$ & 2.2 & (8) \\
\hline
\end{tabular}


A5. Protein A and G-based antibody immunoprecipitation

\begin{tabular}{|c|c|c|c|}
\hline Species & Ig subclass & Protein A & Protein G \\
\hline \multirow{6}{*}{ Human } & $\mathrm{IgG}_{1}, \mathrm{IgG}_{2}, \mathrm{IgG}_{4}$ & +++ & +++ \\
\hline & $\mathrm{IgG}_{3}$ & + & +++ \\
\hline & $\operatorname{IgD}$ & - & - \\
\hline & IgD & + & - \\
\hline & Fab & + & + \\
\hline & $\mathrm{ScF}_{\mathrm{v}}$ & + & - \\
\hline \multirow{3}{*}{ Mouse } & $\mathrm{IgG}_{1}$ & + & ++ \\
\hline & $\mathrm{IgG}_{2 \mathrm{a}}, \mathrm{IgG}_{2 \mathrm{~b}}, \mathrm{IgG}_{3}$ & ++++ & +++ \\
\hline & IgM & - & - \\
\hline \multirow{4}{*}{ Rat } & $\mathrm{IgG}_{1}$ & + & ++ \\
\hline & $\mathrm{IgG}_{2 \mathrm{a}}$ & - & +++ \\
\hline & $\mathrm{IgG}_{2 \mathrm{~b}}$ & - & + \\
\hline & $\mathrm{IgG}_{2 \mathrm{c}}$ & +++ & +++ \\
\hline \multirow[t]{2}{*}{ Goat/Sheep/Bovine } & $\mathrm{IgG}_{1}$ & + & +++ \\
\hline & $\mathrm{IgG}_{2}$ & +++ & +++ \\
\hline \multirow{3}{*}{ Horse } & $\operatorname{IgG}(a b)$ & + & - \\
\hline & $\operatorname{IgG(c)}$ & + & - \\
\hline & $\operatorname{IgG}(\mathrm{T})$ & - & +++ \\
\hline Rabbit & Total IgG & +++ & +++ \\
\hline $\begin{array}{l}\text { Dog/Cat/Pig/Guinea } \\
\text { Pig }\end{array}$ & Total IgG & +++ & + \\
\hline Chicken & Total IgG & - & - \\
\hline
\end{tabular}

+++: strong binding, ++: moderate binding, + : weak binding, -: no binding 


\section{REFERENCES}

1. Berne, S., L. Lah, and K. Sepcic. 2009. Aegerolysins: structure, function, and putative biological role. Protein Sci 18:694-706.

2. Ebina, K., K. Yokota, and O. Sakaguchi. 1983. Studies on toxin of Aspergillus fumigatus XVI. Biological properties of Asp-hemolysin as a parasite factor. Jpn J Med Mycol 24:245-252.

3. Kumagai, T., T. Nagata, Y. Kudo, Y. Fukuchi, K. Ebina, and K. Yokota. 1999. Cytotoxic activity and cytokine gene induction of Asp-hemolysin to murine macrophages. Nippon Ishinkin Gakkai Zasshi 40:217-222.

4. Kumagai, T., T. Nagata, Y. Kudo, Y. Fukuchi, K. Ebina, and K. Yokota. 2001. [Cytotoxic activity and cytokine gene induction of Asp-hemolysin to vascular endothelial cells]. Yakugaku Zasshi 121:271-275.

5. Sepcic, K., S. Berne, C. Potrich, T. Turk, P. Macek, and G. Menestrina. 2003. Interaction of ostreolysin, a cytolytic protein from the edible mushroom Pleurotus ostreatus, with lipid membranes and modulation by lysophospholipids. Eur J Biochem 270:1199-1210.

6. Sepcic, K., S. Berne, K. Rebolj, U. Batista, A. Plemenitas, M. Sentjurc, and P. Macek. 2004. Ostreolysin, a pore-forming protein from the oyster mushroom, interacts specifically with membrane cholesterol-rich lipid domains. FEBS Lett 575:81-85.

7. Malicev, E., H. H. Chowdhury, P. Macek, and K. Sepcic. 2007. Effect of ostreolysin, an Asp-hemolysin isoform, on human chondrocytes and osteoblasts, and possible role of Asp-hemolysin in pathogenesis. Med Mycol 45:123-130.

8. Rebolj, K., U. Batista, K. Sepcic, V. Cestnik, P. Macek, and R. Frangez. 2007. Ostreolysin affects rat aorta ring tension and endothelial cell viability in vitro. Toxicon 49:1211-1213. 
CURRICULUM VITAE 


\section{Ajay Padmaj Nayak}

Department of Microbiology, Immunology and Cell Biology

School of Medicine

Robert C. Byrd Health Sciences Center

West Virginia University

P.O. Box 9100

Morgantown, WV 26506

Tel: (304)285-5721 Ext 6, Cell: (716)704-9685, Fax: (304)285-6126

Email: ajnayak1@gmail.com, fyg1@cdc.gov

\section{EDUCATION}

Ph.D. 2006-2012, West Virginia University, Ph.D. candidate, Biomedical Sciences, Major- Immunology and Microbial Pathogenesis

M.Sc. $\quad$ 2004-2006, University of Mumbai, India, Major- Microbiology

B.Sc. $\quad$ 2001-2004, University of Mumbai, India, Major- Microbiology

\section{SELECT HONORS AND AWARDS}

$2011 \quad$ Nominated to Sigma Xi Research Society (Greenbrier Valley Chapter, WV)

2010 Student travel grant from American Society for Microbiology towards $110^{\text {th }}$ General meeting, San Diego, CA. Selection of abstract to "Outstanding Students" poster session.

2010 Third place award for poster session at Van Liere Convocation and Research Day, West Virginia University, Morgantown, WV.

2009 Second place award for poster session at Van Liere Convocation and Research Day, West Virginia University, Morgantown, WV. 


\section{RESEARCH EXPERIENCE}

2012-Present ASSOCIATE SERVICE FELLOW (BIOLOGICAL SCIENTIST), National Institute for Occupational Safety and Health, Centers for Disease Control and Prevention, Morgantown, WV.

2007-Present REGULAR FELLOW, National Institute for Occupational Safety and Health, Centers for Disease Control and Prevention, Morgantown, WV.

2006-Present GRADUATE ASSISTANT, Department of Microbiology, Immunology and Cell Biology, West Virginia University, Morgantown, WV.

2004-2006 GRADUATE ASSISTANT, Department of Microbiology, Mithibai College, University of Mumbai, Mumbai, India.

\section{PRESENTATIONS/CONFERENCES}

1. Nayak, A.P., Green, B.J. and Beezhold, D.H. 2012. Oral Presentation. Van Liere Convocation and Research Day. West Virginia University, Morgantown, WV.

2. Buskirk, A.D., Templeton, S.P., Hettick, J.M., Nayak, A.P., Green, B.J., Siegel, P.D. and Beezhold, D.H. 2012. Van Liere Convocation and Research Day. West Virginia University, Morgantown, WV.

3. Nayak, A.P., Green, B.J. and Beezhold, D.H. 2012. Annual meeting of American Academy of Allergy, Asthma and Immunology (AAAAI), March 2-6, Orlando, FL.

4. Nayak, A.P., Green, B.J., Hettick, J.M. and Beezhold, D.H. 2010. $110^{\text {th }}$ General meeting of American Society for Microbiology (ASM), May 23-27, San Diego, CA.

5. Nayak, A.P., Green, B.J. and Beezhold, D.H. 2010. Van Liere Convocation and Research Day. West Virginia University, Morgantown, WV.

6. Nayak, A.P., Blachere, F.M., Hettick, J.M., Schmechel, D. and Beezhold, D.H. 2009. Van Liere Convocation and Research Day. West Virginia University, Morgantown, WV.

7. Nayak, A.P., Blachere, F.M., Schmechel, D., Janotka, E. and Beezhold D.H. 2008. Van Liere Convocation and Research Day. West Virginia University, Morgantown, WV. 


\section{MANUSCRIPTS}

1. Nayak, A. P., Blachere, F. M., Hettick, J. M., Lukomski, S., Schmechel D and Beezhold, D. H. 2011. Characterization of recombinant terrelysin, a hemolysin of Aspergillus terreus. Mycopathologia 171(1): 23-34. PMID: 20632211.

2. Nayak, A. P., Green, B. J., Janotka, E., Blachere, F. M., Vesper, S., Beezhold, D. H. and Schmechel, D. 2011. Production and characterization of IgM monoclonal antibodies against hyphal antigens of Stachybotrys species. Hybridoma 30(1):29-36. PMID: 21466283.

3. Nayak, A. P., Green, B. J., Janotka, E., Hettick, J., Friend, S., Vesper, S. J., Schmechel, D. and Beezhold, D. H. 2011. Monoclonal antibodies to hyphal exoantigens derived from the emerging opportunistic pathogen, Aspergillus terreus. Clin Vaccine Immunol 18(9):15681576. PMID: 21734068.

4. Nayak, A. P., Green, B. J., Friend, S., Beezhold, D. H. Development of monoclonal antibodies to recombinant terrelysin and characterization of expression in Aspergillus terreus. J Med Microbiol 61(Pt 4):489-499. PMID: 22160315.

5. Nayak, A. P., Green, B. J. and Beezhold, D. H. Fungal hemolysins: review of literature, current understanding and future research. Med Mycol (Submitted).

6. Buskirk, A. D., Nayak, A. P., Templeton, S. P., Law, B. F., Green, B. J. and Beezhold, D. H. Murine airway immune response to melanin-lacking Aspergillus fumigatus mutant conidia. (In preparation).

\section{REVIEWER}

National Institute for Occupational Safety and Health (CDC/NIOSH)

Aerobiologia

American Journal of Infection Control

Hybridoma

Mycopathologia

Brazilian Journal of Infectious Diseases

Allergologia et Immunopathologia

Mini-Reviews in Medicinal Chemistry 


\section{MEMBERSHIPS IN ACADEMIC SOCIETIES}

2008-Present American Society for Microbiology

2011-Present Sigma Xi

2011-Present American Association for Allergy Asthma and Immunology

2011-Present International Society for Infectious Diseases

\section{ACADEMIC TEACHING}

1. MICB 702- Microbiology (Dental Students Course) Laboratory- 2010

2. MICB 702- Microbiology (Dental Students Course) Laboratory- 2008

3. MICB 327- Microbiology (Medical Technician Course) Laboratory- 2008 